Universidade de São Paulo

Instituto de Física

\title{
Propriedades de termoluminescência, de ressonância paramagnética eletrônica e de centros de cor de diopsídio
}

\section{Nilo Francisco Cano Mamani}

Orientador: Prof. Dr. Shigueo Watanabe

Tese de doutorado apresentada ao Instituto de Física para a obtenção do título de Doutor em Ciências

Banca examinadora:

Prof. Dr. Shigueo Watanabe (IF-USP)

Prof ${ }^{\mathrm{a}}$. Dr ${ }^{\mathrm{a}}$. Ana Regina Blak (IF-USP)

Prof. Dr. Walter Maigon Pontuschka (IF-USP)

Prof $^{a}$. Dra ${ }^{\text {a }}$ Linda V. Ehlin Caldas (IPEN-CNEN)

Prof. Dr. Keizo Yukimitu (FEIS/UNESP)

São Paulo 
Con mucho amor a mis padres Cirilo y Luisa y a mis queridos hermanos(as) Hilda, Noé, Néstor, Martha, Adela y Sandra. 


\section{Agradecimentos}

Apesar de uma tese ser um trabalho individual, sempre existem contribuições, de natureza diversa, que devem ser realçadas. Por esta razão, desejo expressar meus sinceros agradecimentos:

Ao Prof. Dr. Shigueo Watanabe, pela dedicação revelada ao longo destes anos, pelas críticas e sugestões relevantes feitas durante a orientação deste trabalho.

À Enga . Elizabeth Somessari Ribeiro e ao Eng ${ }^{\circ}$. Carlos Gaia de Silveira do CTRIPEN pela irradiação das amostras.

Ao Laboratório de Cristalografia do IF-USP pelas medidas de difração de raio-x

Ao Dr. Juan Carlos Ramirez Mittani pelas suas sugestões e sua colaboração na obtenção dos espectros de emissão TL.

Ao Dr. José Roberto Braz Paião pela ajuda na obtenção das amostras artificiais.

A CAPES, pelo apoio financeiro durante o desenvolvimento do presente trabalho.

À Sra. Edna A. S. Toledo pela sua disposição para ajudar sempre.

Ao pessoal técnico e administrativo do DFN e à Comissão de Pós-Graduação do Instituto de Física da USP.

Aos colegas do LACIFID pela excelente relação pessoal e profissional que criamos, a qual espero que não se perca: José Fernando, Walter, Susana, Gilberto, Juan Carlos, José Roberto, Lara, Roseli, Henry, Wilmer, Luiz, Cassiano, Thiago, René e Dennis.

Aos meus grandes amigos de sempre: Jessica, Henry, Gabriel, Bertha, Alberto, Carlos Alberto e em especial a Alejandro, pelo apoio e amizade em todos os momentos.

A Luz, a pessoa mais corajosa que passou em minha vida, pelo apoio incondicional, carinho e, acima de tudo, pela enorme paciência comigo.

A minha família, pelo estímulo e apoio incondicional desde a primeira hora; pela paciência, compreensão e grande amizade com que sempre me assistiram. 


\section{Resumo}

No presente trabalho foram estudadas algumas propriedades de Termoluminescência (TL), Ressonância Paramagnética Eletrônica (RPE) e Refletância de uma amostra natural e de amostras artificiais de diopsídio.

A curva de emissão TL das amostras tratadas termicamente a $600{ }^{\circ} \mathrm{C} / 1 \mathrm{hr}$ e irradiadas com dose gama mostraram um pico em aproximadamente em $160{ }^{\circ} \mathrm{C}$, que depois ficou demonstrado ser uma superposição de três picos em $160{ }^{\circ} \mathrm{C}, 197{ }^{\circ} \mathrm{C}$ e $230^{\circ} \mathrm{C}$, além dos picos TL em $300{ }^{\circ} \mathrm{C}, 350{ }^{\circ} \mathrm{C}$ e $450{ }^{\circ} \mathrm{C}$, mas de intensidade bem menor que os dos outros. Foram produzidas amostras artificiais de diopsídio, pelo método de devitrificação, uma pura e outras dopadas, separadamente, com Al, Fe e Mn. A amostra artificial pura apresentou todos os picos entre 160 e $350{ }^{\circ} \mathrm{C}$, encontrados no diopsídio natural, indicando que todos esses picos são devido a defeitos intrínsecos. A presença de $\mathrm{Al}$ e $\mathrm{Mn}$ afeta esses picos TL. O Fe, conhecido como "killer" abafa praticamente todos os picos, exceto o de $450{ }^{\circ} \mathrm{C}$ que não depende de irradiação como os outros. O espectro de emissão TL da amostra natural apresentou uma banda em $435 \mathrm{~nm}$ indicando que só há um centro de recombinação, que é devido à presença de $\mathrm{Al}$. A sensibilidade TL aumenta com o tratamento térmico antes da irradiação. Os picos TL crescem linearmente com a dose gama de irradiação, exceto na amostra artificial dopada com $\mathrm{Al}$ onde o pico em $410{ }^{\circ} \mathrm{C}$ cresce sublinearmente. A irradiação UV produz decaimento na intensidade TL (fotoesvaziamento). Por outro lado induz picos TL em $90{ }^{\circ} \mathrm{C}$ e $170{ }^{\circ} \mathrm{C}$ nas amostras naturais pré-recozidas a $600{ }^{\circ} \mathrm{C}$ por uma hora, picos não observados com irradiação- $\gamma$.

No espectro de refletância do diopsídio foram identificadas as bandas em 1050, 1390, 1910, 2310 e $2385 \mathrm{~nm}$. A banda em $1050 \mathrm{~nm}$ é devido a $\mathrm{Fe}^{2+}$ substituindo o $\mathrm{Mg}^{2+}$ na estrutura do cristal de diopsídio, a mesma banda em $1050 \mathrm{~nm}$ também foi observada no diopsídio artificial dopado com Fe; as bandas em 1390 nm (OH), 1910 $\mathrm{nm}\left(\mathrm{H}_{2} \mathrm{O}\right), 2310 \mathrm{~nm}$ e $2385 \mathrm{~nm}$ decrescem de intensidade com o aquecimento, sendo que algumas até desaparecem.

No espectro de RPE foram detectados três centros. Um devido ao $\mathrm{Mn}^{2+}$, cujo 
espectro RPE da amostra em pó apresenta as seis linhas hiperfinas típicas na região de 3000 a $4500 \mathrm{G}$, sendo que esses sinais não são afetados pela radiação gama e nem pelo recozimento térmico. Na amostra monocristalina orientada na direção $z$ foram observadas todas as linhas do $\mathrm{Mn}^{2+}$. O segundo centro é devido ao $\mathrm{Fe}^{3+}$ em $g=4,3$, o recozimento na região de 500 até $900{ }^{\circ} \mathrm{C}$ mostrou que o íon $\mathrm{Fe}^{2+}$ oxida-se para $\mathrm{Fe}^{3+}$, esse mesmo comportamento foi observado nas medidas de refletância. O terceiro centro identificado por RPE localizado em $g=2,007$, é o $E_{1}^{\prime}$. Os três centros observados por RPE na amostra natural, foram confirmados nas amostras artificiais de diopsídio.

A emissão de luz TL envolve centros de Ti, de $\mathrm{Al}$ e centros $\mathrm{E}^{\prime}{ }_{1}$. O seguinte mecanismo de emissão TL e formação dos picos TL entre 160 e $230{ }^{\circ} \mathrm{C}$, em torno de $300{ }^{\circ} \mathrm{C}$ e em torno de $350{ }^{\circ} \mathrm{C}$, é proposto:

- A irradiação cria os centros de $\mathrm{Ti}$, de $\mathrm{Al}$ e o centro $\mathrm{VO}^{2-}$. $\mathrm{VO}^{2-}$ corresponde à vacância de oxigênio que capturou dois elétrons.

- Durante o aquecimento:

- Entre 150 e $250{ }^{\circ} \mathrm{C}$, o centro $\mathrm{VO}^{2-}$ libera um elétron, que se recombina com os centros de Ti e de $\mathrm{Al}$ dando lugar ao centro $\mathrm{E}_{1}^{\prime}$ e emissão de luz TL de $435 \mathrm{~nm}$. O pico TL em torno de $160{ }^{\circ} \mathrm{C}$, composto de 3 picos é formado. O centro de Ti é eliminado, mas parte do centro de $\mathrm{Al}$ ainda permanece.

- Entre 250 e $300{ }^{\circ} \mathrm{C}$, os centros $\mathrm{VO}^{2-}$ continua emitindo elétrons, cada um dos quais se recombina com uma parte do centro de $\mathrm{Al}$ remanescente emitindo a luz TL de $435 \mathrm{~nm}$ e formando mais centros $\mathrm{E}_{1}^{\prime}$. Como, experimentalmente, se sabe que a concentração de centros $\mathrm{E}^{\prime}{ }_{1}$ atinge o máximo em $300{ }^{\circ} \mathrm{C}$, é natural admitir que, todos os centros $\mathrm{VO}^{2-}$ se converteram em centros $\mathrm{E}^{\prime}{ }_{1}$.

- Entre 300 e $400{ }^{\circ} \mathrm{C}$, os elétrons dos centros $E_{1}^{\prime}$, formados acima, são liberados, cada um dos quais se recombina com os centros de $\mathrm{Al}$ que restam, observando-se a emissão de luz TL em $435 \mathrm{~nm}$. Nessa temperatura, tanto os centros $\mathrm{E}_{1}^{\prime}$ dão lugar às vacâncias de oxigênio VO, como os centros de alumínio $\left[\mathrm{AlO}_{4} / \mathrm{h}\right]$ dão lugar aos centros $\left[\mathrm{AlO}_{4}\right]^{-}$que, para neutralidade de carga atraem íons alcalinos $\mathrm{M}^{+}$para formarem os centros $\left[\mathrm{AlO}_{4} / \mathrm{M}^{+}\right]^{0}$. O pico em $350{ }^{\circ} \mathrm{C}$ é originado nesse processo.

A partir de diopsídio natural foi obtido vidro. O vidro apresentou sinais RPE de $\mathrm{Fe}^{3+}$ em torno de $1700 \mathrm{G}$ e as seis linhas típicas do $\mathrm{Mn}^{2+}$ em torno de $3470 \mathrm{G}$. Uma banda de refletância devido a $\mathrm{Fe}^{2+}$ com um máximo ao redor de $1000 \mathrm{~nm}$ é observada. 


\section{Abstract}

Diopside of chemical formula, $\mathrm{CaMgSi}_{2} \mathrm{O}_{6}$, a natural silicate mineral has been investigated concerning its Thermoluminescence (TL), Electron Paramagnetic Resonance (EPR) and Reflectance properties. Synthetic, pure or doped diopside, produced in the laboratory, has been investigated.

Samples annealed at $600{ }^{\circ} \mathrm{C}$ for one hour, to eliminate previously induced TL, and irradiated at several $\gamma$-doses, presented glow curves with TL peaks around 160, 300,350 and $450{ }^{\circ} \mathrm{C}$. Later on, the broad peak around $160{ }^{\circ} \mathrm{C}$ was proved to be a superposition of peaks at 160,197 and $230{ }^{\circ} \mathrm{C}$. The pure synthetic diopside presented TL peaks at 160 to $350{ }^{\circ} \mathrm{C}$, indicating that these peaks are due to intrinsic defects. Synthetic samples containing $\mathrm{Al}$ or $\mathrm{Mn}$ have indicated that these dopants interfere with TL peaks found in the natural diopside. Fe, on the other hand, known as "killer", precludes the appearance of all the peaks, except at $450{ }^{\circ} \mathrm{C}$, peak that is not affected by radiation and heat. The TL emission spectrum has presented only one band around $435 \mathrm{~nm}$. This fact indicates that there is only one kind of recombination center. An annealing at temperatures above $800{ }^{\circ} \mathrm{C}$ up to $1000{ }^{\circ} \mathrm{C}$ yields an enhancement in the TL sensitivity up to a factor of 2 . Beyond $1000{ }^{\circ} \mathrm{C}$ heating, an opposite effect takes place. Except for $410{ }^{\circ} \mathrm{C}$ peak found in the Al-doped artificial diopside, all the other peaks grow linearly with radiation dose, but saturate beyond $\sim 1 \mathrm{kGy}$. In a previously $\gamma$-irradiated sample, all the peaks are bleached rapidly under ultraviolet radiation shining. The UV light, on the other hand is able to induce TL, however only TL peaks around 90 and $170{ }^{\circ} \mathrm{C}$ are observed. No explanation has been found as yet, why $\gamma$-rays and UV light induce TL with different results.

The spectrum of reflectance has shown several bands at 1050, 1390, 1910, 2310 and $2385 \mathrm{~nm}$. The $1050 \mathrm{~nm}$ band is due to $\mathrm{Fe}^{2+}$ which is substitutional to a $\mathrm{Mg}^{2+}$ ion. This band was also observed in Fe- doped synthetic diopside. $1390 \mathrm{~nm}$ band is due to $\mathrm{OH}$ and $1910 \mathrm{~nm}$ to $\mathrm{H}_{2} \mathrm{O}$; they, together with 2310 and $2385 \mathrm{~nm}$ bands decrease with temperature.

In the EPR measurements, hyperfine signals due to $\mathrm{Mn}^{2+}$ in the region of 3000 to 
4000 Gauss, $g=4.3 \mathrm{Fe}^{3+}$ signal and $g=2.007$ lines due to $\mathrm{E}^{\prime}{ }_{1}$ - center have been detected. Two first ones do not depend on irradiation. On the other hand, an annealing between 500 and $900{ }^{\circ} \mathrm{C}$ decreases $1050 \mathrm{~nm} \mathrm{Fe}^{2+}$ band followed by increase in $g=4.3 \mathrm{Fe}^{3+}$ lines, because of the oxidation of $\mathrm{Fe}^{2+}$ converts this ion into $\mathrm{Fe}^{3+}$ ion. The EPR signal of $\mathrm{E}^{\prime}{ }_{1}$ center increases with temperature, reaching a maximum value at $300{ }^{\circ} \mathrm{C}$, but decreasing for higher temperatures, with its extinction at $400{ }^{\circ} \mathrm{C}$.

The TL light emission involves Ti- , Al- and $\mathrm{E}_{1^{\prime}}$ - centers. The following mechanism is here proposed.

- The irradiation creates $\mathrm{Ti}-$, Al- and $\mathrm{VO}^{2-}$ - centers. where the is an oxygen vacancy has captured two electrons. Ti- and Al- centers are of the form $\left[\mathrm{TiO}_{4} / \mathrm{h}\right]$ and $\left[\mathrm{AlO}_{4} / \mathrm{h}\right]$, respectively, where $h$ denotes a hole.

- During heating for TL read out:

- Between 150 and $250{ }^{\circ} \mathrm{C}$, the $\mathrm{VO}^{2-}$ center releases an electron that recombines with the $\mathrm{Ti}$ and $\mathrm{Al}$ centers giving the $\mathrm{E}_{1}^{\prime}$ center and emission of light at $435 \mathrm{~nm}$. The TL peak around $160{ }^{\circ} \mathrm{C}$ composed of three individual peaks is formed. The Ti center is eliminated while the $\mathrm{Al}$ center still stays.

- Between 250 and $300{ }^{\circ} \mathrm{C}$, the $\mathrm{VO}^{2-}$ centers continue to liberate electrons and their recombinations with holes in $\mathrm{Al}$ centers, result in the emission of TL light at $435 \mathrm{~nm}$. Additional $\mathrm{E}^{\prime}{ }_{1}$ center is created. Experimentally it is known that the concentration of $\mathrm{E}^{\prime}{ }_{1}$ centers reaches its maximum at 300 ${ }^{\circ} \mathrm{C}$, for this, we can say that all the $\mathrm{VO}^{2-}$ centers were converted into $\mathrm{E}_{1}^{\prime}$ centers.

- Between 300 and $400{ }^{\circ} \mathrm{C}$, the $\mathrm{E}^{\prime}{ }_{1}$ centers liberate their electrons and each one recombines with a hole in remaining $\mathrm{Al}$ centers. Then, the TL light at $435 \mathrm{~nm}$ is emitted again. At this temperature, the $\mathrm{E}_{1}^{\prime}$ centers give place to oxygen vacancies $\mathrm{VO}$ and the $\left[\mathrm{AlO}_{4} / \mathrm{h}\right]$ centers convert to $\left[\mathrm{AlO}_{4}\right]^{-}$centers. To neutralize the charge this centers attract $\mathrm{M}^{+}$alcali ions to form the $\left[\mathrm{AlO}_{4} / \mathrm{M}^{+}\right]^{0}$ centers. The TL peak at $350{ }^{\circ} \mathrm{C}$ is due to this process.

From the natural diopside samples was obtained glass of diopside. The glass shows EPR component of $\mathrm{Fe}^{3+}$ around $1700 \mathrm{G}$ and six typical lines of $\mathrm{Mn}^{2+}$ around $3470 \mathrm{G}$. A reflectance band due to $\mathrm{Fe}^{2+}$ at approximately $1000 \mathrm{~nm}$ was observed. 


\section{Sumário}

Lista de Figuras $\quad$ x

Lista de Tabelas $\quad$ xvii

1 Introdução 1

1.1 Silício no universo e na terra: sua importância tecnológica . . . . . . . 1

1.2 Minerais de Silicatos . . . . . . . . . . . . . . . . . 2

1.3 Silicatos do grupo de piroxenos . . . . . . . . . . . . . . 6

1.3.1 Nomenclatura e fórmula dos piroxenos . . . . . . . . . . . 6

1.3.2 Composição química . . . . . . . . . . . . . . . 8

1.3.3 Estrutura dos piroxenos . . . . . . . . . . . . 9

1.4 Diopsídio . . . . . . . . . . . . . . . . . . . . . . . . . . 10

1.5 Trabalhos realizados até o momento por outros autores . . . . . . . . . 12

2 Conceitos Básicos $\quad 14$

2.1 Cristais perfeitos e cristais reais . . . . . . . . . . . . . 14

2.1.1 Rede cristalina . . . . . . . . . . . . . . . . . . . . . 14

2.1.2 Bandas de energia . . . . . . . . . . . . . . . 16

2.1.3 Defeitos na rede cristalina . . . . . . . . . . . . . . . . . . 19

2.1.4 Níveis de energia na banda proibida . . . . . . . . . . . . . . 20

2.2 Luminescência nos solidos . . . . . . . . . . . . . . . . . . . . . . 22

2.2.1 Termoluminescência (TL) . . . . . . . . . . . . . . . 24

2.2.2 Curva de emissão TL . . . . . . . . . . . . . . . . . . . 26

2.2.3 Espectro de emissão TL . . . . . . . . . . . . . . . . . 27

2.2.4 Modelos teóricos para a termoluminescência . . . . . . . . . . 28

2.2.5 Métodos para estimar os parâmetros dos modelos TL . . . . . . 33

2.2.6 Linearidade, sub e supralinearidade. . . . . . . . . . . . . . 36

2.2.7 Efeitos de UV próximo . . . . . . . . . . . . . . . . . . . . 42

2.3 Absorção óptica . . . . . . . . . . . . . . . . . . . . . . . 43 
2.4 Ressonância Paramagnética Eletrônica ～. . . . . . . . . . . . . . . . 46

2.4.1 Minúsculo imã de um elétron em rotação num campo magnético externo. . . . . . . . . . . . . . . . 46

2.4.2 Ressonância paramagnética eletrônica . . . . . . . . . . . . . 46

2.4.3 Espectro RPE e fator $g$. . . . . . . . . . . . . . . . . . . 48

2.5 Vidros . . . . . . . . . . . . . . . . . . . 50

2.5.1 Vitrificação a partir de fase líquida . . . . . . . . . . . . . 50

2.5.2 Devitrificação. Cristalização . . . . . . . . . . . . . . . 51

$\begin{array}{lll}3 & \text { Objetivos } & 59\end{array}$

4 Materiais e métodos experimentais $\quad 61$

4.1 Amostras ........................ 61

4.1 .1 Natural . . . . . . . . . . . . . . . . . . . 61

4.1.2 Policristal artificial de diopsídio . . . . . . . . . . . . . 61

4.1 .3 Vidro de diopsídio . . . . . . . . . . . . . . . . . . 63

4.2 Preparação das amostras . . . . . . . . . . . . . . . . . . . 64

4.3 Irradiação e tratamento térmico . . . . . . . . . . . . . . . . . . . . . . 64

$4.3 .1 \quad$ Irradiação . . . . . . . . . . . . . . . . . . . . . . . . 64

4.3.2 Tratamento térmico . . . . . . . . . . . . . . . . 65

4.4 Equipamentos de medidas . . . . . . . . . . . . . . . 66

4.4.1 Termoluminescência . . . . . . . . . . . . . . . 66

4.4.2 Ressonância Paramagnética Eletrônica . . . . . . . . . . . . . . 67

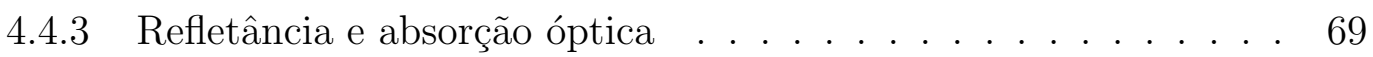

5 Resultados Experimentais $\quad 72$

5.1 Análise da amostra . . . . . . . . . . . . . . . . . . . . 72

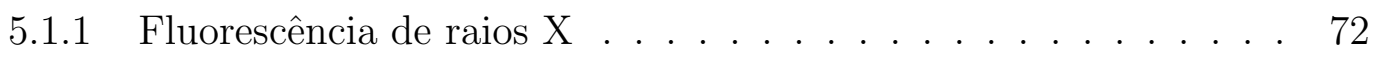

5.1 .2 Difração de raios X . . . . . . . . . . . . . . . 73

5.2 Medidas de Termoluminescência . . . . . . . . . . . . . . . . . 76

5.2.1 Curva de TL do diopsídio natural . . . . . . . . . . . . 76

5.2.2 Dependência da TL com a dose . . . . . . . . . . . . . . . 76

5.2.3 Efeito dos tratamentos térmicos antes da irradiação na TL do diopsídio . . . . . . . . . . . . . . . . . . . . . . 81

5.2.4 Decaimento isócrono da TL da amostra natural de diopsídio . . 82

5.2.5 Análise das curvas de TL . . . . . . . . . . . . . . . . . . 84

5.2.6 Espectro de emissão TL do diopsídio natural . . . . . . . . . . . 86 
5.2 .7 Irradiação com luz UV na amostra natural . . . . . . . . . . . 88

5.2.8 Termoluminescência das amostras artificiais. . . . . . . . . . . . 90

5.3 Medidas de Refletância . . . . . . . . . . . . . . . . . 96

5.3.1 Refletância da amostra natural de diopsídio . . . . . . . . . . 96

5.3.2 Efeito da irradiação gama na amostra natural . . . . . . . . . . 96

5.3.3 Efeito térmico na refletância do diopsídio natural . . . . . . . 97

5.3.4 Refletância das amostras artificiais . . . . . . . . . . . . . 100

5.4 Medidas de RPE . . . . . . . . . . . . . . . . . . . . . . . . . . 101

5.4.1 Espectro RPE para amostra natural . . . . . . . . . . . . 101

5.4.2 Espectro RPE em baixa temperatura $(77 \mathrm{~K})$. . . . . . . . 106

5.4 .3 Monocristal do diopsídio . . . . . . . . . . . . . . . . 106

5.4.4 Espectro RPE das amostras artificiais . . . . . . . . . . . . . 107

5.5 Medidas no vidro de diopsídio . . . . . . . . . . . . . . . 108

5.5.1 Ressonância paramagnética eletrônica . . . . . . . . . . . . . 109

5.5.2 Absorção Ótica . . . . . . . . . . . . . . . . . . . . . 110

6 Discussões $\quad 112$

7 Conclusões $\quad 122$

$\begin{array}{lr}\text { Bibliografia } & 128\end{array}$ 


\section{Lista de Figuras}

1.1 Tetraedro de $\mathrm{SiO}_{4}$ regular inscrito em um cubo (raio iônico $\mathrm{Si}=0,42 \AA$ $e \mathrm{O}=1,40 \AA) \ldots \ldots \ldots \ldots \ldots \ldots \ldots$

1.2 Distancias médias entre os íons de $\mathrm{Si}$ e $\mathrm{O}$ para o tetraedro $\left[\mathrm{SiO}_{4}\right]$ e octaedro $\left[\mathrm{SiO}_{6}\right] \ldots \ldots \ldots \ldots \ldots \ldots$

1.3 Tipos de silicatos de acordo com a formação dos tetraedros. . . . . . . . 5

1.4 Inosilicatos de cadeia (a) simples e (b) dupla. . . . . . . . . . . . . . 5

1.5 Variações da composição química e nomenclatura de (a) clinopiroxenos de $\mathrm{Ca}-\mathrm{Mg}$ - Fe e (b) ortopiroxenos. . . . . . . . . . . . . . 7

1.6 Variações da composição química e nomenclatura dos piroxenos mais comuns $(\mathrm{Ca}-\mathrm{Mg}-\mathrm{Fe})$ e piroxenos com $\mathrm{Na} e \mathrm{Fe}^{3+}$. . . . . . . . . . 8

1.7 Gráfico que mostra a ocupação ideal e a ordem de ocupação dos átomos para as posições T, M1 e M2 na estrutura do piroxeno. . . . . . . . . . 8

1.8 Projeção ao longo do eixo -z da estrutura idealizada de um piroxeno, mostrando as cadeias dos piroxenos e as duas posições distintas dos cátions, M1 e M2. Mais afastados vêem-se os poliedros de oxigênios que também formam cadeias ou bandas paralelas ao eixo -z. Nos piroxenos com o grupo espacial C2/c, as cadeias Si-O nas posições A, B, C e D são todas equivalentes. Nos piroxenos com grupo espacial $P \mathscr{2}_{1} /$ c e $\mathrm{Pbca}$, $C=A$ e $D=B$, mas $A$ e $B$ não são equivalentes. . . . . . . . . . . . . 9

1.9 A estrutura do piroxeno projetado no plano (100) mostrando as posições M1 e M2 para os cátions. . . . . . . . . . . . . . . . . . . . . . . . . 10

1.10 Estrutura idealizado do diopsídio, mostrando as posições das cadeias A, $B, C, D$ e as coordenadas atômicas: (a) observada ao longo do eixo z; (b) ao longo do eixo y. Em (a) alguns átomos de oxigênio sobrepõemse a outros átomos de oxigênio que foram ligeiramente deslocados. Em (b) os átomos de Ca e $\mathrm{Mg}$ deviam estar perfeitamente sobrepostos, mas foram ligeiramente deslocados. . . . . . . . . . . . . . . . . . . . . . 
2.1 Cristal de $\mathrm{NaCl}$. . . . . . . . . . . . . . . . . . 16

2.2 Componentes $\cos ^{2}(x)$ e $\operatorname{sen}^{2}(x)$ para a função de onda $k= \pm \pi / a$ e o potencial exercido por um arranjo unidimensional de átomos com parâmetro de rede a. . . . . . . . . . . . . . . . . . . 17

2.3 Curva $E(k)$ para (a) o modelo de elétrons livres e (b) elétron sob potencial periódico. . . . . . . . . . . . . . . . . . . . . 18

2.4 Primeira zona de Brillouin para a estrutura cúbica de face centrada. . . 18

2.5 Defeito Frenkel. . . . . . . . . . . . . . . . . . . . . . . 20

2.6 Defeito Schottky. . . . . . . . . . . . . . . . . . . 20

2.7 Representação de algumas das transições de elétrons (•) e buracos (०) entre os niveis de energia permitidas em um cristal isolante. . . . . . . 21

2.8 Níveis de energia em um isolante em zero absoluto. . . . . . . . . . . . 22

2.9 (a) - Esquema do processo envolvido com a fluorescência, onde (i) indica a absorção de energia do elétron e (ii) a transição para o estado fundamental com emissão de luz. (b) - Representa, esquematicamente, a fosforescência, com exitação para o estado e seguido do decaimento até o estado $m$ (metaestável), e novamente excitação e decaimento até o estado fundamental g, com emissão de luz. . . . . . . . . . . . . . . .

2.10 Processo termicamente estimulado para um sistema simples com dois tipos de níveis de energia na banda proibida. (i) $O$ diagrama representa o equilibrio estável. (ii) durante a irradiação os pares elétronburaco são formados e capturados nos seus respectivos centros. (iii) armazenamento, o sistema permanece em equilibrio enquanto não ocorre o estímulo. (iv) Durante o aquecimento, os elétrons são liberados das armadilhas, com emissão de luz no processo de recombinação com os buracos.

2.11 Curva de emissão TL. . . . . . . . . . . . . . . . . . . . 26

2.12 Estrutura de bandas de energia, mostrando os centros de armadilhas e os centros de recombinação. Podemos visualizar que, havendo várias profundidades dos centros de recombinação, a emissão TL será composta de diversos comprimentos de onda $\left(\lambda_{1}\right.$ e $\left.\lambda_{2}\right)$. . . . . . . . . . . . . . 27

2.13 Modelo de dois níveis localizados na banda proibida: um tipo de armadilha e um tipo de centro de recombinação. . . . . . . . . . . . . . . 28

2.14 Energia de ativação em função da temperatura $T_{\text {stop }}$ (Nahum and Halperin, 1962). 
2.15 (A) Curvas TL. (B) Perfil Tm-Tstop com uma cinética de primeira ordem e (C) com uma cinética de ordem diferente de 1. (a) um só pico, (b) superposição de picos e (c) distribuição de energias. . . . . . . . . . 36

2.16 Comportamento do LiF (TLD100) com a dose de radiação (adoptado de Zimmerman J. ). A curva tracejada representa o comportamento linear. . . . . . . . . . . . . . . . 37

2.17 Transições no modelo de sistema armadilhas interativas. $N_{i}$ e $N_{n}$ são as concentrações totais das armadilhas TL do tipo interativo e nãointerativo, respectivamente. $n_{i}$ e $n_{n}$ são as armadilhas correspondentes preenchidas. H é a concentrção de armadilhas ocupadas interativas. $\gamma$, $\alpha e, \varepsilon$ são os coeficientes de rearmadilhamento.

2.18 Intensidade TL em função da dose $D$ no modelo de sistema de armadilhas interativas. As curvas $1-5$ são para $a=10 ; 1 ; 0,1 ; 0,01$ e, 0 respectivamente. . . . . . . . . . . . . . .

2.19 (a) Intensidade TL em função da dose para o caso de $a=1$ e diferentes valores de $K=10 ; 1 ; 0,1 ; 0,05 ; 0,01$ e, 0 respectivamente. (b) Intensidade $T L$ em função da dose para $K=0$ e diferentes valores de $a=10$; 1; 0,1; 0,05; 0,01 e, 0 respectivamente. Em ambos a linha da linearidade esta mostrada por a linha tracejada. . . . . . . . . . . . . . . . . . . . . 41

2.20 Espalhamento da luz por partículas pequenas, como na fumaça. . . . . . 44

2.21 (a) - Sem campo magnético, os spins estão orientados aleatoriamente.

(b) - No campo magnético H, os spins se orientam pelo efeito Zeeman.

(c) - A incidência de uma microonda de freqüência apropiada provoca inversão de orientações dos spins. . . . . . . . . . . . . . . . . . . . . . 47

2.22 Niveis de energia de um spin eletrônico em função de $H$. A ressonância

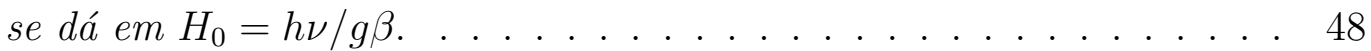

2.23 Absorção da potencia de microonda em torno de $H_{0} \ldots$. . . . . . . . . . 48

2.24 Curva de absorção: Gaussiana (a) e Lorentziana (b) e respectivas derivadas primeiras. . . . . . . . . . . . . . . . . . . . 49

2.25 Contagem do número de linhas num espectro complexo. . . . . . . . . . 50

2.26 Variação do volume específico durante o esfriamento. . . . . . . . . . . 51

2.27 Influência da taxa de esfriamento na posição da $T_{g}: v_{1}<v_{2}<v_{3}$. . . . 52

2.28 A taxa de nucleação I e a taxa de crescimento u em função de T. A cristalização total se dá na região hachurada. . . . . . . . . . . . . . . . 53

2.29 Energia livre molar de um cristal (c) e de do líquido na vizinhança de $T_{f}, L^{\prime}=$ Líquido superesfriado. $C^{\prime}=$ cristal superaquecido. . . . . . . . . . 54 
2.30 Variação da energia livre $\Delta g_{r}$ de formação de um núcleo, em função de seu raio $r . \Delta T r$, é o grau de superesfriamento; $r_{c}=$ raio crítico. . . . . 56

4.1 Amostra de diopsídio natural estudada neste trabalho. . . . . . . . . . . 62

4.2 Amostra de diopsídio artificial. . . . . . . . . . . . . . . . . . . . . 62

4.3 Vidro de diopsídio. . . . . . . . . . . . . . . . . . . . . . 63

4.4 Esquema do leitor TL Daybreak. . . . . . . . . . . . . . . . . 66

4.5 Espectros de transmitância dos filtros azul claro e do azul escuro. . . . . 67

4.6 Espectrômetro RPE que mostra as componentes individuais. . . . . . . 68

4.7 Diagrama de bloco de um aparelho de RPE Bruker. . . . . . . . . . . . 68

4.8 Esquema da esfera integradora do espectrômetro Cary 500 para as medidas de reflectância. . . . . . . . . . . . . . . . . 71

4.9 Esquema do espectrômetro Cary 500 para as medidas de absorção óptica. 71

5.1 Fluorescência de Raios X para a amostra de diopsídio natural. . . . . . 73

5.2 Difratograma de raios $X$ das amostras de diopsídio: (a)-padrão (b)natural, (c)-artificial puro, (d)-artificial com Al, (e)-artificial com Fe e (f)-artificial com Mn. . . . . . . . . . . . . . . 75

5.3 Difratograma de raios X do vidro de diopsídio. . . . . . . . . . . . . . 75

5.4 Curva de emissão TL para amostra natural de diopsídio. . . . . . . . . 76

5.5 (a) - Curva de emissão TL para amostra natural em função das diferentes doses de radiação. (b) - Comportamento do pico TL em $160{ }^{\circ} \mathrm{C}$, em função da dose-gama. . . . . . . . . . . . . . . . . . . . . . . . . . . 77

5.6 (a) - Curva TL da amostra natural para dose baixas até 50 Gy com pré-aquecimento em $600{ }^{\circ} \mathrm{C}$ por uma hora. (b) - Comportamento dos picos TL com as diferentes doses de radiação gama. . . . . . . . . . . . 78

5.7 (a) - Curva TL da amostra natural para dose de 50 Gy até 50 kGy com pré-aquecimento a $600{ }^{\circ} \mathrm{C}$ por uma hora. (b) - Comportamento dos picos TL para diferentes doses de radiação gama. . . . . . . . . . . . . 79

5.8 (a) - Curva de emissão TL após o tratamento em $160{ }^{\circ} \mathrm{C}$. (b) - Comportamento das intensidades do pico de $205{ }^{\circ} \mathrm{C}$ em função da dose. . . . 79

5.9 (a) - Curva de emissão TL após o tratamento em $205{ }^{\circ} \mathrm{C}$. (b) - Comportamento das intensidades do pico de $230{ }^{\circ} \mathrm{C}$ em função da dose. . . . 80

5.10 (a) - Curva TL com tratamento térmico de $900{ }^{\circ} \mathrm{C}$ por uma hora e submetida a diferentes doses. (b) - Intensidade TL em função da dose para a amostra aquecida em $900{ }^{\circ} \mathrm{C}$. . . . . . . . . . . . . . . . . . . 81 
5.11 (a) - Curva de emissão TL para amostra submetida a uma doses de 1 kGy com diferentes tratamentos térmicos. (b) - Efeito da temperatura do tratamento térmico sobre a intensidade máxima do pico em 160 $185{ }^{\circ} \mathrm{C}$ em função da temperatura. . . . . . . . . . . . . . . . . . . . 82

5.12 Decaimento isócrono dos picos TL na amostra natural recozida em $600^{\circ} \mathrm{C}$ por uma hora e irradiada com 5 kGy. . . . . . . . . . . . . . . . . . . 83

5.13 (a)-Decaimento isócrono usando a área total TL com o tratamento térmico. (b)- A derivada da curva de (a). . . . . . . . . . . . . 83

5.14 Energias de ativação obtidas com a técnica E-T $T_{\text {stop }}$. . . . . . . . . . 84

5.15 Deconvolução da curva TL do diopsídio . . . . . . . . . . . . . . . . 86

5.16 Espectro de emissão TL em representação 3D da amostra de diopsídio natural após irradiação beta de 1 kGy. . . . . . . . . . . . . . . . . . . 87

5.17 Curvas de nível da amostra natural após irradiação beta de 1 kGy. . . . 87

5.18 Curva de emissão TL do diopsídio natural com o tempo de irradiação de luz $U V$, as amostras foram previamente recozidas a $600{ }^{\circ} \mathrm{C}$ por uma hora e irradiadas com uma dose gama de 5 kGy. . . . . . . . . . . . . . 88

5.19 Decaimento do pico $T L$ de $160{ }^{\circ} \mathrm{C}$ com o tempo de irradiação de luz UV. 89

5.20 Curva de emissão TL do diopsídio natural recozido a $600{ }^{\circ} \mathrm{C}$ por uma hora e irradiada com luz UV.

5.21 Comportamento das intensidades dos picos em 90 e $170{ }^{\circ} \mathrm{C}$ em função do tempo de irradiação de luz UV. . . . . . . . . . . . . . . . . . . . . . 90

5.22 Curva de emissão TL do diopsídio artificial puro para diversas doses de radiação gama.

5.23 Comportamento das intensidades dos picos em 170 e $275^{\circ} \mathrm{C}$ em função de doses de radiação gama. . . . . . . . . . . . . . . . . . . . . . . . 92

5.24 Curva de emissão TL da amostra artificial dopada com Al com doses gama adicional. . . . . . . . . . . . . . . . . . . . 93

5.25 Crescimento dos picos TL com a dose gama na amostra artificial dopada com Al. . . . . . . . . . . . . . . . . . . . . . . . 93

5.26 Curva de emissão TL da amostra artificial dopada com Fe com doses gama adicional. . . . . . . . . . . . . . . . . . . 94

5.27 Comportamento dos picos TL com a dose gama na amostra artificial dopada com Fe. . . . . . . . . . . . . . . . . . . . . . . . . . 94

5.28 Curva de emissão TL da amostra artificial dopada com Mn para diversas doses de radiação gama. . . . . . . . . . . . . . . . . . . . 95 
5.29 Comportamento dos picos TL com a dose gama na amostra artificial dopada com Mn. . . . . . . . . . . . . . . . . . . . . . . . . . . . 95

5.30 Espectro de refletância da amostra natural. . . . . . . . . . . . . . . . . 96

5.31 Espectro de refletância da amostra natural irradiado com dose gama. . . 97

5.32 Espectro de refletância da amostra natural de diopsídio com diferentes tratamentos térmicos $\left(100\right.$ até $\left.500{ }^{\circ} \mathrm{C}\right)$ por uma hora. . . . . . . . . . . 98

5.33 Espectro de refletância da amostra natural de diopsídio com diferentes tratamentos térmicos $\left(500\right.$ até $\left.1000{ }^{\circ} \mathrm{C}\right)$ por uma hora. . . . . . . . . . 98

5.34 Comportamento com o tratamento térmico da banda em $1050 \mathrm{~nm}$. . . . 99

5.35 Comportamento com o tratamento térmico da banda em: (a) - 1390 nm. (b) - 1910 nm. (c) - 2310. (d) - 2385 nm. . . . . . . . . . . . 99

5.36 Espectro de refletância da amostra natural com tratamento térmico de $900{ }^{\circ} \mathrm{C}$ por uma hora e submetido a diferentes doses gama. . . . . . . . 100

5.37 Espectro de refletância das amostras artificiais. . . . . . . . . . . . . 100

5.38 Espectro de refletância das amostras artificiais na faixa de $300 \mathrm{~nm}$ a $750 n m \ldots \ldots \ldots \ldots 101$

5.39 Espectro RPE da amostra natural com uma potência de microondas de

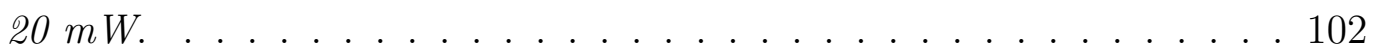

5.40 Intensidade RPE em função da potência de microondas para a amostra natural. Temperatura ambiente. . . . . . . . . . . . . 102

5.41 Espectro RPE da amostra de diopsídio natural submetida a diferentes doses de radiação gama. . . . . . . . . . . . . . . . . . . 103

5.42 Efeito da temperatura do tratamento térmico sobre os espectros de RPE do diopsídio natural. (a)-Com TT=400 ${ }^{\circ} \mathrm{C} / 1 \mathrm{hr}$. (b)-Com TT=900 ${ }^{\circ} \mathrm{C} / 1 \mathrm{hr}$. (c)-Na região de 1000 a 2000 G. (d)-Comportamento da intensidade $R P E$ em $g=4,3$ com a temperatura, é muito importante observar nesta figura o aumento na intensidade RPE, o que evidencia a mudança

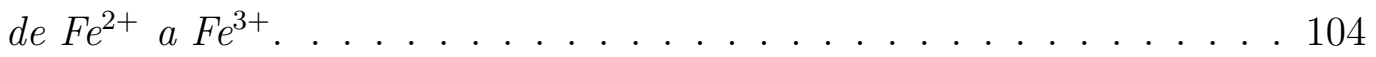

5.43 (a)-RPE do diopsídio natural com tratamento térmico em $400{ }^{\circ} \mathrm{C} / 1 \mathrm{hr}$. e, de uma amostra irradiada com 2 kGy previamente aquecida em 300 ${ }^{\circ} \mathrm{C} / 1 \mathrm{hr}$. (b)-RPE obtido da subtração das intensidades RPE das amostras tratadas termicamente em $400^{\circ} \mathrm{C}$ as de amostras irradiadas com diferentes doses gama com pre-aquecimento em $300^{\circ} \mathrm{C}$. (c)-Comportamento das linhas de RPE em g=2,007 com a irradiação gama. . . . . . . . . . 105

5.44 (a)-Espectro RPE da amostra natural a temperatura ambiente. (b)Espectro de RPE da amostra natural em baixa temperatura $(77 \mathrm{~K})$. . . 106 
5.45 Espectro de RPE da amostra natural (a)- amostra em pó. (b)-Com campo magnético paralelo ao eixo-c. . . . . . . . . . . . . . . 107

5.46 Espectro RPE da amostra natural e das amostras artificiais. . . . . . . 108

5.47 Espectro RPE da amostra pura submetida a diferentes doses de radiação gama. (a)-Em g=4,3 . (b)-Em g=2,007 . (c)-Comportamento da intensidade RPE em g=2,007 e g=4,3 com a irradiação gama. . . . . . . 109

5.48 Espectro RPE do vidro de diopsídio (a) de 0 a 5000 G (b) de 2500 a 5000. . . . . . . . . . . . . . . . . . 110

5.49 Espectro de absorbância do vidro de diopsídio. . . . . . . . . . . . . . . 110

6.1 Comparativo entre as intensidades TL da amostra natural e das amostras artificiais submetidas a uma dose de 1 kGy. . . . . . . . . . . . . . . 114

6.2 Esquema de niveis de energia do ion $\mathrm{Fe}^{2+}$ num campo de simetria octaedrica. . . . . . . . . . . . . . . . . . . . 117

6.3 Curvas de recozimento isócromo dos centros $E_{1}^{\prime}$, de Al e de Ti. . . . . . 120 


\section{Lista de Tabelas}

$2.1 \quad$ Valores médios de $T_{g}(K) \quad \ldots \ldots \ldots \ldots \ldots$. . . . . . . . . . . 51

4.1 Fontes de irradiação gama utilizados . . . . . . . . . . . . . 65

5.1 Energia de ativação e fator de freqüência para o diopsído . . . . . . . . . 85

7.1 Parâmetros associados às cinco armadilhas $T L \ldots \ldots$. . . . . . . . . 123 


\section{1}

\section{Introdução}

\subsection{Silício no universo e na terra: sua importância tecnológica}

Em termos de massa total, número de fases, abundância e sua distribuição no universo, o silício é um dos elementos mais abundantes cobrindo grande área da Terra.

Moléculas de $\mathrm{SiO}$ e SiS foram detectados por Zuckerman [1] e Cosmovici [2] como materiais interestelares. Segundo os minerálogos, o total de Si no gás interestelar pode ser equivalente a alguns porcentos daquele encontrado nas estrelas.

Além dos compostos gasosos de silício, compostos sólidos de silicatos têm sido observados por espectroscopia no intervalo do visível ao infravermelho próximo por Winnewisser et al. [3], ainda no espaço interestelar. Wada et al. [4] encontraram na poeira cósmica cerca de 32 compostos de silicatos. Dados semelhantes foram obtidos no sistema solar, mas, não serão apresentados aqui.

No caso do nosso planeta Terra, pouco se sabe da composição química do núcleo e do manto terrestre, por serem de difícil acesso. Conhece-se, porém, razoavelmente bem a composição química da crosta terrestre. Assim, sabe-se que o número de átomos de silício só é ultrapassado pelo de oxigênio segundo Ronov \& Yaroshevsky [5] e Mieke $[6]$. 


\subsection{Minerais de Silicatos}

Os silicatos constituem uma classe mineral da maior importância, pois representam cerca de $25 \%$ dos minerais conhecidos e quase $40 \%$ dos mais comuns. Com alguns menos significativos, todos os minerais que formam as rochas ígneas são silicatos, que constituem cerca de $90 \%$ do volume da crosta terrestre. Dessa maneira, a grande maioria das rochas é formada por silicatos [7]. Suas propriedades dependem das condições físicas e químicas em que foram formados. A maioria dos silicatos é encontrada como constituintes das rochas eruptivas, formados a temperaturas e pressões elevadas.

A unidade fundamental dos silicatos, sobre a qual se baseia a estrutura de todos estes compostos, consiste de 4 íons de oxigênio nos vértices de um tetraedro regular, rodeando um íon de Silício tetravalente e coordenados por este (Figura 1.1). A relação do raio do silício tetravalente $(0,42 \AA)$ para o raio do íon do oxigênio $(1,40 \AA)$ é de 0,318. A forte ligação que mantém este tetraedro unido é, literalmente, o cimento que sustenta a crosta terrestre. Esta ligação se origina, em parte, da atração iônica devida às cargas opostas, e em parte da interpenetração das nuvens eletrônicas (covalência). Na ligação Si-O, a energia total do Si está distribuída igualmente entre os oxigênios vizinhos. Em conseqüência, a energia de qualquer ligação Si-O isolada é menor do que a energia total disponível no íon O. Portanto, cada oxigênio pode ainda se ligar a outro silício, entrando em outro agrupamento tetraédrico. Assim, grupos de tetraedros podem ser fortemente unidos, e como os quatro oxigênios são equivalentes, existe na natureza um grande número de configurações estruturais possíveis.

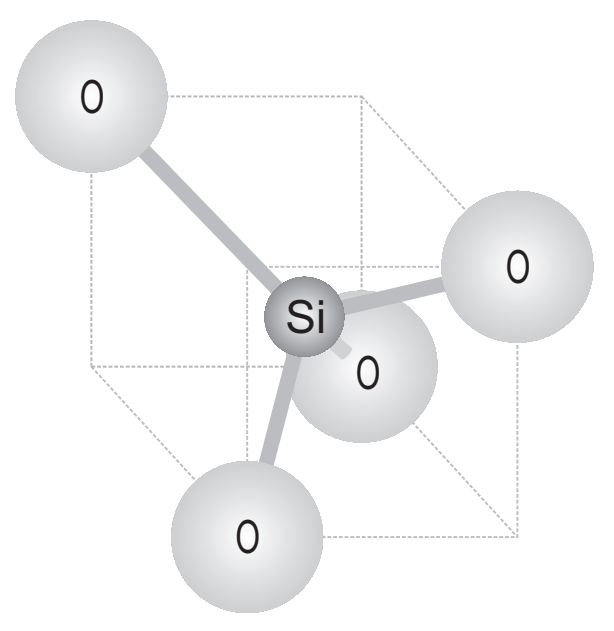

Figura 1.1: Tetraedro de $\mathrm{SiO}_{4}$ regular inscrito em um cubo (raio iônico $\mathrm{Si}=0,42 \AA$ e $\mathrm{O}=1,40 \AA)$. 

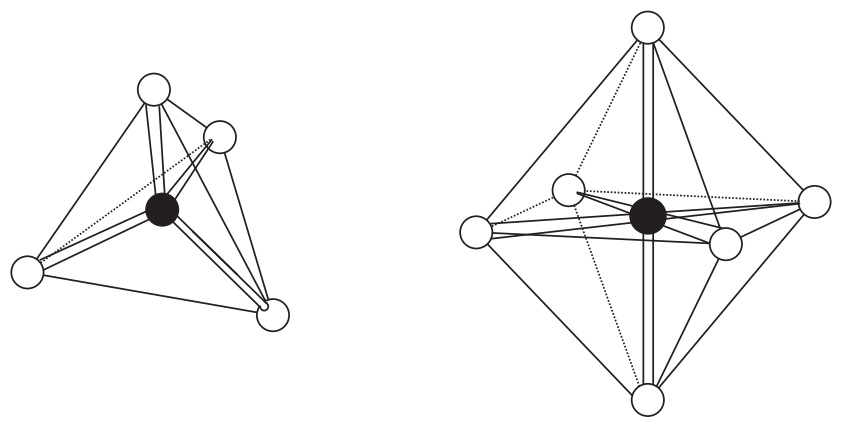

$1,62 \AA$

$2,64 \AA$

$\begin{array}{ll}<\mathrm{d}(\mathrm{Si}-\mathrm{O})> & 1,77 \AA \\ <\mathrm{d}(\mathrm{O}-\mathrm{O})> & 2,50 \AA\end{array}$

Figura 1.2: Distancias médias entre os íons de $\mathrm{Si}$ e $\mathrm{O}$ para o tetraedro $\left[\mathrm{SiO}_{4}\right]$ e octaedro $\left[\mathrm{SiO}_{6}\right]$.

A fórmula geral dos silicatos pode ser escrita na seguinte maneira:

$$
M_{r^{\prime}}^{\prime} M_{r^{\prime \prime}}^{\prime \prime} \ldots S_{s} O_{t}
$$

ou na forma de óxidos:

$$
q^{\prime} M^{\prime} r^{\prime} O q^{\prime \prime} M^{\prime \prime} r^{\prime \prime} O \ldots s S i O_{2}
$$

Onde os cátions M podem ser mono, di, tri, tetra e pentavalentes, metálicos ou fortemente metálicos.

Os íons M metálicos são maiores e têm valências menores do que os íons de silício, as ligações M-O são mais fracas do que as ligações Si-O. Isto significa que o silício atrai mais fortemente os íons de oxigênio do que os íons metálicos, formando tetraedros $\left[\mathrm{SiO}_{4}\right]$, com uma distância media $(\mathrm{Si}-\mathrm{O})=1,62 \AA$ e coordenação 4. Por outro lado, se M, é um metalóide ${ }^{1}$, a ligação M-O pode ser comparável com a ligação Si-O. Os átomos do metalóide, que têm uma carga formal alta, podem competir com os átomos do silício na atração de íons de oxigênio. Assim, essa competição produz uma distancia (Si-O) maior, da ordem de 1,77 A, favorecendo a formação de Si numa coordenação octaédrica (Figura 1.2) [8].

\section{Classificação dos silicatos}

$\mathrm{O}$ arranjo dos tetraedros $\mathrm{SiO}_{4}$ e a relação $\mathrm{Si}$ :O na fórmula química que representa o silicato dão origem ao critério de classificação empregada na Mineralogia [9]. Nessa classificação, existem os silicatos com estrutura em anel, em cadeias, em folhas, e em estruturas tridimensionais.

\footnotetext{
${ }^{1}$ Têm as propriedades intermediárias entre aquelas dos metais e dos não-metais
} 
Os tipos de silicatos são classificados de acordo com a formação interativa dos tetraedros (Figura 1.3). Cada grupo tem uma relação definida entre o silício e o oxigênio, mas em alguns minerais os átomos de silício são substituídos por outros átomos. Em muitas instâncias, os íons de silício são substituídos pelos de alumínio e, em geral, por outros elementos em menor grau, por exemplo, o germânio, titânio, ferro, berílio, etc. Impurezas como metais de transição provocam transições no visível, entre estados $d$ e $f$ desdobrados pelo campo cristalino. Estas são responsáveis pelas inúmeras colorações dos silicatos na natureza $[10,11]$.

A classificação dos silicatos em grupos baseada na formação interativa dos tetraedros é:

- Nesosilicatos ou ortosilicatos, estes minerais são formados por unidades independentes de $\mathrm{SiO}_{4}$ (isto é, sem compartilhamento de oxigênios). As cargas negativas dos tetraedros são atendidas apenas por $\mathrm{Fe}^{2+} \mathrm{e} / \mathrm{ou} \mathrm{Mg}^{2+}$, que os interligam. Desses minerais, as olivinas são as mais comuns.

- Sorosilicatos, dois tetraedros unidos por um vértice formando um grupo $\left[\mathrm{Si}_{2} \mathrm{O}_{6}\right]^{2-}$, exemplo: epidoto.

\section{- Inosilicatos}

a) Cadeia simples (Figura 1.4a), esta estrutura característica dos piroxenos compreende a união de dois oxigênios de cada tetraedro para formar uma cadeia simples e comprida. Unidades $\left[\mathrm{SiO}_{4}\right]_{n}^{2-}$ ou $\mathrm{Si}_{2} \mathrm{O}_{6}$. A augita é o mineral mais comum deste tipo.

b) Cadeias duplas (Figura 1.4b), esta estrutura se forma mediante a junção de duas cadeias simples, de modo que se unam por meio de 2 oxigênios para cada tetraedro (exemplo anfibólios). A unidade básica é: $\left(\mathrm{Si}_{4} \mathrm{O}_{11}\right)_{n}^{6-}$.

- Ciclosilicatos, dois a quatro tetraedros unem-se formando anéis, exemplo turmalina.

- Filosilicatos, esta estrutura é característica das micas. O cristal, formado de empilhamento de camadas muito delgadas, tem aspecto semelhante ao de uma pilha de folhas de papel. As camadas apresentam estrutura em lâminas. A biotita e a muscovita são chamadas de laminares 2:1 onde os ions em coordenação octaédrica se unem aos oxigênios apicais de duas laminas de tetraedros. A relação 
2:1 se refere ao número de camadas de cátions em coodenação tetraédrica em relação ao número de camadas de cátions em coordenação octaédrica.

- Tectosilicatos, os tetraedros formam uma rede complexa com presença do alumínio em lugar do silício em alguns tetraedros o que requer a presença de diversos cátions $\left(\mathrm{Na}^{+}, \mathrm{Ca}^{2+}, \mathrm{K}^{+}\right)$, exemplos: feldspatos e quartzo.

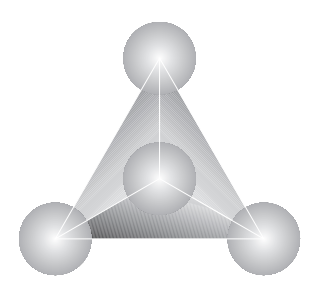

Nesosilicatos

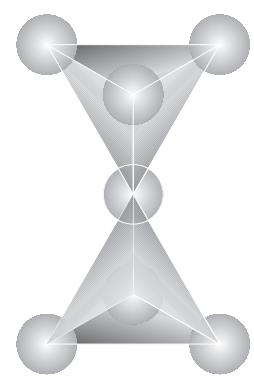

Sorosilicatos

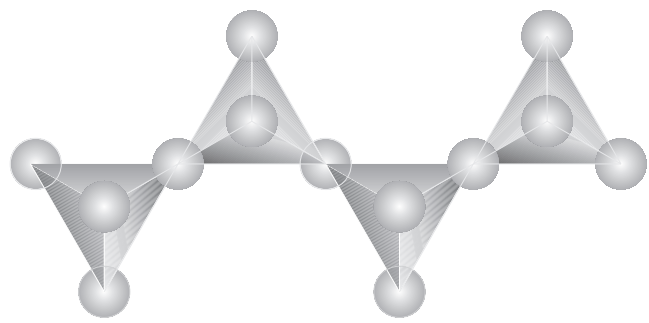

Inosilicatos

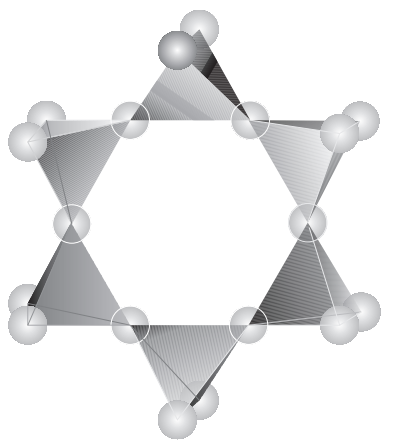

Ciclosilicatos

Figura 1.3: Tipos de silicatos de acordo com a formação dos tetraedros.
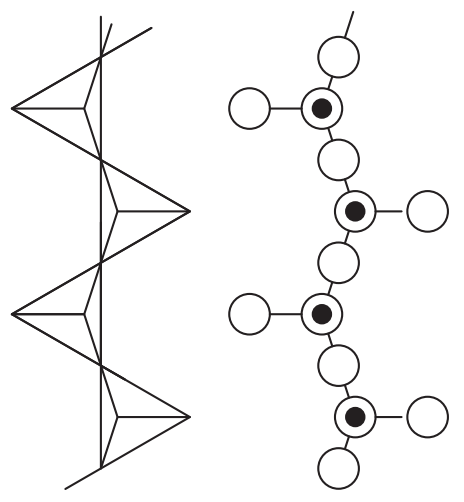

(a)

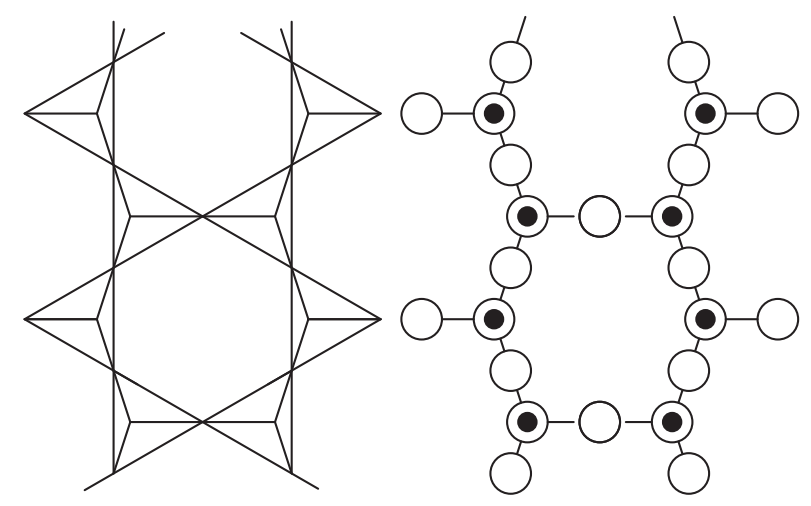

(b)

Figura 1.4: Inosilicatos de cadeia (a) simples e (b) dupla. 


\subsection{Silicatos do grupo de piroxenos}

Os piroxenos $^{2}$ formam o grupo mais importante dos minerais ferromagnesianos constituintes das rochas, ocorrendo como fases estáveis em quase todos os tipos de rochas ígneas. Os piroxenos também se encontram em muitas rochas de composição muito variada e formam-se sob condições, quer de metamorfismo regional ${ }^{3}$, quer de metamorfismo de contacto ${ }^{4}$.

\subsubsection{Nomenclatura e fórmula dos piroxenos}

O grupo dos piroxenos inclui tanto minerais ortorrômbicos como monoclínicos. O subgrupo dos minerais ortorrômbicos (ortopiroxenos) consiste, essencialmente, numa série química simples com minerais de composição $(\mathrm{Mg}, \mathrm{Fe}) \mathrm{SiO}_{3}$, em contraste com o maior grupo dos piroxenos monoclínicos (clinopiroxenos) o qual tem uma extensa variação da sua composição química. Um elevado número de clinopiroxenos pode ser considerado, numa primeira abordagem, como membros de um sistema de quatro componentes $\mathrm{CaMgSi}_{2} \mathrm{O}_{6}-\mathrm{CaFeSi}_{2} \mathrm{O}_{6}-\mathrm{Mg}_{2} \mathrm{Si}_{2} \mathrm{O}_{6}-\mathrm{Fe}_{2} \mathrm{Si}_{2} \mathrm{O}_{6}$. Na Figura 1.5 indica-se a nomenclatura usada para descrição destes piroxenos [12]. Nos minerais que constituem a série dos clinopiroxenos, as substituições isomórficas não se limitam à mútua substituição de cátions bivalentes; na Figura 1.6 indicam-se os campos das composições químicas da grande maioria dos piroxenos, das quais os íons monovalentes e trivalentes são constituintes importantes [12].

Os piroxenos podem ser considerados, globalmente, em termos de três subgrupos principais: piroxenos de magnésio e ferro, nas quais os outros cátions ocupam menos de $10 \%$ das posições M1 e M2 da fórmula geral $\left[(M 2)(M 1) T_{2} O_{6}\right]$, onde $T=S i, A l$; piroxenos cálcicos, nas quais o Ca ocupa mais de dois terços das posições M2 e os piroxenos sódicos, nas quais a posição M2 é ocupada principalmente pelo Na e as posições M1 pelo $\mathrm{Al}, \mathrm{Fe}^{3+}$ ou $\mathrm{Cr}$, como na jadeita, aegirina e cosmoclor, respectivamente. Há ainda a considerar dois subgrupos menores, os piroxenos de cálcio e sódio, representadas pela onfacita e pela aegirina-augita e aos piroxenos de lítio representados pelo espodumênio.

\footnotetext{
${ }^{2}$ Alguns preferem a denominação piroxênio

${ }^{3}$ Metamorfismo regional: as rochas pré-existentes são modificadas por um aumento de temperatura e de tensões não-litostáticas. O metamorfismo regional está relacionado com limites convergentes, onde se verificam altas temperaturas e pressões.

${ }^{4}$ Metamorfismo de contacto: está directamente relacionado com as intrusões magmáticas. Como estão a temperaturas muito elevadas, causam uma instabilidade nos minerais das rochas envolventes à inclusão magmática. Essa instabilidade vai levar ao rearranjo estrutural dos minerais.
} 
Piroxenos de ferro e magnésio

Ortopiroxenos (enstatita - ferrossilita)

$(\mathrm{Mg}, \mathrm{Fe})_{2} \mathrm{Si}_{2} \mathrm{O}_{6}$

Clinoenstatita - clinoferrossilita

$(\mathrm{Mg}, \mathrm{Fe})_{2} \mathrm{Si}_{2} \mathrm{O}_{6}$

Pigeonita

$\left(\mathrm{Mg}, \mathrm{Fe}^{2+}, \mathrm{Ca}\right)\left(\mathrm{Mg}, \mathrm{Fe}^{2+}\right) \mathrm{Si}_{2} \mathrm{O}_{6}$

Piroxenos cálcicos

Diopsidio - hedembergita

$$
\mathrm{Ca}(\mathrm{Mg}, \mathrm{Fe})_{2} \mathrm{Si}_{2} \mathrm{O}_{6}
$$

Augita

$\left(\mathrm{Ca}, \mathrm{Mg}, \mathrm{Fe}^{2+}, \mathrm{Al}\right)_{2}(\mathrm{Si}, \mathrm{Al})_{2} \mathrm{O}_{6}$

Piroxenos com cálcio e sódio

Onfacita

$(\mathrm{Ca}, \mathrm{Na})\left(\mathrm{Mg}, \mathrm{Fe}^{2+}, \mathrm{Fe}^{3+}, \mathrm{Al}\right) \mathrm{Si}_{2} \mathrm{O}_{6}$

Aegirina - augita

$$
(\mathrm{Ca}, \mathrm{Na})\left(\mathrm{Mg}, \mathrm{Fe}^{2+}, \mathrm{Fe}^{3+}\right) \mathrm{Si}_{2} \mathrm{O}_{6}
$$

Piroxenos sódicos

Jadeíta

$\mathrm{NaAlSi}_{2} \mathrm{O}_{6}$

Aegirina

$\mathrm{NaFe}^{3+} \mathrm{Si}_{2} \mathrm{O}_{6}$

Piroxenos de lítio

Espodumênio

$\mathrm{LiAlSi}_{2} \mathrm{O}_{6}$

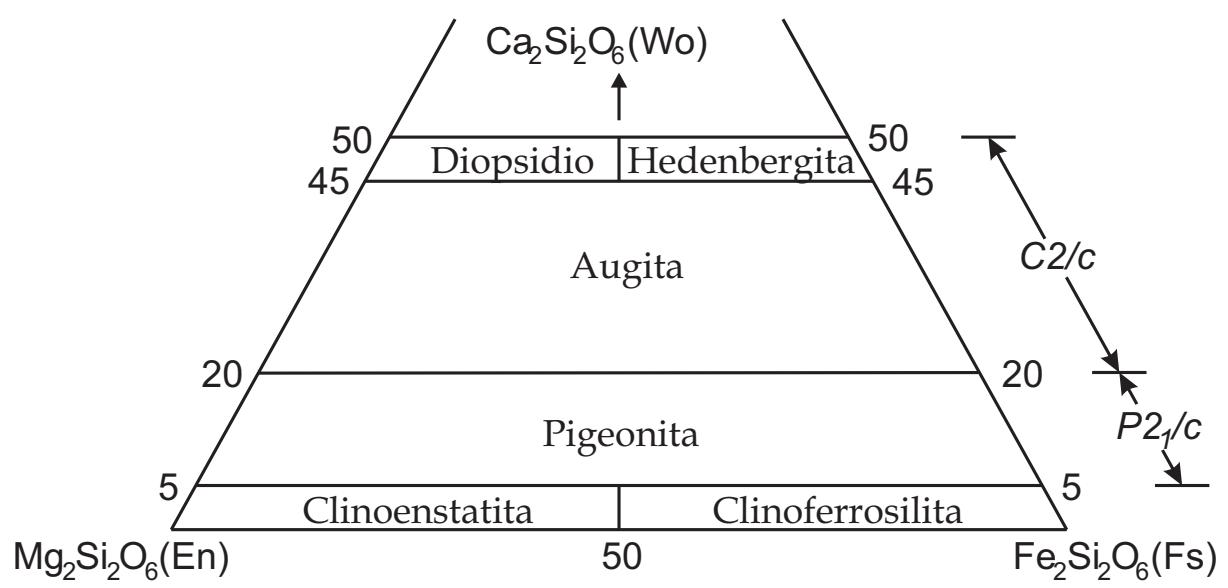

(a)

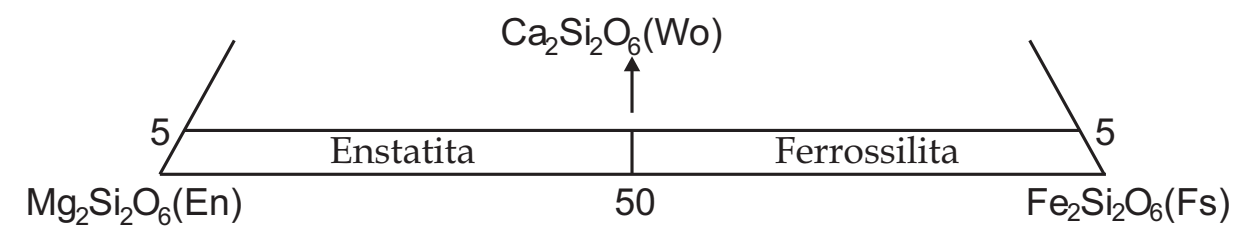

(b)

Figura 1.5: Variações da composição química e nomenclatura de (a) clinopiroxenos de $\mathrm{Ca}-\mathrm{Mg}-\mathrm{Fe}$ e (b) ortopiroxenos. 


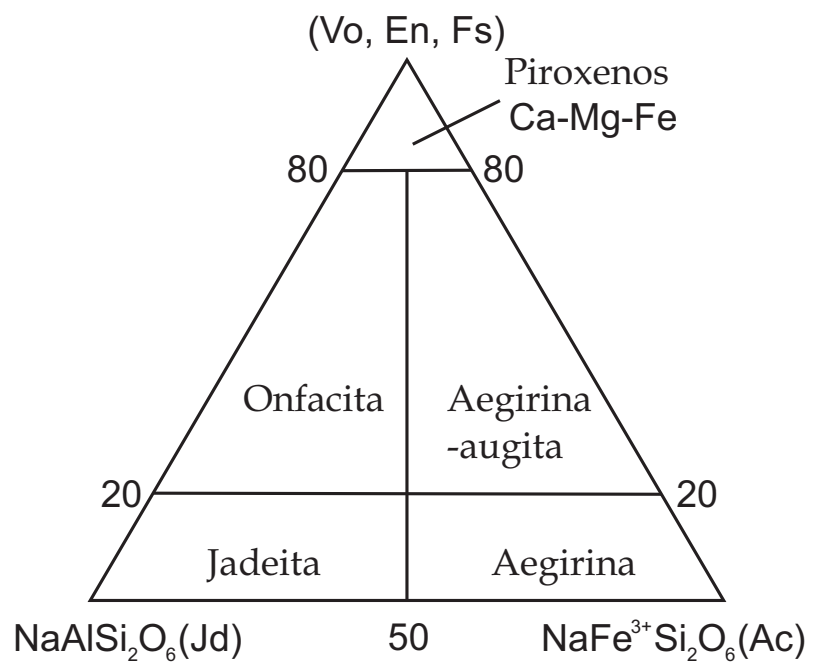

Figura 1.6: Variações da composição química e nomenclatura dos piroxenos mais comuns $(\mathrm{Ca}-\mathrm{Mg}-\mathrm{Fe})$ e piroxenos com $\mathrm{Na} e \mathrm{Fe}^{3+}$.

\subsubsection{Composição química}

Em termos estruturais, a fórmula dos piroxenos pode ser expressa como $\mathrm{M}_{2} \mathrm{M}_{1} \mathrm{~T}_{2} \mathrm{O}_{6} \mathrm{em}$ que M2 e M1 correspondem a cátions com coordenação octaédrica geralmente distorcida e regular, respectivamente, e T refere-se a cátions com coordenação tetraédrica. Na Figura 1.7 representa-se a ocupação ideal das posições M1, M2 e T e a ordem de repartição dos átomos, geralmente aceito, por essas posições [12]. A composição química de muitos piroxenos $\mathrm{Mg}-\mathrm{Fe}$ e cálcicos ${ }^{5}$ pode ser representada pela fórmula.

$$
M 2\left(R^{2+}\right) M 1\left(R^{2+}\right) T_{2}\left(2 R^{4+}\right) O_{6}
$$

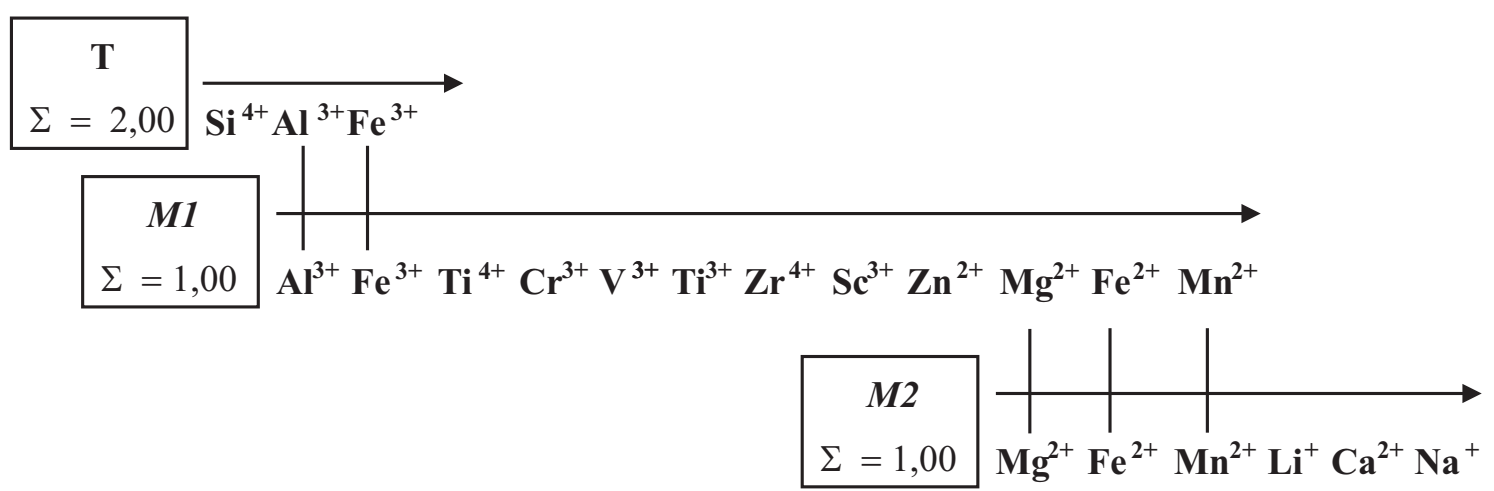

Figura 1.7: Gráfico que mostra a ocupação ideal e a ordem de ocupação dos átomos para as posições T, M1 e M2 na estrutura do piroxeno.

\footnotetext{
${ }^{5}$ Piroxenos cálcicos: diopsídio, hedembergita e augita
} 


\subsubsection{Estrutura dos piroxenos}

A estrutura do grupo dos piroxenos baseia-se em duas unidades: 1-Tetraedros de silício-oxigênio ligados por dois vértices formam uma cadeia infinita $\left(\mathrm{TO}_{3}\right)^{2-}$ paralelo ao eixo - $z$ e, com, a base de cada um dos tetraedros numa disposição aproximadamente paralela ao plano (001). A distância que se repete ao longo do comprimento da cadeia é 5,2 A definindo assim o parâmetro $c$ da célula unitária. 2-As cadeias são ligadas lateralmente por camadas octaédricas contendo cátions $\mathrm{M}(\mathrm{Ca}, \mathrm{Mg}, \mathrm{Fe}, \mathrm{Na}$, etc. ) com coordenação 6-8. Esses poliedros compartilham arestas formando folhas contínuas ou bandas, que se dispõem no plano (100) e são paralelas ao eixo - $z$.

Os cátions M da camada octaédrica ocupam duas posições diferentes, M1 e M2 (Figura 1.8) [13]. Os átomos M1 dispõem-se principalmente entre os vértices das cadeias $\mathrm{SiO}_{3}$, enquanto os átomos M2 se dispõem principalmente entre as bases da cadeia. M2 é a posição ocupada pelo Ca no diopsidio e, em geral, quando está presente um íon de raio maior ( $\mathrm{Ca}, \mathrm{Na}$ ) este ocupa a posição $\mathrm{M} 2$ e não a posição M1. A coordenação do oxigênio em redor de M1 é, aproximadamente, um octaedro regular, mas a coordenação da posição M2 é irregular, variando de acordo com o átomo presente, coordenação 6 para o $\mathrm{Mg}$ e coordenação 8 para Ca e Na.

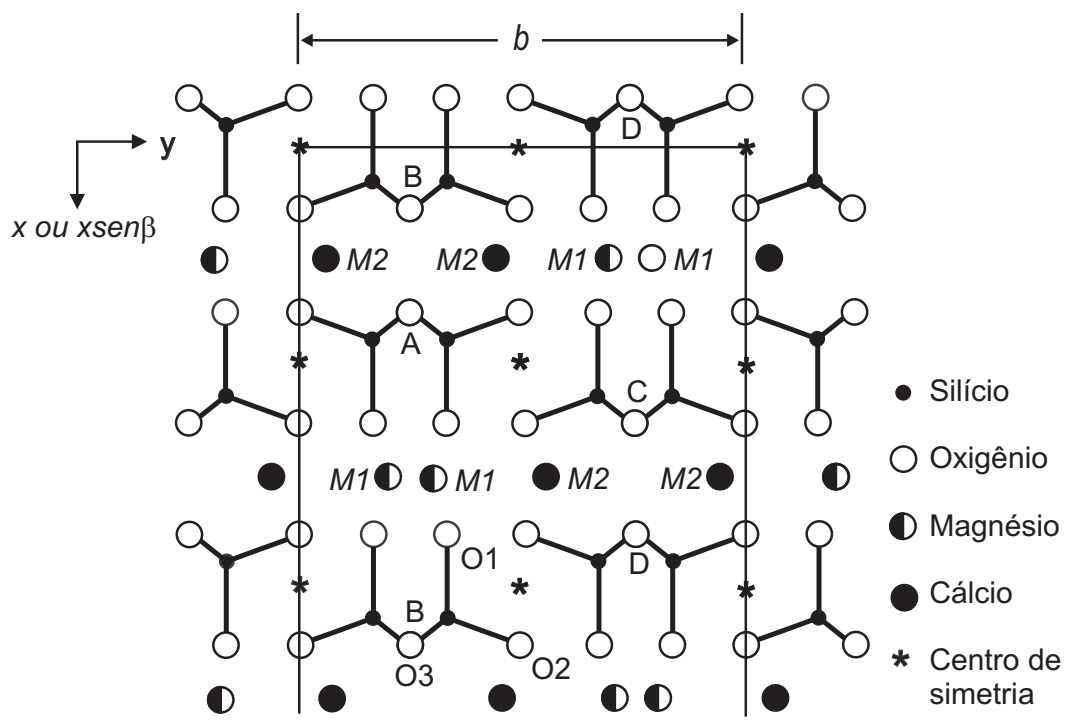

Figura 1.8: Projeção ao longo do eixo -z da estrutura idealizada de um piroxeno, mostrando as cadeias dos piroxenos e as duas posições distintas dos cátions, M1 e M2. Mais afastados vêem-se os poliedros de oxigênios que também formam cadeias ou bandas paralelas ao eixo - z. Nos piroxenos com o grupo espacial C2/c, as cadeias Si-O nas posições $A, B, C$ e $D$ são todas equivalentes. Nos piroxenos com grupo espacial $P \mathscr{Q}_{1} /$ c e Pbca, $C=A$ e $D=B$, mas $A$ e $B$ não são equivalentes. 


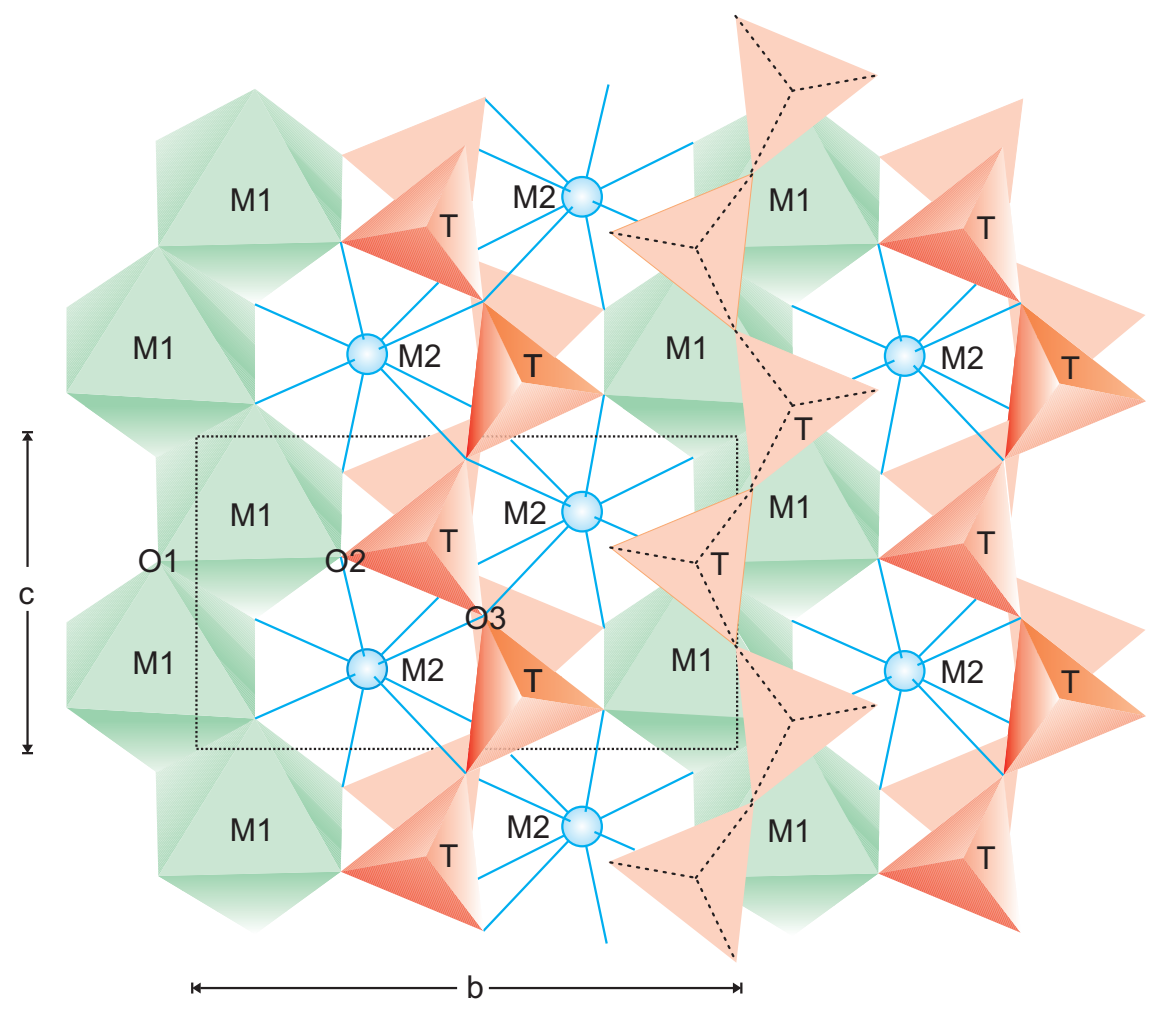

Figura 1.9: A estrutura do piroxeno projetado no plano (100) mostrando as posições M1 e M2 para os cátions.

Os oxigênios (O1 e O2) que coordenam M1 não são de ligação (isto é, pertencem somente a um tetraedro da cadeia de piroxeno), o átomo M2 está coordenado parcialmente pelos oxigênios (O3) que são de ligação (oxigênios ponte, isto é, servem de ponte entre tetraedros vizinhos) [14]. A projeção ao longo do eixo y de uma estrutura idealizada de um piroxeno (Figuta 1.9) mostra que as cadeias $\left[\mathrm{SiO}_{3}\right]$ se dispõem base com base, sem qualquer deslocamento segundo a direção $y$; não mostra como é que elas estão dispostas relativamente a uma outra cadeia paralela ao comprimento e nem revela quaisquer diferenças entre as cadeias. Estes dois aspectos são em grande parte determinados pela natureza e proporções dos diferentes cátions presentes na estrutura.

\subsection{Diopsídio}

O diopsídio é um silicato de cálcio e magnésio de fórmula química $\mathrm{CaMgSi}_{2} \mathrm{O}_{6}$, que faz parte dos minerais da série diopsídio-hedembergita, que forma uma série de soluções sólidas entre $\mathrm{CaMgSi}_{2} \mathrm{O}_{6}$ e $\mathrm{CaFeSi}_{2} \mathrm{O}_{6}$ pertencentes à classe dos inosilicatos e grupo de piroxenos cálcicos. Seu nome vem de duas palavras gregas, dupla e aparência, pois a zona vertical do seu prisma pode ser orientada de duas maneiras. Ele é monoclínico, 
$2 / m$, grupo espacial $C 2 / c$. Sua cor pode ser branco ou verde. Os diopsídios que contêm um alto teor de Cr têm coloração esverdeada. É clivável $\{100\}$ a $87^{\circ} \mathrm{e} 93^{\circ}$. São comuns em rochas metamórficas e são produtos de cristalização ígnea. Frequentemente é encontrado associado à calcita e à fosferita. Suas variedades transparentes são usadas como gemas.

Warren \& Bragg [15] foram os primeiros que estudaram a estrutura do cristal do diopsídio. Segundo esses autores, a estrutura do diopsídio, visto ao longo de $z$ (plano $x y$ ) e ao longo de $y$, estão representados nas Figura 1.10a e 1.10b, respectivamente. As posições M1 são ocupadas por Mg e M2, por Ca. Na Figura 1.10b, os átomos de Ca e Mg estão ligeiramente deslocados das suas posições reais que são superpostas, para se ter a visão de suas posições.

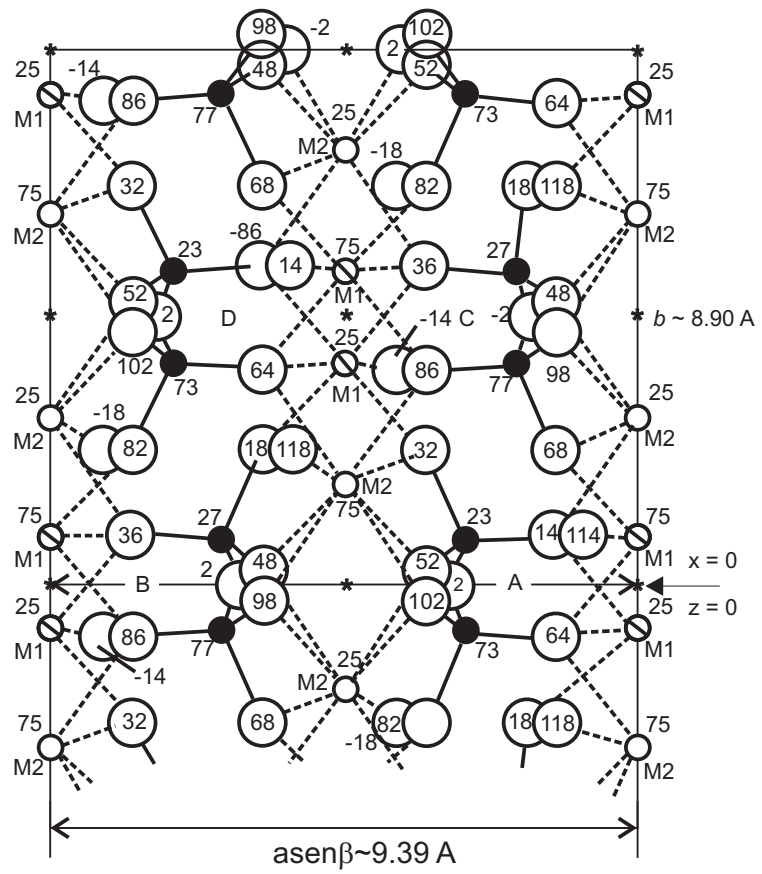

(a)

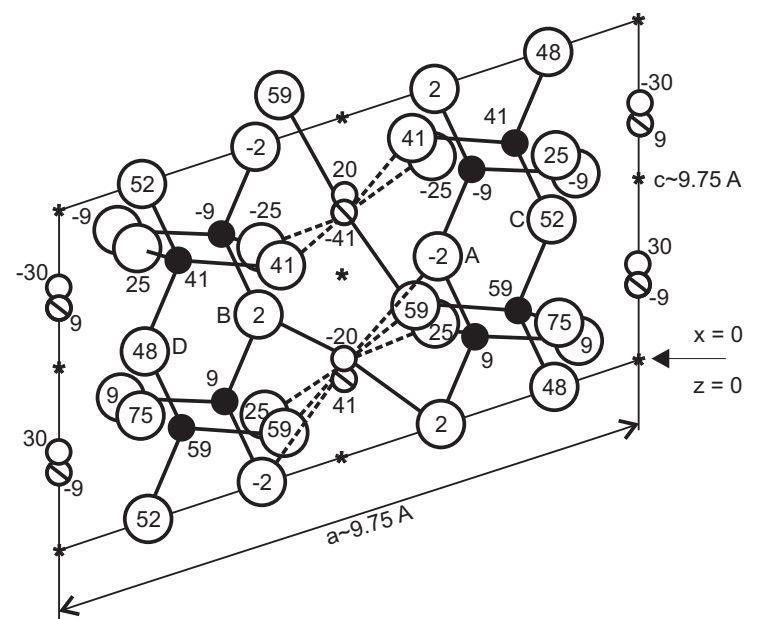

(b)

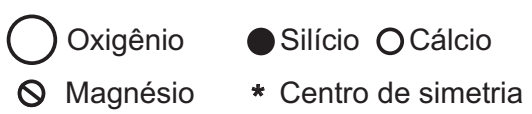

Figura 1.10: Estrutura idealizado do diopsídio, mostrando as posições das cadeias $A, B, C, D$ e as coordenadas atômicas: (a) observada ao longo do eixo z; (b) ao longo do eixo y. Em (a) alguns átomos de oxigênio sobrepõem-se a outros átomos de oxigênio que foram ligeiramente deslocados. Em (b) os átomos de Ca e Mg deviam estar perfeitamente sobrepostos, mas foram ligeiramente deslocados. 


\subsection{Trabalhos realizados até o momento por outros autores}

Warren \& Bragg [15] foram os primeiros em determinar a estrutura do cristal do diopsídio, subsequentemente foi complementado por Clark et al. [16, 17]. Cameron et al. [18] e Finger et al. [19] estudaram as variações dos parametros da estrutura do diopsídio com a temperatura, aproxidamente até $900{ }^{\circ} \mathrm{C}$. Nolam \& Edgar [20] determinaram os parâmetros da célula unitária para um diopsídio sintético.

Devido à importância do diopsídio na obtenção de cerâmicas e vidros, foram reportados vários trabalhos teóricos e experimentais que abordam as condições de obtenção e, as propriedades desses materiais [21, 22, 23, 24, 25].

White et al. [26, 27] foram os primeiros a medir e analisar o espectro de absorção do diopsídio, atraves do estudo da banda em torno de $1000 \mathrm{~nm}$, sendo essa banda associada ao íon ferroso. Por outro lado, Bancroft and Burns [28] mediante medidas de espectro de absorção polarizada e medidas de Mössbauer em piroxenos, mostraram que a banda em $1000 \mathrm{~nm}$ é devido ao $\mathrm{Fe}^{2+}$ em posição octaédrica.

Hunt et al. $[29,30]$ reportaram espectros de refletância de 87 silicatos, na faixa de 325 $\mathrm{nm}$ ate $2500 \mathrm{~nm}$. Os espectros são explicados em termos de transições eletrônicas dos cátions ou impurezas entre os quais o ferro e o cromo são encontrados nas amostras estudadas, ou em termos de processos vibracionais de anions constitucionais, substitucionais ou como impureza. No caso do diopsídio eles identificaram bandas de refletância em: 450, 650, 1070, 1400, 1900, 2320 e 2450 nm. Eles mostraram que as amostras de diopsídio estudadas contém íons ferroso e férrico responsaveis pelas bandas de refletância em 450, 650 e 1070 nm. Também encontraram nesse diopsídio o íon de $\mathrm{Cr}$, que possivelmente substitui o $\mathrm{Mg}$ contribuindo também nas bandas de refletância em 450 e $650 \mathrm{~nm}$. Por outro lado, dentro dos processos vibracionais eles observaram as bandas de 1400 e 1900 nm devido à água e/ou hidroxila.

Schreiber [31] estudou as bandas devido ao Cr em diopsídio sintético azul, concluindo que a cor azul do diopsídio está associada com a estabilização de uma pequena porção do cromo total como Cr(IV) dentro da estrutura do diopsídio.

Herd et al. [32] analisaram a cor violeta de um diopsídio natural e concluíram que a cor violeta é devido à transferência de carga entre $\mathrm{Fe}^{2+}$ e $\mathrm{Ti}^{4+}$ na posição M1 da estrutura do diopsídio. Mediante a catodoluminescência demonstraram que o $\mathrm{Mn}^{2+}$ está presente no lugar M1 e também, mediante a espectroscopia de absorção concluíram que o $\mathrm{Mn}^{3+}$ não contribui à cor violeta. 
Em que posição $\mathrm{Mn}^{2+}$ entra no diopsídio tem sido objeto de estudo de alguns autores. Vinokurov et al. [33] compararam a orientação dos eixos RPE (Ressonãncia Paramagnética Eletrônica) em relação às posições da vizinhança imediata dos íons, que poderiam ser substituídos pelo $\mathrm{Mn}^{2+}$. A sua conclusão foi de que, os cátions $\mathrm{Mn}^{2+}$ podem entrar tanto nos sítios M1 como M2 e, que o $\mathrm{Mn}^{2+}$ no lugar de $\mathrm{Ca}^{2+}$ é responsável pelo espectro com estrutura hiperfina mais intensa. Ghose \& Schindler [34] confirmaram as constantes da Hamiltoniana do spin, determinadas por Vinokurov et al., mas, obtiveram uma inversão nas posições anteriormente supostas. Como a razão de concentração de $\mathrm{Mn}^{2+}$ no lugar de $\mathrm{Ca}^{2+}$ e de $\mathrm{Mg}^{2+}$ depende das condições de crescimento dos cristais, era importante obter um espectro que pudesse distinguir $\mathrm{Mn}^{2+}$ nas duas posições. A fim de resolver essa questão, Gaite [35] fez medidas com muito cuidado dos espectros de RPE de $\mathrm{Mn}^{2+}$, interpretando cada espectro através das constantes de estrutura fina da hamiltoniana do spin. O resultado permitiu-lhe distinguir o espectro devido ao $\mathrm{Mn}^{2+}$ em M1 daquele do $\mathrm{Mn}^{2+}$ em M2. Conclui o autor que, a vizinhança do $\mathrm{Mn}^{2+}$ em M1 tem uma simetria pseudo-cubica, enquanto que $\mathrm{Mn}^{2+}$ em M2 está numa vizinhança bastante distorcida.

Michouler \& Gaite [36] localizaram $\mathrm{Fe}^{3+}$, usando o mesmo método de determinação do sitio para $\mathrm{Mn}^{2+}$, mostraram que o $\mathrm{Fe}^{3+}$ deve ocupar o sitio $\mathrm{M} 1$, porque este é menor e mais distorcido, em concordância com resultados cristalográficos.

Michoulier et al. [37] observaram sinais RPE correspondentes às transições permitidas de $\Delta \mathrm{S}_{z}= \pm 1 / 2$ do estado fundamental ${ }^{6} \mathrm{~S}_{1 / 2}$ do íon $\mathrm{Fe}^{3+}$ num monocristal de diopsídio. As posições dessas transições evoluem com a orientação do campo magnético; a dependência angular do espectro medido apresentou a simetria ortorrômbica com o eixo binário segundo o eixo $b$ do monocristal. Também observaram no mesmo diopsídio os espectros do íon $\mathrm{Mn}^{2+}$ substituindo os sítios de $\mathrm{Ca}$ e $\mathrm{Mg}$. Esses $\mathrm{Mn}^{2+}$ são diferenciados pelas amplitudes da estrutura hiperfina, que são diferentes e característicos dos sítios de Ca e Mg. Eles concluíram também que os eixos RPE do íon $\mathrm{Fe}^{3+}$ coincidem com os do espectro do íon $\mathrm{Mn}^{2+}$ na posição do Ca.

Nenhum trabalho sobre termoluminescência do diopsídio natural ou artificial foi encontrado na literatura. 


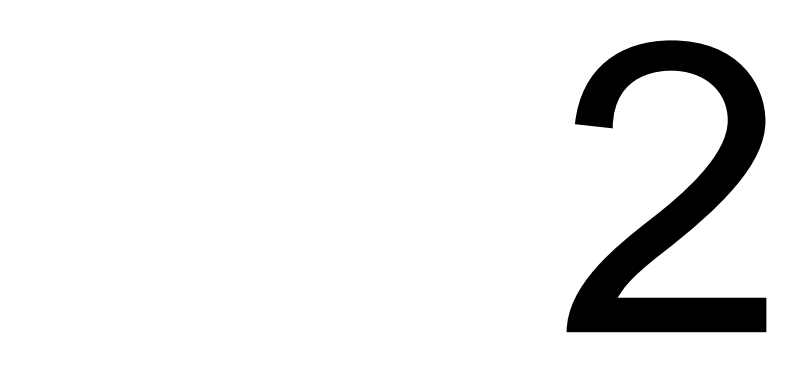

\section{Conceitos Básicos}

\subsection{Cristais perfeitos e cristais reais}

Uma estrutura cristalina perfeita é constituída pela repetição infinita, regular de um agrupamento elementar de átomos ou moléculas. Nos cristais como o ouro ou a prata, a unidade elementar que se repete é o elemento de que o cristal é formado. Há, porém, muitos cristais que são constituídos pela repetição de um conjunto de átomos ou moléculas. Mesmo tratando-se de uma abstração, o conceito de cristal ideal é um modelo bastante aproximado dos cristais reais e permite estudar e compreender mais facilmente, muitos fenômenos e grande parte das propriedades mais elementares de estruturas reais.

\subsubsection{Rede cristalina}

Conceitualmente, um cristal ideal tridimensional é descrito como um conjunto de átomos dispostos numa rede definida por três vetores linearmente independentes $\boldsymbol{a}$, $\boldsymbol{b}, \boldsymbol{c}$, chamados vetores base, ou vetores fundamentais de translação da rede, de modo que o arranjo atômico é, em todos os aspectos, semelhante quando observado de dois pontos, com vetores posição $\boldsymbol{r}$ e $\boldsymbol{r}_{0}$, relacionadas através de: 


$$
\boldsymbol{r}=\boldsymbol{r}_{0}+h \boldsymbol{a}+k \boldsymbol{b}+l \boldsymbol{c}
$$

com $h, k$ e $l$ inteiros arbitrários. Supondo $\boldsymbol{r}_{0}$ fixo, ao conjunto de pontos que se obtém variando $h, k$ e $l$ na equação 2.1, e que preenche todo o espaço dá-se o nome de rede cristalina de Bravais.

Tanto a rede como os vetores de translação $\boldsymbol{a}, \boldsymbol{b}$ e $\boldsymbol{c}$, são chamados primitivos se as configurações forem as mesmas para dois pontos quaisquer $\boldsymbol{r}$ e $\boldsymbol{r}_{0}$ que satisfaçam a equação 2.1 para uma escolha conveniente dos inteiros $h, k$ e $l$. Esta definição dos vetores de translação primitivos garante que não existe nenhuma célula com volume menor que possa servir de bloco elementar para a construção da estrutura. Frequentemente, os vetores de translação são indicados para definir os eixos cristalinos.

Como referido acima, uma rede cristalina fica perfeitamente definida através dos seus vetores fundamentais $\boldsymbol{a}, \boldsymbol{b}$ e $\boldsymbol{c}$. Há, no entanto, redes diferentes que pertencem ao mesmo grupo de simetria e têm, por isso, propriedades de simetria comuns. Em três dimensões, os grupos de simetria pontuais compreendem de 14 tipos de rede, um geral e 13 especiais. As quatorze redes de Bravais, cada uma com uma célula unitária característica, estão agrupadas em sete grupos de simetria. Estes correspondem aos sete sistemas cristalográficos. A esses sete sistemas cristalinos correspondem sete tipos de células unitárias convencionais: triclínico (o mais geral), monoclínico, ortorrômbico, tetragonal, cúbico, trigonal e hexagonal.

\section{Cristais iônicos}

Um critério para classificar os sólidos cristalinos é a natureza das forças que mantêm unidos os átomos (ou moléculas) no ordenamento da rede cristalina. A energia de coesão dos átomos (ou moléculas) num cristal depende das forças de ligação dominantes entre esses átomos (ou moléculas). Os sólidos cristalinos podem ser iônicos, covalentes, moleculares ou metálicos.

Nos cristais iônicos, a rede está formada por íons alternadamente positivos e negativos, resultantes da transferência de um elétron (ou mais) de um tipo de átomo para o outro. A estabilidade da rede cristalina é mantida pela atração eletrostática entre os íons presentes, tais como os íons $\mathrm{Na}^{+} \mathrm{e} \mathrm{Cl}^{-}$na molécula $\mathrm{NaCl}$ (cloreto de sódio Figura 2.1) e os íons $\mathrm{Li}^{+}$e F${ }^{-}$na molécula $\mathrm{LiF}$ (fluoreto de lítio). Vale lembrar que, os íons, que formam a rede cristalina, podem ter uma estrutura formada de ligações iônicas e covalentes. Como será visto mais adiante, o íon $\mathrm{SiO}_{4}$, o tijolo básico de cristais de silicatos é um exemplo. 

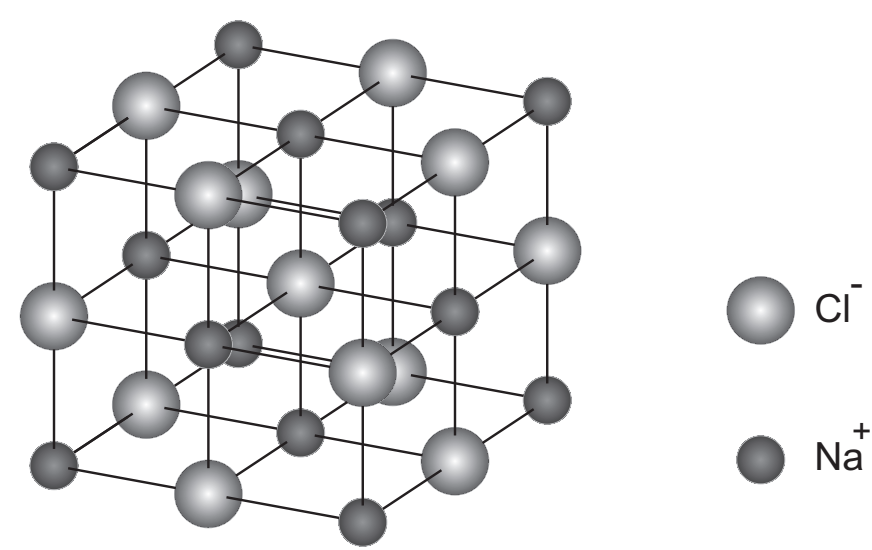

Figura 2.1: Cristal de $\mathrm{NaCl}$.

\subsubsection{Bandas de energia}

A estrutura cristalina consiste num arranjo periódico de íons e, conseqüentemente, apresenta uma distribuição periódica de cargas em três dimensões que produz um potencial periódico. Tal potencial, ignorado no modelo de gás de elétrons livres, pode afetar as soluções da equação de Schröndinger [38].

No caso de elétrons livres, exceto por estarem confinados num cubo de volume $\mathrm{V}$, as funções de onda são da forma

$$
\psi_{k}(\mathbf{r})=\frac{1}{\sqrt{V}} e^{i \mathbf{k} \cdot \mathbf{r}}
$$

que representam ondas progressivas de momento $\mathbf{p}=\hbar \mathbf{k}$. As energias permitidas são:

$$
E_{k}=\frac{\hbar^{2}}{2 m}\left(k_{x}^{2}+k_{y}^{2}+k_{z}^{2}\right)^{2}=\frac{\hbar^{2}}{2 m} k^{2}
$$

Em muitas situações o modelo de elétrons quase livres torna-se útil, em que os elétrons são tratados como sendo fracamente perturbados, pelo potencial periódico de íons, como representado na Figura 2.2. Resulta, nesse caso, uma estrutura de bandas do cristal.

No caso simples de uma rede linear de constante $a$, como da Figura 2.2, com elétrons quase livres, estes ficam sujeitos à condição de difração de Bragg,

$$
(\mathbf{k}+\mathbf{G})^{2}=k^{2}
$$

que no caso unidimensional é escrita como,

$$
k_{n}= \pm \frac{1}{2} G= \pm \frac{n \pi}{a}
$$




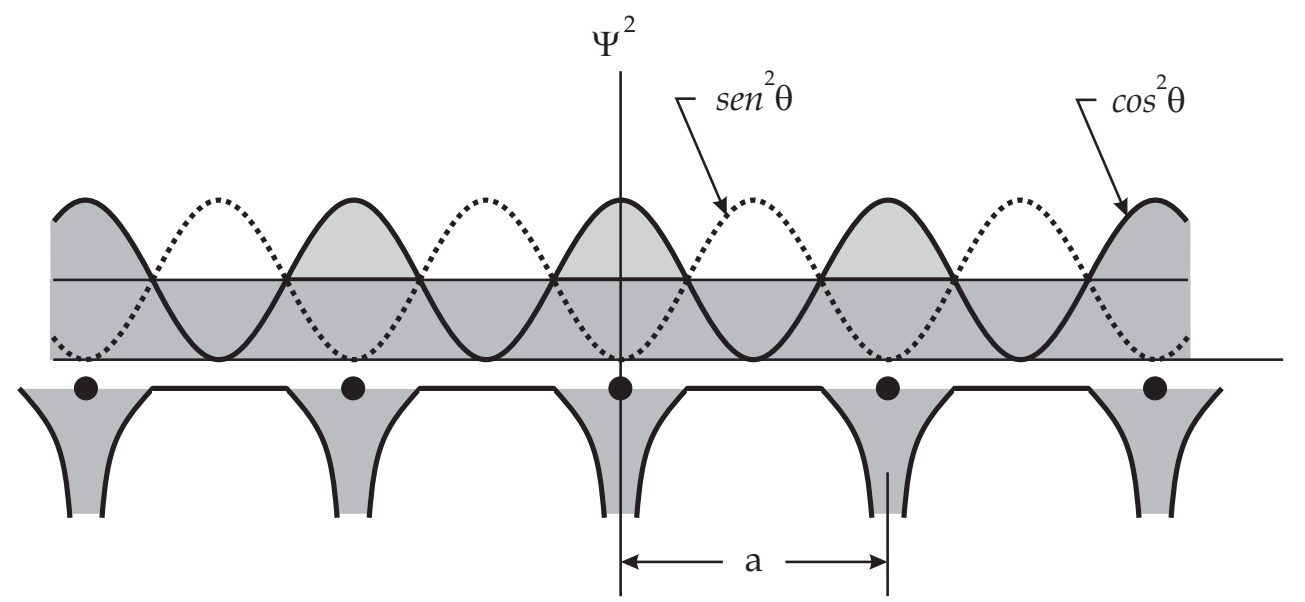

Figura 2.2: Componentes $\cos ^{2}(x)$ e $\operatorname{sen}^{2}(x)$ para a função de onda $k= \pm \pi / a$ e o potencial exercido por um arranjo unidimensional de átomos com parâmetro de rede $a$.

onde $G= \pm 2 n \pi / a$ é o vetor de rede recíproca. Para cada $k_{n}$ há uma reflexão e, a função de onda não é uma onda progressiva $\exp ( \pm i \pi x / a)$.

As soluções da equação de Schröndinger, satisfazendo à condição de Bragg, são formadas de ondas estacionárias da forma:

$$
\begin{aligned}
& \psi(+) \propto \exp \left(+\frac{i \pi x}{a}\right)+\exp \left(-\frac{i \pi x}{a}\right)=2 \cos \left(\frac{\pi x}{a}\right) \\
& \psi(-) \propto \exp \left(+\frac{i \pi x}{a}\right)-\exp \left(-\frac{i \pi x}{a}\right)=2 i \operatorname{sen}\left(\frac{\pi x}{a}\right)
\end{aligned}
$$

$(+)$ e (-) indicam se as ondas são simétricas ou anti-simétricas e, seus quadrados da parte real estão representados na Figura 2.2.

A distribuição de estados de energia em função de $k$ para o modelo do elétron livre é, portanto, afetada com a imposição do potencial periódico como mostra a Figura 2.3 .

A Figura 2.3 revela a presença de contínuo de energias permitidas (bandas), separadas por contínuos de energias proibidas (bandas proibidas ou band gaps). Em três dimensões, as bandas são denominadas zonas de Brillouin e também diferem drasticamente das superfícies de Fermi observadas para o modelo do elétron livre. Como os parâmetros de célula não são necessariamente idênticos nos três eixos cristalográficos, as bandas proibidas podem surgir para diferentes valores de $k$. Portanto, como exemplificamos na Figura 2.4, a forma das zonas de Brillouin no espaço recíproco depende exclusivamente do retículo de Bravais. 


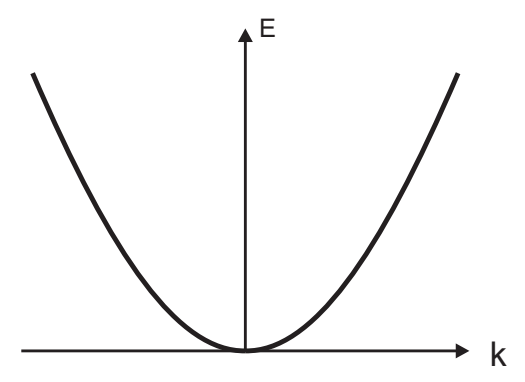

(a)

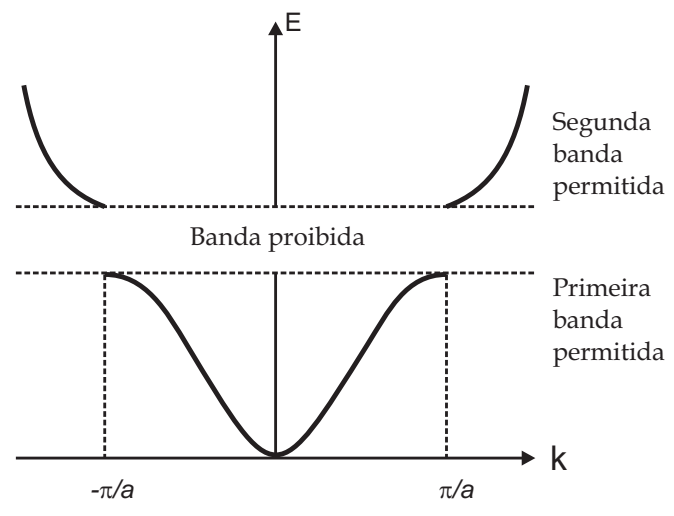

(b)

Figura 2.3: Curva E( $k$ ) para (a) o modelo de elétrons livres e (b) elétron sob potencial periódico.

É importante entender a origem da chamada "energy gap", isto é, da banda proibida e da sua largura.

Ondas estacionárias, que são combinações lineares de ondas planas, a densidade de probabilidade não é constante. De fato, no caso, por exemplo, de $\psi(+)=2 \cos \left(\frac{\pi x}{a}\right)$, $\rho \propto \cos ^{2}\left(\frac{\pi x}{a}\right)$. Na Figura 2.2, na parte inferior, foi representada a energia potencial eletrostática de um elétron no campo dos íons positivos de uma rede linear monoatômica. A energia potencial de um elétron no caso é negativa. A onda progressiva $e^{i k x}$, de densidade $\rho=1$, distribui os elétrons ao longo da reta de ordenada 1 ; a onda $\psi(-)=2 i \operatorname{sen}\left(\frac{\pi x}{a}\right)$, onde $\rho \propto \operatorname{sen}^{2}\left(\frac{\pi x}{a}\right)$, distribui, preferencialmente, os elétrons no espaço intermediário entre dois íons, enquanto que a onda $\psi(+)=2 \cos \left(\frac{\pi x}{a}\right) \operatorname{com} \rho \propto \cos ^{2}\left(\frac{\pi x}{a}\right)$, tem máximo na posição do íon.

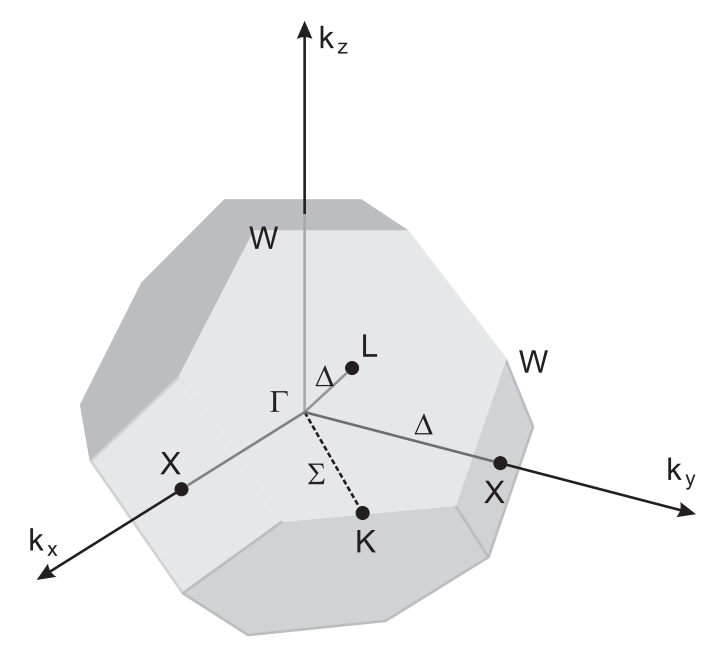

Figura 2.4: Primeira zona de Brillouin para a estrutura cúbica de face centrada. 
Dos valores médios da energia potencial das três distribuições de carga, é de se esperar que, a energia potencial de $\psi(+)$ seja menor do que a da onda progressiva e, a de $\psi(-)$, maior. A diferença entre as energias de $\psi(-)$ e de $\psi(+) E_{g}$, é a largura em energia da banda proibida, ou a "energy gap".

A solução da equação de Schröndinger do elétron livre num potencial periódico mostra o aparecimento de $E_{g}$, ela não será apresentada aqui.

\subsubsection{Defeitos na rede cristalina}

Como já foi mencionado, o tipo de agregado atômico determina as respectivas formas cristalinas. Nos sólidos cristalinos os átomos dispõem-se em arranjos ordenados periódicos constituindo as estruturas cristalinas. Contudo, em cristais reais podem ocorrer desvios quanto à ordenação e quanto à regularidade, designadas por defeitos ou imperfeições. As próprias fronteiras do cristal correspondem a defeitos cristalinos, na medida em que quebram a periodicidade do cristal. Em materiais de grande pureza as imperfeições representam muito menos de $1 \%$ do volume total da estrutura cristalina. Muitas vezes esses defeitos são suficientes para alterar as propriedades do sólido.

Os tipos de defeitos cristalinos mais comuns são a substituição intencionada ou não de um elemento por outro com propriedades ligeiramente diferentes; pontos da rede desocupados (vacâncias); átomos em posição não pertencente à rede. A seguir, serão revistas os tipos de defeitos pontuais.

\section{Defeitos pontuais}

As imperfeições ou defeitos pontuais são irregularidades que se verificam com dimensão de um ou poucos átomos. Os defeitos podem ser da própria rede, quando são chamados intrínsecos; podem ser devido a átomos estranhos ao cristal, quando são considerados extrínsecos e chamados de impurezas. Uma vacância corresponde a uma posição desocupada da estrutura cristalina. Um defeito intersticial resulta da ocupação de uma posição intersticial na estrutura cristalina. Os defeitos intrínsecos podem resultar do empacotamento imperfeito durante a cristalização original ou da agitação térmica ou, ainda, da irradiação do material.

Um átomo de um cristal pode, sob certas circunstâncias ${ }^{1}$, abandonar a sua posição na estrutura cristalina (fazendo assim, surgir uma vacância) e fixar-se num interstício. Aos pares vacância-interstício dá-se o nome de pares Frenkel (Figura 2.5). Nos cristais

\footnotetext{
${ }^{1}$ Por exemplo, mediante um aquecimento
} 


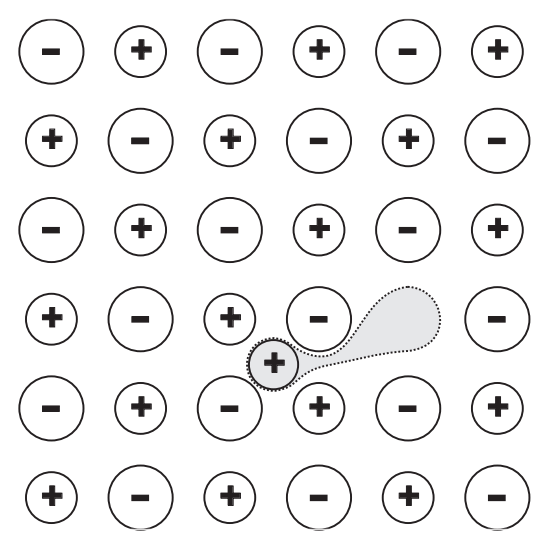

Figura 2.5: Defeito Frenkel.

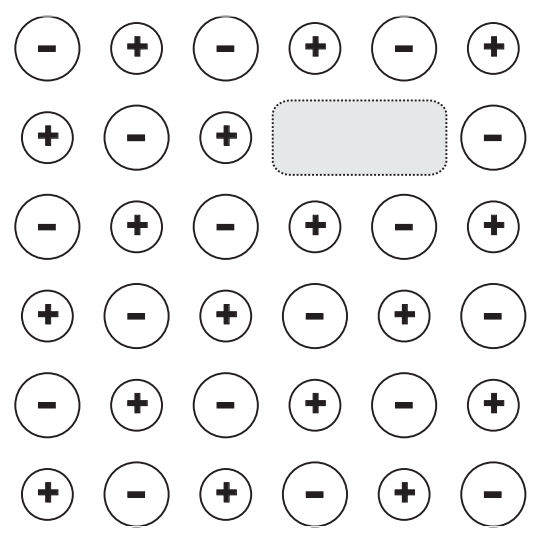

Figura 2.6: Defeito Schottky.

iônicos do tipo $\mathrm{NaCl}$, as vacâncias podem aparecer aos pares, mantendo dessa forma a neutralidade elétrica do cristal. Esses pares de vacâncias são designados por pares Schottky (Figura 2.6).

As impurezas são sempre encontradas num cristal, principalmente, se este for extraído da natureza, mas, mesmo aquele crescido no laborátorio contém traços de átomos estranhos.

Esses átomos, que não fazem parte da composição do cristal, são chamados de impurezas e são, também, defeitos ou imperfeições, e muito importantes.

\subsubsection{Níveis de energia na banda proibida}

Um fato extraordinário é que os defeitos pontuais criam níveis de energia na banda proibida, inexistentes no cristal perfeito. Vejamos um exemplo.

Num composto MX formado por átomos divalentes $\mathrm{M}^{2+}$ e $\mathrm{X}^{2-}$, a substituição de $\mathrm{M}^{2+}$ por um átomo $\mathrm{N}^{+}$monovalente resulta em deficiência local de carga positiva e consequentemente uma diminuição da energia necessária para liberar um elétron de um átomo $\mathrm{X}^{2-}$ adjacente em comparação com um cristal perfeito. Isso equivale à introdução de um nível de energia logo acima da banda de valência. Além disso, a liberação de um elétron dá lugar à formação de um buraco. Então, podemos afirmar que tal defeito atua como um nível de energia de buraco. Da mesma forma, a substituição de $\mathrm{M}^{2+}$ por um átomo $\mathrm{R}^{3+}$ produz uma deficiência local de carga negativa, introduzindo um nível logo abaixo da banda de condução que pode capturar elétrons. Tal efeito atua como um nível de energia de elétrons. Diferenças de eletronegatividade fazem com que uma impureza substitucional produza um nível de energia de elétron ou buraco mesmo quando não existe diferença de valência entre a impureza e o átomo do cristal que ela está substituindo [39]. 
Os níveis de energia, na banda proibida, criados pelos defeitos são chamados armadilhas de elétrons e armadilhas de buracos, pois, podem capturar elétrons ou buracos. Muitas vezes, as armadilhas com carga (elétron ou buraco) são chamadas de centros.

A banda proibida é dividida ao meio pelo nível de Fermi $E_{F}$. As armadilhas de elétrons encontram-se entre $E_{F}$ e a banda de condução, portanto, as de buracos entre $E_{F}$ e a banda de valência.

Aqui se adota o termo "armadilha", qualquer nível de energia, na banda proibida capaz de capturar uma carga positiva ou negativa.

Os elétrons e os buracos, neste esquema de bandas de energia, podem executar transições entre banda de valência, banda de condução, armadilhas de elétrons e de buracos. A Figura 2.7 ilustra algumas dessas transições.

(1) Banda de valência à banda de condução quando um elétron da banda de valência recebe suficiente energia (criação de elétron-buraco).

(2) O elétron na banda de condução se move livremente até ser capturado por uma armadilha de elétron (2).

(3) O elétron numa armadilha pode transitar para a banda de condução, por exemplo por aquecimento (3).

(4) O elétron na banda de condução pode, também, efetuar transições do tipo (5), quando há emissão de um fóton. A armadilha de buraco, no caso, recebe o nome de centro de recombinação e, o processo (5) de recombinação.

(5) Uma transição do tipo (6), sem passar pela banda de condução (ou banda de valência) é um tunelamento.

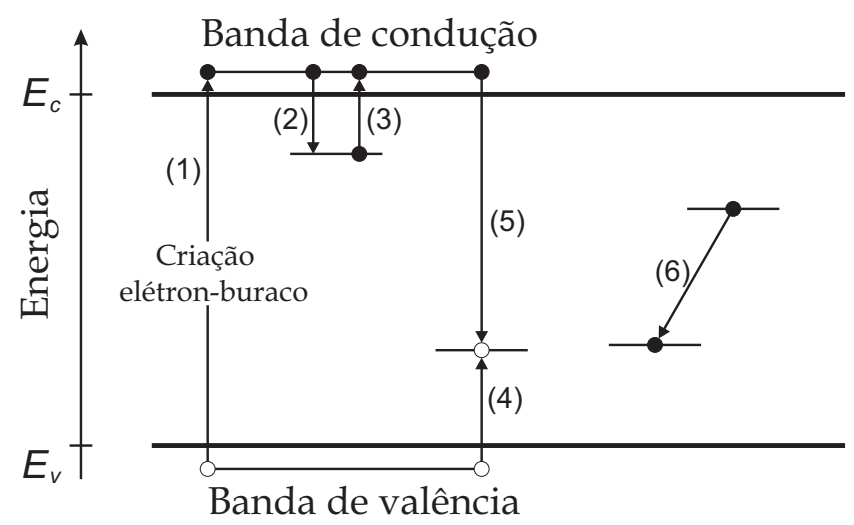

Figura 2.7: Representação de algumas das transições de elétrons (•) e buracos (o) entre os niveis de energia permitidas em um cristal isolante. 


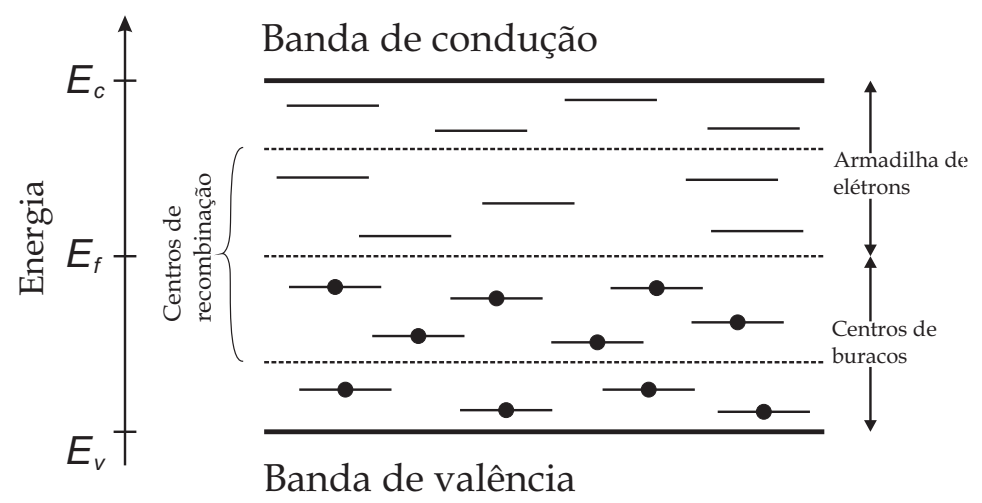

Figura 2.8: Níveis de energia em um isolante em zero absoluto.

(6) O simétrico de tudo que foi visto em (1)-(5) vale ao trocar o elétron pelo buraco.

Face ao exposto, adotou-se aqui, o esquema da Figura 2.8 [40]. Os centros de recombinações são armadilhas, não vazias, mais próximas a $E_{F}$. Como será visto depois, as armadilhas próximas a banda de condução (ou banda de valência) que capturarem elétrons (buracos) são às que dão origem à emissão termoluminescentes, por isso, chamadas centros de termoluminescência.

\subsection{Luminescência nos solidos}

Quando algum tipo de radiação incide sobre um material, uma parte da energia pode ser absorvida pelo material e, ser reemitida sob forma de luz. A emissão dessa luz constitui o fenômeno de luminescência. O comprimento de onda da luz emitida é característico da substância luminescente e não da radiação incidente. Usualmente, os estudos do fenômeno luminescente estão relacionados com a emissão de luz na região do visível, porém outros comprimentos de onda podem estar presentes no espectro de emissão da substância.

O fenômeno da luminescência pode ser caracterizado pelo intervalo de tempo entre a excitação (absorção de energia) e a emissão de luz $(\tau)$, sendo que para $\tau<10^{-8} s$ o fenômeno é classificado como fluorescência e para $\tau>10^{-8} s$ o fenômeno é denominado de fosforescência. Contudo, esta classificação não é muito clara, então pode-se distinguir os fenômenos de fluorescência e fosforescência quando usamos a dependência de $\tau$ com a temperatura. Para isso consideramos um nível de energia referente ao estado fundamental de um elétron $(g)$ e um nível de energia referente ao estado excitado $(e)$, como ilustra a Figura 2.9a. Na fluorescência a emissão de luz se dá quando o elétron é excitado a partir do estado fundamental $g$ até o estado excitado $e$, e subseqüentemente 
este elétron retorna ao nível fundamental de energia $g$. O tempo de vida do elétron no estado excitado é muito curto, mas se a transição envolver mudança de paridade ou estados de spin proibidos, o elétron pode permanecer no estado excitado por alguns milisegundos [41].

Ainda, a transição do estado excitado para o estado fundamental pode não ocorrer diretamente, ou seja, o elétron pode passar para um estado intermediário metaestável $(m)$. Depois de algum tempo decorrido o elétron pode transitar para o estado excitado $e$, então para o estado fundamental emitindo luz (Figura 2.9b). Neste caso, o processo é denominado de fosforescência. Se a transição ao nível $m$ ocorre a uma temperatura absoluta $T$, e a separação de energia entre os níveis $m e$ é dado por $E$, tal que $E>>k T$ ( $k$ constante de Boltzmann), o elétron permanece no estado $m$ por um longo período. Neste caso, admitindo que a distribuição de energia é de Boltzmann, a probabilidade $p$ por unidade de tempo de que um elétron escape do nível metaestável (armadilha) a uma dada temperatura é dado por:

$$
p=s \cdot \exp \left(\frac{-E}{k T}\right)
$$

onde $s$ é uma constante denominada de fator de freqüência e possui uma fraca dependência com a temperatura. Dessa forma fica claro que o processo irá depender sensivelmente da temperatura em virtude da função exponencial, e isto nos dá uma melhor maneira de distinguir a fluorescência, que depende fracamente da temperatura e da fosforescência que depende fortemente da temperatura.

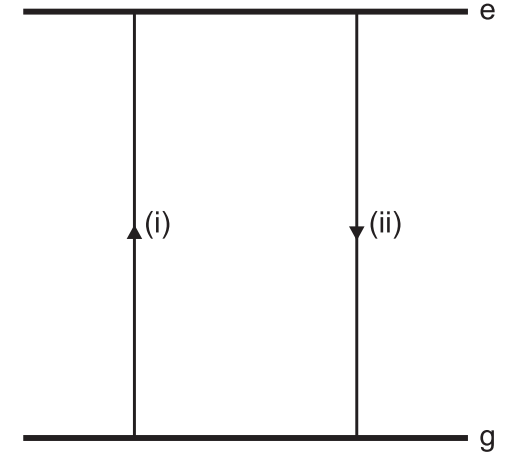

(a)

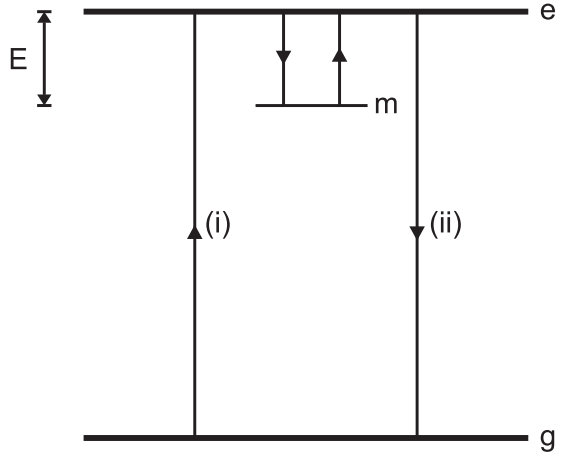

(b)

Figura 2.9: (a) - Esquema do processo envolvido com a fluorescência, onde (i) indica a absorção de energia do elétron e (ii) a transição para o estado fundamental com emissão de luz. (b) - Representa, esquematicamente, a fosforescência, com exitação para o estado e seguido do decaimento até o estado $m$ (metaestável), e novamente excitação e decaimento até o estado fundamental g, com emissão de luz. 
De acordo com a forma que se dá a excitação para posterior emissão de luz a partir de um material, a luminescência recebe uma variedade de nomes: a fotoluminescência (excitação por luz visível ou ultravioleta), radioluminescência (excitação por radiação nuclear, raios gama, raios X, etc;), catodoluminescência (excitação a partir de um feixe de elétrons), quimioluminescência (excitação por energia química), triboluminescência (excitação por energia mecânica), eletroluminescência (excitação por energia elétrica), bioluminescência (excitação por fatores biológicos) e sonoluminescência (excitação por ondas de som). Em todos esses casos a emissão pode ocorrer diretamente com o decaimento eletrônico do estado excitado para o estado fundamental, ou com a participação do estado metaestável $m$.

\subsubsection{Termoluminescência (TL)}

A TL é caracterizada pela emissão de luz por aquecimento num material semicondutor ou isolante, quando o mesmo tenha sido submetido, previamente, à radiação ionizante armazenando energia. Podemos explicar o fenômeno utilizando-se a teoria de bandas de energia de um sólido, invocando as transições eletrônicas vistas na Figura 2.7.

Podemos explicar o mecanismo de TL da seguinte forma: quando a radiação ionizante incide sobre o material, transfere energia suficiente aos elétrons para passarem da banda de valência para a banda de condução por efeito do tipo fotoelétrico ou efeito Compton, onde se movem livremente. Eventualmente, os elétrons ficam retidos nas bandas proibidas, em armadilhas que são caracterizadas pela distância $E$, medida a partir do fundo da banda de condução. A estabilidade da carga armadilhada depende da profundidade $E$ da armadilha. Com a saída do elétron da banda de valência, produz-se um buraco que, como o elétron na banda de condução, torna-se móvel na banda de valência e, se não se recombinar quase que imediatamente com um elétron, pode ser capturado por uma armadilha de buracos, cuja profundidade é medida a partir do topo da banda de valência. Se as profundidades das armadilhas de elétrons ou de buracos, forem pequenas, o elétron ou buraco aprisionado, tem a probabilidade considerável de escapar, na temperatura ambiente, mas se a profundidade é relativamente grande, a meia-vida da carga armadilhada torna-se grande para manter a carga presa por um longo tempo. Com a excitação térmica, o elétron recebe suficiente energia para voltar à banda de condução, onde se move até se recombinar com um buraco armadilhado, emitindo luz TL. Fenômeno similar pode ocorrer para os buracos mas neste caso a banda de valência é que recebe o buraco desarmadilhado, onde caminham até encontrar os elétrons armadilhados e se recombinarem emitindo luz. 
(i) Equilíbrio estável

Banda de condução

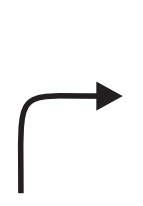

(iv) Aquecimento

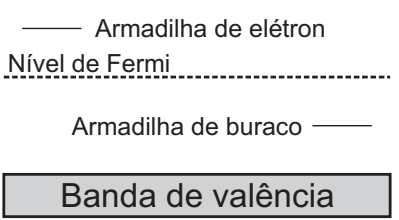

(iii) Armazenamento
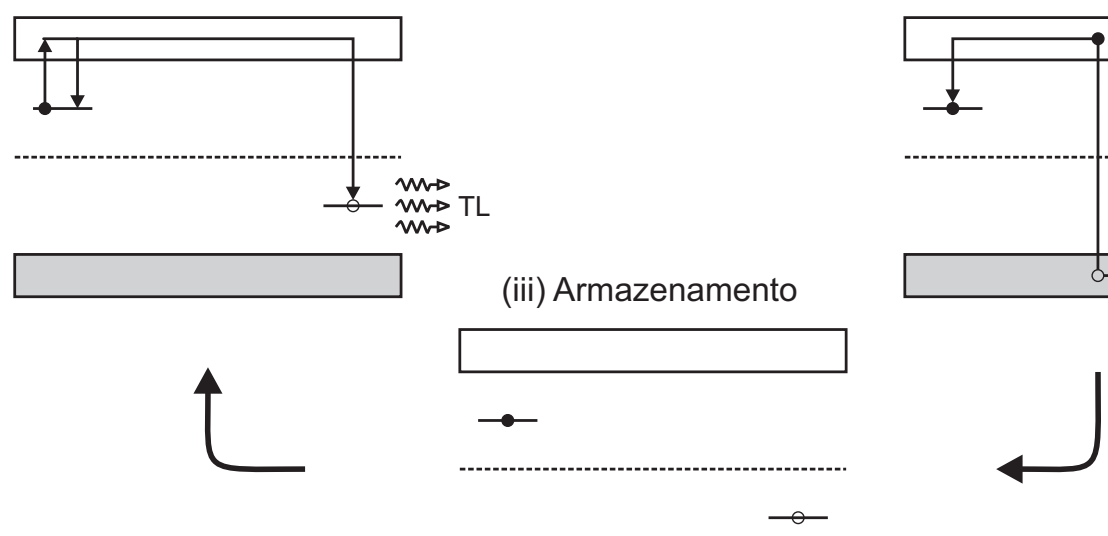

(ii) Irradiação

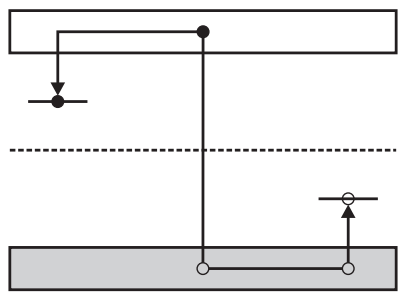

Figura 2.10: Processo termicamente estimulado para um sistema simples com dois tipos de níveis de energia na banda proibida. (i) O diagrama representa o equilibrio estável. (ii) durante a irradiação os pares elétron-buraco são formados e capturados nos seus respectivos centros. (iii) armazenamento, o sistema permanece em equilibrio enquanto não ocorre o estímulo. (iv) Durante o aquecimento, os elétrons são liberados das armadilhas, com emissão de luz no processo de recombinação com os buracos.

Podemos ordenar o processo em quatro etapas distintas (Figura 2.10) (i) equilíbrio estável; (ii) geração de cargas livres, devido à absorção da energia de radiação ionizante; (iii) armadilhamento destas cargas, devido às imperfeições da rede cristalina; (iv) liberação das cargas a partir das armadilhas, devido ao aquecimento do cristal e, finalmente temos a recombinação e emissão de luz TL [42].

Devemos enfatizar ainda, que há uma distinção entre a termoluminescência e uma outra forma de emissão luminosa devido ao aquecimento do material, fenômeno denominado de incandescência. A diferença é que a incandescência ocorre, geralmente, em temperaturas elevadas, não havendo necessidade de excitação prévia e o processo pode ocorrer novamente após resfriamento e reaquecimento; diferentemente da termoluminescência na qual após o resfriamento do material não é possível obter a luminescência, a não ser que o material seja irradiado novamente. Outra diferença importante é que, 
ao contrário da incandescência, na qual a temperatura do material tem relação com o espectro de luz emitida, na termoluminescência as características espectroscópicas do centro de luminescência são os que definem o espectro da luz emitida, não havendo relação direta com a temperatura da amostra.

Durante o aquecimento do material TL a grandeza monitorada é a luz emitida, que é transformada em corrente elétrica, e dessa forma pode ser estabelecida uma relação da intensidade luminosa com a dose de radiação. Esta grandeza, geralmente, é monitorada em função da temperatura ou do comprimento de onda. No primeiro caso a curva obtida da intensidade TL versus temperatura é denominada curva de emissão TL e, no segundo caso, intensidade TL versus comprimento de onda $(\lambda)$, é o espectro de emissão TL.

\subsubsection{Curva de emissão TL}

A curva de emissão acima definida, em geral, é caracterizada por diversos picos, cada um deles estando associado a uma determinada armadilha, que tanto pode ser de elétrons quanto de buracos, caracterizados por uma profundidade $E$ e por uma temperatura onde ocorre o máximo da emissão TL (Figura 2.11 [43]). Cada material termoluminescente apresenta uma curva de emissão que é característica do mesmo.

A formação de um pico de emissão TL está relacionada com a probabilidade de escape do elétron da armadilha que por sua vez, é dependente da temperatura (Equação 2.8). A forma de um pico TL é definida pela chamada ordem de cinética, como será visto na secção 2.2.4.

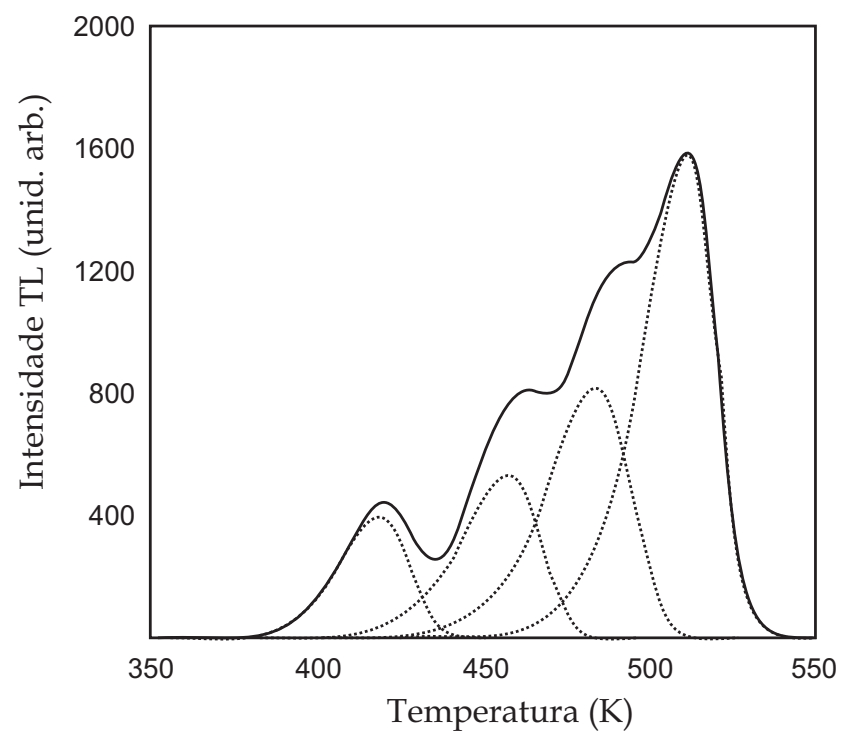

Figura 2.11: Curva de emissão TL. 
Um fato que merece destaque é que a curva de emissão depende, como já foi citado, dos tipos de armadilhas e dos centros de recombinação presentes no cristal. A presença de mais de um pico revela que o cristal apresenta mais de um tipo de armadilhas, consequentemente várias energias de ativação.

\subsubsection{Espectro de emissão TL}

A medida mais convencional efetuada na emissão TL é a que registra a intensidade em função da temperatura, que por sua vez está relacionado com a profundidade das armadilhas. Todavia, pode-se efetuar a medida da intensidade luminescente em função do comprimento de onda da luz emitida, que está relacionada com as transições especificas aos centros de recombinação. Isto permite realizar um estudo de centros de recombinação presentes no material, quanto ao número aos comprimentos de onda em que aparecem as bandas.

A Figura 2.12 dá um exemplo da presença de um ou vários centros de recombinação, com profundidades diferentes, de modo que a emissão é caracterizada por vários comprimentos de onda. A profundidade do centro de recombinação determina o comprimento de onda da luz emitida numa determinada faixa de temperatura, dessa forma, podemos esperar que cada pico de emissão TL esteja associado a uma banda espectral de um conjunto de centros de recombinação. A medida da intensidade TL em função do comprimento de onda, revela bandas espectrais que compõem o espectro de emissão TL.

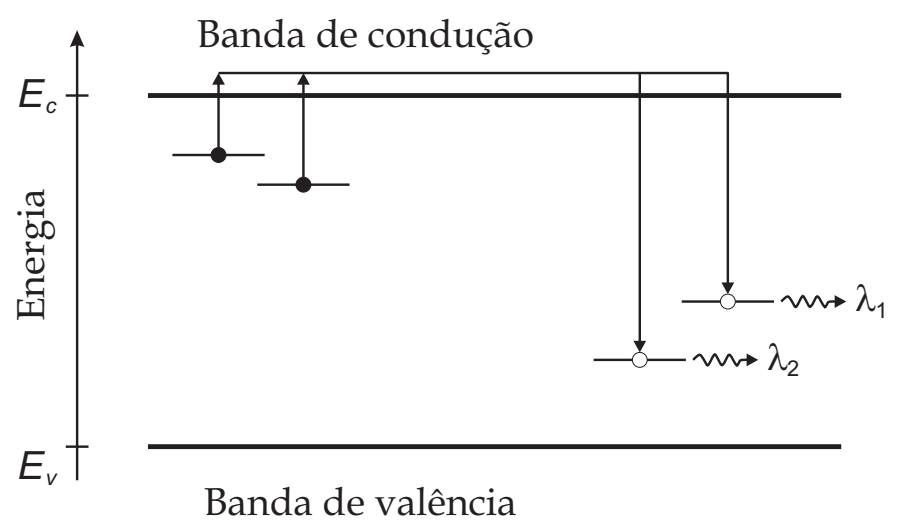

Figura 2.12: Estrutura de bandas de energia, mostrando os centros de armadilhas e os centros de recombinação. Podemos visualizar que, havendo várias profundidades dos centros de recombinação, a emissão TL será composta de diversos comprimentos de onda $\left(\lambda_{1}\right.$ e $\left.\lambda_{2}\right)$. 


\subsubsection{Modelos teóricos para a termoluminescência}

O modelo mais simples que pode ser formulado para descrever a TL é para dois tipos de níveis localizados na banda proibida: uma armadilha de elétrons $n(t)$ e um centro de recombinação $m(t)$ (Figura 2.13). A intensidade TL observada pode ser escrita em função da taxa de variação de concentração de buracos $(d m / d t)$ nos centros de recombinação e da eficiência de luminescência $\eta(T)$.

$$
I(t)=\eta(T)\left(-\frac{d m}{d t}\right)
$$

Em geral $\eta(T) \simeq 1$

$n(t)$ e $n_{c}(t)$ são concentrações de elétrons nas armadilhas e na banda de condução, respectivamente, e $m(t)$ a concentração de buracos nos centros de recombinação no instante $t$ e $\mathrm{N}$ a concentração total de armadilhas para elétrons. A conservação de carga no material para este modelo deve cumprir a seguinte relação:

$$
n+n_{c}=m
$$

Seja $(N-n) \sigma_{n} \nu_{e}$ a probabilidade de recaptura dos elétrons pela armadilha e $m \sigma_{m} \nu_{e}$ pelo centro de recombinação, onde $\sigma_{n}$ e $\sigma_{m}$ são as seções de choque de captura eletrônica pela armadilha e pelo centro de recombinação e $\nu_{e}$ a velocidade térmica dos elétrons na banda de condução.

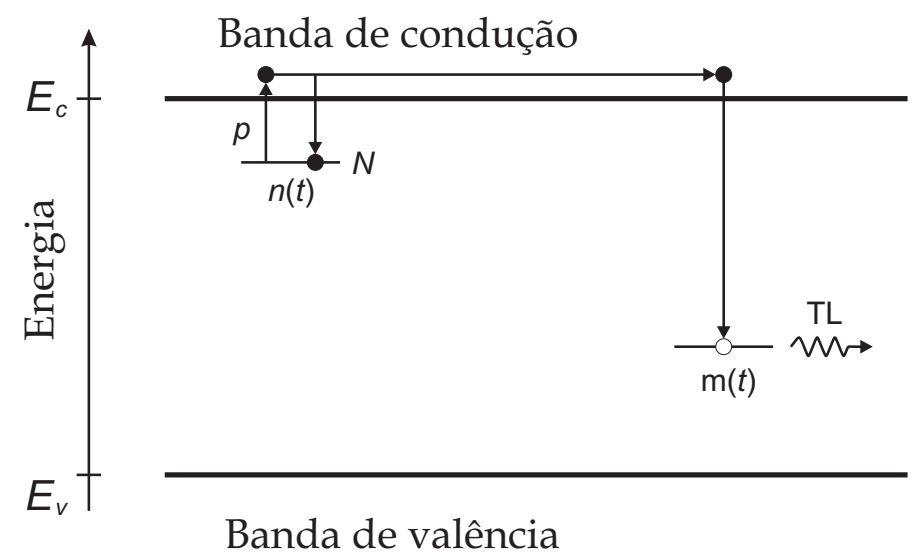

Figura 2.13: Modelo de dois níveis localizados na banda proibida: um tipo de armadilha e um tipo de centro de recombinação. 
Com as considerações acima mencionadas, podemos formular as equações para a taxa de variação das variáveis $n, m$ e $n_{c}$. A taxa de variação em $n$ tem a contribuição dos elétrons que são desarmadilhados $(-n p)$ e dos elétrons que são recapturados $\left[n_{c}(N-\right.$ n) $\left.\sigma_{n} \nu_{e}\right]$ :

$$
\frac{d n}{d t}=-n p+n_{c}(N-n) \sigma_{n} \nu_{e}
$$

onde $p$ é dado pela equação 2.8 .

A quantidade de buracos $m$ decresce com as transições dos elétrons da banda de condução para os centros de recombinação. A variação de $m$ é:

$$
\frac{d m}{d t}=-n_{c} m \sigma_{m} \nu_{e}
$$

Derivando a equação (2.10) de conservação de carga, obtém-se:

$$
\frac{d n_{c}}{d t}=-\frac{d n}{d t}+\frac{d m}{d t}
$$

As equações [2.11, 2.12 e 2.13] compõem o sistema de equações diferenciais acoplados para um modelo simples de dois tipos de níveis localizados na banda proibida da termoluminescência.

\section{A condição de "quasi-equilibrium"(QE)}

A concentração de elétrons na banda de condução, inicialmente zero, não varia significativamente no proceso da leitura TL, isto é, os elétrons que são desarmadilhados e que passam pela banda de condução são rapidamente capturados pelos centros de recombinação ou recapturados pelas armadilhas, não existindo acúmulo de elétrons na banda de condução. Essa condição é denominada de condição de QE, e matematicamente pode ser representada pela seguinte desigualdade:

$$
\left|\frac{d n_{c}}{d t}\right| \ll\left|\frac{d n}{d t}\right|,\left|\frac{d m}{d t}\right|
$$

e

$$
n_{c}(t) \ll n(t), m(t)
$$

A equação 2.13 sob condição de QE equivale a: 


$$
\frac{d m}{d t} \cong \frac{d n}{d t}
$$

e a equação de conservação de carga 2.10, fica:

$$
m(t) \cong n(t)
$$

Com a condição de QE, a equação 2.9 da intensidade TL é proporcional à taxa de variação de elétrons nas armadilhas.

$$
I(t) \propto-\frac{d m}{d t}=-\frac{d n}{d t}
$$

Substituindo as derivadas 2.18 pelas expressões dadas nas equações 2.11 e 2.12 obtémse:

$$
n_{c}=\frac{n p}{(N-n) \sigma_{n} \nu_{e}+m \sigma_{m} \nu_{e}}
$$

Substituindo a equação anterior para $n_{c}$ na equação 2.11, obtém-se:

$$
\frac{d n}{d t}=-n p \frac{m \sigma_{m}}{(N-n) \sigma_{n}+m \sigma_{m}}
$$

Aplicando a aproximação de QE para a conservação de carga 2.17 e definindo $R=$ $\sigma_{n} / \sigma_{m}$, a equação 2.20 fica da seguinte forma:

$$
\frac{d n}{d t}=-\frac{n^{2} p}{n(1-R)+N R}
$$

As equações 2.18 e 2.21 representam a solução geral para o modelo de dois tipos de níveis localizados na condição de QE.

\section{Modelo de Randall-Wilkins}

No modelo de Randall-Wilkins, denominado também modelo de cinética de primeira ordem, a probabilidade de recaptura dos elétrons pela armadilha é considerada muito pequena: 


$$
m \sigma_{m} \gg(N-n) \sigma_{n}
$$

Aplicando-se essa condição de recaptura quase nula na equação 2.20, obtém-se:

$$
\frac{d n}{d t}=-n p
$$

A solução para a equação 2.23 para a probabilidade $p$ independiente de $t$, é:

$$
n(t)=n_{0} e^{-p t}
$$

sendo $n_{0}$ a concentração de elétrons nas armadilhas para $t=0$. Substituindo a equação 2.24 na equação 2.23 obtemos a expressão para a variação do numero de elétrons nas armadilhas:

$$
\frac{d n}{d t}=-n_{0} p e^{-p t}
$$

Da equação 2.18 podemos escrever a intensidade TL:

$$
I_{T L}(t)=I_{0} e^{-p t}
$$

sendo $I_{0}=n_{0} p$.

Considerando um aquecimento linear: $T(t)=T o+\beta t$, temos que $d T=\beta d t$ e, substituindo a expressão para $p$ (equação 2.8) na equação 2.23 , obtemos uma expressão para a concentração $n(T)$ de elétrons nas armadilhas em função da temperatura:

$$
n(T)=n_{0} \exp \left[-\frac{s}{\beta} \int_{T_{0}}^{T} \exp \left(-\frac{E}{k T^{\prime}}\right) d T^{\prime}\right]
$$

A intensidade TL é então obtida com as equações 2.18 e 2.23 e, considerando $\eta(T)=1$, obtem-se a conhecida fórmula de Randall-Wilkins [44, 45].

$$
I(T)=n p=n_{o} \operatorname{sexp}\left(-\frac{E}{k T}\right) \exp \left[-\frac{s}{\beta} \int_{T_{0}}^{T} \exp \left(-\frac{E}{k T^{\prime}}\right) d T^{\prime}\right]
$$




\section{Modelo de Garlick-Gibson}

Se a probabilidade de recombinação for muito menor que a de recaptura, o que é expresso por: $m \sigma_{m} \ll(N-n) \sigma_{n}$, e admitindo, adicionalmente, que as seções de choque de recaptura e recombinação são iguais $\left(\sigma_{m}=\sigma_{n}\right)$ e que a ocupação das armadilhas está longe de saturação $(N \gg n)$ e, utilizando a conservação de carga na condição de QE, a equação 2.20 reduz-se a:

$$
\frac{d n}{d t}=-\frac{n^{2} p}{N}
$$

e que a intensidade TL para um aquecimento linear com taxa $\beta$ é:

$$
I(T)=\frac{n_{o}^{2} s}{N} \exp \left(-\frac{E}{k T}\right)\left[1+\frac{n_{o} s}{N \beta} \int_{T_{0}}^{T} \exp \left(-\frac{E}{k T^{\prime}}\right) d T^{\prime}\right]^{-2}
$$

Esta é a expressão obtida por Garlick-Gibson [46], denominada de cinética de segunda ordem.

\section{Modelo de ordem geral}

Experimentalmente, têm sido encontrados picos TL que não se ajustam nem à cinética de primeira ordem e nem a de segunda. Por isso, May \& Partridge [47] propuseram uma expressão empírica para uma cinética de ordem geral, que é dada pela seguinte relação:

$$
\frac{d n}{d t}=-n^{b} s^{\prime} \exp \left(-\frac{E}{k T}\right)
$$

onde $s^{\prime}=\frac{s}{N^{b-1}}$ e $b$ é definido como um parâmetro de ordem geral, e não necessariamente igual a 1 ou 2. A solução dessa equação dá:

$$
I(T)=s^{\prime \prime} n_{0} \exp \left(-\frac{E}{k T}\right)\left[1+(b-1) \frac{s^{\prime \prime}}{\beta} \int_{T_{0}}^{T} \exp \left(-\frac{E}{k T^{\prime}}\right) d T^{\prime}\right]^{-\frac{b}{b-1}}
$$

onde $s^{\prime \prime}=s^{\prime} n_{0}^{(b-1)}$.

A dificuldade com o desenvolvimento empírico para a equação de ordem geral, reside na dificuldade de dar um significado para o parâmetro $s^{\prime}$, cuja dimensão altera 
de acordo com a ordem da cinética envolvida. Para superar este problema Rasheedy [48] propôs uma nova forma para o modelo, partindo da equação 2.31:

$$
I(T)=-\frac{d n}{d t}=\left(\frac{n^{b}}{N^{b-1}}\right) s \exp \left(-\frac{E}{k T}\right)
$$

que resolve o problema com as dimensões.

Integrando a equação 2.33, obtém-se:

$$
I(T)=n_{0}^{b} s \exp \left(-\frac{E}{k T}\right) N^{1-b}\left[1+\frac{s(b-1)\left(n_{0} / N\right)^{b-1}}{\beta} \int_{T_{0}}^{T} \exp \left(-\frac{E}{k T^{\prime}}\right) d T^{\prime}\right]^{-\frac{b}{b-1}}
$$

esta expressão remove a dificuldade na interpretação de $s^{\prime}$.

Da equação acima pode ser reduzida à expresão de Randall-Wilkins para $b \rightarrow 1$ e à de Garlik e Gibson para $b=2$.

\subsubsection{Métodos para estimar os parâmetros dos modelos TL}

Nos modelos matemáticos que prevêem a intensidade TL em função da temperatura, e que se baseam na teoria de bandas de energia, cada pico TL está associado a uma armadilha de energia $E$ e a um fator de freqüência $s$. Isto significa que esses parâmetros $E$ e $s$ podem ser determinados a partir da curva de emissão experimental utilizando um método.

Existem vários métodos de análise para determinar os parâmetros dos modelos TL. Uma descrição detalhada dos métodos mais importantes pode ser encontrada nos textos de McKeever [40] e Chen \& McKeever [41].

\section{Método da subida inicial}

Nas equações 2.28, 2.30 e 2.34 de Randall \& Wilkins, de Garlick \& Gibson e de ordem geral respectivamente, observa-se que para $\mathrm{T} \rightarrow \mathrm{To}$,

$$
I(T) \propto \exp (-E / k T)
$$

Nesse limite, pouca liberação de cargas tem lugar ficando a população $n$ aproximadamente constante $\left(n \approx n_{o}\right)$, portanto, a equação 2.35 não depende da ordem da cinética. 
A regressão linear dos pontos $\ln (I) \times 1 / T$ para a região inicial fornece o coeficiente angular da curva $-E / k$ da qual a energia de ativação é facilmente determinada. Nas equações de Randall \& Wilkins e de Garlick \& Gibson pode-se ver que, o método de subida inicial é bom no intervalo de $\left(T_{0}, T_{c}\right)$ de temperatura, onde $T_{c}$ deve garantir a condição:

$$
\frac{s}{\beta} \int_{T o}^{T c} \exp \left(\frac{-E}{k T}\right) d T<0,01
$$

em geral $T_{c}$ não deve exceder uma temperatura correspondente a uma intensidade de 10-15\% da intensidade TL máxima [49].

O método de subida inicial deve portanto ser usado, quando o pico TL é isolado. Se houver superposição de picos TL, uma das maneiras consiste em, inicialmente, caracterizar o primeiro pico, cuja subida inicial pode ser usada. Feito isso, limpa-se termicamente o primeiro pico, aquecendo a amostra até uma temperatura um pouco além da temperatura do primeiro pico. Em seguida, é aplicada a técnica para o segundo pico, etc.

Se a superposição entre um pico e o seguinte for grande, a limpeza térmica deixa dúvidas quanto ao uso do método de subida inicial. A limpeza térmica pode não limpar o pico anterior ou então afetar a subida inicial do pico seguinte.

\section{Método de E-T $\mathbf{T}_{\text {stop }}$}

Nahum \& Halperin [50] desenvolveram um método, no qual vários ciclos de limpeza térmica são executados, cada vez usando uma temperatura mais alta. Aplicando-se o método da subida inicial nas curvas TL residuais, é calculado o valor de $E$ para cada aquecimento. Essa temperatura de aquecimento em cada ciclo é chamada de $T_{\text {stop. }}$ A curva resultante de energia de ativação $E$ em função de $T_{\text {stop }}$ é, em geral, em forma de escada, embora os degraus não apareçam de uma forma muito nítida, Figura 2.14.

O método de $\mathrm{E}_{\text {- }} \mathrm{T}_{\text {stop }}$ de Nahum \& Halperim enfrenta dificuldades quando as energias de ativação são muito próximas e quase contínuas.

O método envolve erros quando são valores das energias de ativação maiores do que as diferenças entre os valores das energias dos picos, nesse caso, a curva $\mathrm{E}_{-} \mathrm{T}_{\text {stop }}$ não tem o aspecto de uma escada. 


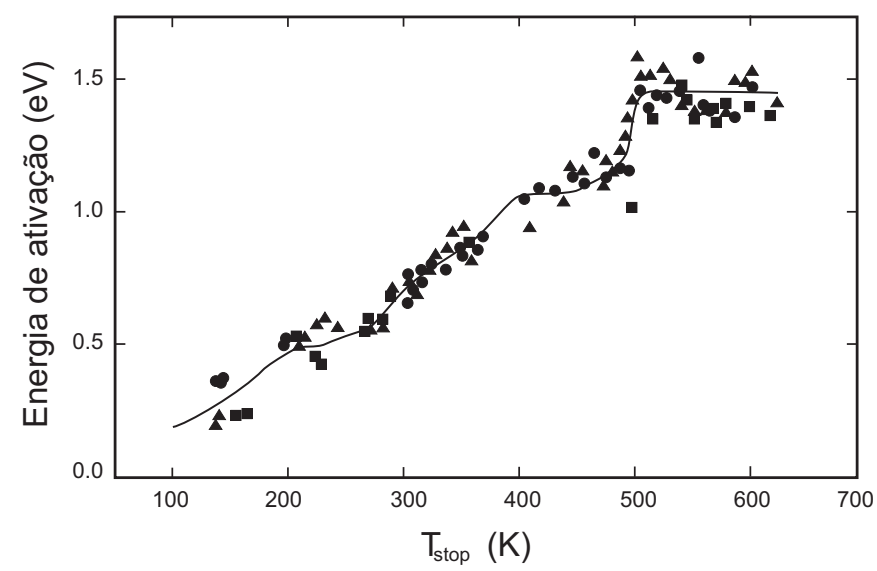

Figura 2.14: Energia de ativação em função da temperatura $T_{\text {stop }}$ (Nahum and Halperin, 1962).

\section{Separação dos picos TL pelo método $\mathbf{T}_{m}-\mathbf{T}_{\text {stop }}$}

McKeever [51] introduziu um método em que, ao invés de $\mathrm{E}$, a temperatura $\mathrm{T}_{p}$ do pico TL é dada em função de $\mathrm{T}_{\text {stop }}$. $\mathrm{O}$ método $\mathrm{T}_{m}-\mathrm{T}_{\text {stop }}$ permite obter uma estimativa inicial do número de picos e das suas posições. Este método consiste em:

a) a amostra é pré-aquecida linearmente até uma temperatura $T_{\text {stop }}$.

b) atingida a temperatura $T_{\text {stop }}$ deixa-se que a amostra esfrie.

c) segue-se a leitura da curva TL completa com a mesma taxa de aquecimento e anota-se o primeiro máximo de emissão $T_{m}$ que ocorre durante o aquecimento.

d) a seqüência é repetida diversas vezes com amostras nas mesmas condições iniciais que as da amostra anterior, aumentando-se a temperatura $T_{\text {stop }}$ a cada repetição. Ao final, os valores obtidos são colocados em um gráfico de $\mathrm{T}_{m} \mathrm{x} \mathrm{T}_{\text {stop }}$.

O pré-aquecimento é empregado para diminuir parcialmente a concentração de portadores de carga nas armadilhas. Um pico de primeira ordem mantém-se na mesma posição independentemente da população da armadilha correspondente, o perfil $T_{m^{-}}$ $T_{\text {stop }}$ de uma curva com diversos picos de primeira ordem superpostos deve ter a forma de escada onde cada patamar corresponde a um pico TL (Figura 2.15). No caso de picos de ordem diferente de 1 , os picos se deslocam para temperaturas mais altas à medida que a população das armadilhas diminui devido ao pré-aquecimento e nesse caso $T_{m}$ apresenta aumento com $T_{\text {stop }}$ e o perfil $T_{m}-T_{\text {stop }}$ não terá a forma de escada. $\mathrm{O}$ deslocamento dos picos para temperaturas mais altas pode ocorrer também em função da existência de picos associados a distribuções de energias. 


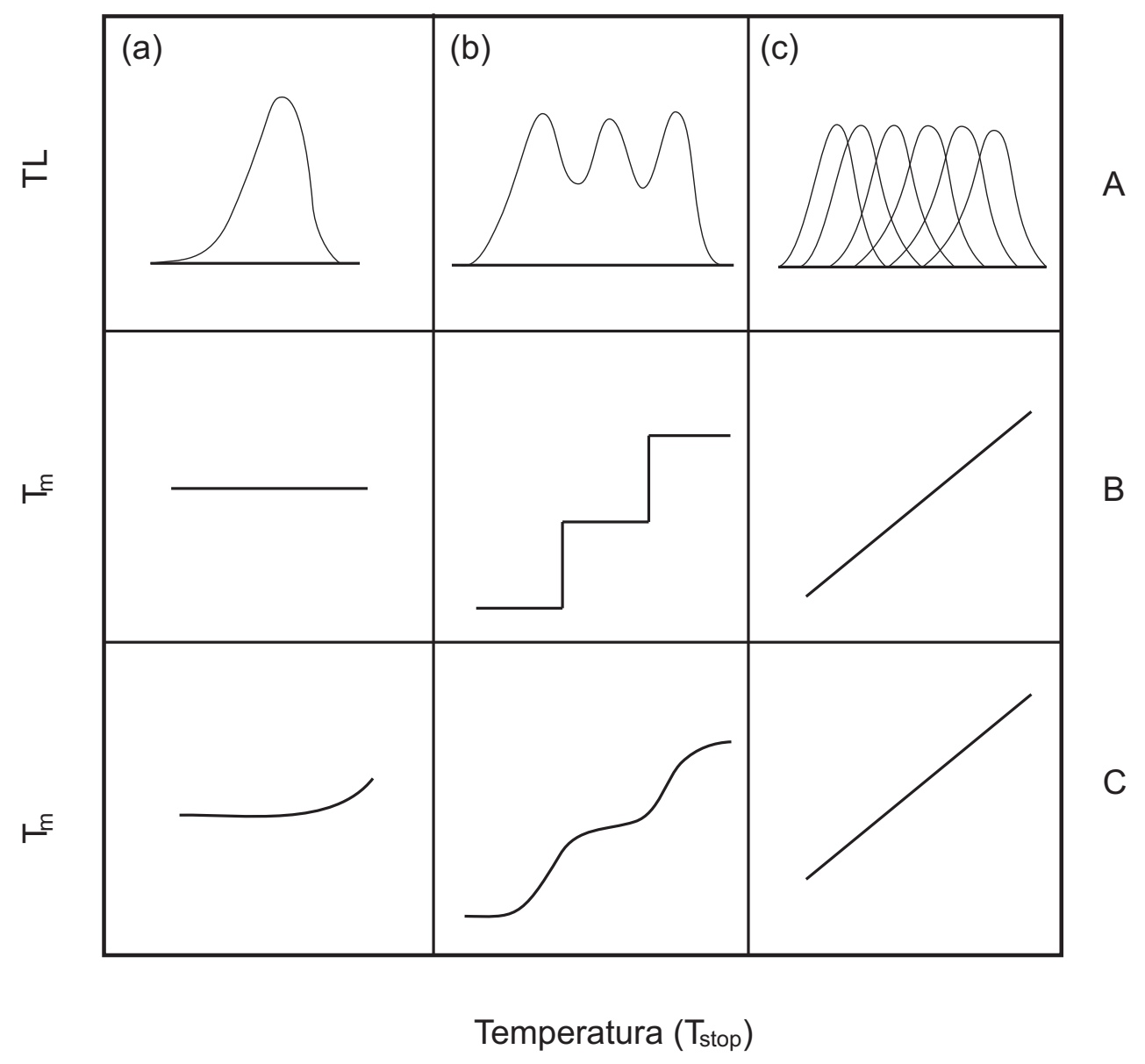

Figura 2.15: (A) Curvas TL. (B) Perfil Tm-Tstop com uma cinética de primeira ordem $e(\mathrm{C})$ com uma cinética de ordem diferente de 1. (a) um só pico, (b) superposição de picos e (c) distribuição de energias.

\subsubsection{Linearidade, sub e supralinearidade.}

O uso de materiais termoluminescentes em dosimetria e datação baseiam-se no conhecimento da sua resposta TL com a dose. É desejável que a dependência da resposta TL à dose de radiação seja linear. Nos haletos de alcalinos e alcalino-terrosos, nos sulfatos, carbonatos e óxidos, na maioria dos casos tem sido observado uma dependência linear em baixas doses e, partir de uma certa dose $D$, a resposta torna-se mais que linear; daí o nome de supralinearidade.

Devido ao número finito de armadilhas disponíveis, eventualmente, a relação resposta TL versus dose da radiação torna-se sublinear e se satura.

Há cristais em que a supralinearidade não ocorre. $\mathrm{Li}_{2} \mathrm{~B}_{4} \mathrm{O}_{7}: \mathrm{Cu}$ é um exemplo, onde a resposta TL é linear com dose até cerca de $10^{3}$ Gy e depois entra em saturação [52]. $\mathrm{MgO}$ é outro exemplo [53]. 
Um exemplo de material que exibe comportamento supralinear é o LiF (TLD-100). Este cristal apresenta linearidade para doses baixas, mas a partir de cerca de 10 Gy sua resposta TL exibe um comportamento supralinear. O termo supralinearidade, descreve o tipo de comportamento no qual a primeira derivada da resposta aumenta com a dose. Na Figura 2.16 pode-se verificar que há uma região supralinear (região de doses superiores a 10 Gy) e seguido de um comportamento sublinear [54].

Atualmente há dois modelos, que tentam explicar a ocorrência de supralinearidade.

(a) Modelo de Mische \& McKeever [55]

Esses autores introduziram a idéia de uma associação espacial entre centros de elétrons e centros de recombinação. Há dois tipos de associação, uma em que centros de elétrons estão a uma distância $\leq s$ associados a centros de recombinação, $s$ sendo pequena suficiente para não haver nenhum outro tipo de centro dentro do volume de raio $s$. Supondo $K$ a fração desses centros, espera-se que $(1-K)$ seja a fração de centros separados de distância $>s$ não associados a centros de recombinação. Uma hipótese importante é a de que as duas famílias de centros contribuem para o mesmo pico TL.

Outra hipótese adicional consiste em admitir que há, (1) uma só espécie de centros TL que emite luz TL de concentração $n_{1}$, (2) uma só espécie de centro de recombinação de concentração $m$, e uma só espécie de armadilhas de competição, que não emitem luz TL, de concentração $n_{2}^{\prime}$.

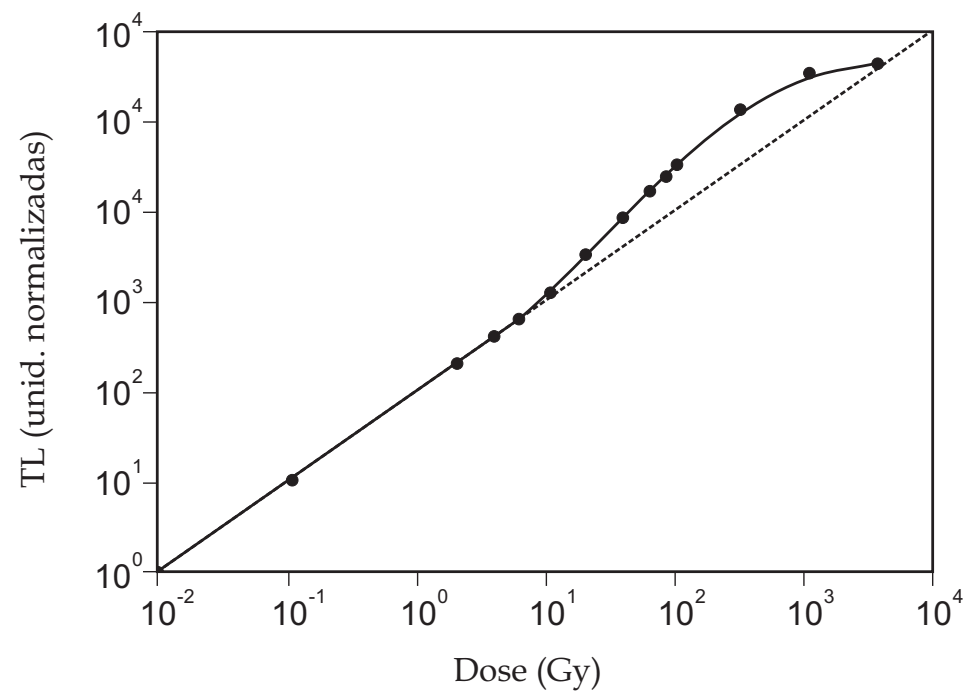

Figura 2.16: Comportamento do LiF (TLD100) com a dose de radiação (adoptado de Zimmerman J. ). A curva tracejada representa o comportamento linear. 
O caminho livre médio $\mu$ de um elétron entre os eventos de armadilhamento é dado por:

$$
\mu=\left(\sigma_{m} m+\sigma_{2} n_{2}^{\prime}\right)^{-1}
$$

No caso de LiF:Mg, os centros mostram que $n_{2}^{\prime}$ tem que corresponder a armadilhas de elétrons vazias. Então, de um total $N_{2}$ de armadilhas desse tipo,

$$
n_{2}=N_{2}-n_{2}^{\prime}
$$

não estão vazias e, a condição de neutralidade fica:

$$
n_{1}+n_{2}=m
$$

Dentro do volume $(4 / 3) \pi s^{3}$, a probabilidade de que o elétron liberado pelo aquecimento na leitura TL se recombine com um buraco no centro de recombinação é $\sigma_{m} / 4 \pi s^{2}$. O significado de $\sigma_{m}$ foi dado na seção 2.2.4. Por outro lado, a probabilidade de que um elétron sem par dentro da distância $s$, se desloque por uma distância $R$ e se recombine, é dada por:

$$
P(R)=\left(1-\frac{\sigma_{m}}{4 \pi s^{2}}\right) \mu \sigma_{m} m\left[1-\exp \left(-\frac{R}{\mu}\right)\right]
$$

A probabilidade total, de que um elétron dentro da fração $K$ se recombine em algum ponto, é dada por:

$$
P_{K}^{t o t}=n_{1} K\left[\frac{\sigma_{m}}{4 \pi s^{2}}+\left(1-\frac{\sigma_{m}}{4 \pi s^{2}}\right) \mu \sigma_{m} m\right]
$$

Incluindo a fração $(1-K)$ de elétrons, a probabilidade total final fica:

$$
P^{t o t}=P_{K}^{t o t}+(1-K) n_{1} \mu \sigma_{m} m
$$

Como a intensidae de TL é $=\eta P^{t o t}$,

$$
I_{T L}=\eta n_{1}\left[K \frac{\sigma_{m}}{4 \pi s^{2}}+\left(1-K \frac{\sigma_{m}}{4 \pi s^{2}}\right) \mu \sigma_{m} m\right]
$$

Se não houver competidores, $\mu=1 / \sigma_{m} m$ e $I_{T L}=\eta n_{1}$. Como $n_{1}=N_{1} \exp (-\alpha D), I_{T L}$ não tem supralinearidade. 
Se houver, um grande número de competidores, $\mu=\left[\sigma_{m} m / \sigma_{2}\left(N_{2}-n_{2}^{\prime}\right)\right]$ e o segundo termo da equação 2.43 dá a supralinearidade e o primeiro, a parte linear.

(b) Modelo de armadilhas interativas

Sunta et al. $[56,57]$ introduziram o sistema de armadilhas interativas para explicar o fenômeno de supralinearidade e a sensibilidade na TL.

O sistema de armadilhas interativas é valido para qualquer número de armadilhas e centros de recombinação. Sunta et al. consideram um sistema de armadilhas interativas constituído de duas armadilhas e um centro de recombinação. Também eles admitem que as armadilhas são de elétrons, o que permite analisar o problema baseado na Figura 2.17. O modelo é aplicável também se as armadilhas forem de buracos.

Em primeiro lugar, as armadilhas H não são afetadas pelas temperaturas em que as armadilhas $\mathrm{N}$ são esvaziadas. As armadilhas $\mathrm{N}$ são de dois tipos: $\mathrm{N}_{i}$ são interativas e $\mathrm{N}_{n}$ não-interativas. $\mathrm{h}, \mathrm{n}_{i}$ e $\mathrm{n}_{n}$ são as concentrações de armadilhas preenchidas das $\mathrm{H}$, $\mathrm{N}_{i}$ e, $\mathrm{N}_{n}$ existentes. No modelo de Mische \& McKeever as armadilhas $\mathrm{N}_{n}$ são aquelas especialmente associadas a centros de recombinação luminescente (CRL).

Note-se, no modelo de Sunta et al. os elétrons das armadilhas $\mathrm{N}_{i}$ além de alguns se recombinarem com outros centros CRL o restante é capturado por armadilhas H. $\alpha$ e $\varepsilon$ são as probabilidades de rearmadilhamento das armadilhas vazias $\mathrm{N}$ e $\mathrm{H}$, respectivamente, enquanto que $\gamma$ é a probabilidade de recombinação com CRL.

A condição de neutralidade de carga impõe que o número de centros de recombinação disponíveis seja a $n_{i}+n_{n}+h$.

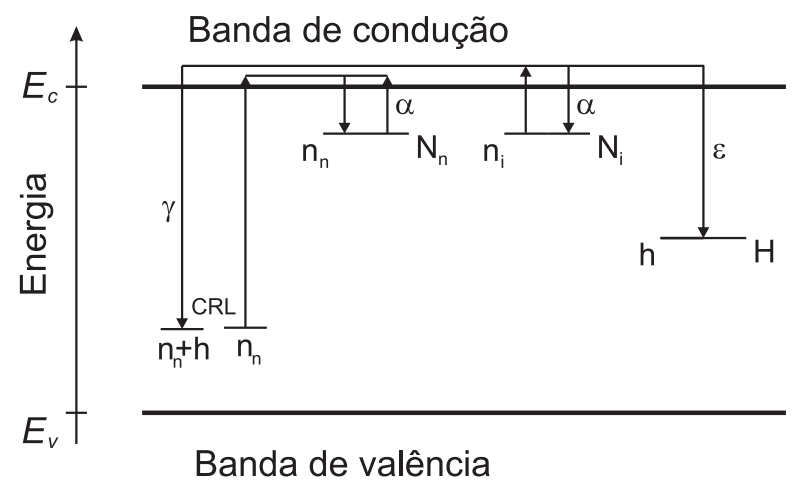

Figura 2.17: Transições no modelo de sistema armadilhas interativas. $N_{i}$ e $N_{n}$ são as concentrações totais das armadilhas TL do tipo interativo e não-interativo, respectivamente. $n_{i}$ e $n_{n}$ são as armadilhas correspondentes preenchidas. $H$ é a concentrção de armadilhas ocupadas interativas. $\gamma, \alpha$ e, $\varepsilon$ são os coeficientes de rearmadilhamento. 
Durante a irradiação as armadilhas $\mathrm{N}$ são preenchidas proporcionalmente à dose $D$ da radiação [58].

$$
d n=\alpha^{\prime}(N-n) d D
$$

onde $\alpha^{\prime}$ é a fração de armadilhas vazias que captura elétrons por unidade de dose. Se antes da irradiação não haviam armadilhas com elétron, isto é, $n=0$ para $D=0$, a solução de (2.44) é:

$$
n(D)=N\left[1-\exp \left(-\alpha^{\prime} D\right)\right]
$$

Da mesma forma para as armadilhas $\mathrm{H}$ :

$$
h(D)=H\left[1-\exp \left(-\varepsilon^{\prime} D\right)\right]
$$

onde $\varepsilon^{\prime}$ é o equivalente de $\alpha^{\prime}$, porém, para H. $\alpha^{\prime}$ e $\varepsilon^{\prime}$ são $<<1$ e $n(D)$ e $h(D)$ crescem linearmente com a dose $\mathrm{D}$.

Os possíveis caminhos que os elétrons seguirão durante a leitura TL são mostrados na Figura 2.17. Admitindo-se que as armadilhas preenchidas $n$ sejam interativas (sem colocar o índice $i$ ), na temperatura $T_{m}$ do pico, omitindo os fatores constantes $\operatorname{sexp}\left(-E / K T_{m}\right)$, a intensidade da luz TL emitida na recombinação de uma fração de $n$ com CRL pode ser escrita:

$$
I=\frac{n(n+h) \gamma}{(H-h) \varepsilon+(n+h) \gamma}
$$

Supondo ainda que as armadilhas profundas não preenchidas $(H-h)$ capturam muito mais elétrons do que aqueles que se recombinam com $(n+m)$ - CRL, isto é, supondo $\varepsilon(H-h)>>(n+h) \gamma, \varepsilon=\gamma, 2.47$ pode ser reescrita:

$$
I=\frac{N(a+1)\left[1-\exp \left(-\alpha^{\prime} D\right)\right]^{2}}{a+1-\exp \left(-\alpha^{\prime} D\right)}
$$

Para $\alpha^{\prime} D<<1$,

$$
I=\frac{N(a+1)\left(\alpha^{\prime} D\right)^{2}}{a+\alpha^{\prime} D}
$$

Na região de doses baixas, certamente $\alpha^{\prime} D<<a$, onde a é uma constante, e a intensidade TL dada por 2.49 cresce quadraticamente com a dose. A Figura 2.18 mostra curvas de $I$ em função de $D$, obtidas de 2.48 para $a=10 ; 1 ; 0,1 ; 0,01$ e, 0 [58]. O resultado mostra que as curvas 1 a 4 são supralineares para todo $D$ e a 5 , linear. 
A seguir mostraremos que a separação das armadilhas $I$ em interativas $\left(N_{i}, n_{i}\right)$ e não interativas $\left(N_{n}, n_{n}\right)$ pode levar à intensidade TL a crescer lineramente e depois supralinearmente com a dose.

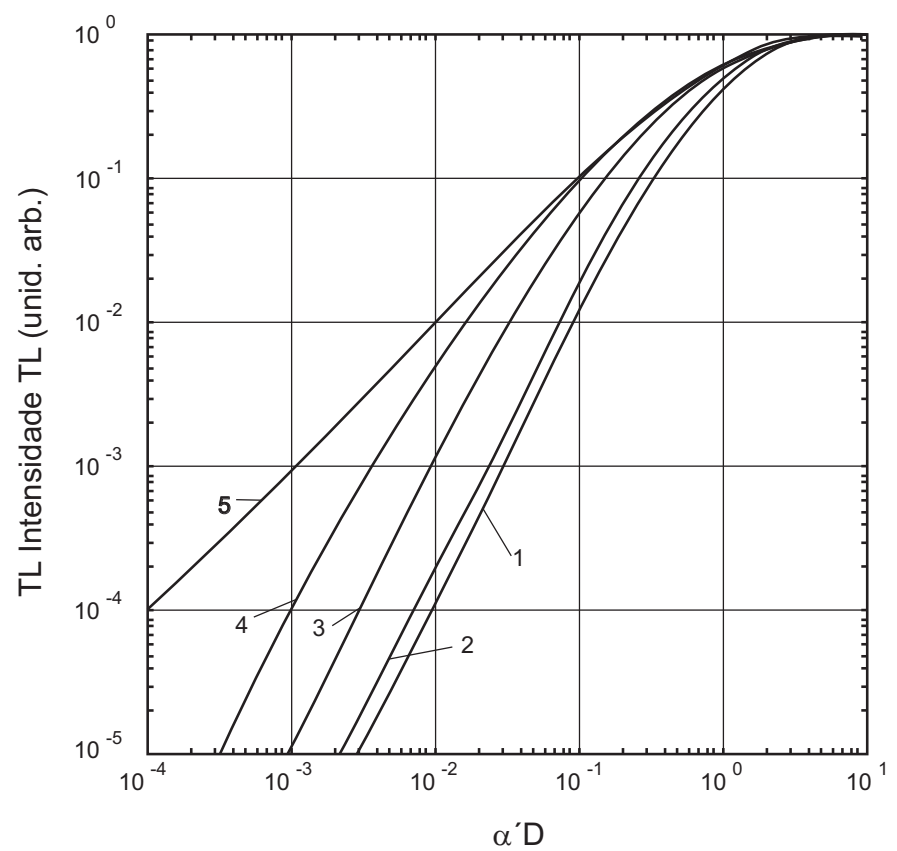

Figura 2.18: Intensidade TL em função da dose $D$ no modelo de sistema de armadilhas interativas. As curvas $1-5$ são para $a=10 ; 1 ; 0,1 ; 0,01$ e, 0 respectivamente.
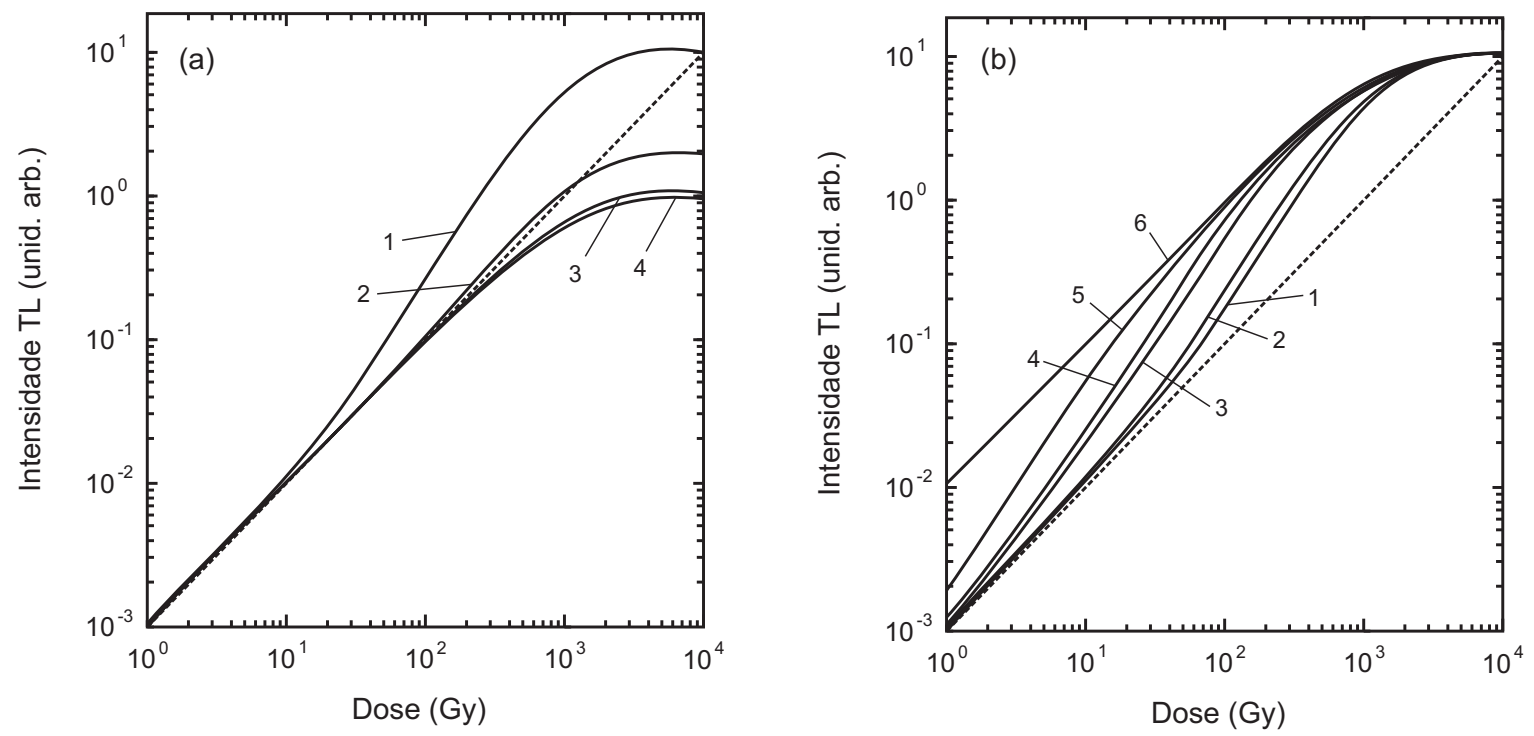

Figura 2.19: (a) Intensidade TL em função da dose para o caso de $a=1$ e diferentes valores de $K=10 ; 1 ; 0,1 ; 0,05 ; 0,01$ e, 0 respectivamente. (b) Intensidade TL em função da dose para $K=0$ e diferentes valores de $a=10 ; 1 ; 0,1 ; 0,05 ; 0,01$ e, 0 respectivamente. Em ambos a linha da linearidade esta mostrada por a linha tracejada. 
A equação 2.48 é fruto da hipótese de que, as armadilhas $N$, lá consideradas, são do tipo interativas. Para as armadilhas não interativas, quando $\varepsilon=0$, pode-se ver da equação 2.47 que a intensidade TL devido a $n_{n}$ é dada por:

$$
I_{n}=n_{n}=N_{n}\left[1-\exp \left(-\alpha^{\prime} D\right)\right]
$$

onde a probabilidade de rearmadilhamento $\alpha$ ' é a mesma do caso interativo, pois, as armadilhas $N_{i}$ e $N_{n}$ são de mesma natureza. A intensidade TL total $I_{t}=I_{i}+I_{n}$ e, $N_{i}=K N_{n}$, obtemos:

$$
I_{t}=N_{n}\left(1-e^{-\alpha^{\prime} D}\right)\left[1+K \frac{(a+1)\left(1-e^{-\alpha^{\prime} D}\right)}{a+1-e^{-\alpha^{\prime} D}}\right]
$$

A Figura 2.19 mostra o resultado do cálculo usando a equação 2.51 para valores de $a$ e $K$ indicados na Figura [58]. Há valores de $a$ e $K$ para os quais a seqüência linearsupralinear é visível ${ }^{2}$.

\subsubsection{Efeitos de UV próximo}

Aqui, somente raios ultravioletas próximos serão considerados. Os fótons de $\lambda=222$ ou $300 \mathrm{~nm}$ possuem energias de 5,6 eV ou 4,14 eV. Como a largura da banda proibida (Energy Gap) de um cristal de silicato é da ordem de 6 a 9 eV, um fóton de UV próximo não é capaz de promover um elétron da banda de valência para a banda de condução. Então, em principio, raios ultravioletas próximos não são capazes de induzir a TL.

A experiência, no entanto, tem mostrado que essas radiações induzem TL. Por quê?

Lin S.H. [59] escreve na página de seu livro: "Most optical effects studied in the parst can be attributed to single photon processes... Single photon processes are typical for how intensity light where the electron interacts with a single photon at a time and the probability that other photons arrive during the interaction is low. By increasing the intensity of a light beam one can observe more and more events where an electron will be perturbed by the electric field of more than one photon at a time".

Em 1929, Marie Göppert-Mayer [60] mostrou na tese de doutoramento que a probabilidade de um elétron interagir com dois fótons (processo de dois fótons) não é desprezível e aumenta com a intensidade do feixe da luz. É claro, que ela depende, também, da energia do fóton.

\footnotetext{
${ }^{2}$ Os dois modelos acima apresentados admitem que, o processo de supralinearidade acontece durante o aquecimento para a leitura TL.
} 
A segunda é transferir os elétrons já capturados em armadilhas de uma dada energia $E$ para outras de energia $E^{\prime}<E$, este processo é denominado de TL fototransferida (PTTL - Phototransferred Thermoluminescence).

A explicação básica para o fenômeno de PTTL está no entendimento de que os elétrons capturados nas armadilhas profundas podem ser opticamente liberados durante a iluminação com luz UV para serem capturados pelas armadilhas menos profundas. Na realidade, poderia haver a fototransferência no sentido inverso também.

\subsection{Absorção óptica}

Quando um feixe de luz, UV-Vis-IV atravessa um material, qualquer que seja seu estado, sua propagação é sempre afetada.

Em primeiro lugar, a intensidade sempre decresce, em maior ou menor grau, à medida que a luz penetra no meio.

Em segundo lugar, a velocidade de propagação diminui comparada com a do vácuo.

A perda da intensidade é devido, principalmente, à absorção pelo meio, mas, o espalhamento pode, também, acontecer. O efeito do meio sobre a velocidade de propagação é devido à dispersão.

Diz-se que uma substância apresenta uma absorção geral se ela reduz a intensidade de todos os comprimentos de onda da luz, por aproximadamente o mesmo valor. Se a luz incidente for visível, a luz transmitida é sentida por uma pessoa, sem cor especifica, porém, com uma redução na intensidade total, o que dá ao observador, uma sensação de uma cor cinzenta.

Não há, na realidade, nenhuma substância que absorve igualmente todas as freqüências da luz. Experimentalmente, um filme fino semitransparente de platina, produz uma absorção de quase todos os comprimentos de onda visíveis, mais ou menos igualmente.

Em contraposição, numa absorção seletiva, alguns comprimentos da onda são mais intensamente absorvidos. Praticamente, todas as substâncias coloridas são devido à absorção seletiva. Assim, um vidro verde absorve os comprimentos de onda na região de vermelho e azul.

Na Figura 2.20, um feixe de luz de intensidade $I_{0}$ atravessa um tubo de vidro contendo fumaça. A intensidade $I$ da luz, que emerge da outra extremidade é $<I_{0}$. Se $d$ for o comprimento do tubo de vidro, experimentalmente, observa-se que

$$
I=I_{0} \cdot \exp (-\alpha d)
$$




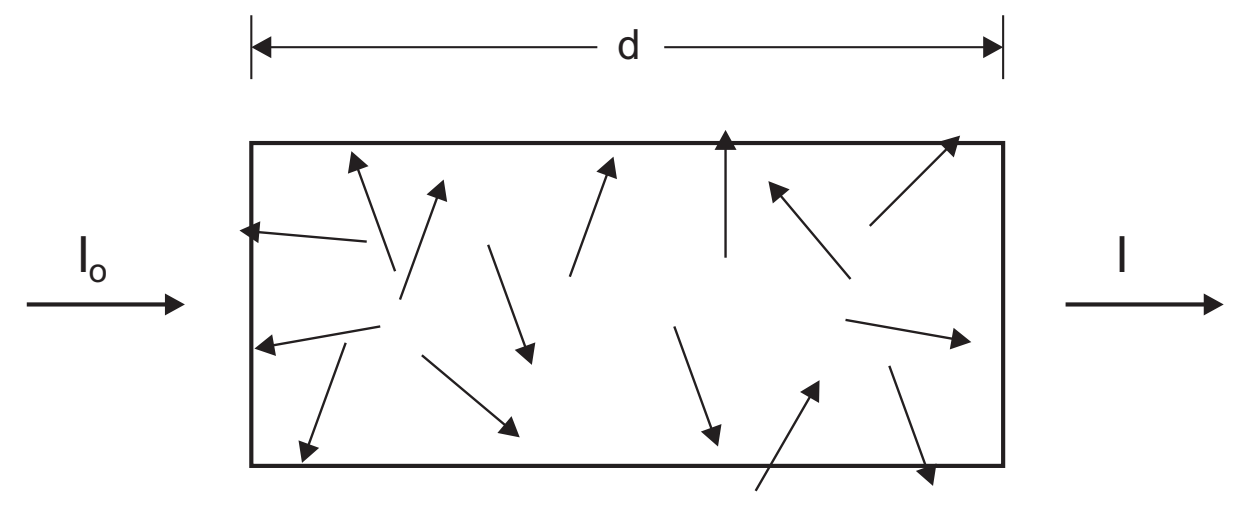

Figura 2.20: Espalhamento da luz por partículas pequenas, como na fumaça.

onde $\alpha$ é chamado de coeficiente de absorção, que no caso depende da natureza e densidade da fumaça. Neste experimento, a diminuição da intensidade da luz não é devido ao desaparecimento da luz, mas, sim devido ao espalhamento pelas partículas da fumaça. A parte espalhada é removida do feixe de luz incidente.

A absorção ótica se deve ao desaparecimento real de freqüências em torno de um $\lambda_{0}$, cuja energia é convertida em movimento térmico das moléculas do absorvedor.

Na equação 2.52 , se $d$ for $d x$ infinitésima, a variação $d I$ da intensidade pode ser escrita:

$$
d I=-\alpha I d x
$$

e é chamada de lei de Beer-Lambert.

A integração de 2.53 fornece a equação 2.52 , da qual se tem:

$$
\ln \frac{I_{0}}{I}=\alpha d
$$

$\mathrm{Ou}$

$$
\log _{10} \frac{I_{0}}{I}=\alpha \cdot d \cdot \log _{10} e
$$

Chama-se densidade ótica $D O$, o valor de $\log _{10} \frac{I_{0}}{I}$. Como $\log _{10} e \simeq 0.434$,

$$
D O=0.434 \cdot \alpha \cdot d
$$

Através de medidas de absorção óptica em um determinado material, nas regiões do espectro óptico (infravermelho, visível e ultravioleta), podemos estudar quais são as impurezas e/ou defeitos da rede cristalina que dão origem à sua cor. 
$\mathrm{Na}$ região espectral do infravermelho, são identificados grupos moleculares nas amostras. Podemos considerar as ligações no cristal como molas unindo os átomos ou moléculas do cristal, então todo o sistema pode vibrar. Considerando que uma molécula é constituída por $N$ átomos, existem $3 N-6$ modos normais de vibrações chamados de fundamentais, onde cada vibração pode ocorrer aproximadamente em múltiplos da freqüência fundamental original. Como a energia incidente no cristal é relativamente baixa, provoca apenas torções e vibrações dos átomos como um todo, tanto daqueles pertencentes à rede, quanto das impurezas presentes nas amostras.

Uma molécula isolada com modos degenerados pode apresentar os modos em freqüências ligeiramente diferentes num cristal, isto é devido às influenciais antissimétricas do campo cristalino.

$\mathrm{Na}$ região espectral do visível e do ultravioleta são observadas as excitações eletrônicas dos átomos da rede e das impurezas. Um átomo isolado apresenta estados de energia discreta. Os processos de absorção ou emissão de fótons ocorrem através das transições entre o estado fundamental e um dos estados excitados de menor energia. Para o grupo dos elementos de transição, os orbitais desocupados possuem energias semelhantes às do íon isolado, mas os níveis de energia são separados quando o átomo está localizado num campo cristalino. No processo só estão envolvidos os elétrons das camadas mais externas dos íons, denominados de elétrons opticamente ativos. O ambiente no qual o íon está inserido determina a estrutura do campo cristalino e, portanto, a separação dos níveis de energia. A absorção de um fóton com uma energia, que é a diferença da separação dos níveis de energia, permite que o elétron transite de um nível de energia menor a outro de energia maior. Os níveis de energia são determinados pelo estado de valência do átomo, número de coordenação e a simetria do lugar que ocupa. Também são influenciados pelo tipo de ligantes, a extensão da distorção do lugar e o valor da distância interatômica metal-ligante. O campo cristalino varia com a estrutura do cristal; dessa forma, a quantidade de desdobramentos varia de mineral a mineral para um mesmo íon, produzindo diferentes absorções e possibilitando a identificação de um mineral especifico por meio da espectroscopia. 


\subsection{Ressonância Paramagnética Eletrônica}

\subsubsection{Minúsculo imã de um elétron em rotação num campo magnético externo.}

A técnica de Ressonância Paramagnética Eletrônica (RPE) é um processo físico envolvendo o spin eletrônico dentro de um campo magnético.

Um elétron, classicamente, é considerado uma pequeníssima esfera carregada negativamente, em rotação em torno de um eixo próprio. Em eletrodinâmica, uma carga negativa em rotação produz uma corrente circulando no sentido oposto da rotação da esfera. A lei de Biot - Savart diz que uma corrente circular produz um campo magnético na sua vizinhança, semelhante ao de um minúsculo imã, a que, então, o elétron é equivalente. Num átomo ou numa molécula com mais de dois elétrons, há uma tendência dos dois elétrons vizinhos formarem pares magneticamente neutros, caso em que não há momento magnético diferente de zero. Em átomos de metais de transição e de terras raras, os elétrons $d$ e $f$, respectivamente, apresentam spin total diferente de zero.

Na secção 2.1.4 foi mencionado que, quando uma radiação eletromagnética energética incide sobre um material, ioniza-o criando pares elétrons-buracos. Esses elétrons são capturados pelas armadilhas (devido a defeitos pontuais) e dão origem a átomos ou complexos com excesso de elétrons (pode ser falta de elétrons, i.e., excesso de buracos), os quais têm, agora, momento magnético total diferente de zero. Os spins não pareados, quando colocados num campo magnético, tendem a se alinhar, paralelamente, ao campo e se imantam. As propriedades magnéticas, resultantes dessa situação, são referidas como paramagnetismo eletrônico.

\subsubsection{Ressonância paramagnética eletrônica}

A Figura 2.21 mostra três situações de spins eletrônicos não-pareados, dentro de um material [61]. Em (a), não há campo magnético externo e, os spins eletrônicos têm orientações aleatórias. Em $(b)$, um campo magnético $\vec{H}$ é aplicado. Os spins se orientam paralela ou antiparalelamente ao campo $\vec{H}$. Em $(c)$, uma microonda se incide sobre o material. Se sua freqüência for apropriada $\nu_{o}$, alguns elétrons invertem sua orientação. Diz-se que houve uma ressonância, que permitiu a inversão da orientação de alguns spins. Uma energia $h \nu_{o}$ foi absorvida nesse processo, tem-se, então, a ressonância paramagnética eletrônica. 


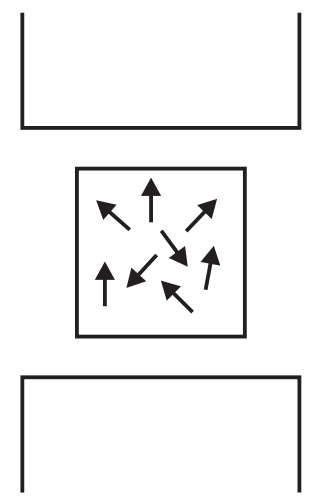

(a)

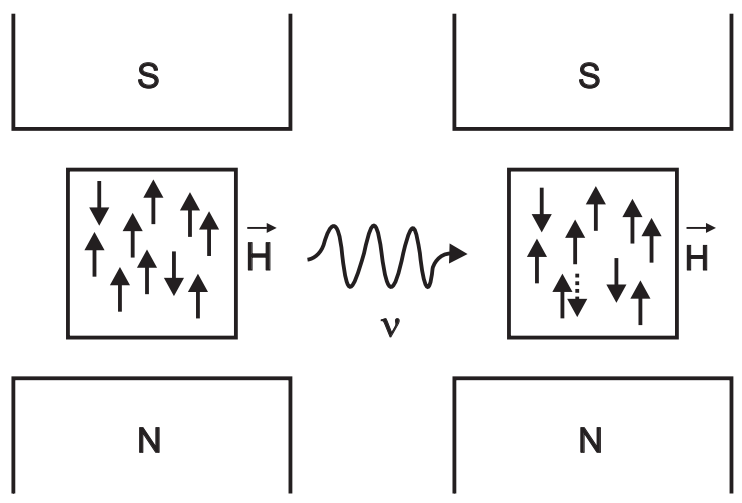

(b)

(c)

Figura 2.21: (a) - Sem campo magnético, os spins estão orientados aleatoriamente. (b) - No campo magnético H, os spins se orientam pelo efeito Zeeman. (c) - A incidência de uma microonda de freqüência apropiada provoca inversão de orientações dos spins.

Os elétrons não pareados são caracterizados por:

Momento angular do spin: $S$ em unidades de $\hbar=h / 2 \pi, h=$ const. Planck

Número quântico do Spin: $S$ com $S=1 / 2$ para um elétron.

Numero quântico magnético: $M, M= \pm 1 / 2$

Magnéton de Bohr: $\beta=\frac{e \hbar}{2 m_{e}}$ e $m_{e}=$ massa do elétron

Momento magnético: $\vec{\mu}_{e}=-g \beta S$

Fator de separação espectroscópica : $g, g=2.0023$ para um elétron livre

Num campo magnético $\vec{H}$, a energia do momento magnético $\vec{\mu}_{e}$ é dada por

$$
E_{H}=g \beta H M=-\overrightarrow{\mu_{e}} \cdot \vec{H}
$$

A condição de ressonância é dada, então, por:

$$
h \nu=g \beta H
$$

Na absorção ótica, varia-se a freqüência para descobrir à de ressonância; na EPR mantem-se fixa a freqüência e varia o campo $H$ e o valor $H o=h \nu / g \beta$ é o de ressonância.

A unidade internacional do campo magnético é Tesla (T), mas, Gauss é, também, usado. $1 \mathrm{~T}=10^{4}$ gauss. Na prática, a subunidade $m T(1 m T=10$ gauss $)$ é muito usado.

A Figura 2.22 mostra os níveis de energia na separação Zeeman no campo magnético. A ressonância ocorre para $H=H o=h \nu / g \beta$. 


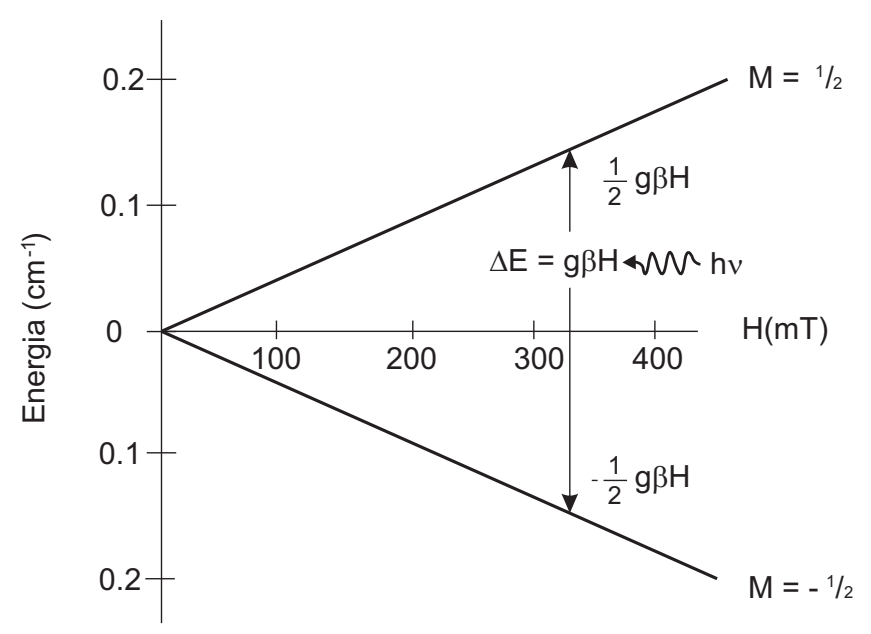

Figura 2.22: Niveis de energia de um spin eletrônico em função de $H$. A ressonância se dá em $H_{0}=h \nu / g \beta$.

Na Figura 2.23 a potencia da microondas é dada em função de $H$. Em $H o$, observa-se a banda de absorção.

\subsubsection{Espectro RPE e fator $g$}

A Figura 2.23 é a de um espectro RPE de absorção. A forma da curva de absorção pode ser Gaussiana ou Lorentziana. Na prática, o espectro é registrado na forma de derivada primeira $d P / d H$ em função de $H$. A Figura 2.24 mostra as formas Gaussiana e Lorentziana, bem como suas derivadas primeiras. Isto é devido, em primeiro lugar a maior distinção das linhas individuas, num espectro complexo e, em segundo lugar, à conveniência técnica de registrar a derivada primeira. A intersecção da derivada com a linha zero corresponde ao valor do campo magnético de ressonância. Num espectro complexo, o número de linhas é contado em relação aos valores máximos (ou mínimos) das curvas da derivada primeira como se vê na Figura 2.25.

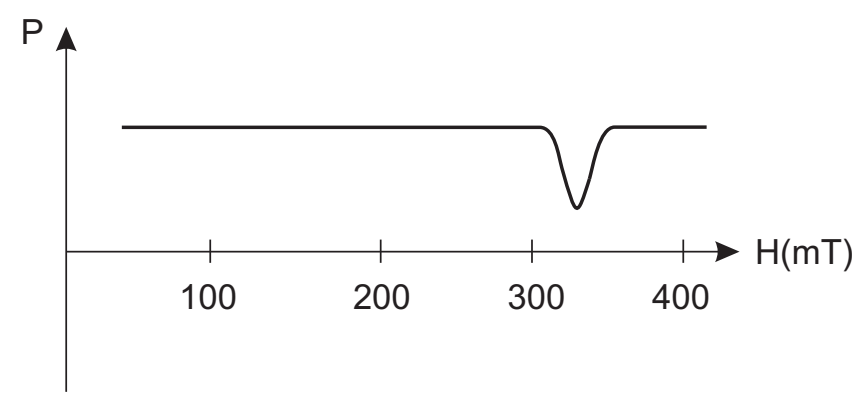

Figura 2.23: Absorção da potencia de microonda em torno de $H_{0}$. 
O fator $g$ de separação espectroscópica de um sinal RPE é um parâmetro muito importante, quando se analisa um espectro RPE. Elétrons não pareados, em diferentes ambientes, têm valores ligeiramente diferentes de $g$ e, essa pequena diferença pode servir para identificar os diferentes centros paramagnéticos. A variação do fator $g$ é devido, indiretamente, à interação magnética entre o momento magnético do spin e o momento magnético orbital, isto é, à interação spin-órbita.

O fator $g$ de um elétron livre sem o movimento orbital é 2; a correção relativística dá $g_{e}=2.0023$. Esse valor é muito próximo do fator $g$ do hidrogênio atômico nos cristais e, também, dos centros -F.

O fator $g$ de um íon paramagnético livre, que é o fator de Landé, não só depende do spin, mas, também do movimento orbital, é determinado pela fórmula de Landé:

$$
g_{L}=1+\frac{I(I+1)+S(S+1)-L(L+1)}{2 I(I+1)}
$$

onde $L, S$ e $I$ são números quânticos dos momentos angulares orbital, do spin e total. $I=L+S$.

No caso de estado de spin puro, quando $L=0, I=S$ e $g=2$, isto é, obtém-se o fator $g$ de um elétron livre ou de estados com um momento orbital "congelado".

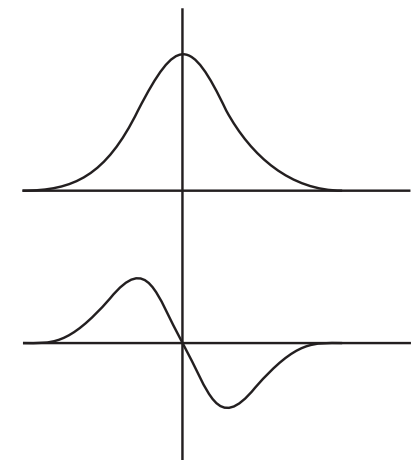

(a)

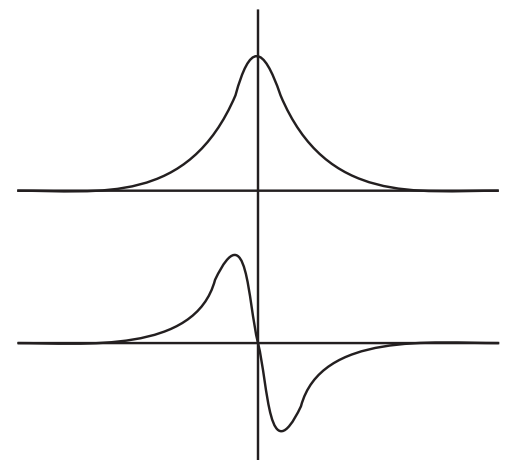

(b)

Figura 2.24: Curva de absorção: Gaussiana (a) e Lorentziana (b) e respectivas derivadas primeiras. 


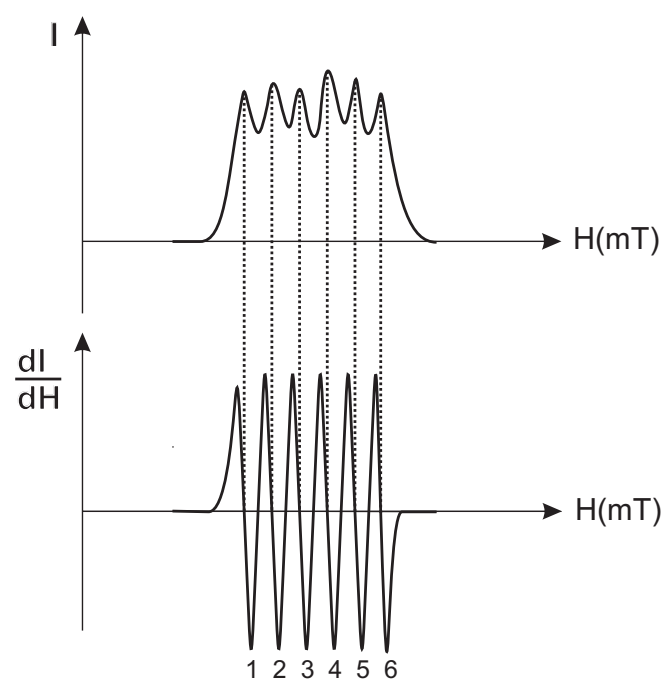

Figura 2.25: Contagem do número de linhas num espectro complexo.

\section{$2.5 \quad$ Vidros}

\subsubsection{Vitrificação a partir de fase líquida}

\section{Transição vítrea}

Qualquer material sólido, ao atingir a temperatura de fusão $T_{f}$, passa para a fase líquida, caracterizada por baixa viscosidade de poucos centipoises ${ }^{3}$.

Um líquido apresenta comportamentos diferentes, durante seu resfriamento para baixo da $T_{f}$, isto é, depende da velocidade de esfriamento. Para entender melhor, costuma-se escolher uma variável termodinâmica, que pode ser o volume especifico, o coeficiente de dilatação, o índice de refração, etc.

Tomando, por exemplo, o volume específico, pode-se analisar sua variação em função da temperatura $T$ (absoluta), para diferentes velocidades de esfriamento. Na Figura 2.26, tem-se o volume especifico em função da temperatura $T$. Partindo da fase líquida $L$, o esfriamento progressivo causa diminuição do volume. Quando se atinge a temperatura de fusão $T_{f}$, se o esfriamento for suficientemente lento, pode ter a cristalização, com uma variação $\Delta V_{f}$ de volume, sem mudanças de temperatura. Lembre-se que há casos em que $\Delta V_{f}$ é uma variação positiva. Uma vez completada a cristalização, a temperatura e o volume diminuem; este último com um coeficiente angular menor do que na fase $L$. Se, porém, a velocidade de esfriamento for bem maior, a substância continua líquida, mesmo para $T<T_{f}$. É a fase de líquido superesfriado (SE). Chega-se,

\footnotetext{
${ }^{3} 1$ poise $=0.1 \mathrm{~Pa} \mathrm{~s}=1 \mathrm{~g} / \mathrm{cm} \mathrm{s}$
} 
porém, a uma temperatura $T_{g}$, em que muito rapidamente a substancia se solidifica. $T_{g}$ chama-se temperatura de transição vítrea e é uma função da velocidade $v_{e}$ de esfriamento. A Figura 2.27 mostra como taxa de esfriamento não só altera a $T_{g}$, como também, o volume final do produto.

Há, porém, uma taxa máxima e uma taxa mínima, que definem o intervalo dos valores de $T_{g}$. A Tabela 2.1 lista valores experimentais de valores médios da temperatura de transição vítrea $T_{g}$ de alguns compostos [62].

Tabela 2.1: Valores médios de $T_{g}(K)$

\begin{tabular}{ll}
\hline Materiais & $T_{g}(\mathrm{~K})$ \\
\hline $\mathrm{SiO}_{2}$ & $1500-2000$ \\
$\mathrm{Na}_{2}-\mathrm{CaO}-\mathrm{SiO}_{2}$ (vidro mais comum) & $800-820$ \\
$\mathrm{~B}_{2} \mathrm{O}_{3}$ & $470-530$ \\
$\mathrm{~S}$ & 244 \\
Glucose & $280-300$ \\
\hline
\end{tabular}

\subsubsection{Devitrificação. Cristalização}

Um cristal de silicato, ou uma mistura de dois ou mais óxidos, se funde em temperatura $T_{f}$ de fusão e, acima dessa temperatura tem-se a substância em fase líquida. Como já foi visto, com um esfriamento suficientemente rápido, ao atingir uma temperatura $T_{g}<T_{f}$, obtém-se um vidro.

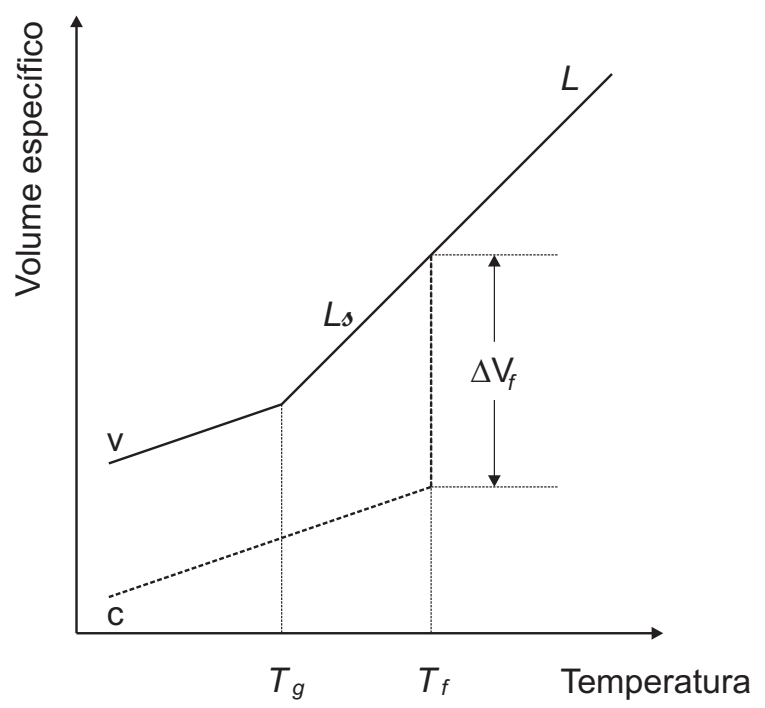

Figura 2.26: Variação do volume específico durante o esfriamento. 


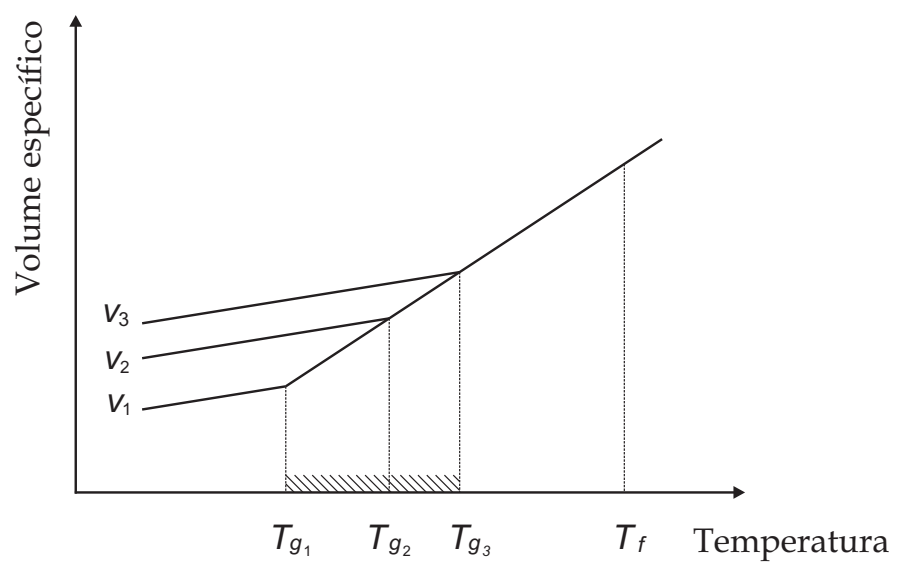

Figura 2.27: Influência da taxa de esfriamento na posição $d a T_{g}: v_{1}<v_{2}<v_{3}$.

Agora, se se esfria bem lentamente, pode haver formação de cristais, cujos tamanhos dependem de vários fatores. O líquido se cristaliza no caso.

Sem entrar em detalhe, será visto, a seguir o mecanismo e as condições de cristalização.

\section{Mecanismo de cristalização}

Aqui se considera uma fase líquida homogenia de uma substância.

A primeira observação experimental é o fato de que a cristalização não é uma transformação que ocorre pelo volume todo, de uma só vez. Há centros iniciais de cristalização, no começo e se estende gradualmente a partir desses centros. Esse processo passa pelos seguintes estágios.

\section{Nucleação}

À medida que o líquido é esfriado quando entra no estágio de nucleação, formamse, primeiro, aglomerações de átomos ou moléculas, que servem de pontos de partida para o desenvolvimento de regiões ordenadas. Essas aglomerações recebem o nome de embriões, que se formam e se desfazem, provocando uma flutuação estrutural devido à agitação térmica. O gradual esfriamento, eventualmente, favorece a formação e o crescimento de embriões, dando origem à cristalização.

É possível mostrar que, um embrião deve ter uma dimensão crítica para poder servir de ponto de partida para entrar na fase de cristalização. Nesse estágio, o embrião se torna o núcleo da cristalização.

A nucleação é considerada homogênea, quando ela se dá de modo completamente aleatório. A condição sob a qual isto acontece é que os elementos de volume na fase 
inicial sejam estrutural, química e energeticamente idênticos. Esta condição implica, por outro lado, que o volume todo seja quimicamente homogêneo, sem imperfeições estruturais. Na prática, isto nunca acontece, pois, a superfície do líquido e as paredes do vaso são, por razões óbvias, imperfeições. Além disso, mesmo partindo de compostos, quimicamente bastante puros, é inevitável que, de fato, haja impurezas. Todas essas imperfeições servem de sítios de nucleações, pois, a energia de ativação de formação é menor do que num meio totalmente homogêneo. Nucleação a partir de impurezas é denominada heterogênea.

Contudo, uma nucleação homogênea é mais fácil de ser tratada teoricamente, por isso, considera-se, primeiro, esse caso ideal.

\section{Tratamento clássico da nucleação homogênea}

Entre outros parâmetros, de que depende a cristalização, os dois seguintes são, sem duvida, os mais importantes.

O número $I$ de núcleos, produzidos por unidade de volume e por unidade de tempo, chama-se taxa de nucleação.

A velocidade $u$, com que os núcleos crescem, é a taxa de crescimento. A Figura 2.28 mostra a taxa de nucleação $I$ e a taxa de crescimento $u$ em função da temperatura.

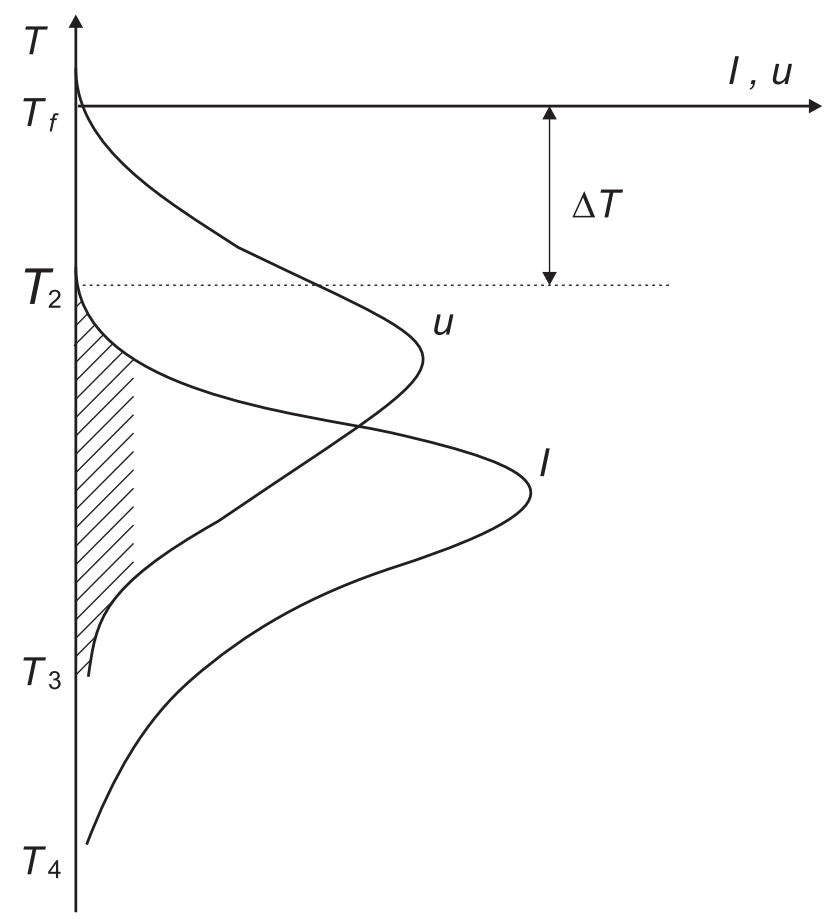

Figura 2.28: A taxa de nucleação I e a taxa de crescimento u em função de T. A cristalização total se dá na região hachurada. 
Como já foi visto, acima da temperatura $T_{f}$ de fusão, tem-se a fase líquida estável, mas, abaixo de $T_{f}$, teoricamente, é possível haver formação de núcleos entre $T_{f}$ e $T_{3}$. A cristalização propriamente dita requer, porém, o estágio de crescimento que se dá entre $T_{2}$ e $T_{4}$.

Vê-se, então, que entre $T_{2}$ e $T_{3}$, região de superposição de entre a nucleação e o crescimento, i.e., é nesse intervalo $\left(T_{2}, T_{3}\right)$ de temperaturas que os núcleos crescem para dar origem a cristais. Se entre $T_{2}$ e $T_{3}$, ou $I$ ou $u$ ou ambos forem muito pequenos, não há cristalização observável e, o material pode passar para a fase vítrea.

Em temperaturas, em que há ainda razoável mobilidade atômica, ocorre contínua formação e desagregação de embriões, por agitação térmica. Mas, à medida que a temperatura cai, a fase se torna metastável, favorece-se a formação de aglomerações cada vez mais estáveis.

Volmer \& Weber [63] e Becker \& Döring [64] propuseram um modelo clássico, termodinâmico, com a hipótese de que os embriões têm estrutura uniforme, com propriedades e composição idênticas às da futura fase, diferindo somente na forma e tamanho.

A Figura 2.29 mostra o comportamento da energia livre molar das fases líquida e cristalina. As curvas da fase líquida e da fase cristalina interceptam-se em $T_{f}$, que é o ponto de equilíbrio das duas fases.

Nessa temperatura, a diferença nas energias livres $G$ entre as duas fases é zero. As linhas cheias representam as fases estáveis e, as linhas pontilhadas, o líquido superesfriado e o cristal superaquecido, que são estados metastáveis.

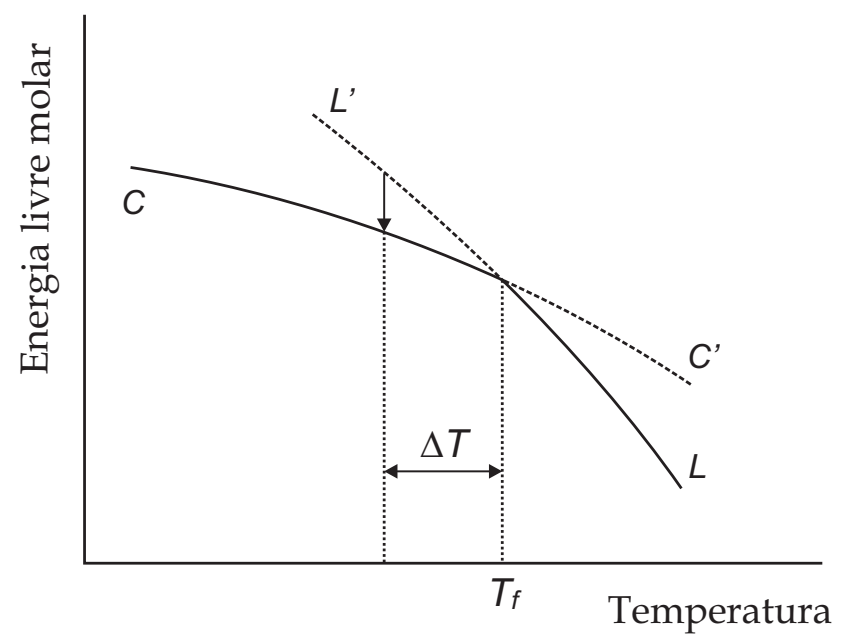

Figura 2.29: Energia livre molar de um cristal (c) e de do líquido na vizinhança de $T_{f}, L^{\prime}=$ Líquido superesfriado. $C^{\prime}=$ cristal superaquecido. 
Em temperatura $T<T_{f}$, o ponto sobre a linha $L^{\prime}$ é um estado superesfriado e $\Delta T=T_{f}-T$ é usado como sendo grau de superesfriamento.

A passagem do ponto $L^{\prime}$ para o ponto em $C$, ainda na temperatura $T$, se dá por uma variação $\Delta g_{v}$ de energia livre por unidade de volume. Esse valor é negativo. Para um embrião esférico de radio $r$, à variação da densidade de energia $\Delta g_{v}$ corresponde a quantidade de energia igual a $\frac{4}{3} \pi r^{3} \Delta g_{v}$.

A formação de um embrião, por outro lado, é feita à custa da criação de uma interface ao longo de sua superfície externa, o que requer uma energia $\Delta g_{s}$ por unidade de área. Assim, para um embrião esférico de raio $r$, foi necessária uma energia de interfase igual a $4 \pi r^{2} \Delta g_{s}$.

A soma dessas energias é nada mais do que a energia total $\Delta g_{r}$, necessária para a formação de um embrião de raio $r$, ou de um núcleo proveniente de um embrião:

$$
\Delta g_{r}=\frac{4}{3} \pi r^{3} \Delta g_{v}+4 \pi r^{2} \Delta g_{s}
$$

A Figura 2.30 mostra, qualitativamente, a energia livre $\Delta g_{r}$ de formação de um núcleo, em função do raio $r$, para diferentes valores de $\Delta T r$ de superesfriamento.

Para $r$ pequeno (núcleo pequeno), o termo em $r^{2}$ é predominante e, para $r$ grande, o termo em $r^{3}$ é predominante. Então, há um raio cristalino $r_{c}$, para o qual $\Delta g_{r}$ é máximo, quando:

$$
\frac{\partial \Delta g_{r}}{\partial r}=0 \Longrightarrow r_{c}=-\frac{2 \Delta g_{s}}{\Delta g_{v}}
$$

$W_{c}$ é o valor de $\Delta g_{r}$ para $r_{c}$ :

$$
W_{c}=\frac{16 \pi}{3} \frac{\Delta g_{s}{ }^{3}}{\Delta g_{v}{ }^{2}}
$$

$W_{c}$ é a energia de ativação para formação de um núcleo.

$\mathrm{N}$ sendo o número de Avogadro e $V_{m}$ o volume molar do cristal, o número $n_{c}^{\prime}$ de moléculas no núcleo é dado por:

$$
n_{c}^{\prime}=\frac{4}{3} \pi r^{3} N\left(V_{m}\right)^{-1}
$$

Para o núcleo de raio $r_{c}$, o numero de moléculas é dado por:

$$
n_{c}=\frac{4 \pi}{3}\left(\frac{\Delta g_{s}}{\Delta g_{v}}\right)^{3} \frac{N}{V_{m}}
$$




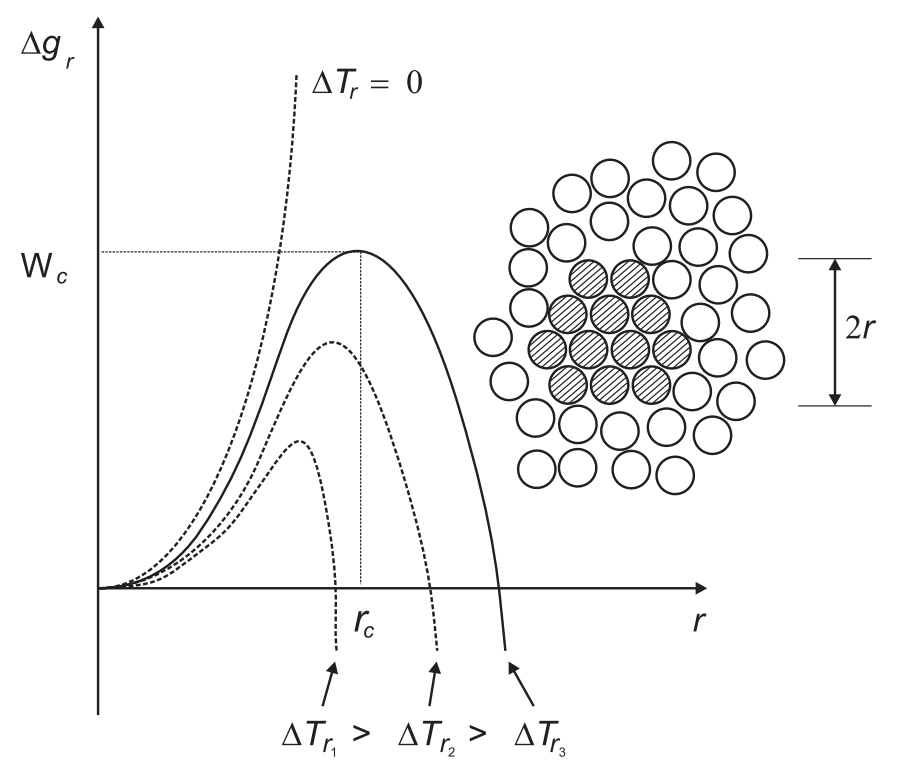

Figura 2.30: Variação da energia livre $\Delta g_{r}$ de formação de um núcleo, em função de seu raio $r . \Delta T r$, é o grau de superesfriamento; $r_{c}=$ raio crítico.

\section{Dependência de $r_{c}$ e $W_{c}$ com a temperatura}

Será admitido que as entalpias do líquido e do sólido, na vizinhança da temperatura de fusão $T_{f}$, variam linearmente.

$\Delta H$ e $\Delta S$ sendo as diferenças nas entalpias e entropias entre o sólido e líquido, a energia livre $\Delta G$ é dada por:

$$
\Delta G=\Delta H-T \Delta S
$$

$\operatorname{Em} T_{f}, \Delta G=0$ e,

$$
0=\Delta H_{f}-T_{f} \Delta S_{f}
$$

Para $T$ muito próxima a $T_{f}$, os valores de $\Delta H$ e $\Delta S$ são, praticamente, iguais a $\Delta H_{f}$ e $\Delta S_{f}$, respectivamente,

$$
\Delta G=\Delta H_{f}-T_{f} \Delta S_{f}=\Delta H_{f}-\frac{T}{T_{f}} \Delta H_{f}
$$

$\mathrm{Ou}$

$$
\Delta G=\frac{\Delta H_{f}}{T_{f}}\left(T_{f}-T\right)=\frac{\Delta H_{f} \Delta T}{T_{f}}=\Delta S_{f} \Delta T
$$

A variação da energia livre por unidade de volume é então: 


$$
\Delta g_{v}=\frac{\Delta G}{V_{m}}=\frac{\Delta S_{f} \Delta T}{V_{m}}=\frac{\Delta H_{f}}{T_{f}} \frac{\Delta T}{V_{m}}
$$

Walton [65] mostrou que, para o grau de superesfriamento $\Delta T$ grande, pode-se considerar:

$$
\Delta G=\frac{T}{T_{f}} \Delta S_{f} \Delta T
$$

Então,

$$
\Delta g_{v}=\frac{\Delta H_{f}}{T_{f}} \frac{\Delta T}{V_{m}}\left(\frac{T}{T_{f}}\right)
$$

A estimativa do termo de energia de superfície encontra dificuldades. Turnbull et al. [66] mostraram que, na interface líquido-cristal, $\Delta g_{s}$ pode ser dada por:

$$
\Delta g_{s}=\alpha \Delta H_{f} N^{-\frac{1}{3}} V_{m}^{-\frac{2}{3}}
$$

$\alpha$ sendo um parâmetro sem dimensão para um tipo particular de fluido. Para metais $\alpha \sim \frac{1}{2}$, para materiais mais complexos, $\alpha \sim \frac{1}{3}$. Em geral $\frac{1}{4}<\alpha<\frac{1}{2}$.

O significado físico de $\alpha$ é dado pelo número de camadas monomoleculares, por unidade da superfície do cristal, que deve ser fundido, na temperatura $T_{f}$, pela energia livre igual a $\Delta g_{s}$.

Chamando de $\beta$ :

$$
\beta=\frac{\Delta S_{f}}{R}=\frac{\Delta H_{f}}{R T_{f}}
$$

onde $R$ é a constante dos gases perfeitos, com $1<\beta<10$. Os valores baixos correspondem a líquidos monoatômicos. Para $\beta$ se aproximando de 10, estruturas mais complexos estão envolvidas, com entropias de fusão maiores.

A influência da temperatura pode ser obtida introduzindo a temperatura reduzida $T_{r}=T / T_{f}$ e parâmetro de superesfriamento $\Delta T_{r}=\frac{\Delta T}{T_{f}}=1-T_{r}$. Com isso, podem ser deduzidas as relações:

$$
r_{c}=\frac{2 \alpha V_{m}^{\frac{1}{3}}}{N^{\frac{1}{3}} \Delta T_{r}}
$$

e

$$
W_{c}=\frac{16 \pi R}{3 N} \frac{\alpha^{3} \beta T_{f}}{(\Delta T)^{2}}
$$


A Figura 2.30, como já foi dito, mostra a forma da função $\Delta g_{r}$ para diferentes graus de superesfriamento. No equilíbrio, $\Delta T_{r}=0$ e a curva não tem o máximo e $r_{c}$ é infinito, assim como $W_{c}$. À medida que $\Delta T_{r}$ cresce, $r_{c}$ diminui e a nucleação torna-se possível. 


\section{3}

\section{Objetivos}

Os anos entre 1960 e 1980 foram caracterizados, no campo de cristais, por um extenso trabalho envolvendo estudos de centros de cor, secundado pelo de termoluminescência e auxiliado pelos processos de ressonância paramagnética eletrônica e nuclear e de ressonância dupla elétron nuclear. Os cristais mais explorados foram os haletos de alcalinos, enquanto os óxidos, sulfatos e carbonatos complementaram esses estudos.

Como foi comentado na introdução, na crosta terrestre, os minerais de silicatos são encontrados em abundância. Isto inclui o solo brasileiro. No entanto, excetuando-se os minerais gemológicos como a esmeralda, o topázio, a turmalina, etc. , os demais, não têm sido objetos de investigação quanto às suas propriedades físicas.

A partir de 2000, com o projeto temático aprovado pela FAPESP, foram iniciados, no Laboratório de Cristais Iônicos, Filmes Finos e Datação (LACIFID) do Instituto de Física da USP, estudos de minerais naturais brasileiros de silicatos. Até momento foram estudados 15 minerais.

No presente trabalho, escolheu-se o diopsídio natural, um mineral de fórmula química $\mathrm{CaMgSi}_{2} \mathrm{O}_{6}$, para estudar suas propriedades de centros de cor, termoluminescência e RPE, procurando a correlação entre elas, através de defeitos pontuais de que dependem.

Nos 15 minerais já estudados, foram observadas as seguintes propriedades: 
a) A supralinearidade, que consiste numa resposta TL à dose $\mathrm{D}$ da radiação, caracterizada por logaritmo da intensidade TL crescer acima da linearidade em relação a $\log$ D, e, observada em muitos dos cristais de haletos, sulfatos, carbonatos e óxidos de alcalinos, alcalino-terrosos e outros metais, é encontrado em menos de $15 \%$ dos minerais de silicatos.

b) Na maioria dos silicatos estudados, um recozimento entre 800 e $1000{ }^{\circ} \mathrm{C}$ ao invés de desarranjar a rede cristalina e tornar o mineral menos sensível à termoluminescência e à ressonância paramagnética eletrônica, a sensibilidade aumentau de três a sete ou oito vezes. Em 10\% dos minerais, o recozimento afetou diferentemente os picos TL.

c) A luz ultravioleta próxima, pelo processo de absorção de dois fótons, induz a termoluminescência, que não coincide com aquela induzido por radiação ionizante.

Essas propriedades serão verificados no diopsídio também.

Serão, por isso, investigados os efeitos da irradiação com raios-gama e, também, da radiação ultravioleta. Os efeitos de recozimentos em altas temperaturas (de 500 a $1200{ }^{\circ} \mathrm{C}$ ), bem como efeitos térmicos isócronos de amostras irradiadas, digamos $\sim 5$ kGy, serão examinados.

Os óxidos componentes do diopsídio e das várias impurezas incorporadas na sua formação no solo serão determinadas pela fluorescência de raios-x, a fim de tentar descobrir quais impurezas (defeitos extrínsecos) são responsáveis pelos centros de cor, de TL e de RPE.

Serão produzidos policristais artificiais de diopsídio puro e dopados com impurezas, com concentrações controladas pelo método de devitrificação. Espera-se com isso, descobrir os defeitos intrínsecos ou extrínsecos responsáveis pela TL e pela RPE.

A partir do diopsídio natural será obtido vidro, do qual será obtido um espectro de absorção ótica e de RPE para comparar com as do diopsídio natural.

Por fim, através da análise dos dados a serem obtidos, será proposto, onde puder, o mecanismo de indução de TL.

Será, ainda, examinada a possibilidade do efeito do tratamento em altas temperaturas sensibilizar o mineral estar relacionada a defeitos intrínsecos, através de policristais artificiais puros, que serão produzidos. 


\section{4}

\section{Materiais e métodos experimentais}

Neste capítulo descrevemos o material investigado, o método de obtenção do policristal artificial e do vidro de diopsídio. Descrevemos ainda a preparação das amostras para os processos de irradiação gama, irradiação UV e os tratamentos térmicos empregados. Também apresentamos de uma forma esquemática e geral o funcionamento dos equipamentos de medida.

\subsection{Amostras}

\subsubsection{Natural}

A amostra natural de diopsídio $\left(\mathrm{CaMgSi}_{2} \mathrm{O}_{6}\right)$ usada no presente trabalho é um cristal de cor branca, o qual foi-nos doado gentilmente pela Mineração São Judas do Estado de São Paulo, Brasil (Figura 4.1).

\subsubsection{Policristal artificial de diopsídio}

Uma mistura estequiométrica preparada com os principais compostos do diopsídio (25,89 \% de $\mathrm{CaO}, 18,61 \%$ de $\mathrm{MgO}$ e $55.49 \%$ em peso de $\mathrm{SiO}_{2}$ ) foi bem homogeneizada, com a tentativa de obtenção de policristal de diopsídio puro. A mistura foi fundida em um cadinho de platina em forno de alta temperatura até $1450{ }^{\circ} \mathrm{C}-1500{ }^{\circ} \mathrm{C}$. A 
amostra permaneceu no forno por 2 horas a $1450{ }^{\circ} \mathrm{C}$ e 30 minutos a $1500{ }^{\circ} \mathrm{C}$ e depois foi mantida dentro do forno, para um resfriamento lento durante 48 horas, até atingir a temperatura ambiente. Para obtenção das amostras dopadas com diferentes impurezas foi seguido o mesmo procedimento de preparação do diopsídio puro, acrescentando $\mathrm{MnO}, \mathrm{Fe}_{2} \mathrm{O}_{3}$ e, $\mathrm{Al}_{2} \mathrm{O}_{3}$ em concentrações encontradas no diopsídio natural.

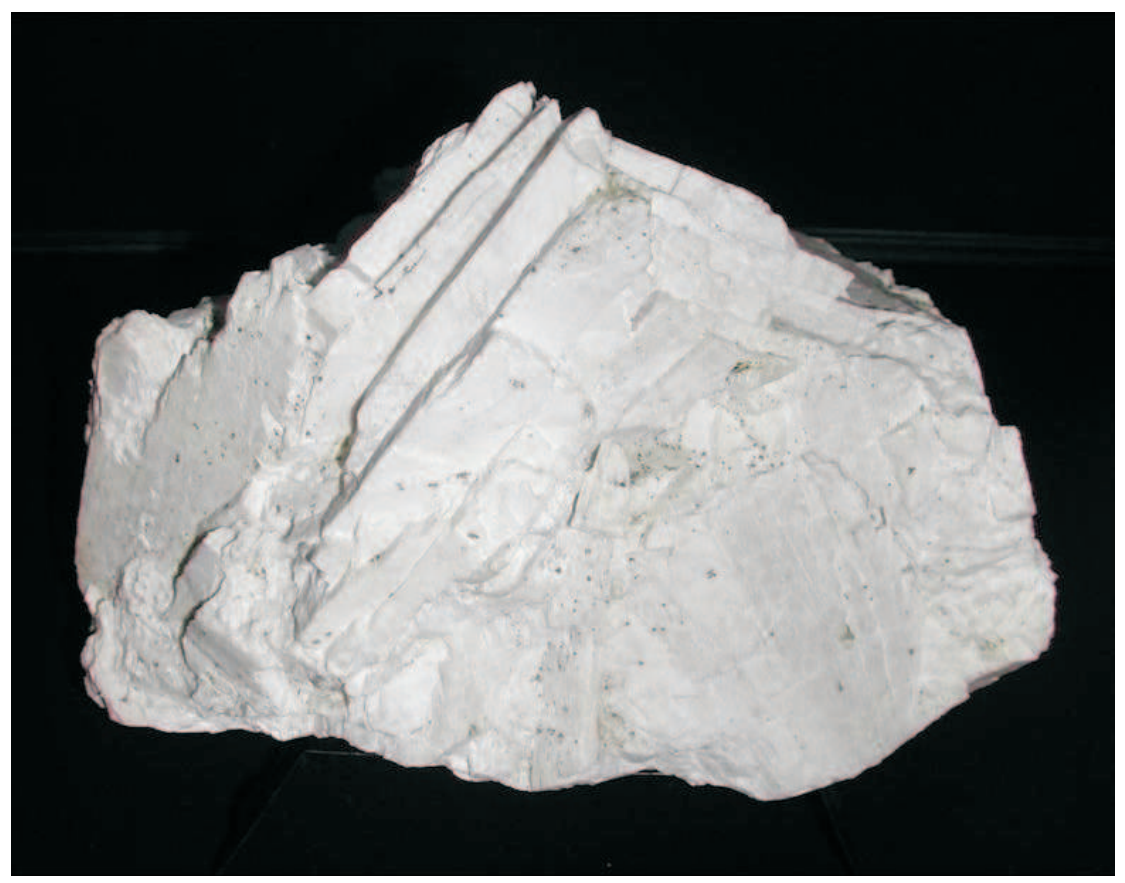

Figura 4.1: Amostra de diopsídio natural estudada neste trabalho.

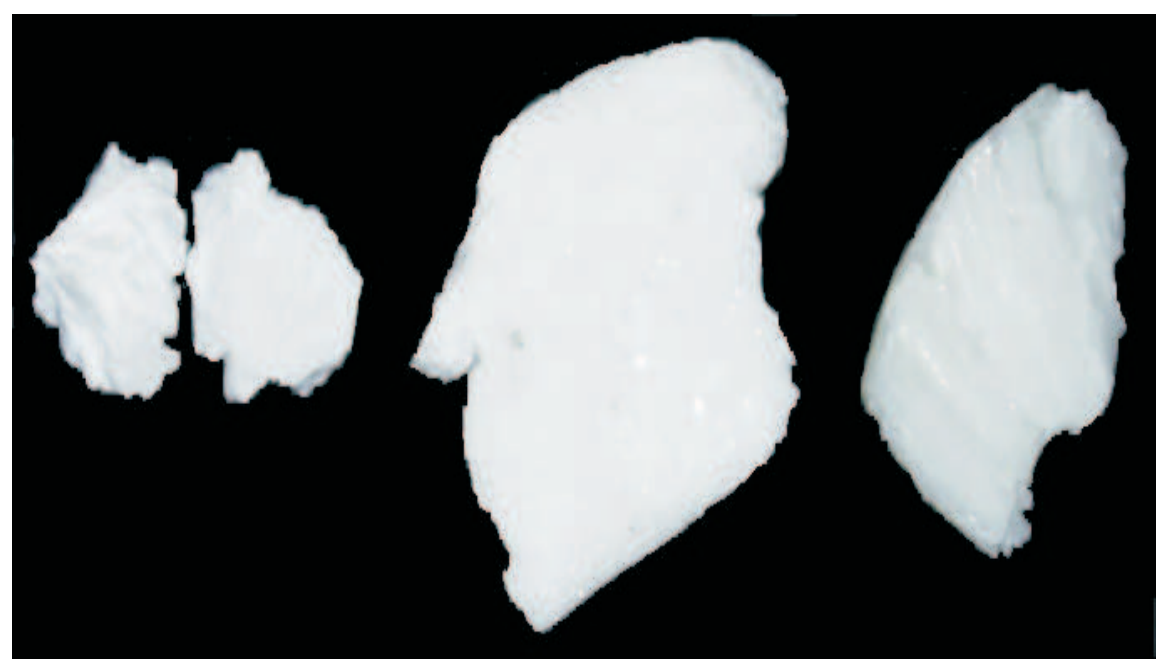

Figura 4.2: Amostra de diopsídio artificial. 


\subsubsection{Vidro de diopsídio}

Os vidros no laboratório são produzidos, geralmente, em cadinhos de platina, uma vez que, este material é capaz de suportar longos períodos de fusão, sem que suas paredes sejam atacadas quimicamente pelo material fundido. Cadinhos de outros materiais, tais como alumina, mulita, ZAS (zircônio, alumina e sílica), sílica, também são utilizadas para este fim, todavia, estes últimos não resistem a longos períodos de fusão devido à relativa facilidade com que suas paredes são corroídas. A corrosão pode levar à contaminação e produção de vidros com composições diferentes da desejada. Em nosso caso, os grãos menores do que $0,080 \mathrm{~mm}$ do diopsídio natural foram fundidos em cadinho de platina, em forno de alta temperatura de até $1500{ }^{\circ} \mathrm{C}$ e, esfriado rapidamente até temperatura ambiente. O resultado foi um vidro de diopsídio de cor verde (Figura 4.3).

Como em nosso laboratório só dispomos de um cadinho de platina, a limpeza do cadinho se torna de extrema importância, para evitar a contaminação do diopsídio artificial ou do vidro de diopsídio, o que exige, cada vez mais, o cuidado de limpá-lo adequadamente. O procedimento de limpeza do cadinho é feito da seguinte maneira: Com o cadinho revirado, deixamos escoar o material fundido e depois fazemos um ataque químico com ácido $\mathrm{HCl}$ por um período de 24 horas.
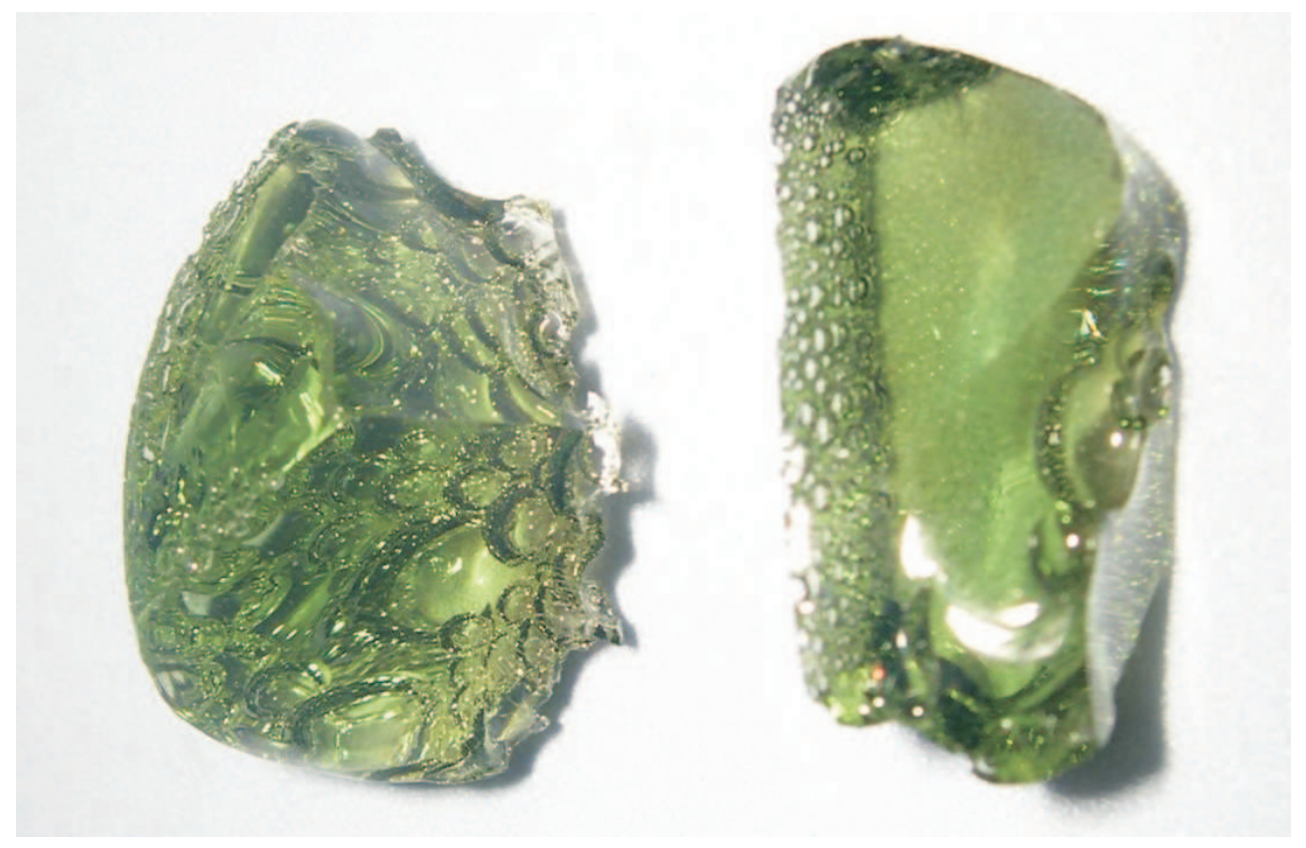

Figura 4.3: Vidro de diopsídio. 


\subsection{Preparação das amostras}

A preparação das amostras depende da finalidade para a qual elas serão usadas. As amostras foram trituradas em um almofariz com a ajuda de um pistilo, ambos do mesmo material. Por meio de peneiras apropriadas foram selecionados grãos com diâmetros entre 0,180 e 0,080 $\mathrm{mm}$ para as medidas de termoluminescência e ressonância paramagnética eletrônica, e grãos com diametros menores do que 0,080 $\mathrm{mm}$ para as análises por fluorescência e difração de raios X e, também, para preparar vidro.

Devido à dificuldade de se obterem lâminas finas $(<2 \mathrm{~mm})$ de diopsídio natural e/ou artificial para as medidas de absorção ótica, devido à sua opacidade, optou-se pelas medidas de refletância.

Para as medidas de refletância do diopsídio natural e artificiais foram cortadas lâminas com uma espessura de $\sim 4 \mathrm{~mm}$, utilizando-se uma serra Isomet. Da mesma forma, do vidro de diopsídio, foram obtidas lâminas de $\sim 2 \mathrm{~mm}$ de espessura para as medidas de absorção ótica. As lâminas obtidas foram polidas com diferentes granulações de alumina.

\subsection{Irradiação e tratamento térmico}

\subsubsection{Irradiação}

O processo de irradiação envolve a exposição da amostra a uma determinada radiação, eletromagnética, no presente caso, a raios gama de ${ }^{60} \mathrm{Co}$.

A utilização de radiação de alta energia pode ocasionar deslocamentos drásticos dos átomos de suas posições de equilíbrio no cristal, além de ionização, produzindo defeitos intrínsecos e centros de elétrons e buracos.

\section{Raios-Gama}

As irradiações foram realizadas no laboratório do $\mathrm{CTR}^{-\mathrm{IPEN}^{1}}$, onde as amostras são expostas a raios gama de ${ }^{60} \mathrm{Co}$ à temperatura ambiente, em condições de equilíbrio eletrônico. As características das fontes são listadas na Tabela 4.1. As amostras (lâminas e em pó) foram envolvidas em papel vegetal e posteriormente embrulhadas em papel alumínio para proteger as amostras da luz durante e após o processo de irradiação.

\footnotetext{
${ }^{1}$ CTR-IPEN: Centro de Tecnologia das Radiações - Instituto de Pesquisas Energéticas e Nucleares
} 
Tabela 4.1: Fontes de irradiação gama utilizados

\begin{tabular}{llc}
\hline Tipo & Fonte & Taxa \\
\hline Panorâmica & ${ }^{60} \mathrm{Co}$ & $0,37 \mathrm{kGy} / \mathrm{h}$ \\
Gama Cell & ${ }^{60} \mathrm{Co}$ & $5,50 \mathrm{kGy} / \mathrm{h}$ \\
\hline
\end{tabular}

\section{Raios-Ultravioleta}

As irradiações com a luz ultravioleta foram realizadas usando uma lâmpada de $\mathrm{Hg}$ de $60 \mathrm{~W}$, à temperatura ambiente. Para este experimento uma camada fina de amostra é espalhada sobre uma superficie plana, de tal forma que a luz UV incidisse perpendicularmente sobre a amostra.

\subsubsection{Tratamento térmico}

A emissão TL, a RPE, e a absorção ótica são, muitas vezes alteradas com recozimento térmico, portanto, é importante efetuar esse tipo de experimento. No nosso Laboratório, há 4 fornos de até $1000{ }^{\circ} \mathrm{C}, 2$ de até $1500{ }^{\circ} \mathrm{C}, 1$ de até $1700{ }^{\circ} \mathrm{C}$, sendo os 6 primeiros montados no laboratório.

A energia térmica provoca modificações internas no material através da dissolução de alguns agregados e formação de outros, da migração de defeitos ou do desarmadilhamento dos portadores de carga. É, também, conhecida a formação de vacâncias.

Para ver o efeito dos diferentes tratamentos térmicos nas amostras, foram variados os tempos e temperaturas de recozimento a que as amostras foram submetidas. Tanto para a amostra em pó como para as lâminas, o forno é monitorado com um controlador de temperatura através de um termopar. Depois de fazer os tratamentos térmicos a amostra é submetida a resfriamentos rápidos, colocando as amostras em chapas de alumínio à temperatura ambiente.

O forno de $1500{ }^{\circ} \mathrm{C}$, empregado para fundir a amostra natural ou uma mistura apropiada de óxidos (policristal e do vidro de diopsidio) foi construído no laboratório com resistências de Carbeto de Silício ( $\mathrm{SiC}$ ) com forma cilíndrica. A taxa de aquecimento é controlada com um sistema de controle do tipo Júnior da Ecil e um termopar situado na parte superior do forno, do tipo b (Pt-Pt/Rh). 


\subsection{Equipamentos de medidas}

\subsubsection{Termoluminescência}

As medidas de termoluminescência foram realizadas utilizando-se um aparelho Leitor TL Daybreak, Modelo 1100, do Laboratório LACIFID. Uma característica deste aparelho é a capacidade de fazer leituras automáticas sucessivas de 20 amostras, utilizado para fazer trabalhos de rotina, como de dosimetria e datação. O aparato experimental necessário, para observar a luz emitida de materiais TL, é simples, sendo constituído de um dispositivo para o aquecimento do material, uma válvula fotomultiplicadora para captar a luz emitida e um filtro óptico que permite a discriminação da influência da emissão infravermelha à elevada temperatura. Um esquema simplificado do sistema TL é apresentado na Figura 4.4.

O método de aquecimento consiste em colocar a amostra sobre uma prancheta metálica de alta resistência, que é alimentada por uma fonte de corrente elétrica, cuja intensidade é governada por um controlador de temperatura, através de um termopar de chromel-alumel, soldada à plancheta metálica. O intervalo de temperatura em que a plancheta opera é de $50{ }^{\circ} \mathrm{C}$ a $700{ }^{\circ} \mathrm{C}$, com a possibilidade de mudar a taxa de aquecimento de 1 a $25^{\circ} \mathrm{C} / \mathrm{s}$. As funções deste aparelho são controladas por meio do software TLAPPLIC.

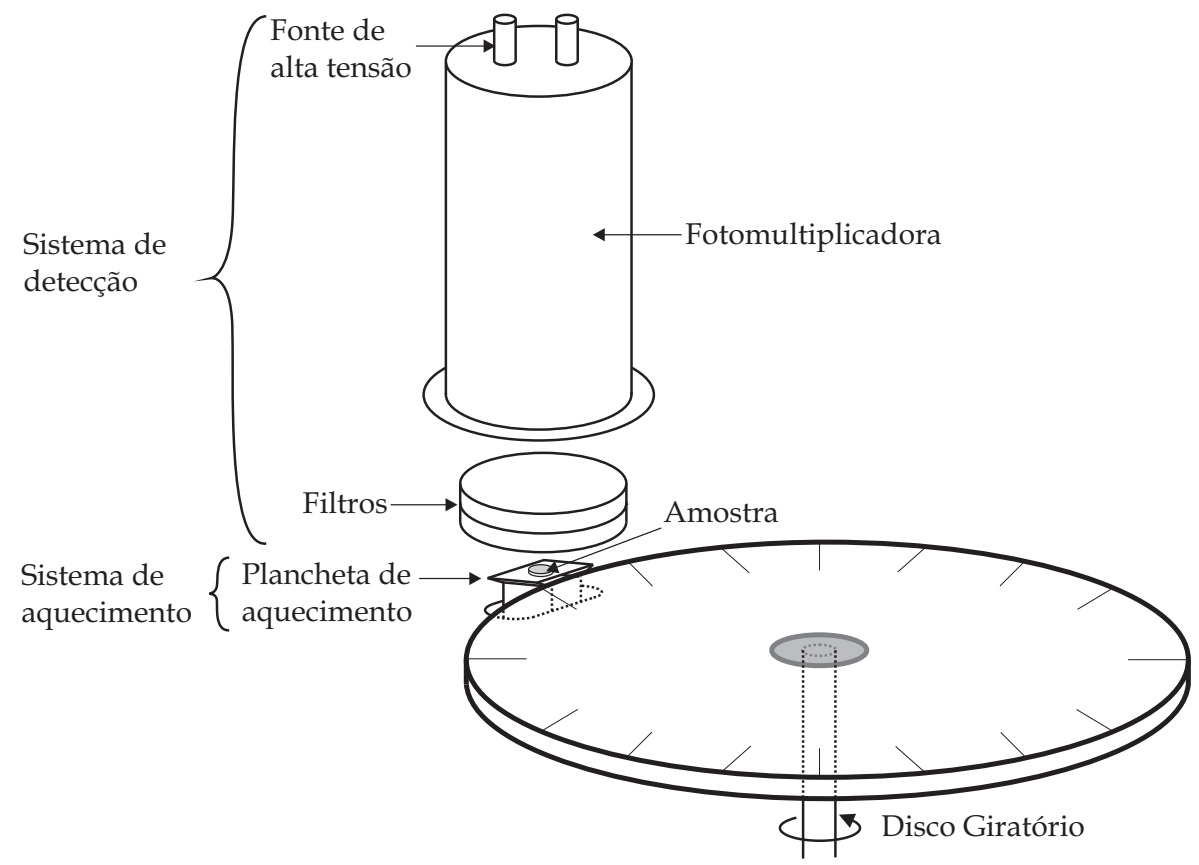

Figura 4.4: Esquema do leitor TL Daybreak. 


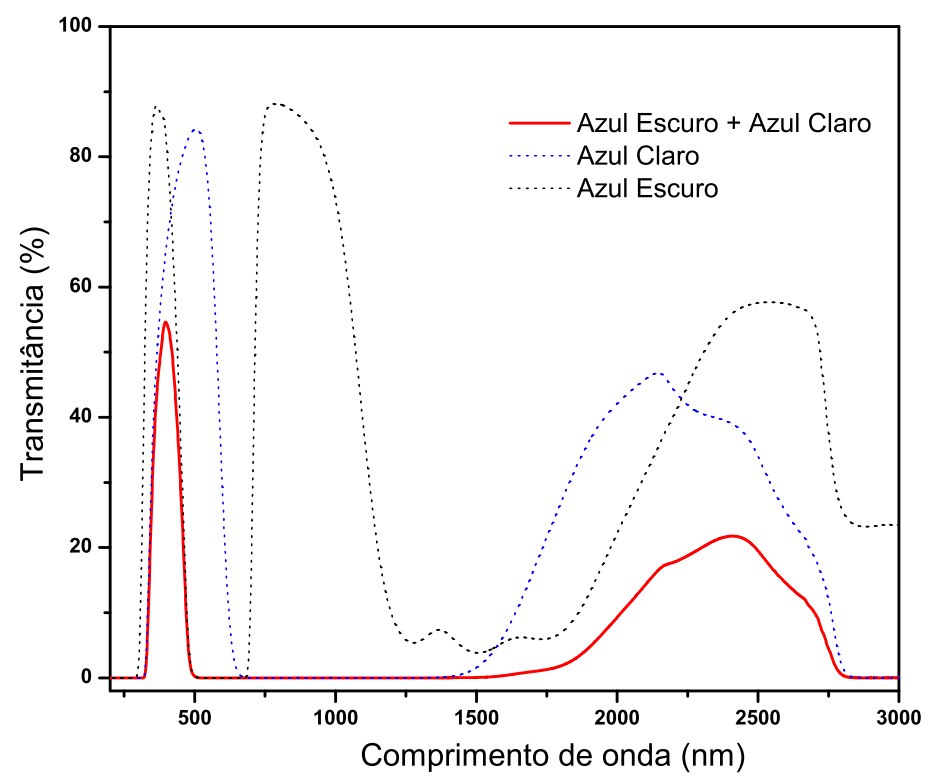

Figura 4.5: Espectros de transmitância dos filtros azul claro e do azul escuro.

A fotomultiplicadora (EMI 9235QA) opera com uma fonte de alta tensão, com um fluxo de $\mathrm{N}_{2}$ entre ela e o material termoluminescente, com o objetivo de evitar o sinal devido à presença de oxigênio e vapor de água durante o aquecimento da amostra. O leitor Daybreak utiliza dois filtros, um azul escuro Corning 7-59 e outro azul claro Schott BG-39, cujas curvas de transmitância são apresentadas na Figura 4.5. Os filtros atenuam os fótons com comprimento de onda na região do infravermelho próximo, sendo possível só registrar a luminescência na faixa de 300 a $500 \mathrm{~nm}$.

Todas as medidas de TL foram realizados no intervalo de temperaturas de $50{ }^{\circ} \mathrm{C}$ a $500{ }^{\circ} \mathrm{C}$ com uma taxa de aquecimento de $4{ }^{\circ} \mathrm{C} / \mathrm{s}$. Para cada leitura do material na forma de pó foram utilizadas em média $\sim 4 \mathrm{mg}$ da amostra.

\subsubsection{Ressonância Paramagnética Eletrônica}

O sistema de medição utilizado para observar o fenômeno de RPE é um espectrômetro RPE Bruker EMX ${ }^{2}$, com cavidade modelo ER 4102ST que opera na banda X (Figura 4.6).

O espectrômetro é, basicamente, composto de um controlador de campo magnético (eletroímã), uma fonte de microondas, uma cavidade ressonante e um sistema de detecção da microonda (Figura 4.7). A fonte de microondas emite radiação eletro-

\footnotetext{
${ }^{2}$ Projeto Multiusuários do Instituto de Física da USP
} 
magnética monocromática com freqüência de $9,75 \mathrm{GHz}$. A radiação de microondas é conduzida por um guia de ondas até a cavidade ressonante. Em ressonância, as microondas não são refletidas pela cavidade, permanecendo armazenadas nela. A cavidade é caracterizada por um parâmetro chamada fator de qualidade "Q", que determina a eficiência com que a energia é armazenada. O fator "Q" é definido como:

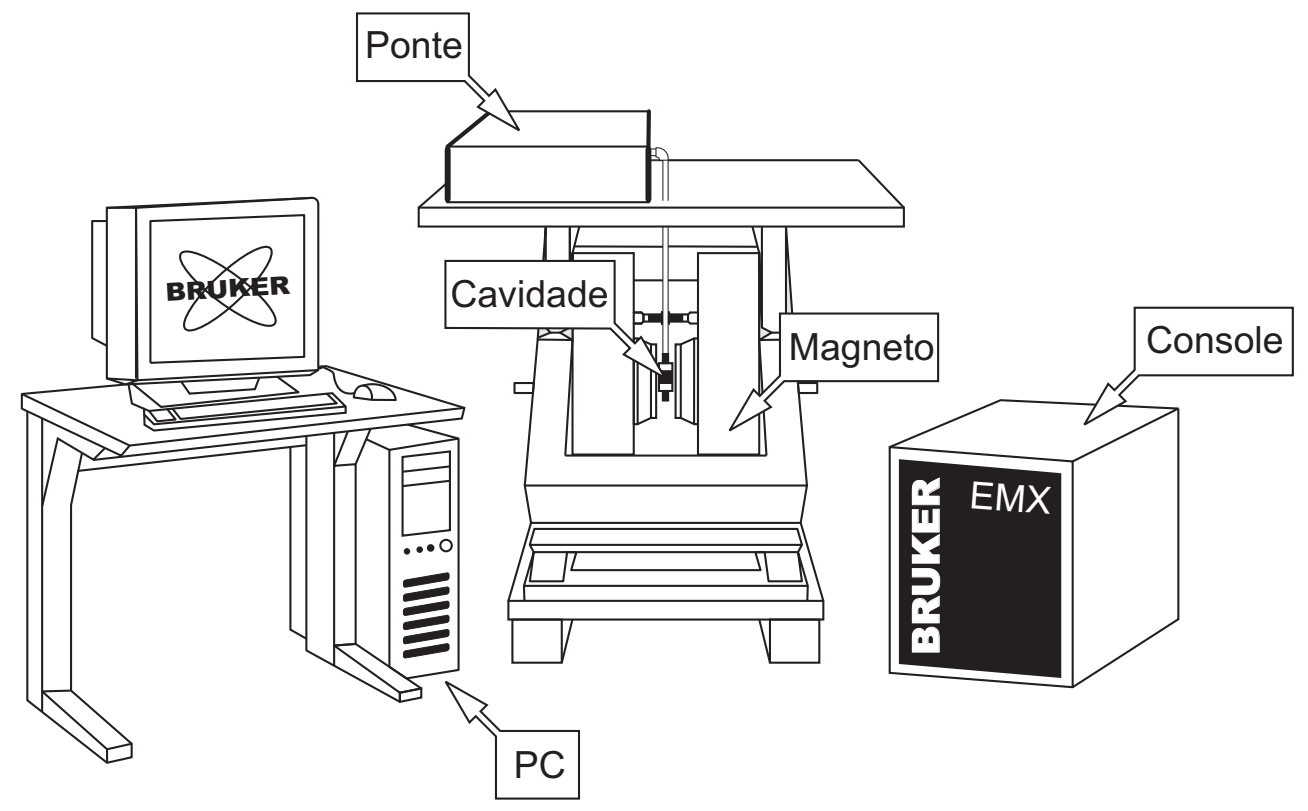

Figura 4.6: Espectrômetro RPE que mostra as componentes individuais.

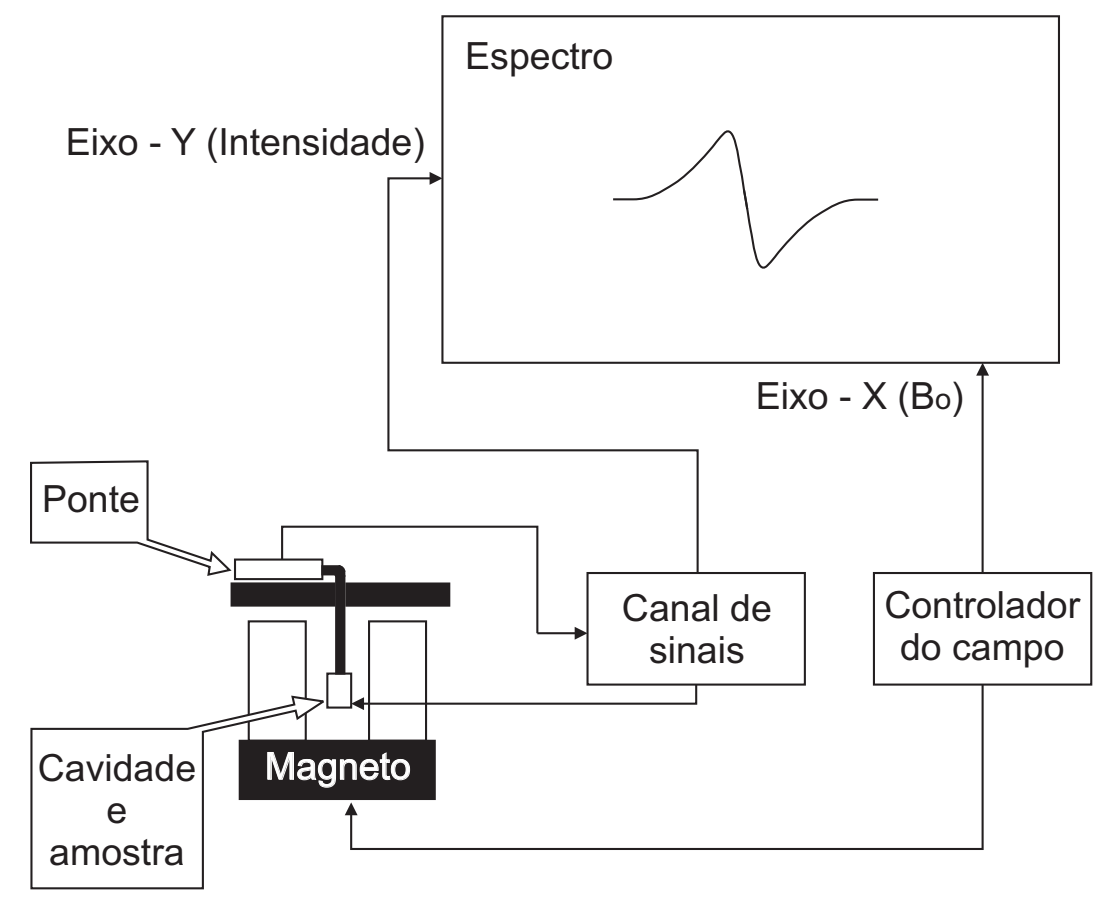

Figura 4.7: Diagrama de bloco de um aparelho de RPE Bruker. 


$$
Q=\frac{2 \pi \cdot \text { energia armazenada }}{\text { energia dissipada por ciclo }}
$$

A detecção da absorção é realizada medindo-se a quantidade de radiação refletida pela cavidade ressonante contendo a amostra. Quando a amostra absorve energia das microondas, a impedância da cavidade é modificada, variando a freqüência de ressonância e aumentando a reflexão. A detecção das microondas é realizada através de diodo de barreira Schottky que converte a potência de microondas em corrente elétrica.

O espectrômetro de RPE utiliza um conjunto de processos chamado detecção sensível em fase para obter um aumento na sensibilidade. A técnica consiste em modular a intensidade do campo magnético externo, sinusoidalmente, com a freqüência apropriada de modulação. Considerando que, no intervalo de modulação do campo magnético, o sinal de absorção de RPE inicialmente é aproximadamente linear, o sinal resultante da modulação é uma onda sinusoidal com amplitude proporcional à derivada da curva de absorção na região. Esse sinal é, então, comparado com um sinal de referência de freqüência igual à modulação do campo. Apenas os sinais que possuem a mesma freqüência e fase de modulação do campo são detectados, reduzindo os sinais provenientes de outras fontes como o ruído e as interferências elétricas. Para eliminar o ruído por integração e filtragem, aplica-se um filtro que elimina os sinais com freqüência maior do que $1 / \tau$ ( $\tau$ é chamado constante de tempo).

A escolha adequada dos parâmetros experimentais, como a amplitude de modulação, freqüência de modulação e constante de tempo, é essencial para que os sinais não sejam distorcidos ou para que não ocorra perda de resolução.

O monitoramento dos parâmetros experimentais, os componentes e interconexões do espectrofotômetro são feitos por meio de um computador através do software winEPR.

As medidas foram realizadas com $150 \mathrm{mg}$ de amostra em pó, colocados dentro de tubos de quartzo de $4 \mathrm{~mm}$ de diâmetro, com os seguintes parâmetros experimentais do espectrômetro RPE: modulação de amplitude de $1 \mathrm{G}$, modulação de freqüência de $100 \mathrm{kHz}$ e constante de tempo 327,68 ms.

\subsubsection{Refletância e absorção óptica}

Para todas medidas de refletância e absorção óptica utilizamos um espectrômetro Varian Cary 500 UV-Vis-NIR, que opera na faixa de 175 a 3500 nm para absorção 
óptica e de 250 a $2500 \mathrm{~nm}$ para as medidas de refletância. O espectrofotômetro tem uma lâmpada de deutério, que é empregada para região UV e uma lâmpada de quartzo-halogênio usada para a região visível e infravermelho próximo. O feixe da fonte do espectrofotômetro passa por um monocromador antes de atingir a amostra. As medidas foram sempre efetuadas à temperatura ambiente.

\section{Refletância}

Para a obtenção dos espectros de refletância no espectrômetro Cary 500, foi utilizado o acessório de refletância difuso. O acessório consiste, basicamente, de uma esfera integradora de $110 \mathrm{~mm}$ de diâmetro, um sistema de espelhos que direcionam o feixe procedente da fonte e um sistema de detecção. A esfera integradora tem um orifício na parte lateral feito para colocar a amostra com um tamanho mínimo de $8 \mathrm{~mm}$ x $12 \mathrm{~mm}$ e no máximo de $100 \mathrm{~mm}$ x $200 \mathrm{~mm}$. Toda a superfície interior da esfera está coberta de uma camada de politetrafluoroetileno (PTFE). O sistema de detecção consiste de um tubo fotomultiplicador (PMT) e um diodo de sulfeto de chumbo (PbS). Para estabelecer a linha base foi utilizado PTFE. A Figura 4.8 mostra o funcionamento do acessório de refletância do espectrômetro Cary 500.

\section{Absorção óptica}

Neste sistema, o feixe proveniente da fonte do espectrofotômetro se divide em dois, sendo que um deles atravessa a amostra e o outro o meio de referência, Figura 4.9. Os espectros de absorção podem ser espectros relativos, cujo meio de referência pode ser outro cristal ou espectros absolutos, cujo meio de absorção é o ar, como foi utilizado em nossos experimentos. As amostras, cuja absorção óptica, se quer medir são fixadas a uma placa de alumínio com um orifício de $5 \mathrm{~mm}$ x $5 \mathrm{~mm}$. Esse porta-mostra é encaixado em uma moldura fixa ao compartimento de amostra e uma placa similar é colocada na posição de referência. Os espectros são registrados por um computador por intermédio de um detector e a detecção é realizada por uma válvula fotomultiplicadora (175 - $700 \mathrm{~nm}$ ) e um diodo de PbS na faixa de 700 - $3300 \mathrm{~nm}$. 


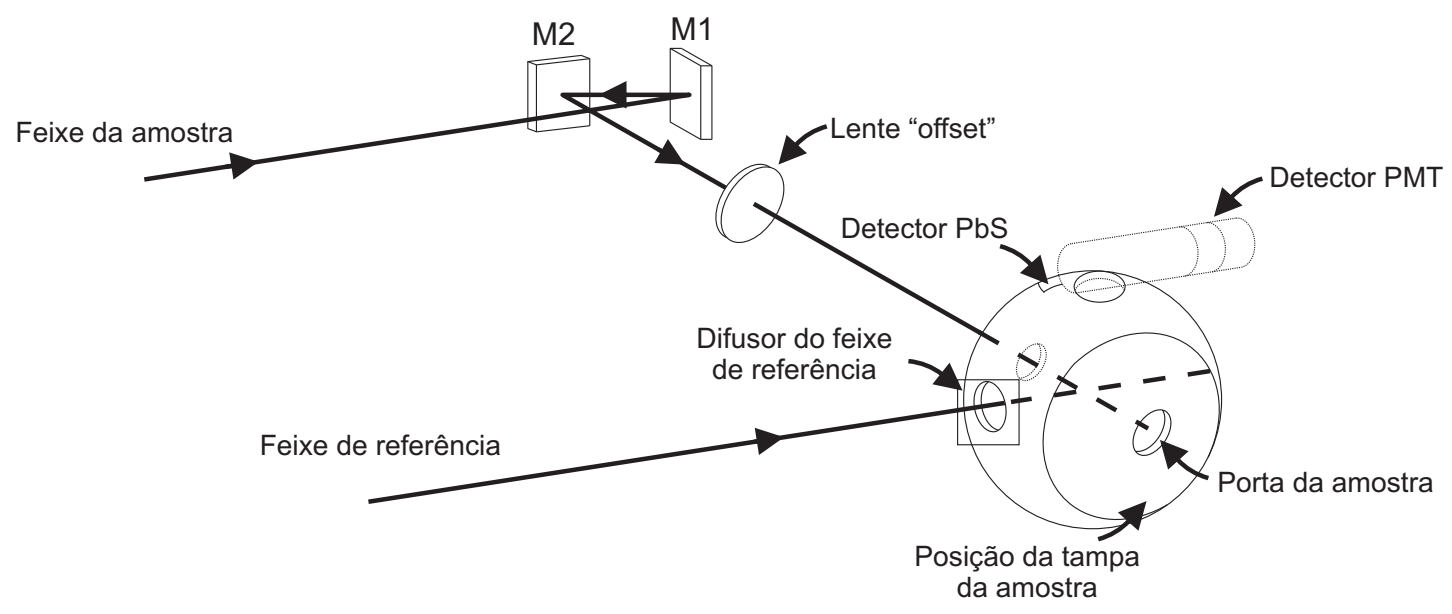

Figura 4.8: Esquema da esfera integradora do espectrômetro Cary 500 para as medidas de reflectância.

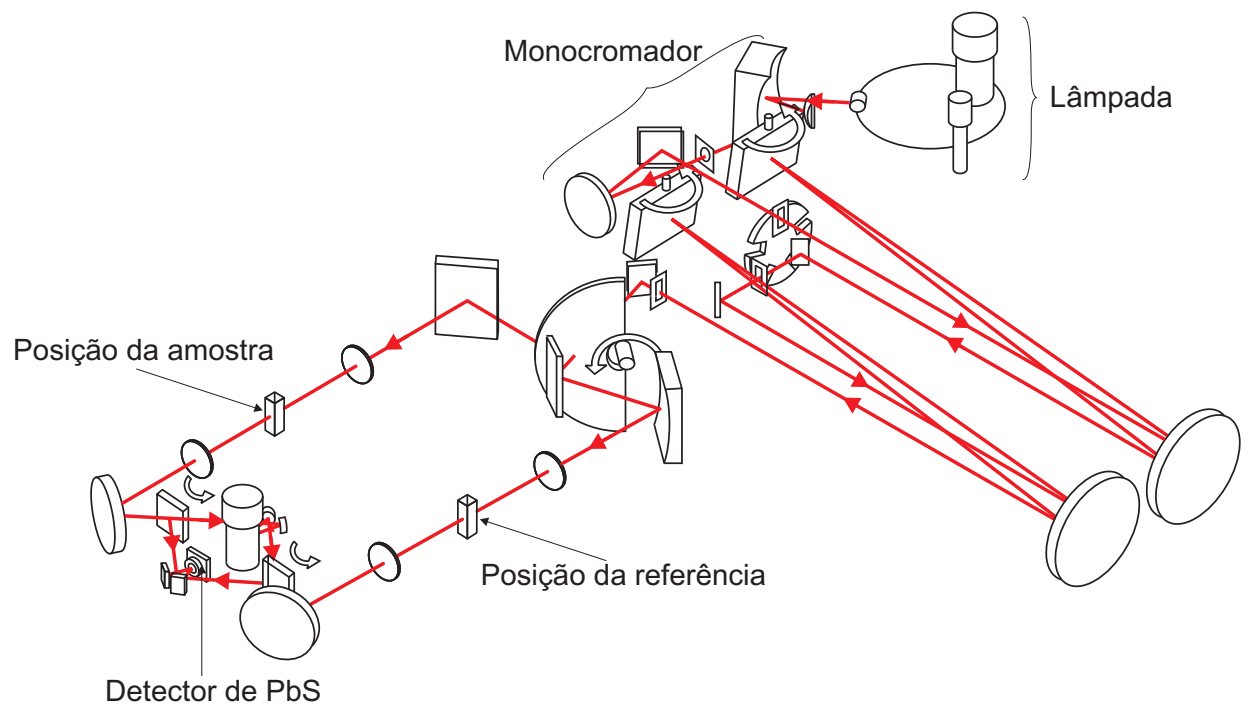

Figura 4.9: Esquema do espectrômetro Cary 500 para as medidas de absorção óptica. 


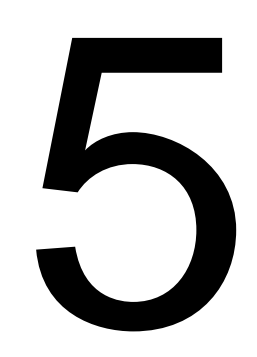

\section{Resultados Experimentais}

\subsection{Análise da amostra}

Neste item estão resumidamente descritas as técnicas empregadas na análise das impurezas presentes na amostra estudada e apresentamos os resultados obtidos. As técnicas utilizadas foram: fluorescência de raios $\mathrm{X}$ e difração de raios X.

\subsubsection{Fluorescência de raios $\mathrm{X}$}

A fluorescência de raios $\mathrm{X}$ é de grande utilidade na análise de rochas e minerais, sendo especialmente recomendada para a determinação dos constituintes presentes em grande quantidade, muito embora conquistas tecnológicas recentes tenham permitido estender sua aplicação a níveis de traços. Esta técnica chega a ser indispensável na análise de muitos elementos em concentrações da ordem de parte por milhão, para os quais a espectroscopia óptica se mostra deficiente.

A irradiação e a excitação de uma dada substância por meio de um feixe de raios X emanado de um tubo operado em condições de alta voltagem, trazem como resultado a produção de uma radiação secundária característica de elementos presentes na fase. Conhecendo-se os ângulos de reflexão e as intensidades dessa radiação, é possível, não apenas identificar os elementos componentes, como determinar sua quantidade. 


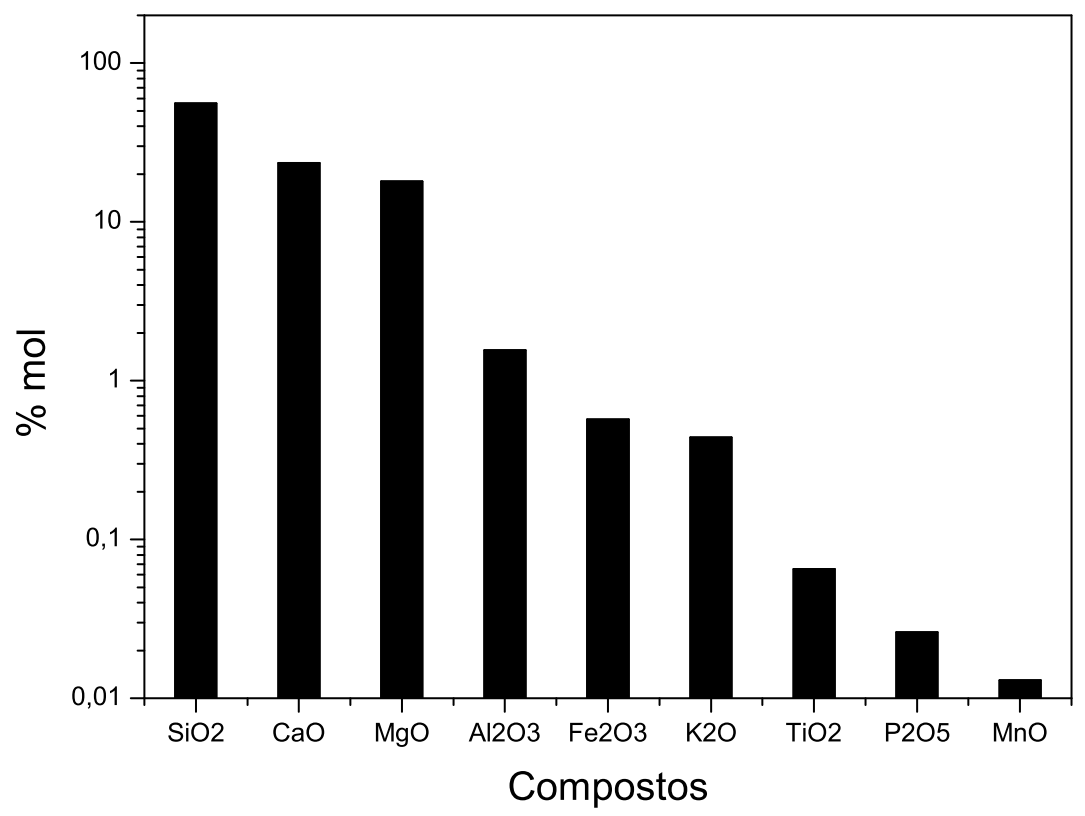

Figura 5.1: Fluorescência de Raios X para a amostra de diopsídio natural.

Pode-se observar na Figura 5.1 que além de seus elementos constitutivos $\left(\mathrm{SiO}_{2}\right.$ - 55,81 \% mol, $\mathrm{CaO}$ - 23,47 \% mol e $\mathrm{MgO}$ - 18,03 \% mol), a amostra natural de diopsídio contem várias impurezas na sua composição. As medidas foram realizadas no Centro de Química e Meio Ambiente do Instituto de Pesquisas Energéticas e Nucleares (CQMA-IPEN).

Podemos observar através da Figura acima que o composto como impureza em maior quantidade é o $\mathrm{Al}_{2} \mathrm{O}_{3}\left(1,56 \%\right.$ mol), seguido de outros compostos como $\mathrm{Fe}_{2} \mathrm{O}_{3}$ $(0,57 \% \mathrm{~mol}), \mathrm{K}_{2} \mathrm{O}(0,44 \% \mathrm{~mol}), \mathrm{TiO}_{2}(0,065 \% \mathrm{~mol}), \mathrm{P}_{2} \mathrm{O}_{5}(0,026 \% \mathrm{~mol}), \mathrm{Na}_{2} \mathrm{O}$ $(0,01 \% \mathrm{~mol})$ e $\mathrm{MnO}(0,013 \% \mathrm{~mol})$. Cr (6 ppm), Ni (7 ppm), Sr (46 ppm), V (15 ppm), Zn (29 ppm), Zr (43 ppm) aparecem em concentração menor, alguns dos quais podem desempenhar papel importante nas propriedades TL, RPE e AO no cristal de diopsídio.

\subsubsection{Difração de raios $\mathrm{X}$}

Devido à repetição regular de suas estruturas, os cristais são capazes de difratar uma radiação com um comprimento de onda próximo ao da separação atômica (aproximadamente $1 \AA$ ). Desta forma, a técnica de difração de raios X torna-se uma técnica eficaz para a obtenção de muitas informações. 
O uso mais importante desta técnica está na identificação qualitativa de fases cristalinas ou compostos, uma vez que a maioria dos métodos químicos de análises dão informação somente sobre os elementos presentes na amostra. Através da difração de raios X também é possível determinar as distâncias interplanares, a partir das quais são identificados os índices de Miller dos planos cristalinos, o tipo e os parâmetros de rede do cristal.

Três tipos de radiação são utilizados para estudos de difração em cristais: raios X, elétrons e nêutrons.

No presente caso, foi utilizada a técnica de difração de raios $\mathrm{X}$ através do método do pó, onde um feixe de raios $\mathrm{X}$ monocromático atinge uma amostra em forma de pó muito fino distribuído uniformemente sobre uma porta-amostra. Os pequenos cristais são dispostos aleatoriamente, portanto, vários planos da rede presentes em todas as orientações possíveis são encontrados. Desta forma, para cada conjunto de planos, pelo menos alguns cristais devem difratar os raios, satisfazendo à Lei de Bragg. Os feixes difratados são interceptados por um detector móvel conectado a um registrador. O pó do material é aderido ao porta-amostra por um adesivo adequado e distribuído uniformemente sobre sua superfície.

As medidas dos difratogramas foram feitas no Laboratorio de Cristalografia do IF-USP.

\section{Cristal de diopsídio}

Na Figura 5.2 apresentamos os difratogramas da amostra natural, artificiais e o padrão de difração para o diopsídio. A comparação com o espectro do padrão mostra que, todas as amostras estudadas, praticamente, apresentam os mesmos planos de reflexão, isto é, são todas de diopsídio, exceto em amostras de artificial puro, com $\mathrm{Al}$ e com Mn que apresentaram linhas em $\simeq 21,6^{\circ}$, que é de cristobalita.

\section{Vidro de diopsídio}

O difratograma de raios $\mathrm{X}$ foi obtido para a amostra de vidro de diopsídio com a finalidade de se verificar o grau de cristalinidade da sua estrutura. Com o resultado mostrado pela Figura 5.3 podemos dizer que se trata de estrutura vítrea amorfa por apresentar um alargamento, centrado em aproximadamente $28^{\circ}$, característico de difração de raios $\mathrm{X}$ de materiais amorfas. 


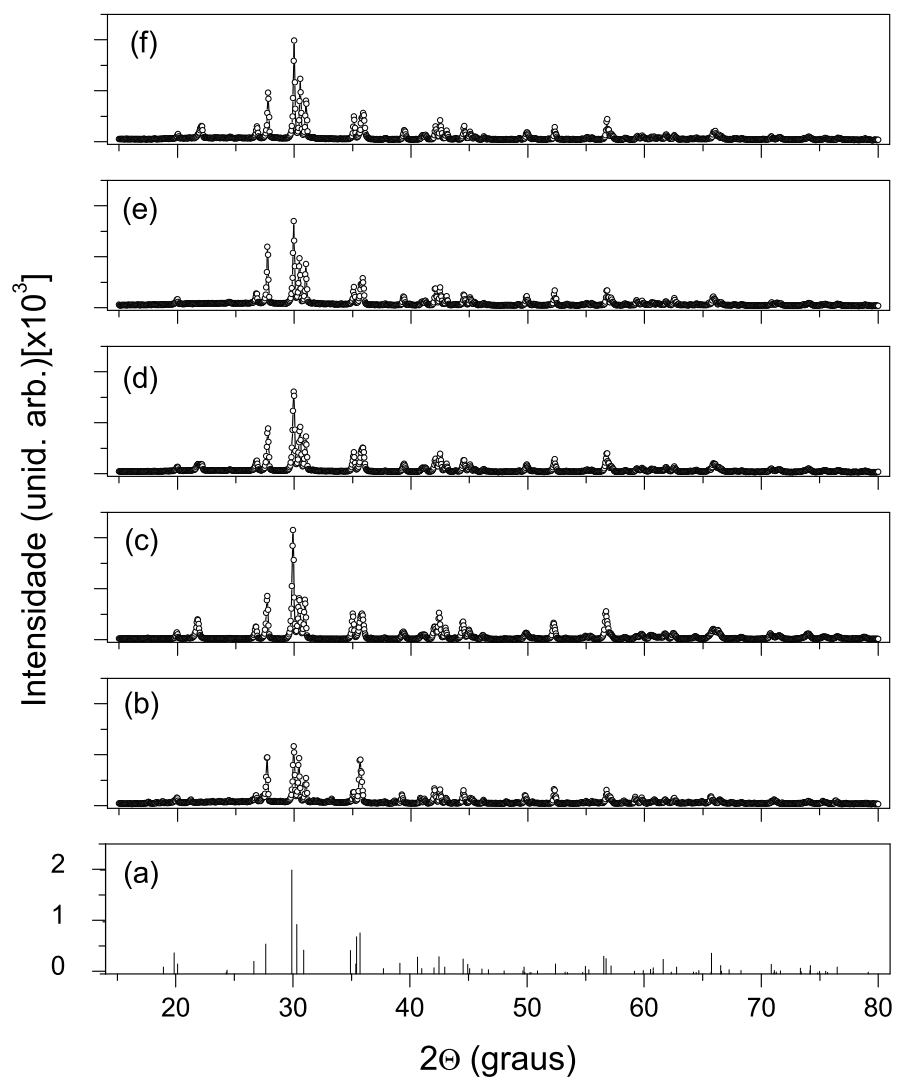

Figura 5.2: Difratograma de raios $X$ das amostras de diopsídio: (a)-padrão (b)-natural, (c)-artificial puro, (d)-artificial com Al, (e)-artificial com Fe e (f)-artificial com Mn.

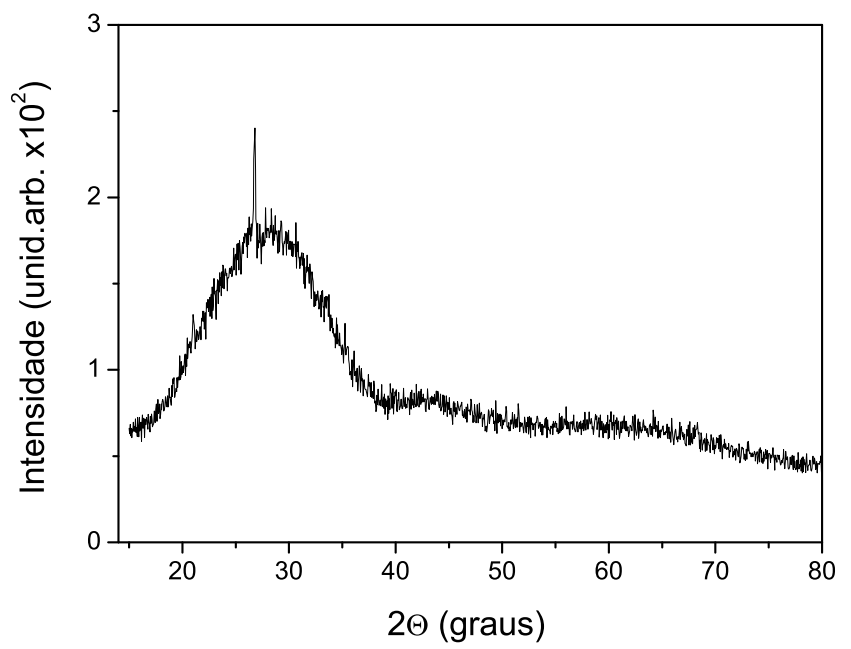

Figura 5.3: Difratograma de raios $X$ do vidro de diopsídio. 


\subsection{Medidas de Termoluminescência}

O presente item apresenta as principais características das curvas e dos espectros de emissão TL, da resposta TL com a dose, e da influência dos tratamentos térmicos, além de investigar o efeito da iluminação com a luz UV.

\subsubsection{Curva de TL do diopsídio natural}

A primeira curva TL foi obtida da amostra natural sem qualquer tratamento térmico inicial, apenas com a radiação natural a que foram submetidas durante todo o tempo geológico a que estiveram expostas como pode ser visto na Figura 5.4. A curva TL da amostra natural é caracterizada pela presença de quatro picos, o primeiro pico de baixa intensidade ao redor de $160{ }^{\circ} \mathrm{C}$, o segundo pico bem intenso em $280{ }^{\circ} \mathrm{C}$, um terceiro pico em aproximadamente $350{ }^{\circ} \mathrm{C}$ e o quarto na região de $450{ }^{\circ} \mathrm{C}$.

\subsubsection{Dependência da TL com a dose}

Além da importância para aplicações em dosimetria da radiação e de datação, o comportamento da curva de emissão TL do material em função da dose está vinculado a processos de transferência de portadores de carga tanto durante a irradiação quando durante o aquecimento no processo de leitura TL, podendo revelar a existência de processos de competição entre os defeitos pela captura de portadores de carga [55].

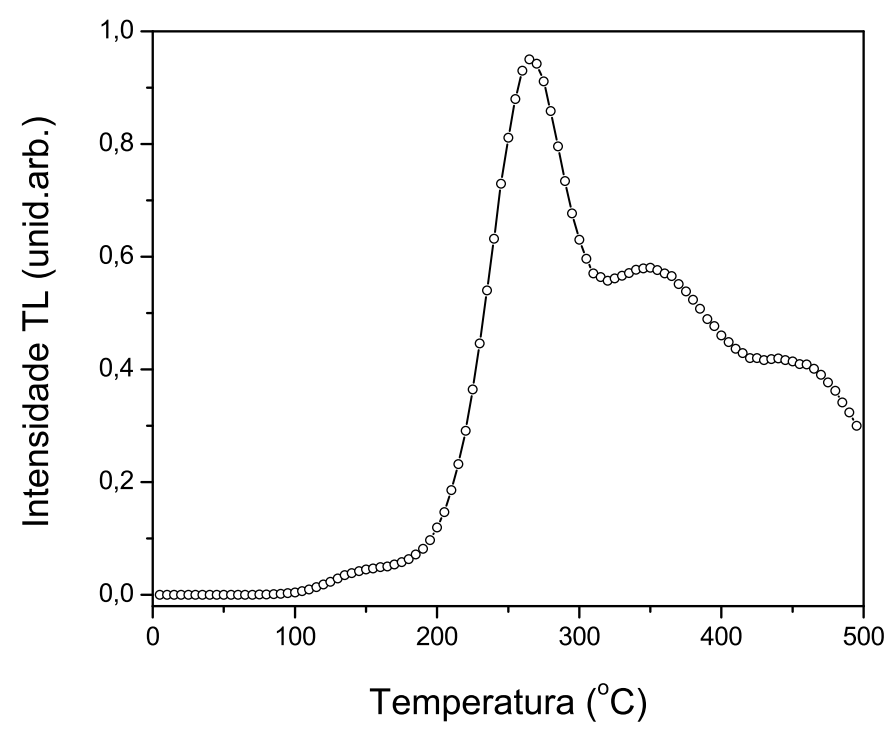

Figura 5.4: Curva de emissão TL para amostra natural de diopsídio. 
A resposta TL em função da dose e as variações na curva TL foram estudadas para a amostra de diopsídio natural sem e com recozimento adicional.

A Figura 5.5a apresenta as curvas TL para diversas doses sem pré-recozimento antes da irradiação. Nela é possível observar um pico TL muito largo em torno de $160{ }^{\circ} \mathrm{C}$ que cresce linearmente com a dose e entra em saturação na região acima de 1 kGy (Figura 5.5b). Este pico cresce mais rápido do que os outros impedindo que outros picos sejam observados.

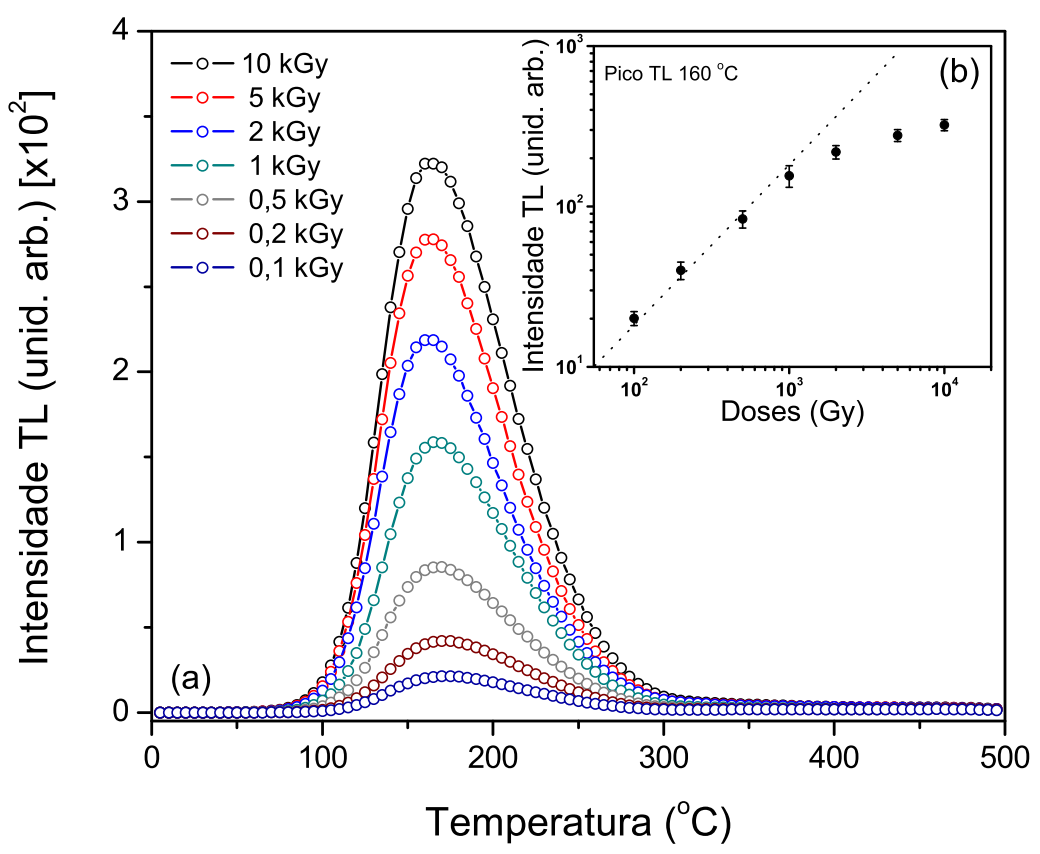

Figura 5.5: (a) - Curva de emissão TL para amostra natural em função das diferentes doses de radiação. (b) - Comportamento do pico TL em $160{ }^{\circ} \mathrm{C}$, em função da dosegama.

Para esvaziar as armadilhas e garantir a eliminação de efeitos anteriores devido à irradiação natural foi realizado um recozimento térmico a $600{ }^{\circ} \mathrm{C}$ por uma hora seguido de um resfriamento rápido para posteriormente serem efetuadas irradiações gama. A Figura 5.6a mostra a curva de emissão TL para as mostras de diopsídio irradiados com raios gama de 0,5 Gy até $50 \mathrm{~Gy}$, observamos três picos TL em $160{ }^{\circ} \mathrm{C}, 370{ }^{\circ} \mathrm{C}$ e $475{ }^{\circ} \mathrm{C}$. $\mathrm{O}$ pico TL de $160{ }^{\circ} \mathrm{C}$ cresce rapidamente com a dose de radiação gama, apresentando um comportamento linear na faixa de doses baixas, como pode ser visto na Figura 5.6b. O pico em $280{ }^{\circ} \mathrm{C}$ superpôs-se ao de $160{ }^{\circ} \mathrm{C}$, dando um pico largo, que se estende de $120{ }^{\circ} \mathrm{C}$ a $250{ }^{\circ} \mathrm{C}$. 


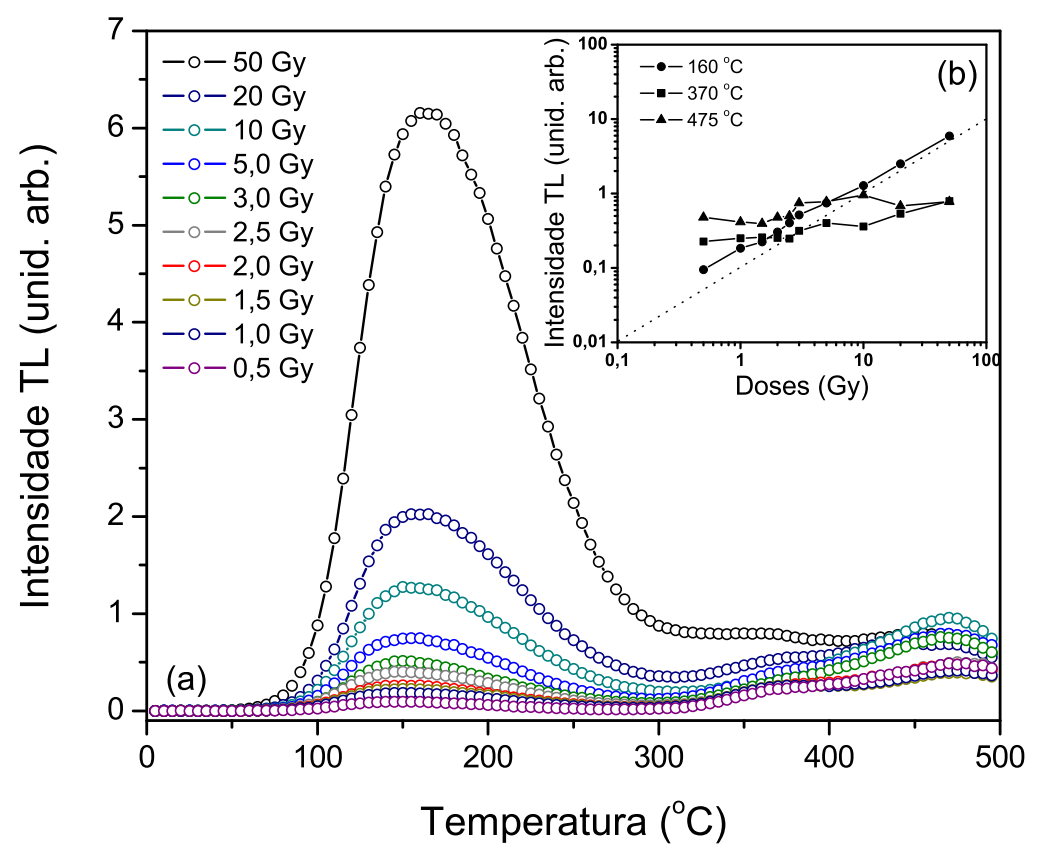

Figura 5.6: (a) - Curva TL da amostra natural para dose baixas até 50 Gy com préaquecimento em $600{ }^{\circ} \mathrm{C}$ por uma hora. (b) - Comportamento dos picos TL com as diferentes doses de radiação gama.

A Figura 5.7a mostra a curva de emissão TL, para as amostra irradiadas com doses de radiação gama de 50 Gy até 10 kGy, apresentando um pico TL em torno de 160 ${ }^{\circ} \mathrm{C}$, que cresce muito rapidamente e, encobre os picos de alta temperatura. Exceto pela curva de emissão da amostra irradiada com $10 \mathrm{kGy}$, que mostra claramente o pico em $370{ }^{\circ} \mathrm{C}$, o resto é comparável com as curvas da Figura 5.5a. O comportamento dos picos TL com as diferentes doses de irradiação é apresentado na Figura 5.7b. O crescimento do pico em $160{ }^{\circ} \mathrm{C}$ é linear e posteriormente satura para dose superiores a 1 kGy, como aconteceu com o resultado apresentado na Figura 5.5b.

Um pico TL largo é formado frequentemente de vários picos superpostos, embora, pareça aparentemente, um só pico. Como no nosso caso, o pico em $160{ }^{\circ} \mathrm{C}$ é muito largo, é possivel que isso esteja acontecendo. Uma forma de constatar essa possibilidade, bem como, para ver como esses picos se comportam em função da dose, as amostras irradiadas com doses acima mencionadas foram primeiro recozidas em $160{ }^{\circ} \mathrm{C}$ por 10 segundos, tratamento esse que elimina o pico de $160{ }^{\circ} \mathrm{C}$ e permite destacar os outros picos. O resultado está mostrado nas Figura 5.8a e 5.8b. Com esse tratamento térmico, nota-se o pico TL em $205{ }^{\circ} \mathrm{C}$ como mostra a Figura 5.8. 


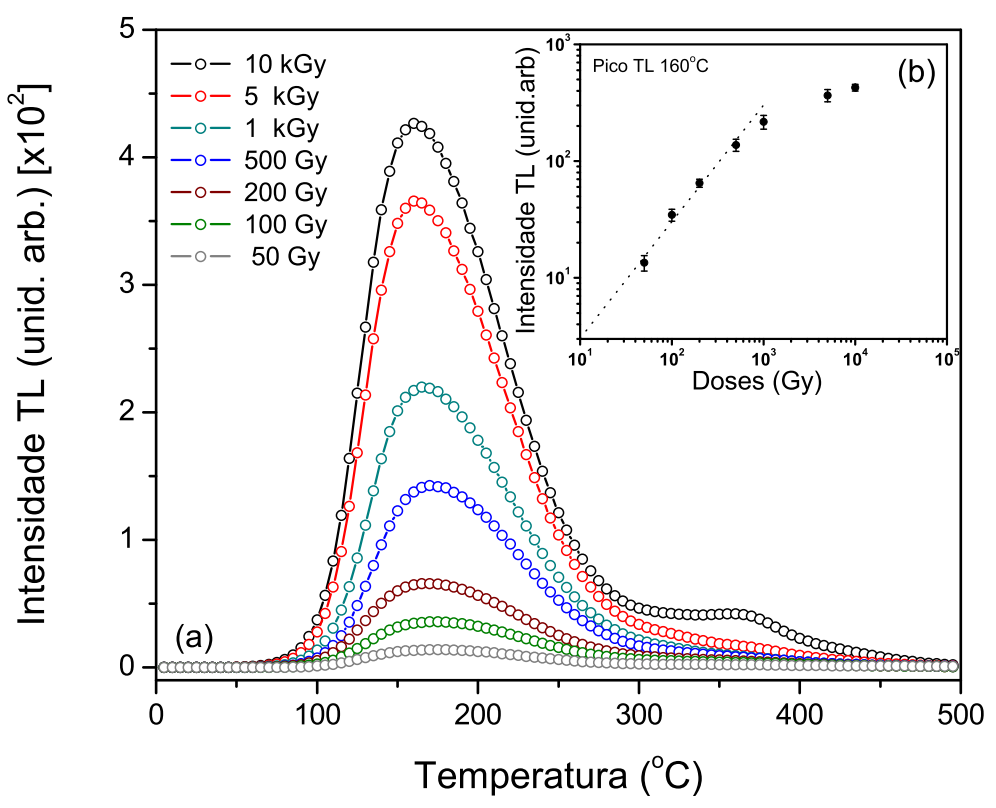

Figura 5.7: (a) - Curva TL da amostra natural para dose de 50 Gy até 50 kGy com pré-aquecimento a $600{ }^{\circ} \mathrm{C}$ por uma hora. (b) - Comportamento dos picos TL para diferentes doses de radiação gama.

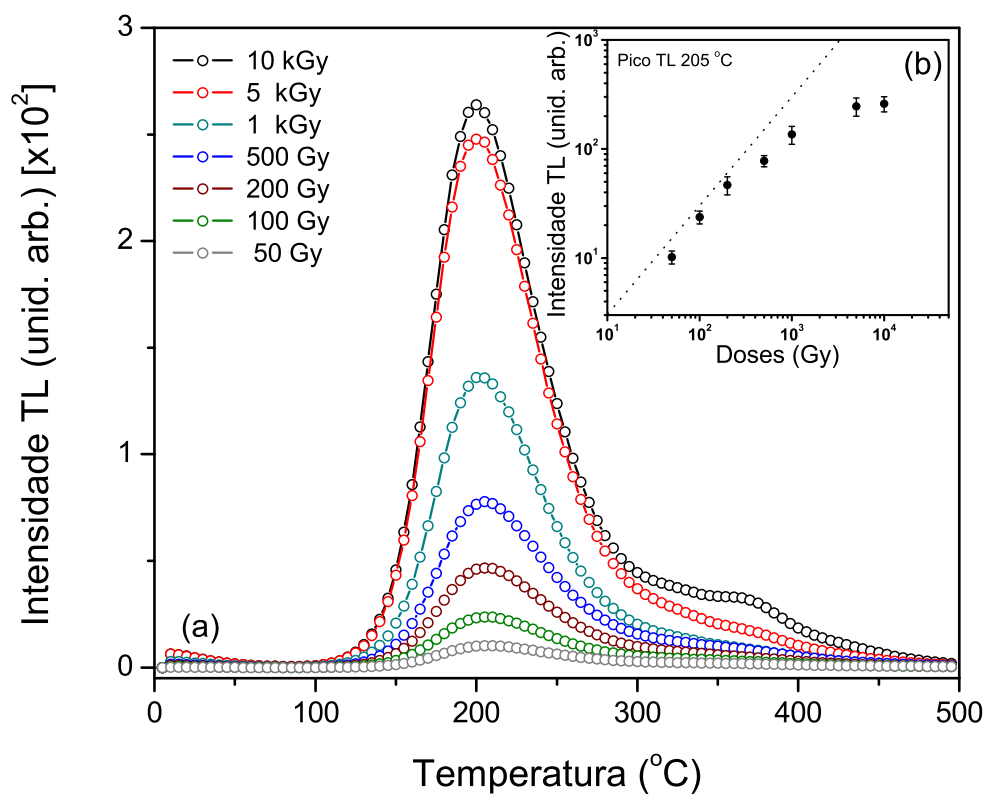

Figura 5.8: (a) - Curva de emissão TL após o tratamento em $160{ }^{\circ} \mathrm{C}$. (b) - Comportamento das intensidades do pico de $205{ }^{\circ} \mathrm{C}$ em função da dose. 
Para eliminar o pico de $205{ }^{\circ} \mathrm{C}$, a amostra foi recozida em $205{ }^{\circ} \mathrm{C}$ por 10 segundos. O resultado é mostrado na Figura 5.9. Esse resultado indica que há picos em $230{ }^{\circ} \mathrm{C}$.

O método de deconvolução poderia, também, ser usado para obter os picos componentes de um pico largo, como no caso da amostra natural.

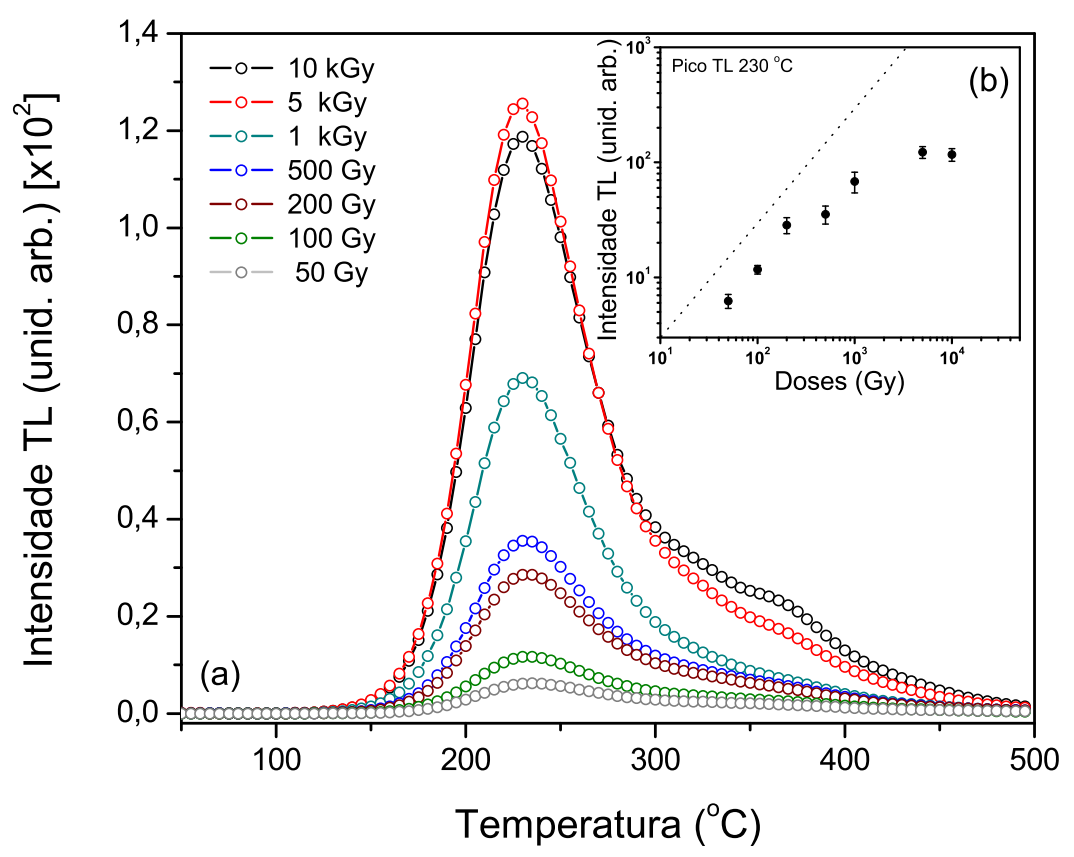

Figura 5.9: (a) - Curva de emissão TL após o tratamento em $205{ }^{\circ} \mathrm{C}$. (b) - Comportamento das intensidades do pico de $230{ }^{\circ} \mathrm{C}$ em função da dose.

Também foram feitos tratamentos térmicos a $900{ }^{\circ} \mathrm{C}$ por uma hora e posteriormente irradiados com doses de radiação gama no intervalo de 50 Gy até 10 kGy. Mais adiante mostraremos que os tratamentos térmicos em temperaturas acima de $500{ }^{\circ} \mathrm{C}$ alteram a sensibilidade TL do diopsídio natural. A Figura 5.10a apresenta a curva de emissão TL para a amostra tratada termicamente a $900{ }^{\circ} \mathrm{C} / 1 \mathrm{hr}$, tratamento este que causa um ligeiro deslocamento do pico de $160{ }^{\circ} \mathrm{C}$ com a dose gama. Para doses menores até 1 kGy as curvas mostram uma superposição dos picos. A intensidade do pico entre 160 e $185^{\circ} \mathrm{C}$ cresce linearmente até aproximadamente 1 kGy e a partir daí começa a saturar (Figura 5.10b). 


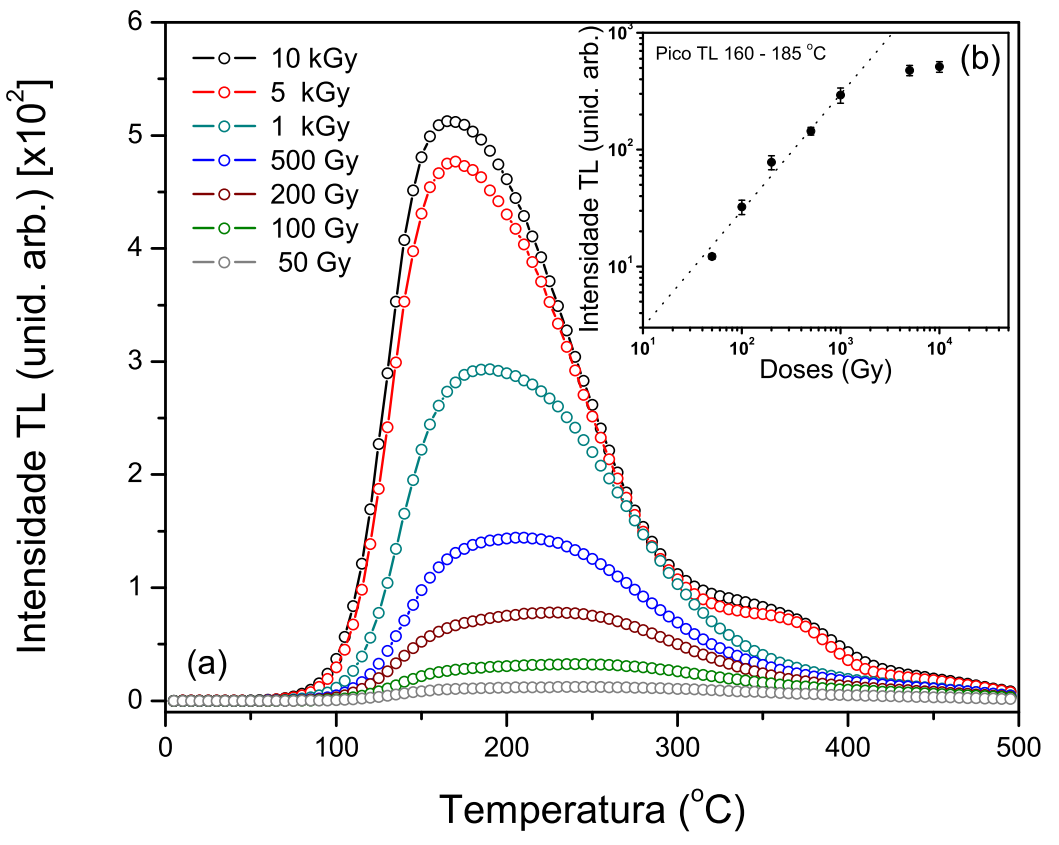

Figura 5.10: (a) - Curva TL com tratamento térmico de $900{ }^{\circ} \mathrm{C}$ por uma hora e submetida a diferentes doses. (b) - Intensidade TL em função da dose para a amostra aquecida em $900{ }^{\circ} \mathrm{C}$.

\subsubsection{Efeito dos tratamentos térmicos antes da irradiação na TL do diopsídio}

Para estudar o efeito dos tratamentos térmicos antes da irradiação, as amostras foram recozidas a $500{ }^{\circ} \mathrm{C}, 600{ }^{\circ} \mathrm{C}, 700{ }^{\circ} \mathrm{C}, 800{ }^{\circ} \mathrm{C}, 900{ }^{\circ} \mathrm{C}, 1100{ }^{\circ} \mathrm{C}$ e $1200{ }^{\circ} \mathrm{C}$ durante 1 hora e posteriormente irradiadas com uma dose de $1 \mathrm{kGy}$. Nota-se na Figura 5.11a que há diferença significativa entre cada recozimento, principalmente os recozimentos em $800{ }^{\circ} \mathrm{C}$ e $900{ }^{\circ} \mathrm{C}$, mostrando que esses recozimentos alteram a intensidade e a largura do pico na curva de emissão TL. As curvas de TL mostram que a sensibilidade do pico em $160-185{ }^{\circ} \mathrm{C}$ aumenta com a temperatura de recozimento até $900{ }^{\circ} \mathrm{C}$. Quando a amostra é recozida, a temperaturas superiores de $1000{ }^{\circ} \mathrm{C}$ a emissão TL diminui rapidamente com o tratamento térmico, Figura 5.11b. Há aparente deslocamento da temperatura do pico, devido à superposição do pico em torno de $200{ }^{\circ} \mathrm{C}$, que cresce. 


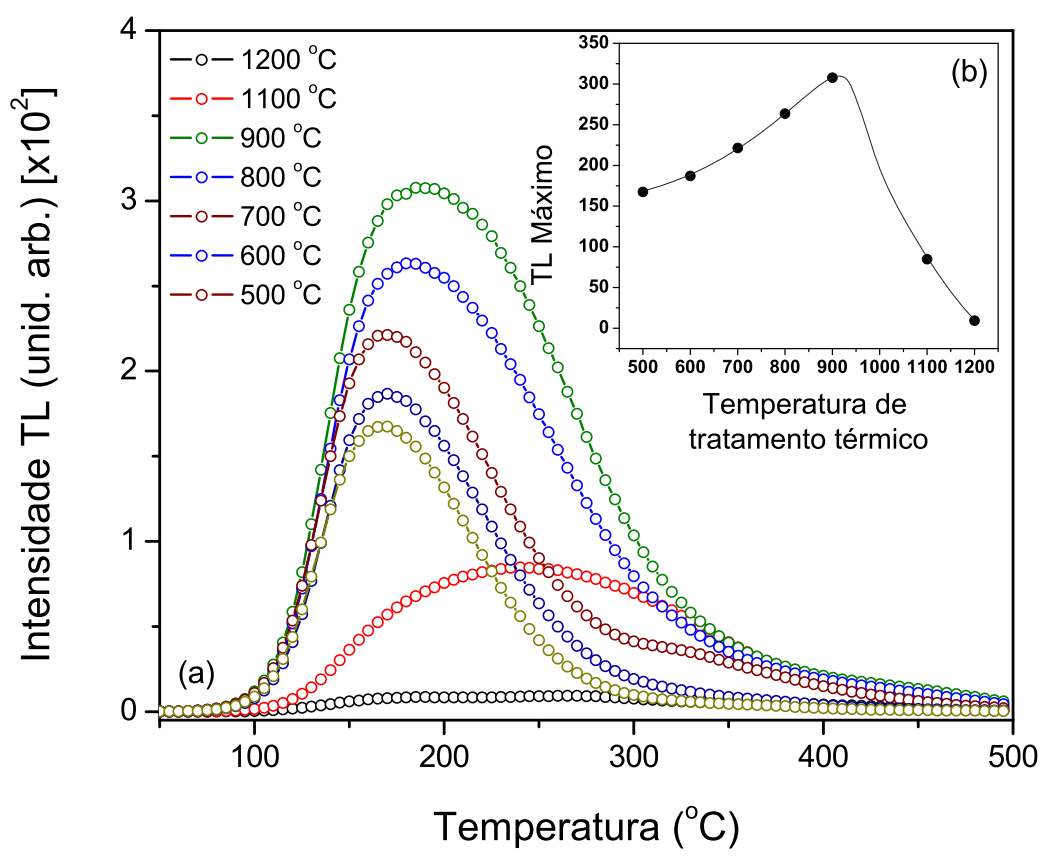

Figura 5.11: (a) - Curva de emissão TL para amostra submetida a uma doses de 1 kGy com diferentes tratamentos térmicos. (b) - Efeito da temperatura do tratamento térmico sobre a intensidade máxima do pico em $160-185{ }^{\circ} \mathrm{C}$ em função da temperatura.

\subsubsection{Decaimento isócrono da TL da amostra natural de diop- sídio}

Uma forma de verificar a estabilidade e visualizar os picos que formam a curva TL é efetuar o decaimento isócrono, que consiste fundamentalmente em submeter a amostra a diferentes tratamentos térmicos por um mesmo intervalo de tempo. Para isso, separamos uma grande quantidade da amostra em pó irradiada com dose de $5 \mathrm{kGy}$, tendo sido previamente aquecida em $600{ }^{\circ} \mathrm{C}$ por uma hora. A Figura 5.12 mostra as curvas de emissão obtidas através da técnica de decaimento isócrono. Observamos nessa figura, que parece haver vários picos que, superpostos produzem o pico centrado em $160{ }^{\circ} \mathrm{C}$ da Figura 5.7.

Considerando que a intensidade TL está relacionada com a área sob a curva de emissão, foi construído um gráfico das áreas das curvas TL para verificar o seu decaimento com a temperatura de tratamento térmico. A Figura 5.13a, dá a área acima mencionada em função dos tratamentos térmicos. Vê-se que existe uma queda acentuada, desaparecendo a curva TL para uma temperatura em torno de $360{ }^{\circ} \mathrm{C}$. 
A curva da Figura 5.13b é a da derivada da curva da Figura 5.13a. Os picos em 160 ${ }^{\circ} \mathrm{C}, 230{ }^{\circ} \mathrm{C}, 300{ }^{\circ} \mathrm{C}$ e em $360{ }^{\circ} \mathrm{C}$ aparecem como pontos de inflexão na curva (b).

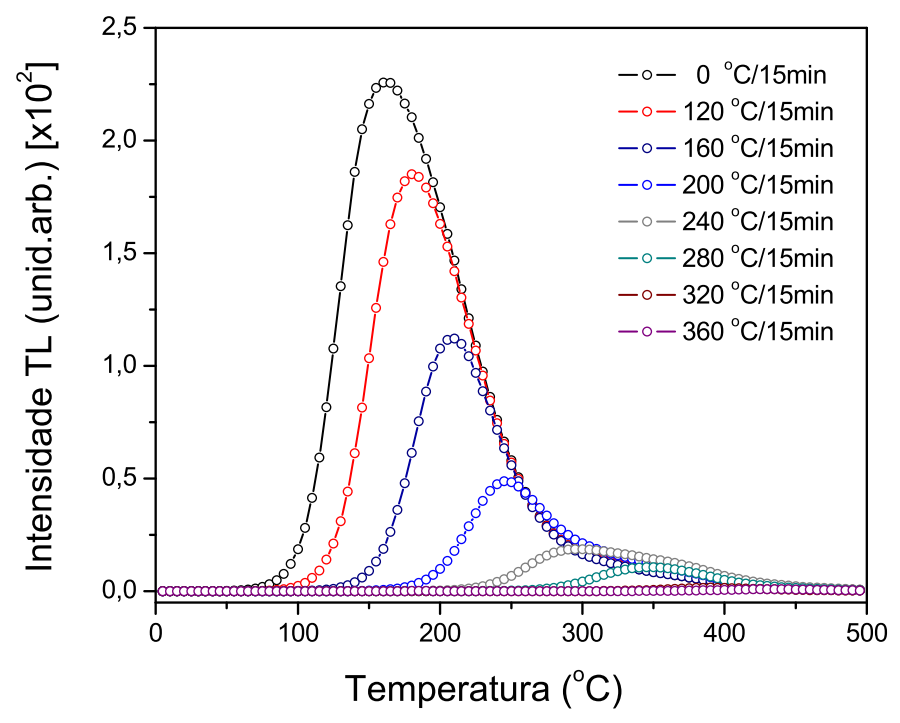

Figura 5.12: Decaimento isócrono dos picos TL na amostra natural recozida em $600^{\circ} \mathrm{C}$ por uma hora e irradiada com $5 k G y$.
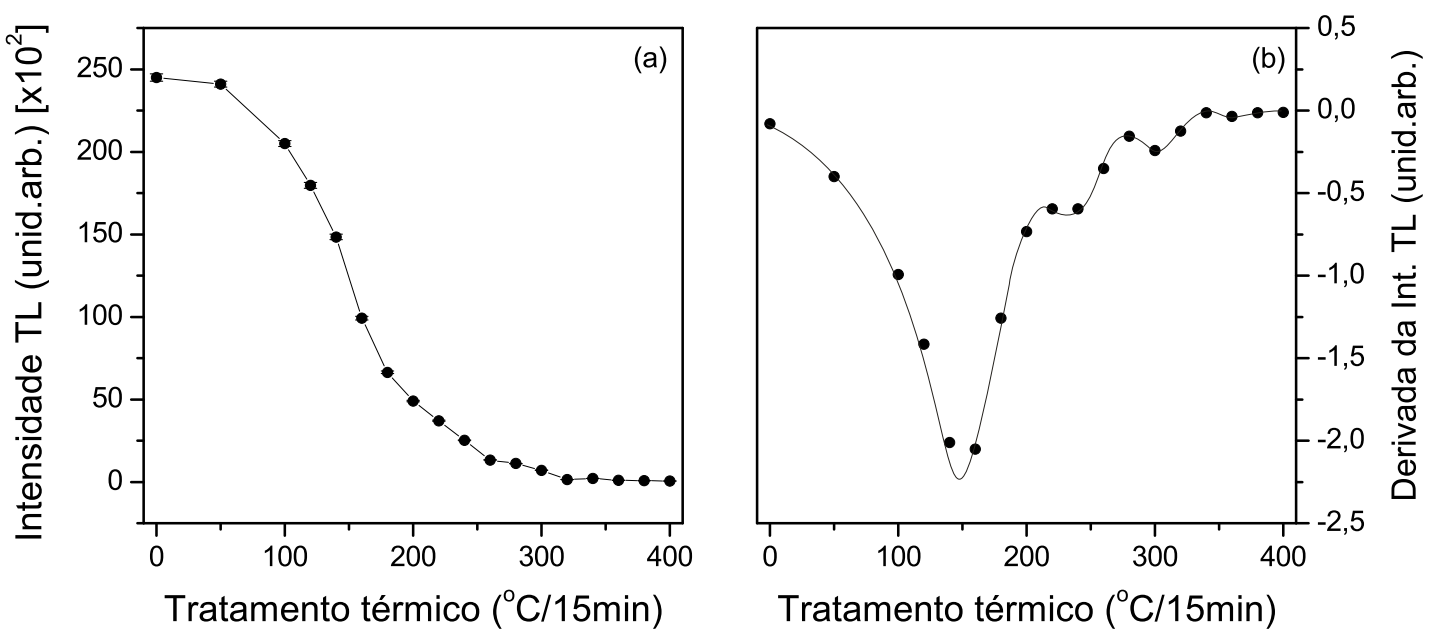

Figura 5.13: (a)-Decaimento isócrono usando a área total TL com o tratamento térmico. (b)- A derivada da curva de (a). 


\subsubsection{Análise das curvas de TL}

O objetivo desta seção é mais especificamente estimar os parâmetros dos modelos TL através de diferentes métodos, como por exemplo o método da subida inicial, e posteriormente com os resultados deconvoluir as curvas de emissão TL do diopsídio.

\section{Determinação das energias de ativação pelo método da subida inicial}

O método da subida inicial foi aplicado com o objetivo de estimar as energias de ativação $E$ dos picos que compõem as curvas de emissão do diopsídio. As amostras foram pré-aquecidas linearmente a uma taxa de $4{ }^{\circ} \mathrm{C} / \mathrm{s}$ até temperaturas finais $\mathrm{T}_{\text {stop }}$ crescentes, sendo a curva TL residual lida em seguida com a mesma taxa de aquecimento.

O método foi aplicado à amostra de diopsídio natural recozida a $600{ }^{\circ} \mathrm{C}$ por uma hora e irradiada com uma dose gama de 1 kGy. Na Figura 5.14 apresentam-se a curva da energia de ativação em função da temperatura $T_{\text {stop }}$. Na Figura observam-se linhas quase contínuas, porém, podemos observar concentrações de pontos em torno das linhas tracejadas em forma de escadas os quais são as energias dos picos TL. A Tabela 5.1 apresenta os valores das energias (E) e os fatores de freqüência $s$.

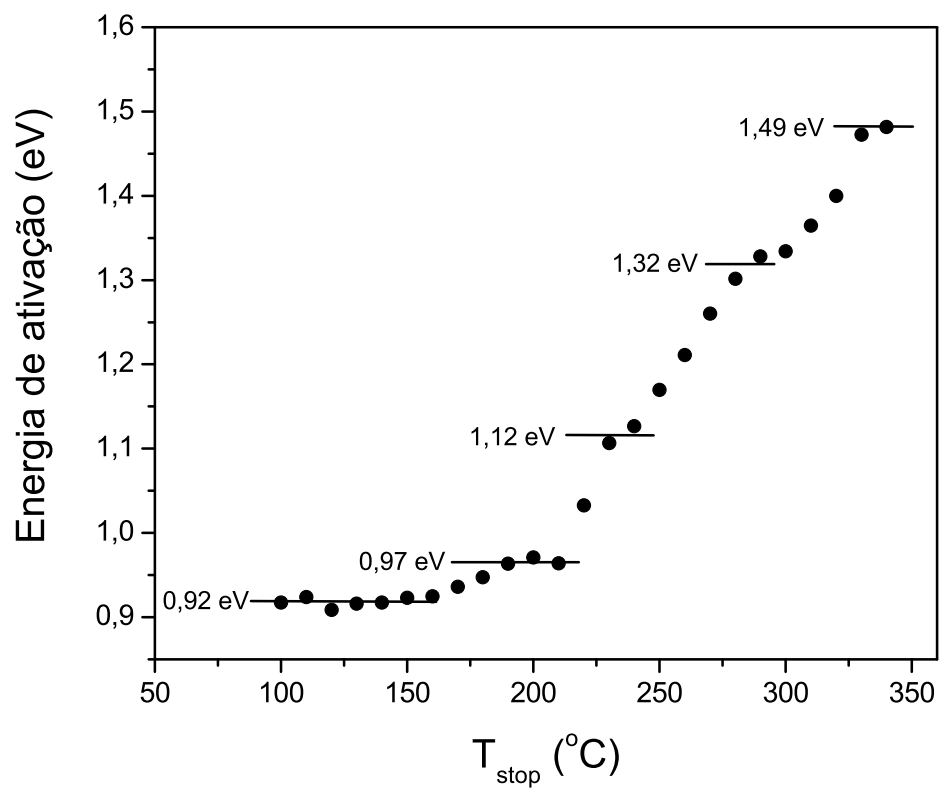

Figura 5.14: Energias de ativação obtidas com a técnica $E-T_{\text {stop }}$ 
Tabela 5.1: Energia de ativação e fator de freqüência para o diopsído

\begin{tabular}{lll}
\hline $\mathrm{T}_{\text {stop }}\left({ }^{\circ} \mathrm{C}\right)$ & $\mathrm{E}(\mathrm{eV})$ & $\mathrm{s}\left(\mathrm{s}^{-1}\right)$ \\
\hline $160-160$ & 0.918 & $1,12 \times 10^{10}$ \\
$190-210)$ & 0.966 & $4,63 \times 10^{9}$ \\
$230-240$ & 1.117 & $3,15 \times 10^{10}$ \\
$280-300$ & 1.321 & $7,81 \times 10^{10}$ \\
$340-350$ & 1.321 & $1,49 \times 10^{11}$ \\
\hline
\end{tabular}

\section{Deconvolução das curvas de emissão TL (GCD)}

A deconvolução foi feito usando o método GCD (Glow-Curve Deconvolution) desenvolvida por Kitis et al. [43]. As funções propostas por Kitis et al. foram consideradas as mais precisas dentro de 13 funções propostas até então. Para cinética de primeira ordem:

$$
I(T)=I_{m} \exp \left[1+\frac{E}{k T} \frac{T-T_{m}}{T_{m}}-\frac{T^{2}}{T_{m}^{2}} \cdot \exp \left(\frac{E}{k T} \frac{T-T_{m}}{T_{m}}\right)(1-\Delta)-\Delta_{m}\right]
$$

segunda ordem:

$$
\begin{gathered}
I(T)=4 I_{m} \exp \left(\frac{E}{k T} \frac{T-T_{m}}{T_{m}}\right) \cdot\left[\frac{T^{2}}{T_{m}^{2}}(1-\Delta) \cdot \exp \left(\frac{E}{k T} \frac{T-T_{m}}{T_{m}}\right)+1+\Delta_{m}\right]^{-2} \\
\Delta=\frac{2 k T}{E} \quad \text { e } \Delta_{m}=\frac{2 k T_{m}}{E}
\end{gathered}
$$

onde $T_{m}$ é a temperatura do pico, $I_{m}$ a intensidade máxima do pico TL e, $k$ a constante de Boltzmann. Os valores de $E$ obtidos pelo método E- $\mathrm{T}_{\text {stop }}$ e utilizando a equação para cinética de segunda ordem proposto por Kitis et al. e, variando somente $\mathrm{T}_{m}$ foram deconvoluidas as curvas de emissão TL do diopsído, Figura 5.15.

O cálculo do fator de freqüência $s$ foi feito substituindo os valores da energia de ativação determinados pelo método $\mathrm{E}_{-} \mathrm{T}_{\text {stop }}$, temperatura do pico $\mathrm{T}_{m}$ corrigido por GCD e, a taxa de aquecimento ( $\beta$ ) na equação 3.83 do livro de Chen \& McKeever [41]. Os resultados são mostrados no quadro interno da Figura 5.15.

A deconvolução mostra que a curva de emissão TL é formada da superposição de cinco picos, em aproximadamente 160, 197, 230, 300 e $350{ }^{\circ} \mathrm{C}$. Estes picos não foram observados na curva de emissão TL experimental, posto que devido à quantidade e intensidade dos picos TL individuais, há uma forte superposição entre eles originando a formação de um só pico largo, que não é mais do que a soma de picos menores. 


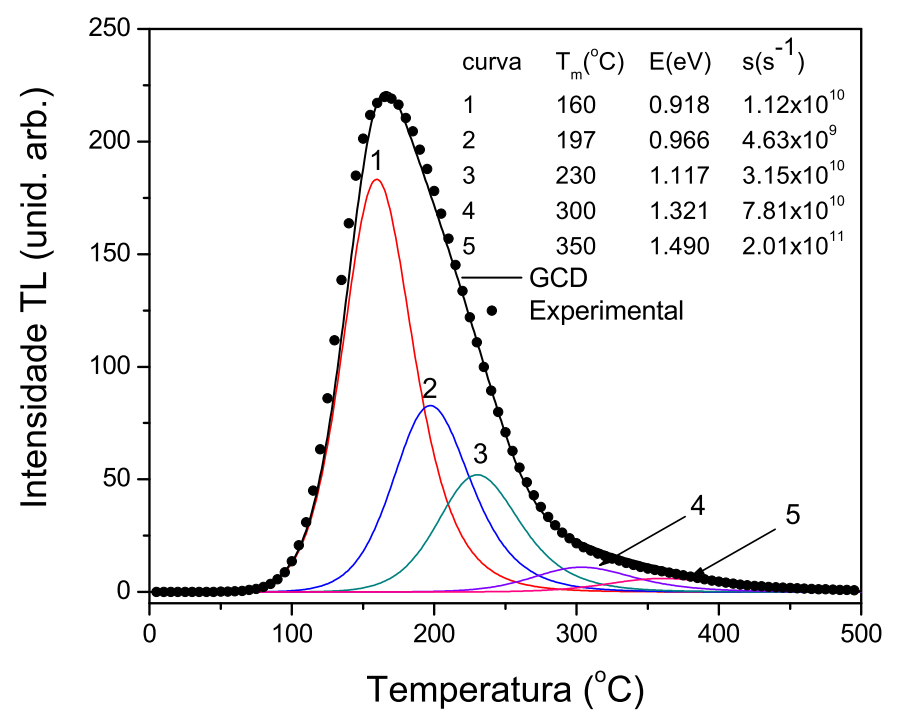

Figura 5.15: Deconvolução da curva TL do diopsídio

\subsubsection{Espectro de emissão TL do diopsídio natural}

Como já foi mencionado na seção 2.2.3, o conhecimento dos espectros de emissão é essencial para uma interpretação adequada dos mecanismos TL e para o uso do material em qualquer aplicação. O mecanismo de emissão da luz TL, por um cristal iônico, admite que os elétrons em determinadas armadilhas, ao serem aquecidos a uma dada temperatura T, são liberados para a banda de condução, quando se movem livremente pelo cristal, até sofrerem transições aos chamados centros de recombinação, que são armadilhas de buracos. Durante essa recombinação emitem luz (visível, em geral) de freqüência $\nu_{o}$. No espectro de luz TL de um cristal, a(s) banda(s) de emissão em torno da freqüência $\nu_{o}$ (e outra se existir), indica o centro de recombinação. Tem sido provada em vários trabalhos a existência de um só tipo de centro de recombinação, mas, existem casos em que há dois ou mais centros de recombinação.

Não se deve esquecer, que há a possibilidade de os buracos serem liberados pelo aquecimento, irem para a BV, onde após sofrerem transições para os centros de elétrons (agora de recombinação), produzem a emissão de luz TL.

Para obter o espectro de emissão TL ${ }^{1}$ foram utilizadas amostras de diopsídio natural com dose adicional de $1 \mathrm{kGy}$, irradiadas numa fonte beta ${ }^{90} \mathrm{Sr} /{ }^{90} \mathrm{Y}$ a uma taxa de 79 mGy/s. Apresentamos nas Figuras 5.16 e 5.17 as medidas dos espectros de emissão

\footnotetext{
${ }^{1}$ As medidas de espectro de emissão TL foram realizadas no Optically and Thermally Stimulated Laboratory da Oklahoma State University (Stillwater, USA).
} 
TL do diopsídio, observando-se que a intensidade é máxima em torno de $435 \mathrm{~nm}$ e só há uma banda extremadamente larga. Isto indica que no diopsídio existe um só centro de recombinação, que dá origem à emissão da luz TL para qualquer pico TL.

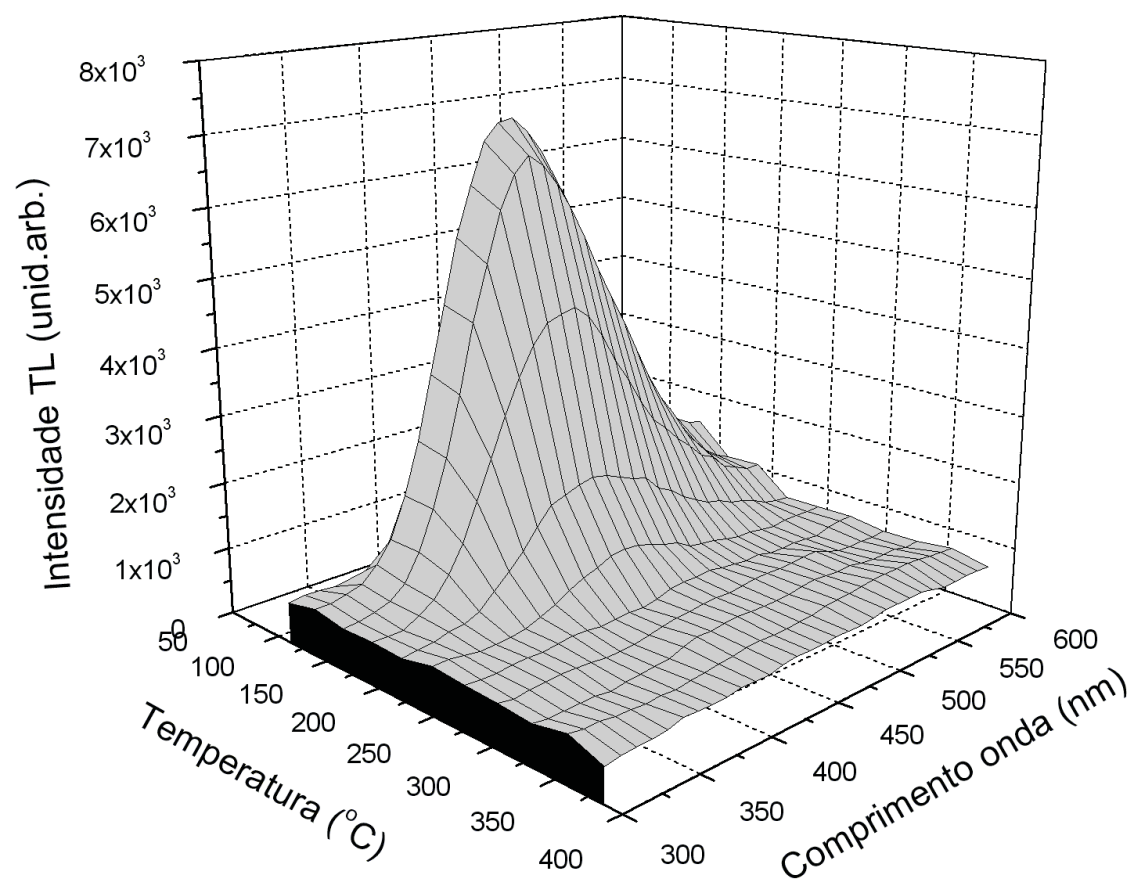

Figura 5.16: Espectro de emissão TL em representação 3D da amostra de diopsídio natural após irradiação beta de 1 kGy.

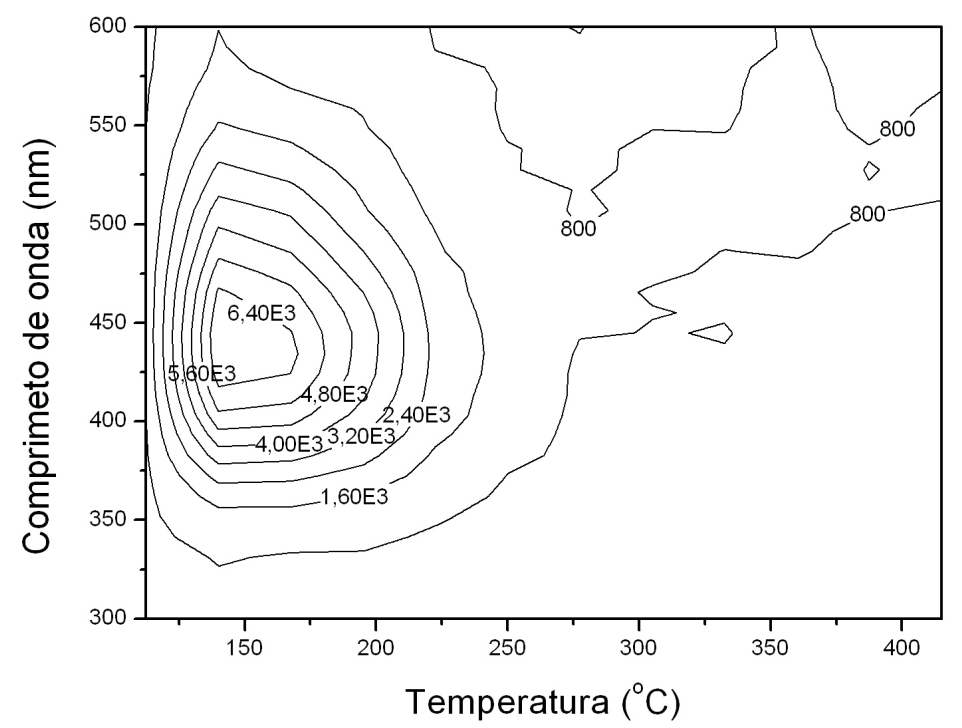

Figura 5.17: Curvas de nível da amostra natural após irradiação beta de 1 kGy. 


\subsubsection{Irradiação com luz UV na amostra natural}

Há dois efeitos da luz violeta sobre a termoluminescência de um cristal. Um se refere ao cristal irradiado, portanto, com a TL nele induzida. O outro é um efeito sobre um cristal tratado termicamente, de modo que toda TL nele existente já foi eliminada.

\section{Decaimento dos picos TL com a irradiação de luz UV}

As amostras tratadas termicamente a $600{ }^{\circ} \mathrm{C}$ por uma hora, foram irradiadas com 5 kGy de radiação gama e depois foram iluminadas com uma lâmpada comum de luz UV de 60 Watts por diferentes tempos de iluminação. Na Figura 5.18 observamos o efeito de fotoesvaziamento produzido pela luz UV. Um ligeiro aumento na intensidade TL com a iluminação UV pode ser observado para temperaturas menores de $120{ }^{\circ} \mathrm{C}$. Observa-se, ainda, na Figura 5.19 que o pico TL em $160{ }^{\circ} \mathrm{C}$ decai rapidamente com o tempo de iluminação de luz UV.

O decaimento observado na Figura 5.19 é exponencial, onde os parâmetros P1, P2 e P3 são constantes; especificamente P3 representa a intensidade termoluminescente residual após um longo tempo de decaimento devido à irradiação UV. P1 e P3 são intensidades TL antes da exposição à luz UV. Os valores dos parâmetros de ajuste para o pico TL em $160{ }^{\circ} \mathrm{C}$ são mostrados no quadro interno da Figura 5.19.

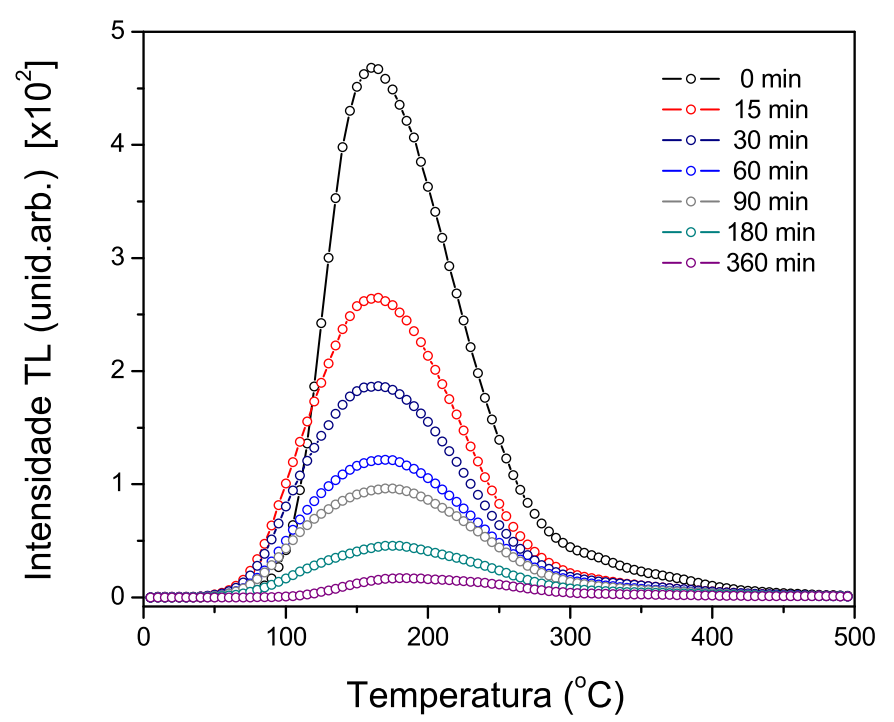

Figura 5.18: Curva de emissão TL do diopsídio natural com o tempo de irradiação de luz $U V$, as amostras foram previamente recozidas a $600{ }^{\circ} \mathrm{C}$ por uma hora e irradiadas com uma dose gama de 5 kGy. 


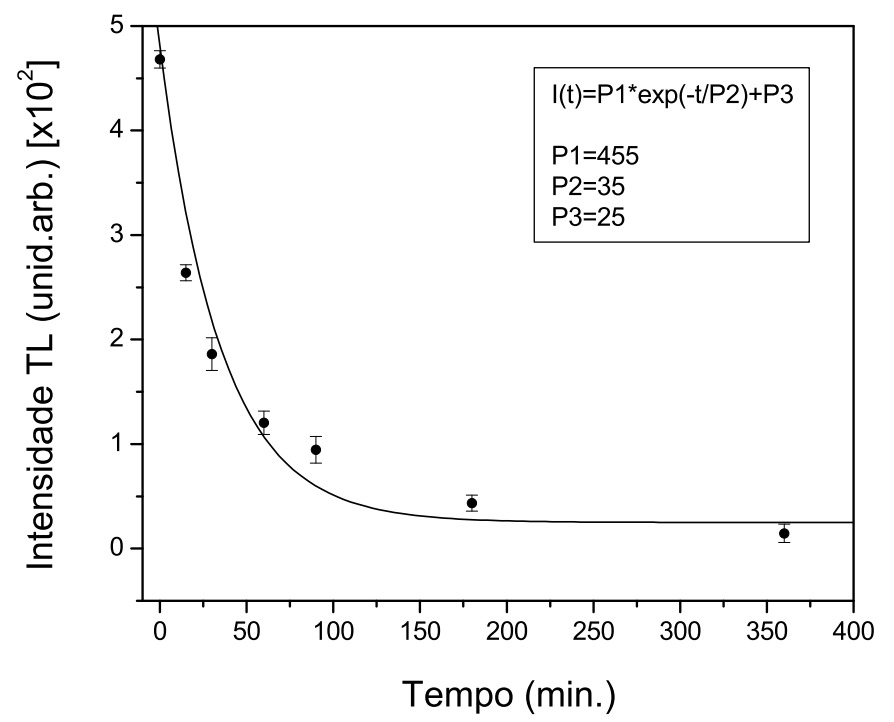

Figura 5.19: Decaimento do pico TL de $160{ }^{\circ} \mathrm{C}$ com o tempo de irradiação de luz UV.

Efeito da iluminação UV na amostra natural de diopsídio com recozimento térmico a $600{ }^{\circ} \mathrm{C}$

A dependência da resposta TL com a irradiação de luz ultravioleta foi estudada para a amostra natural, recozida por uma hora em $600{ }^{\circ} \mathrm{C}$. Com a irradiação de luz ultravioleta, surgem picos TL em 90, 170 e $450{ }^{\circ} \mathrm{C}$ (Figura 5.20). Como podemos observar na Figura 5.21 a indução de TL com o tempo de irradiação começa aumentar sublinearmente e, satura para um tempo de iluminação de 5 min. A luz UV incidindo sobre a amostra previamente tratada a $600{ }^{\circ} \mathrm{C}$, tem a capacidade de induzir TL. O fóton da luz UV não possui a energia suficiente para transferir um elétron da banda de valência à banda de condução. Goepper- Mayer [60] mostrou que, há probabilidade do elétron absorver dois fótons possibilitando a indução TL.

A questão de porque os picos TL devido a raios- $\gamma$ são diferentes quando a TL é induzida pela luz UV, ainda não tem resposta. 


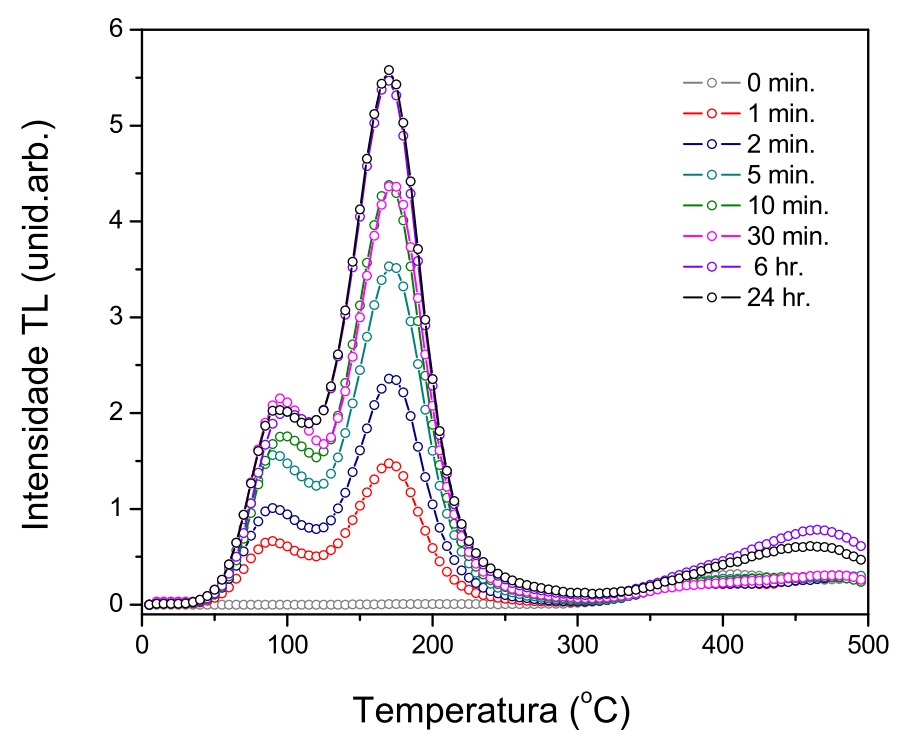

Figura 5.20: Curva de emissão TL do diopsídio natural recozido a $600{ }^{\circ} \mathrm{C}$ por uma hora e irradiada com luz UV.

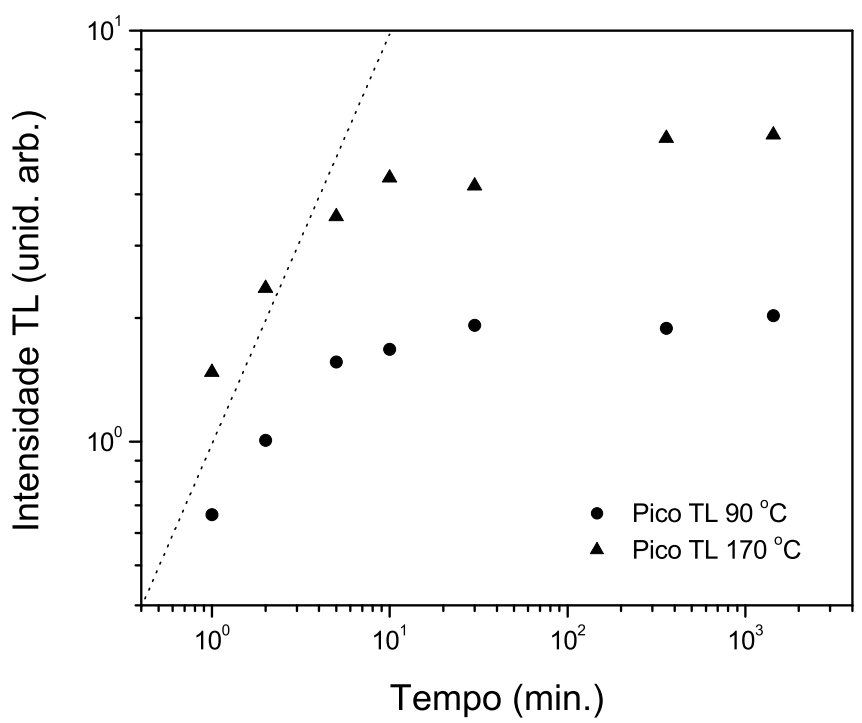

Figura 5.21: Comportamento das intensidades dos picos em 90 e $170{ }^{\circ} \mathrm{C}$ em função do tempo de irradiação de luz UV.

\subsubsection{Termoluminescência das amostras artificiais.}

A partir de uma composição estequiométrica de $\mathrm{SiO}_{2}, \mathrm{MgO}$ e $\mathrm{CaO}$ foram preparadas amostras sintéticas de diopsídio puro e dopadas com as concentraçães de impurezas 
com que aparecem no material natural: óxidos de aluminio, de manganês e de ferro. Foi usado o método da devitrificação, descrito no capitulo 2.5.2.

A amostra artificial pura revela, quais as propriedades (TL, RPE, refletância, etc) observadas em amostras naturais que são provenientes de defeitos intrínsecos.

\section{Artificial pura $\left(\mathrm{SiO}_{2}-\mathrm{MgO}-\mathrm{CaO}\right)$}

A amostra artificial pura de diopsídio foi submetida à irradiação gama para verificação dos picos TL que possam ser devido apenas a defeitos intrínsecos, já que esta amostra foi obtida da forma mais pura possível. O resultado pode ser visto na Figura 5.22. Como pode ser observado, surgem alguns picos TL com a dose, sendo os mais evidentes em torno de 160 e $280{ }^{\circ} \mathrm{C}$. O pico em $280{ }^{\circ} \mathrm{C}$ cresce rapidamente com a dose, mais do que o pico em $160-170{ }^{\circ} \mathrm{C}$. O pico de alta temperatura, aparentemente, fica totalmente encoberto. É impressionante que esses picos tenham intensidades iguais ou superiores àquelas observadas na amostra natural de diopsídio. Os picos de 160 e $280{ }^{\circ} \mathrm{C}$ crescem com a dose de radiação gama, como pode ser visto na Figura 5.23.

Foram produzidas outras amostras artificiais de diopsídio, com diferentes impurezas encontradas na amostra natural, cada impureza entrando separadamente na amostra. Isto foi feito para observar o efeito de cada impureza na curva de emissão TL. A seguir mostramos as medidas de TL para as diferentes dopagens, como também o comportamento dos picos com a dose de irradiação gama.

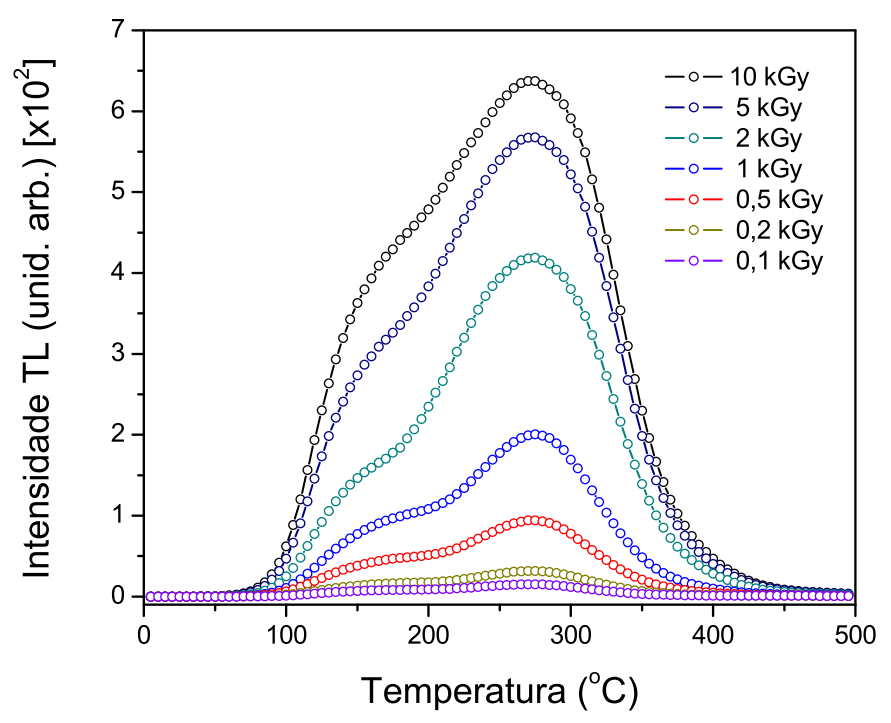

Figura 5.22: Curva de emissão TL do diopsídio artificial puro para diversas doses de radiação gama. 


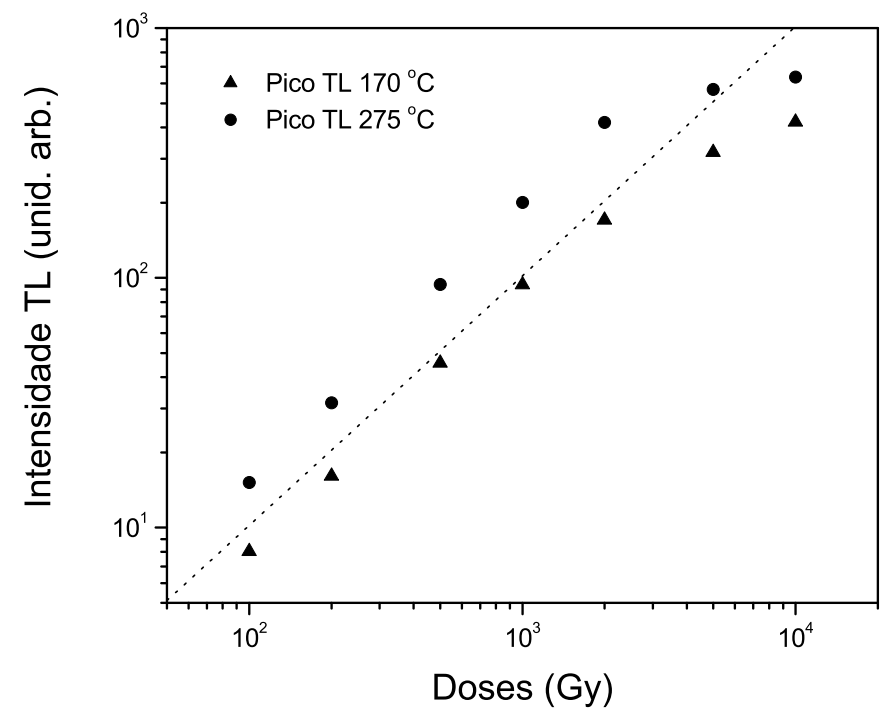

Figura 5.23: Comportamento das intensidades dos picos em 170 e $275{ }^{\circ} \mathrm{C}$ em função de doses de radiação gama.

\section{Artificial dopada com Al}

Segundo a análise química do cristal de diopsídio natural observou-se a presença de aproximadamente $1,56 \%$ em peso de $\mathrm{Al}_{2} \mathrm{O}_{3}$. Dessa forma o alumínio foi a primeira impureza utilizada como dopante. Com relação ao material artificial puro vemos que não houve aumento consideravel da sensibilidade TL do pico em $175^{\circ} \mathrm{C}$, revelando que esse pico, de ordem estrutural, não tem a sua sensibilidade TL alterada pela presença do alumínio (Figura 5.24). O pico em $280{ }^{\circ} \mathrm{C}$, por outro lado, apresentou um aumento com a dose, menor que o da amostra pura. Além disso, é visível o pico entre $350{ }^{\circ} \mathrm{C}$ e $450{ }^{\circ} \mathrm{C}$. Em outras palavras, a presença de $\mathrm{Al}$ na amostra não interferiu no pico em $160-170{ }^{\circ} \mathrm{C}$, mas, serviu de inibidor do pico em $280{ }^{\circ} \mathrm{C}$ e de criador do pico de 350 - $450{ }^{\circ} \mathrm{C}$. Na Figura 5.25 tem-se o comportamento da curva de crescimento dos picos em função da dose.

\section{Artificial dopada com Fe}

A análise química da composição do cristal de diopsídio indicou uma presença de aproximadamente $0,57 \%$ em peso de $\mathrm{Fe}_{2} \mathrm{O}_{3}$, dessa forma foi o segundo dopante acrescentado na amostra artificial de diopsídio, com essa concentração.

O diopsídio artificial dopado com Fe apresenta dois picos bem definidos, um em $180^{\circ} \mathrm{C}$ e outro em $445^{\circ} \mathrm{C}$. O pico em $180{ }^{\circ} \mathrm{C}$ cresce com a dose de radiação gama até 
5 kGy e, o pico em $445^{\circ} \mathrm{C}$ não apresenta uma mudança significativa com relação à dose de radiação, como pode-se ver nas Figuras 5.26 e 5.27. Nota-se, porém, que a intensidade TL é cem vezes menor no diopsídio artificial dopado com Fe, comparado com a da amostra pura e da amostra dopada com Al.

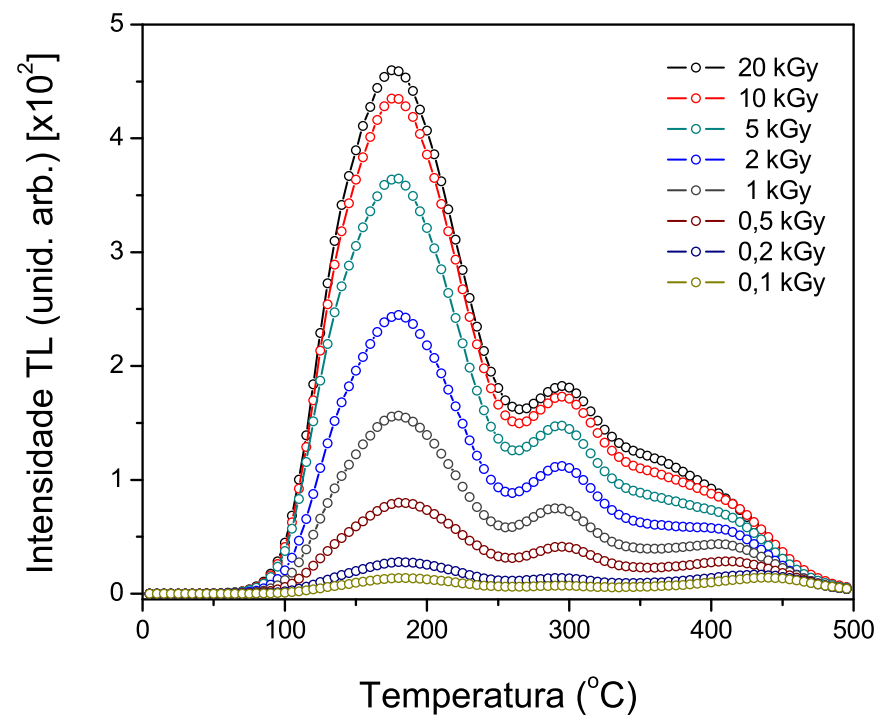

Figura 5.24: Curva de emissão TL da amostra artificial dopada com Al com doses gama adicional.

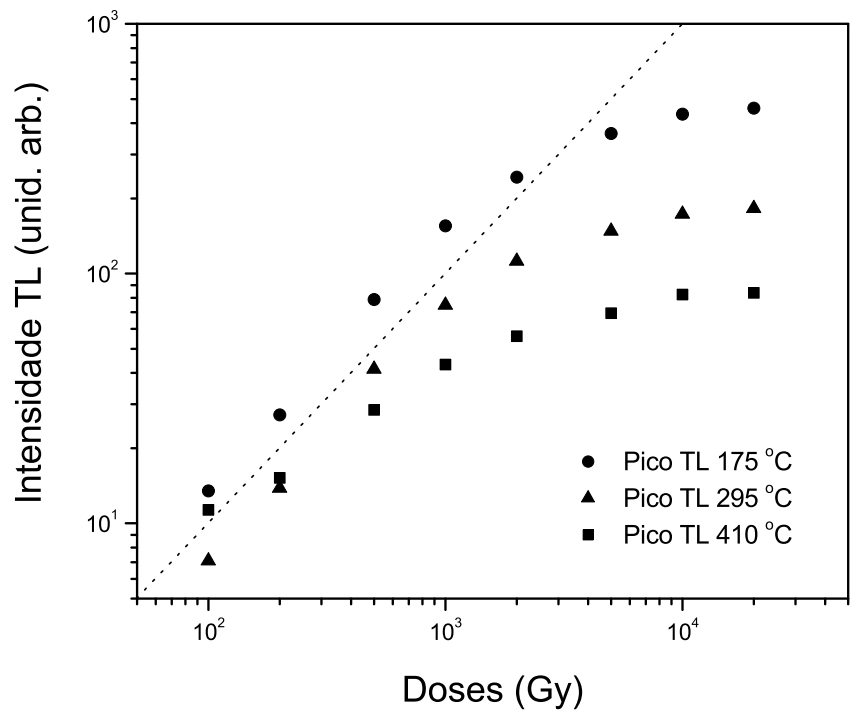

Figura 5.25: Crescimento dos picos TL com a dose gama na amostra artificial dopada com Al. 


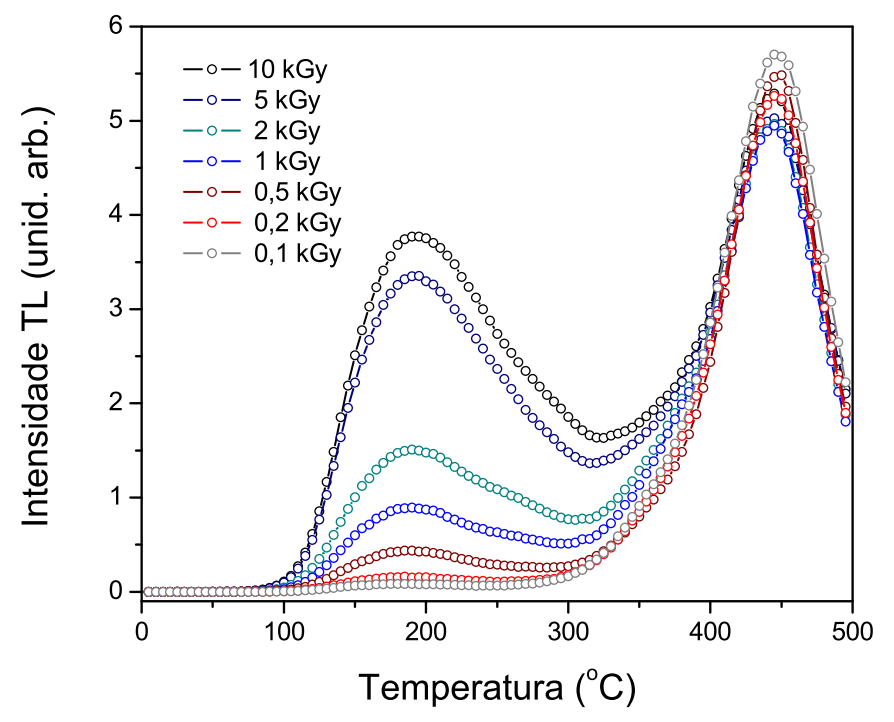

Figura 5.26: Curva de emissão TL da amostra artificial dopada com Fe com doses gama adicional.

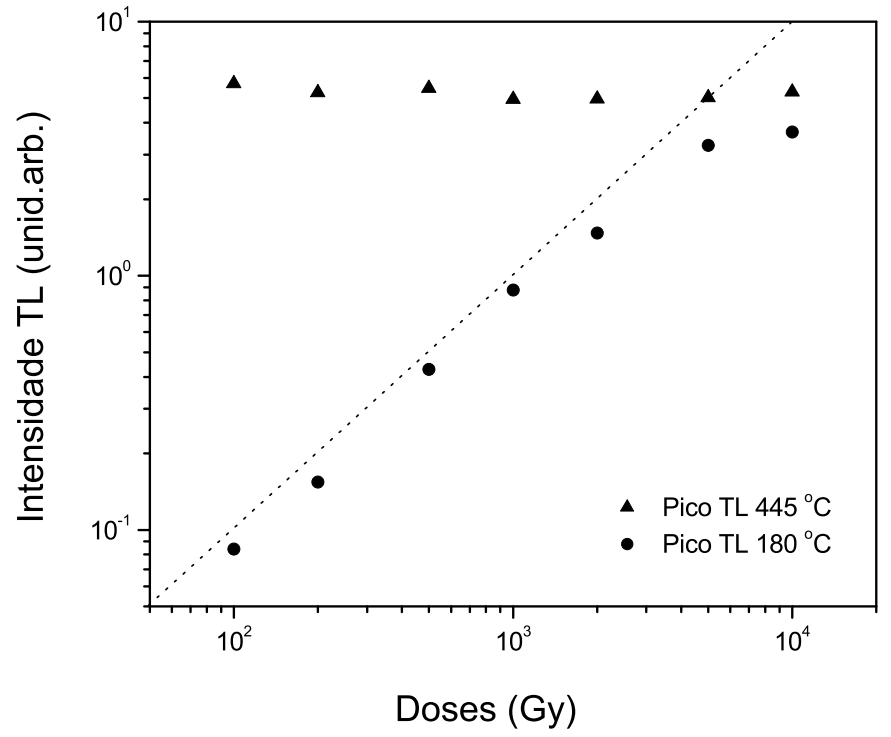

Figura 5.27: Comportamento dos picos TL com a dose gama na amostra artificial dopada com $\mathrm{Fe}$.

\section{Artificial dopada com Mn}

A Figura 5.28 apresenta o comportamento da curva TL para o diopsídio artificial dopado com Mn. Observam-se os mesmos picos TL identificados no diopsídio artificial 
puro, mas, os picos são mais definidos. A curva de crescimento dos picos em função da dose é mostrada na Figura 5.29.

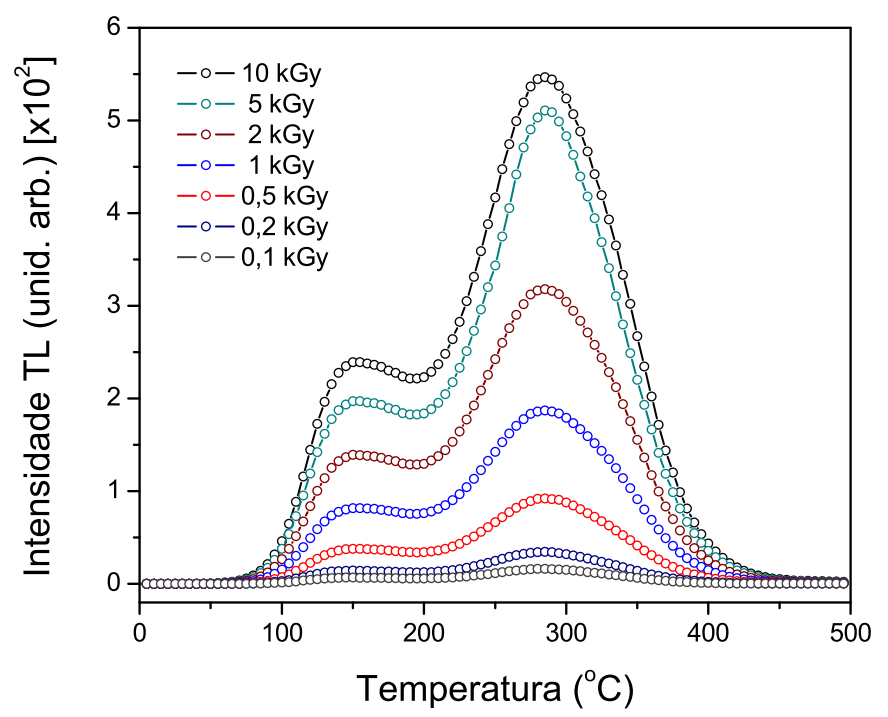

Figura 5.28: Curva de emissão TL da amostra artificial dopada com Mn para diversas doses de radiação gama.

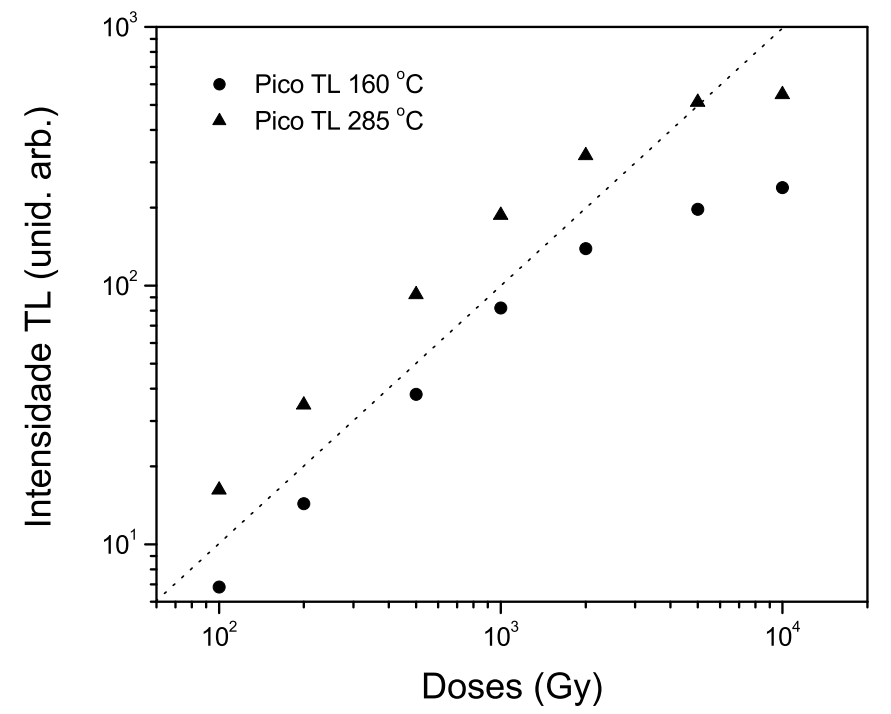

Figura 5.29: Comportamento dos picos TL com a dose gama na amostra artificial dopada com $M n$. 


\subsection{Medidas de Refletância}

Neste item apresentamos as bandas de refletância encontradas nas amostras naturais e artificias de diopsído, além de estudar a influência da radiação gama e o efeito dos diferentes tratamentos térmicos.

\subsubsection{Refletância da amostra natural de diopsídio}

O espectro de refletância obtido da amostra natural de diopsídio pode ser visto na Figura 5.30. Assim, este espectro mostra que o diopsídio natural apresenta várias bandas no infravermelho próximo. Na região abaixo de $300 \mathrm{~nm}$, observa-se uma intensa absorção UV. Na região do visível há forte refletância, o que dá a cor branca ao diopsídio natural.

\subsubsection{Efeito da irradiação gama na amostra natural}

Para estudar o efeito da radiação no comportamento das intensidades de refletância do diopsídio natural, principalmente na parte visível do espectro, medidas de refletância foram efetuadas, irradiando uma lâmina com diferentes doses gama. A Figura 5.31, apresenta as bandas de refletância para as lâminas de diopsídio irradiadas com doses de radiação gama, de 5 até 50 kGy. Observamos que a amostra natural de diopsídio irradiado com doses gama mostra pequenas mudanças na intensidade das bandas de refletância.

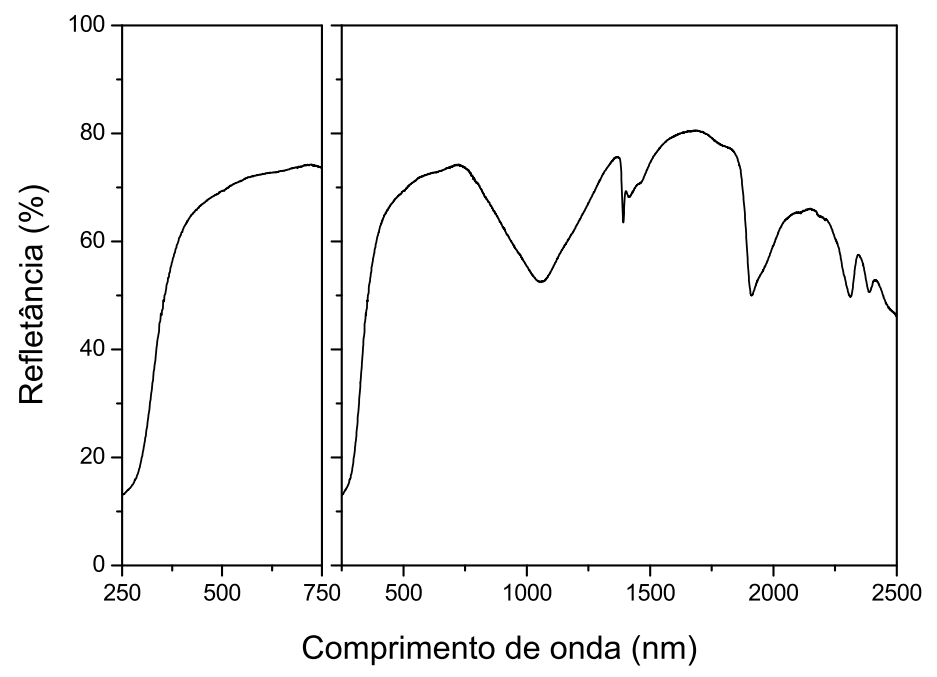

Figura 5.30: Espectro de refletância da amostra natural. 


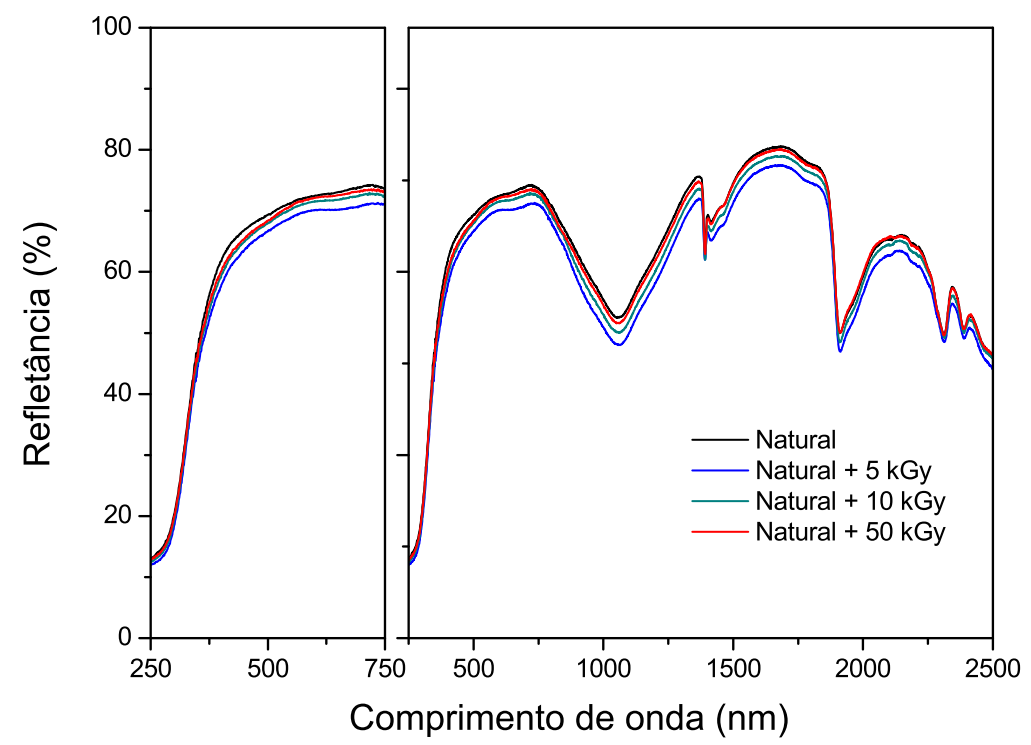

Figura 5.31: Espectro de refletância da amostra natural irradiado com dose gama.

\subsubsection{Efeito térmico na refletância do diopsídio natural}

As lâminas de diopsídio natural foram submetidas a diferentes aquecimentos entre as temperaturas de $100{ }^{\circ} \mathrm{C}$ até $1000{ }^{\circ} \mathrm{C}$ por uma hora e os resultados das medidas estão nas Figuras 5.32 e 5.33. A banda de refletância em $1050 \mathrm{~nm}$ diminui com um aquecimento entre $200{ }^{\circ} \mathrm{C}$ e $500{ }^{\circ} \mathrm{C}$. Para temperaturas superiores a $500{ }^{\circ} \mathrm{C}$ a banda em $1050 \mathrm{~nm}$ cresce (Figura 5.34). Cresce até cerca de $900{ }^{\circ} \mathrm{C}$, depois parece decrescer.

O comportamento das bandas em 1390 e 1910 nm é mostrado nas Figuras 5.35a e 5.35b respectivamente. A banda em $1390 \mathrm{~nm}$ tem um comportamento similar ao da banda em $1050 \mathrm{~nm}$. A banda decresce entre $200{ }^{\circ} \mathrm{C}$ e $500{ }^{\circ} \mathrm{C}$, depois cresce, mas, apenas ligeiramente, até cerca de $800{ }^{\circ} \mathrm{C}$, quando decresce rapidamente. Já a banda em $1910 \mathrm{~nm}$ decai exponencialmente.

As bandas em 2310 e 2385 nm, mostradas nas Figuras 5.35c e 5.35d, têm um comportamento caracterizado por não variarem de intensidade até cerca de $600{ }^{\circ} \mathrm{C}$, mas, para temperaturas superiores, elas decaem.

É importante notar que entre $300 \mathrm{~nm}$ e $800 \mathrm{~nm}$, a refletância cai de $70 \%$ a cerca de $28 \%$ entre $100{ }^{\circ} \mathrm{C}$ e $500{ }^{\circ} \mathrm{C}$, mas acima de $500{ }^{\circ} \mathrm{C}$ cresce até cerca de $80 \%$.

A amostra com tratamento térmico a $900{ }^{\circ} \mathrm{C}$ por uma hora foi irradiada com doses gama no intervalo de 50 Gy até 50 kGy. Os espectros são mostrados na Figura 5.36. Este resultado e aquele apresentado na Figura 5.31 mostram que a irradiação afeta muito pouco a refletância do diopsídio. 


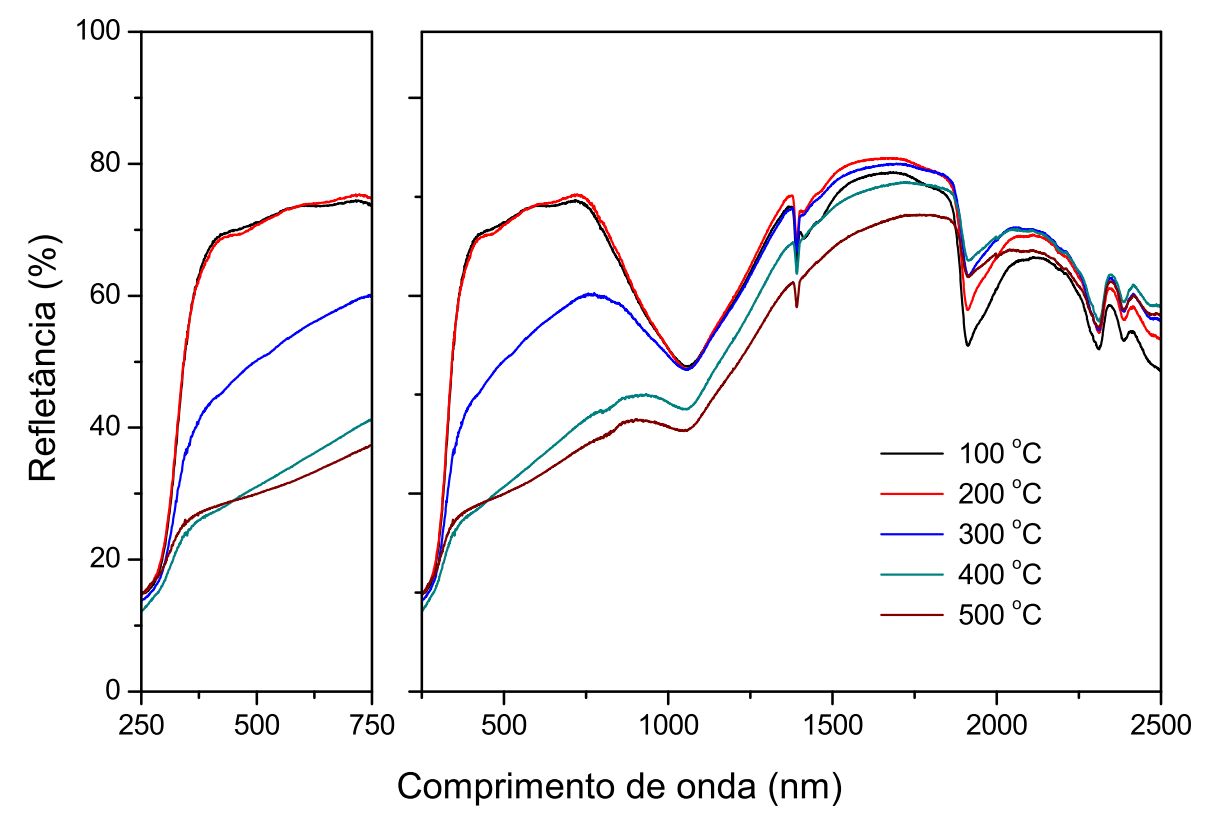

Figura 5.32: Espectro de refletância da amostra natural de diopsídio com diferentes tratamentos térmicos $\left(100\right.$ até $\left.500{ }^{\circ} \mathrm{C}\right)$ por uma hora.

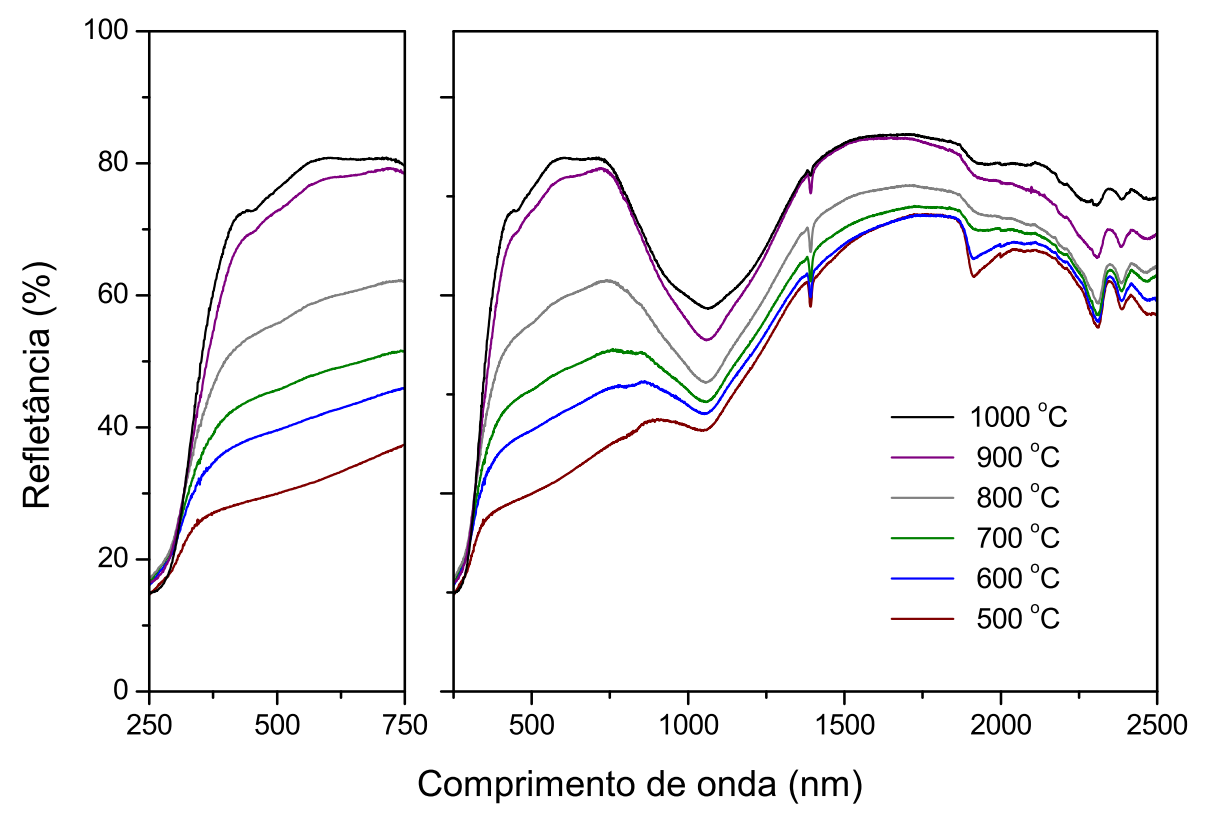

Figura 5.33: Espectro de refletância da amostra natural de diopsídio com diferentes tratamentos térmicos (500 até $1000{ }^{\circ} \mathrm{C}$ ) por uma hora. 


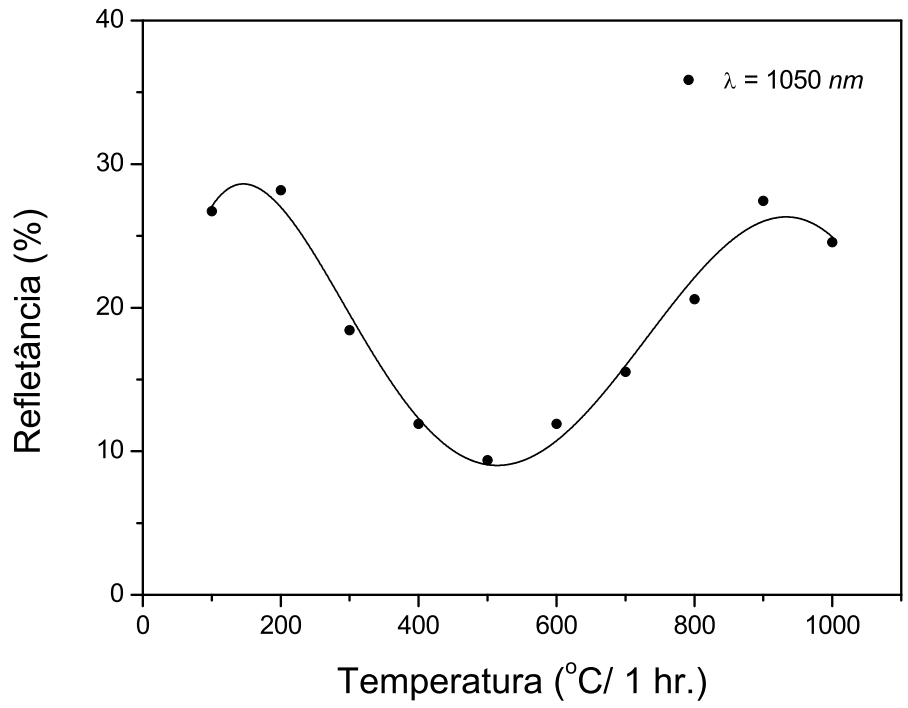

Figura 5.34: Comportamento com o tratamento térmico da banda em $1050 \mathrm{~nm}$.

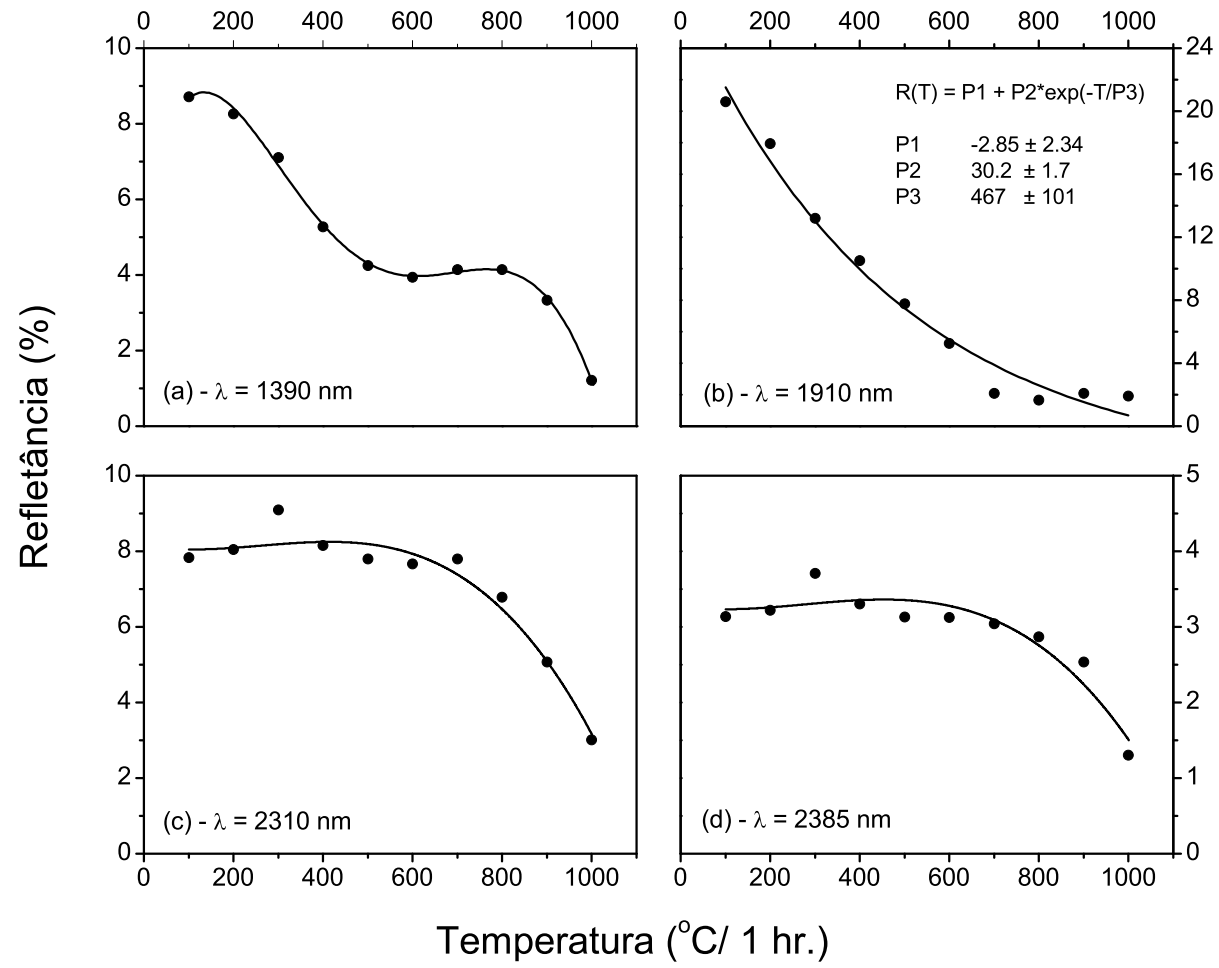

Figura 5.35: Comportamento com o tratamento térmico da banda em: (a) - $1390 \mathrm{~nm}$. (b) $-1910 \mathrm{~nm}$. (c) - 2310. (d) - $2385 \mathrm{~nm}$. 


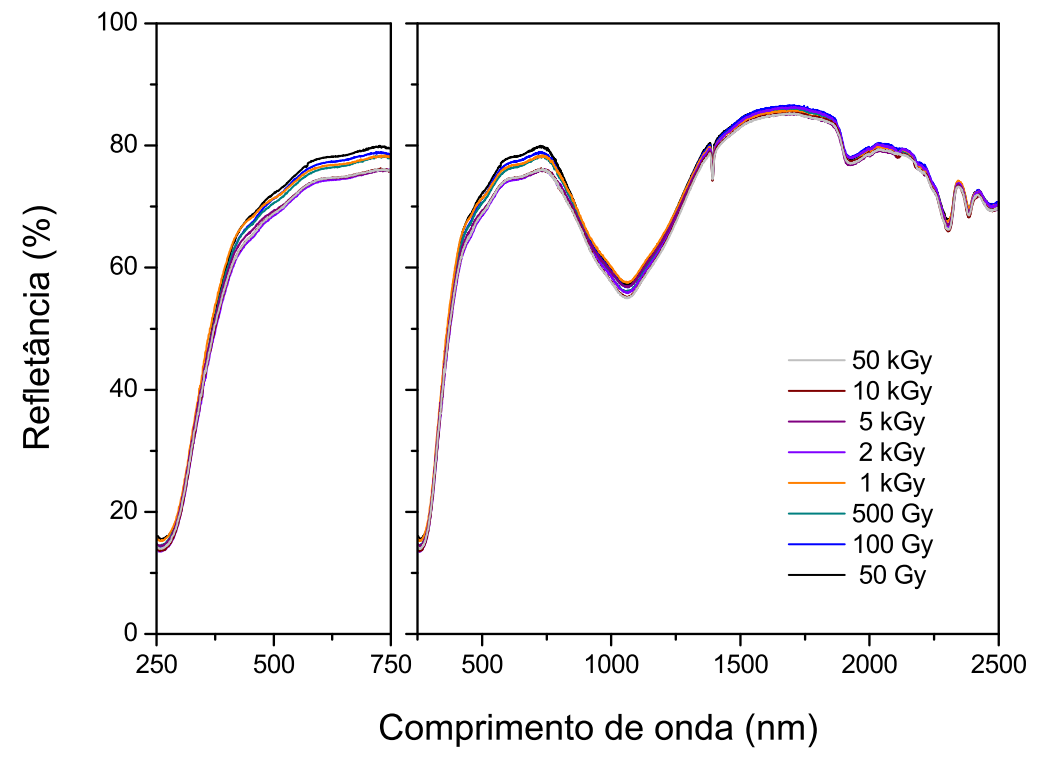

Figura 5.36: Espectro de refletância da amostra natural com tratamento térmico de $900{ }^{\circ} \mathrm{C}$ por uma hora e submetido a diferentes doses gama.

\subsubsection{Refletância das amostras artificiais}

A Figura 5.37 mostra os espectros de refletância obtidos das amostras artificiais dopadas com Al, Fe e Mn. Estas lâminas mostraram bandas na faixa entre 250 e

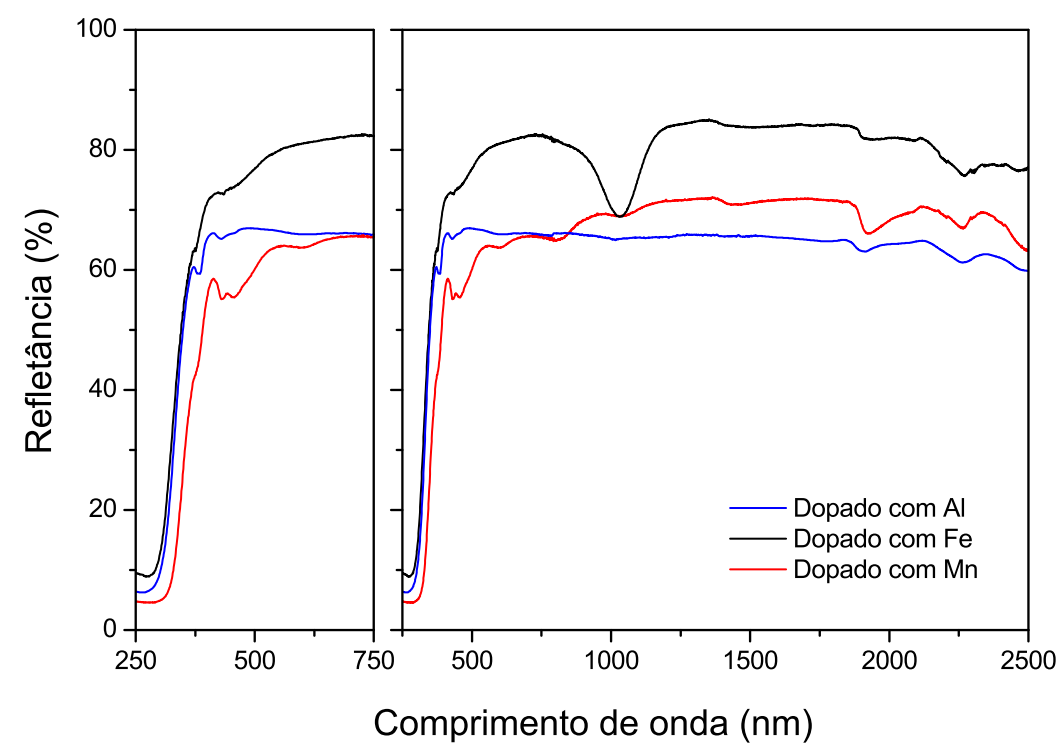

Figura 5.37: Espectro de refletância das amostras artificiais. 
$2500 \mathrm{~nm}$, podendo ser destacada a banda em $1050 \mathrm{~nm}$ na amostra do diopsídio dopado com Fe. As bandas, já citadas, em 1390 nm (muito fraca) e em 1910 nm e 2310 nm aparecem em todas as amostras. Nota-se, também, bandas em 380, 430 e 456 nm (Figura 5.38), além da banda intensa na região de UV próxima.

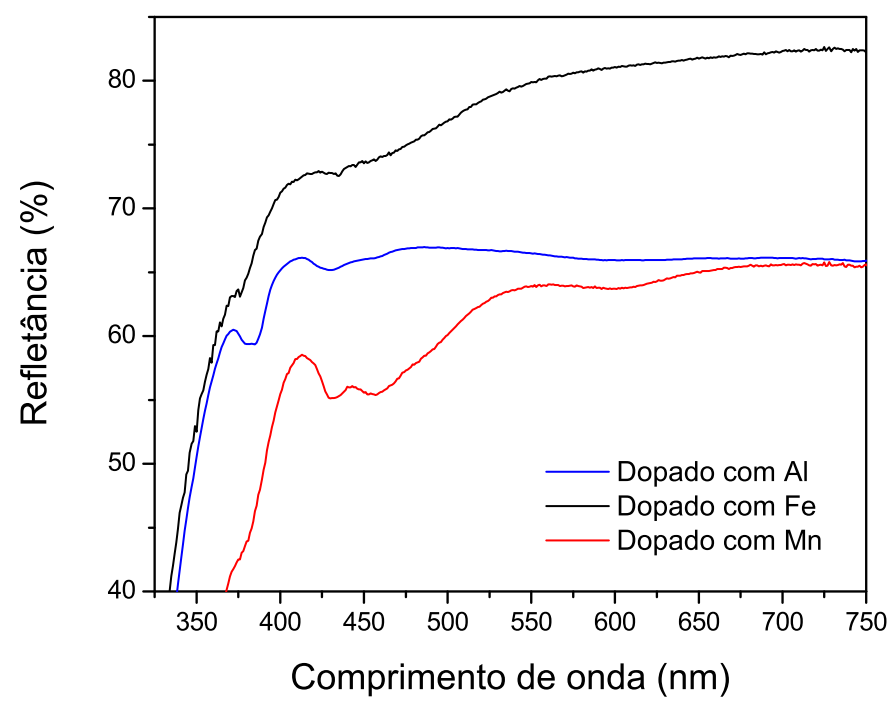

Figura 5.38: Espectro de refletância das amostras artificiais na faixa de $300 \mathrm{~nm}$ a $750 \mathrm{~nm}$.

\subsection{Medidas de RPE}

\subsubsection{Espectro RPE para amostra natural}

A Figura 5.39 apresenta o espectro de RPE do diopsídio natural em pó, no intervalo de 700 até 6500 Gauss para uma potência de microndas de $20 \mathrm{~mW}$. Observa-se que há sinais bem intensos na região de 3000 a 4000 Gauss, típicos de $\mathrm{Mn}^{2+}$.

Depois de fazer medições do espectro da amostra natural, foi feito um teste do comportamento dos sinais com a potência de microondas, para assim encontrar a potência adequada que nos proporcione a melhor medida do sinal sem chegar à saturação. Em geral todos os sinais crescem com a potência, obedecendo a uma curva de saturação, que se dá acima de cerca de $70 \mathrm{~mW}$. Como pode ser obvervado na Figura 5.40, a potência de $20 \mathrm{~mW}$ é razoável para fazer nossas medições de RPE, embora, talvez seja mais apropiado usar potência entre 35 e $38 \mathrm{~mW}$. 


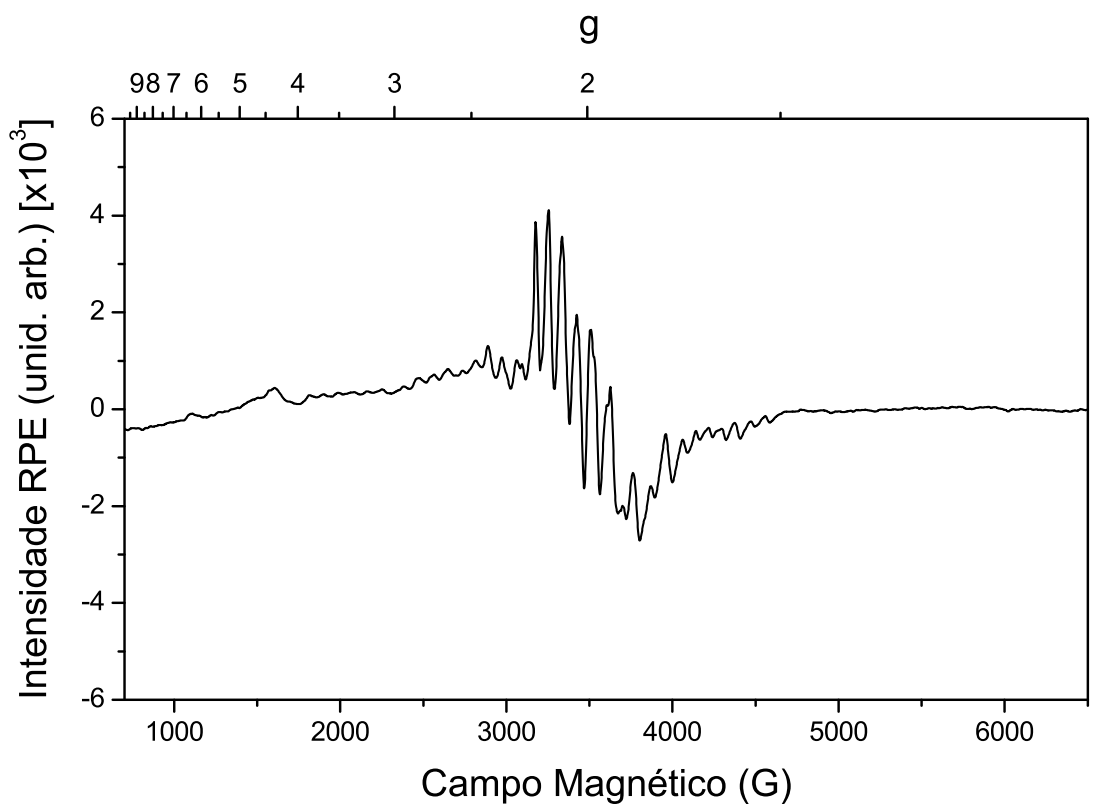

Figura 5.39: Espectro RPE da amostra natural com uma potência de microondas de $20 m W$.

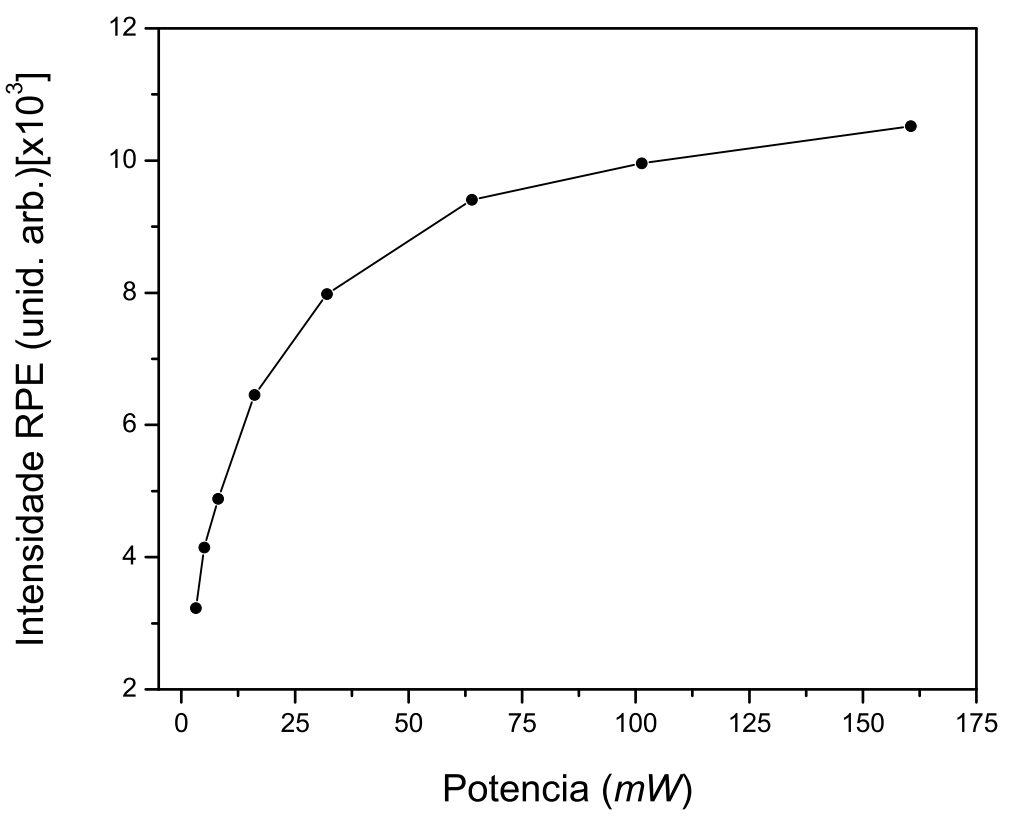

Figura 5.40: Intensidade RPE em função da potência de microondas para a amostra natural. Temperatura ambiente. 


\section{Efeito da irradiação gama}

Inicialmente foram realizadas medidas do espectro RPE em amostra natural irradiadas com diferentes doses de radiação gama na região de 700 a 6500 G (Figura 5.41). Não foi possível observar variações na intensidade dos sinais RPE com a dose aplicada. Para confirmar se os sinais RPE não apresentam nenhuma mudança, será mostrado mais adiante medidas em regiões especificas, principalmente em torno de 1500 de $3500 \mathrm{G}$.

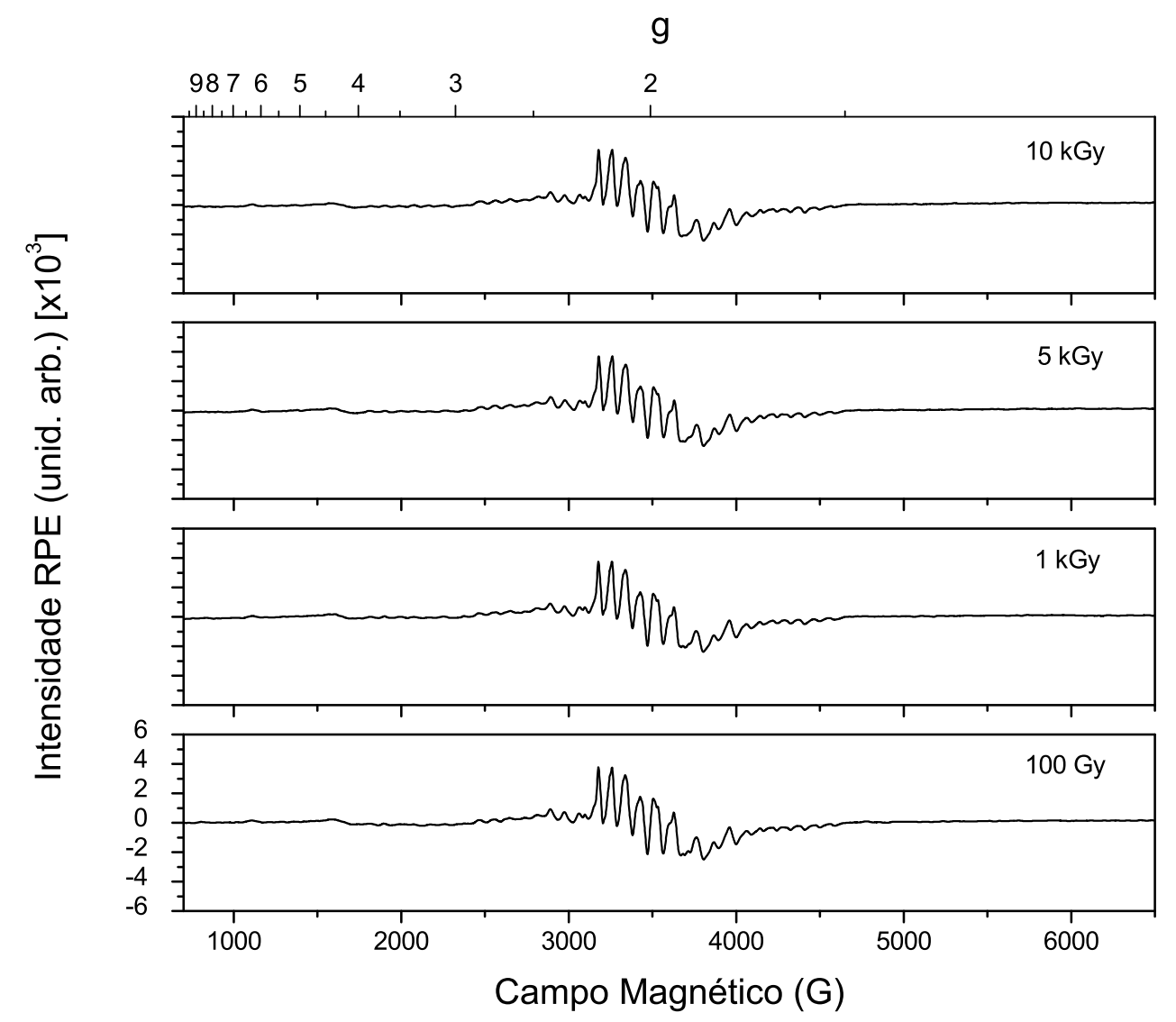

Figura 5.41: Espectro RPE da amostra de diopsídio natural submetida a diferentes doses de radiação gama.

\section{Efeito do tratamento térmico}

A amostra de diopsídio natural foi submetida a tratamentos térmicos no intervalo de 100 até $900{ }^{\circ} \mathrm{C}$ por uma hora e posterior leitura RPE sem qualquer dose gama adicional. A Figura $5.42 a$ e $5.42 \mathrm{~b}$ mostram o espectro RPE para as amostras com 
tratamento térmico em 400 e $900{ }^{\circ} \mathrm{C}$ respectivamente, no intervalo de 700 a 6500 G. Podemos ver sinais na região de 1000 a 2000 G e na região de 3000 a 4500 G. Para observar em detalhe o comportamento desses sinais foram mostrados em escalas adequadas (Figura 5.42c), os sinais na região de 1000 a 2000 G que são devidos a Fe ${ }^{3+}$ e já foram encontradas em outros cristais de silicatos. A variação da intensidade RPE em $g=4,3$ com tratamento térmico é mostrado na Figura 5.42d. Podemos observar que o tratamento térmico em $500{ }^{\circ} \mathrm{C}$ produz um incremento da intensidade RPE do sinal em $g=4,3$. Portanto poderíamos dizer que do recozimento resulta numa mudança de $\mathrm{Fe}^{2+}$ para $\mathrm{Fe}^{3+}$, por oxidação, fato que já foi observado nas medidas de refletância.

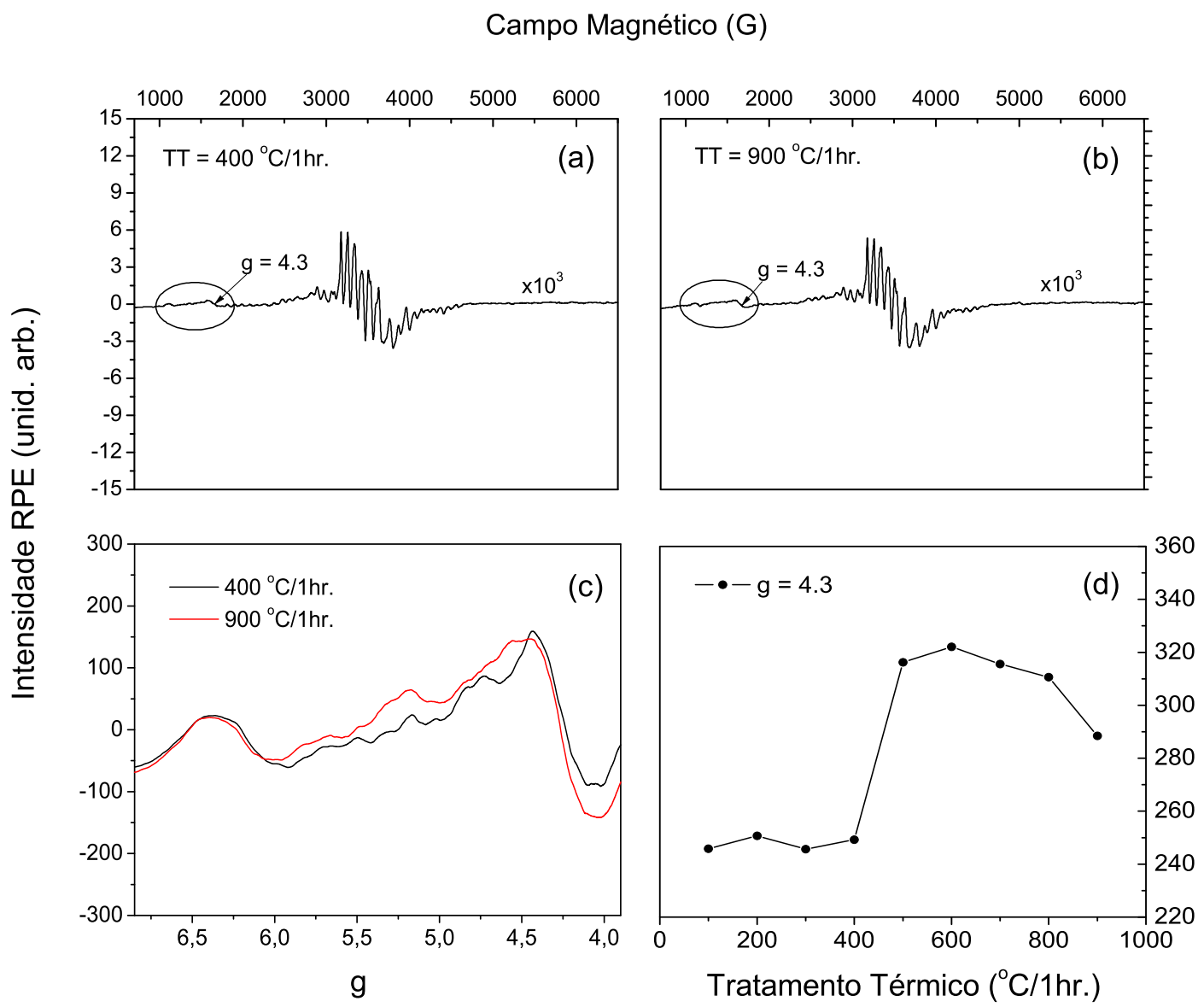

Figura 5.42: Efeito da temperatura do tratamento térmico sobre os espectros de RPE do diopsídio natural. (a)-Com TT=400 ${ }^{\circ} \mathrm{C} / 1 \mathrm{hr}$. (b)-Com TT=900 ${ }^{\circ} \mathrm{C} / 1 \mathrm{hr}$. (c) $-\mathrm{Na}$ região de 1000 a 2000 G. (d)-Comportamento da intensidade RPE em g=4,3 com a temperatura, é muito importante observar nesta figura o aumento na intensidade RPE, o que evidencia a mudança de $\mathrm{Fe}^{2+}$ a $\mathrm{Fe}^{3+}$. 


\section{Efeito do tratamento térmico e subseqüente irradiação gama}

Para estudar o comportamento das intensidades RPE do diopsídio natural com o tratamento térmico e subseqüente irradiação gama, especialmente para ver o efeito da irradiação gama na região de $g=2$, as medidas foram efetuadas irradiando as amostras depois de um pré-aquecimento em $300{ }^{\circ} \mathrm{C}$ por uma hora. É sabido que no quartzo para o tratamento térmico em $300{ }^{\circ} \mathrm{C}$, a concentração de centros $\mathrm{E}_{1}^{\prime}$ é máxima [67]. Esses centros diminuem ao mínimo com o tratamento térmico a $400{ }^{\circ} \mathrm{C}$ e por esta razão foi feito uma subtração das intensidades RPE das amostras tratadas termicamente em $400{ }^{\circ} \mathrm{C}$ e as de amostras irradiadas com diferentes doses gama, mas, tratadas termicamente em $300{ }^{\circ} \mathrm{C}$ por uma hora (Figura 5.43b). Na Figura 5.43c apresentamos o comportamento do sinal em $g=2,007$ em função da dose-gama.

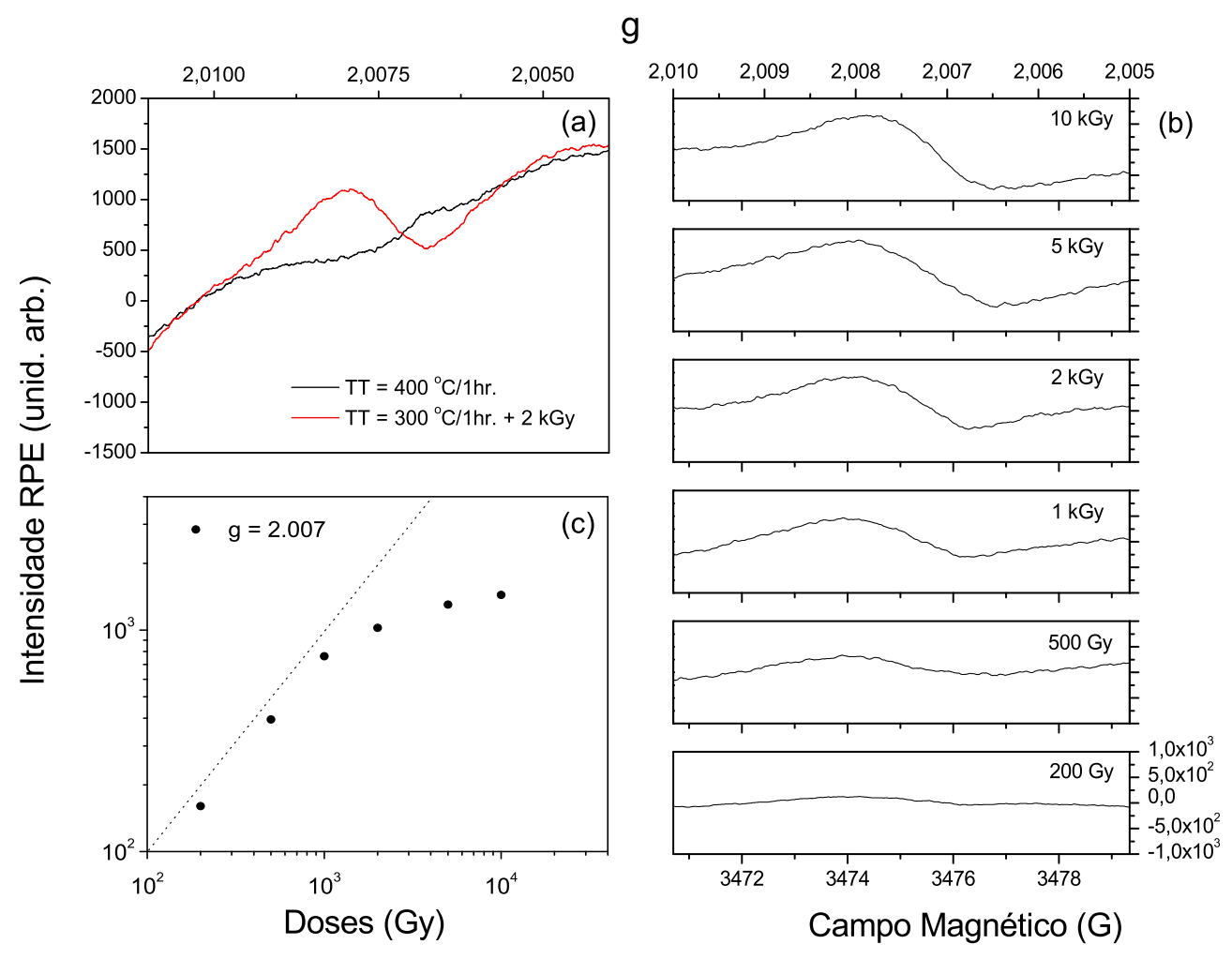

Figura 5.43: (a)-RPE do diopsídio natural com tratamento térmico em $400{ }^{\circ} \mathrm{C} / 1 \mathrm{hr}$. e, de uma amostra irradiada com $2 \mathrm{kGy}$ previamente aquecida em $300{ }^{\circ} \mathrm{C} / 1 \mathrm{hr}$. (b)-RPE obtido da subtração das intensidades RPE das amostras tratadas termicamente em $400^{\circ} \mathrm{C}$ as de amostras irradiadas com diferentes doses gama com pre-aquecimento em $300^{\circ} \mathrm{C}$. (c)-Comportamento das linhas de RPE em g=2,007 com a irradiação gama. 


\subsubsection{Espectro RPE em baixa temperatura (77 K)}

Com a finalidade de reduzir o efeito da vibração da rede cristalina, foram realizadas medidas de RPE em temperatura de nitrogênio líquido $(77 \mathrm{~K})$. As medidas a baixa temperatura foram feitas utilizando amostra de diopsídio natural em pó, colocada em tubos de quartzo, os tubos de quartzo foram colocados dentro de um dewar contendo nitrogênio liquido $(77 \mathrm{~K})$. Observa-se na Figura 5.44 os mesmos sinais já observados à temperatura ambiente com intensidade menor.

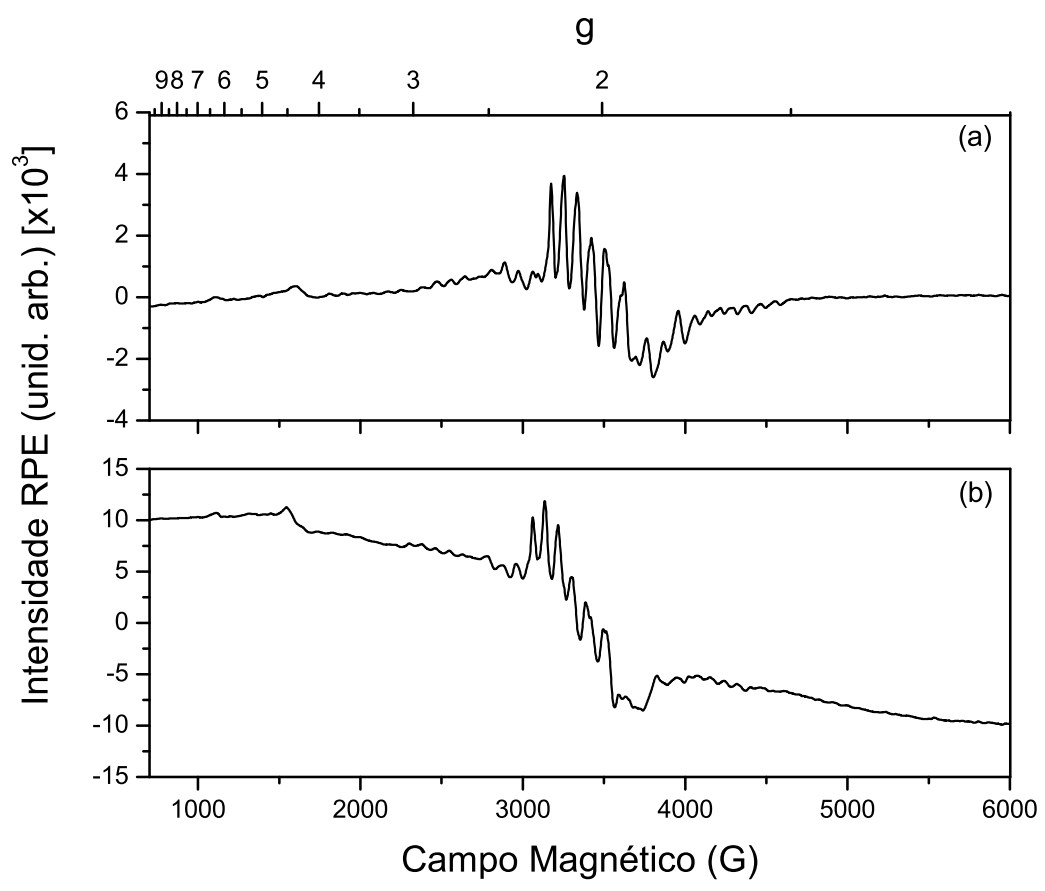

Figura 5.44: (a)-Espectro RPE da amostra natural a temperatura ambiente. (b)Espectro de RPE da amostra natural em baixa temperatura $(77 \mathrm{~K})$.

\subsubsection{Monocristal do diopsídio}

As medidas foram realizadas aplicando o campo magnético na direção $z$, o qual é facilmente identificável por ser normal ao plano de clivagem do diopsídio. Os espectros tomados com essa orientação do cristal mostram as linhas típicas do $\mathrm{Mn}^{2+}$ (Figura $5.45)$, de transição $-\frac{5}{2} \rightarrow-\frac{3}{2},-\frac{3}{2} \rightarrow-\frac{1}{2},-\frac{1}{2} \rightarrow \frac{1}{2}, \frac{1}{2} \rightarrow \frac{3}{2}$ e $\frac{3}{2} \rightarrow \frac{5}{2}$, linhas que, na amostra em pó não aparecem, exceto aqueles que aparecem entre 3000 e 4500 G. 


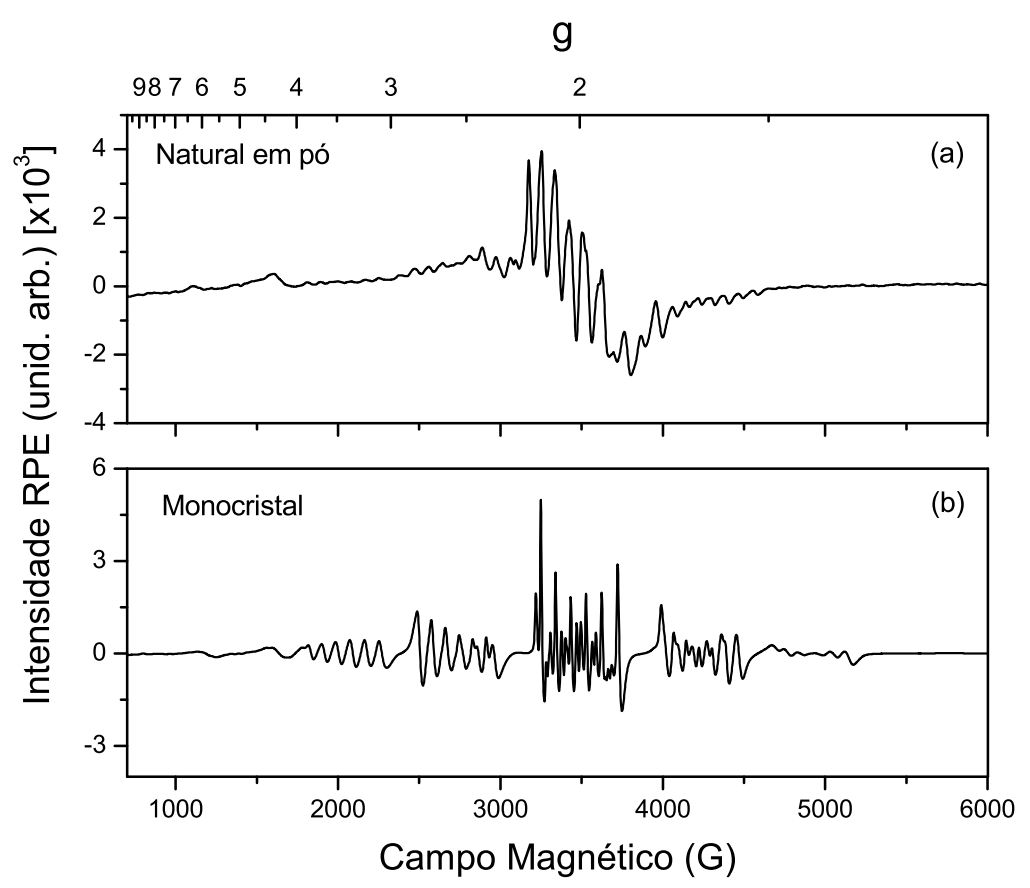

Figura 5.45: Espectro de RPE da amostra natural (a)-amostra em pó. (b)-Com campo magnético paralelo ao eixo-c.

\subsubsection{Espectro RPE das amostras artificiais}

Foram também feitas medidas de RPE em amostras artificiais de diopsídio em pó, puras e dopadas com Mn, Al e Fe. A Figura 5.46 mostra os espectros RPE desses amostras. Os sinais de $\mathrm{Mn}^{2+}$ são proeminentes na amostra dopada só com o manganês, assim como na amostra natural. Apesar dos óxidos de partida serem "puros", na amostra pura e nas dopadas com $\mathrm{Al}$ e $\mathrm{Fe}$, aparecem os sinais de $\mathrm{Fe}^{3+}$, tanto em $g=4,3$ como em torno de $g=2,0$.

Por outro lado a irradiação gama na amostra artificial pura, para doses entre 100 ate $10 \mathrm{kGy}$, produz intensidade RPE crescente em $g=2,007$ enquanto que, o sinal em $g=4,3$ não sofre uma mudança significativa com a dose (Figura 5.47). 


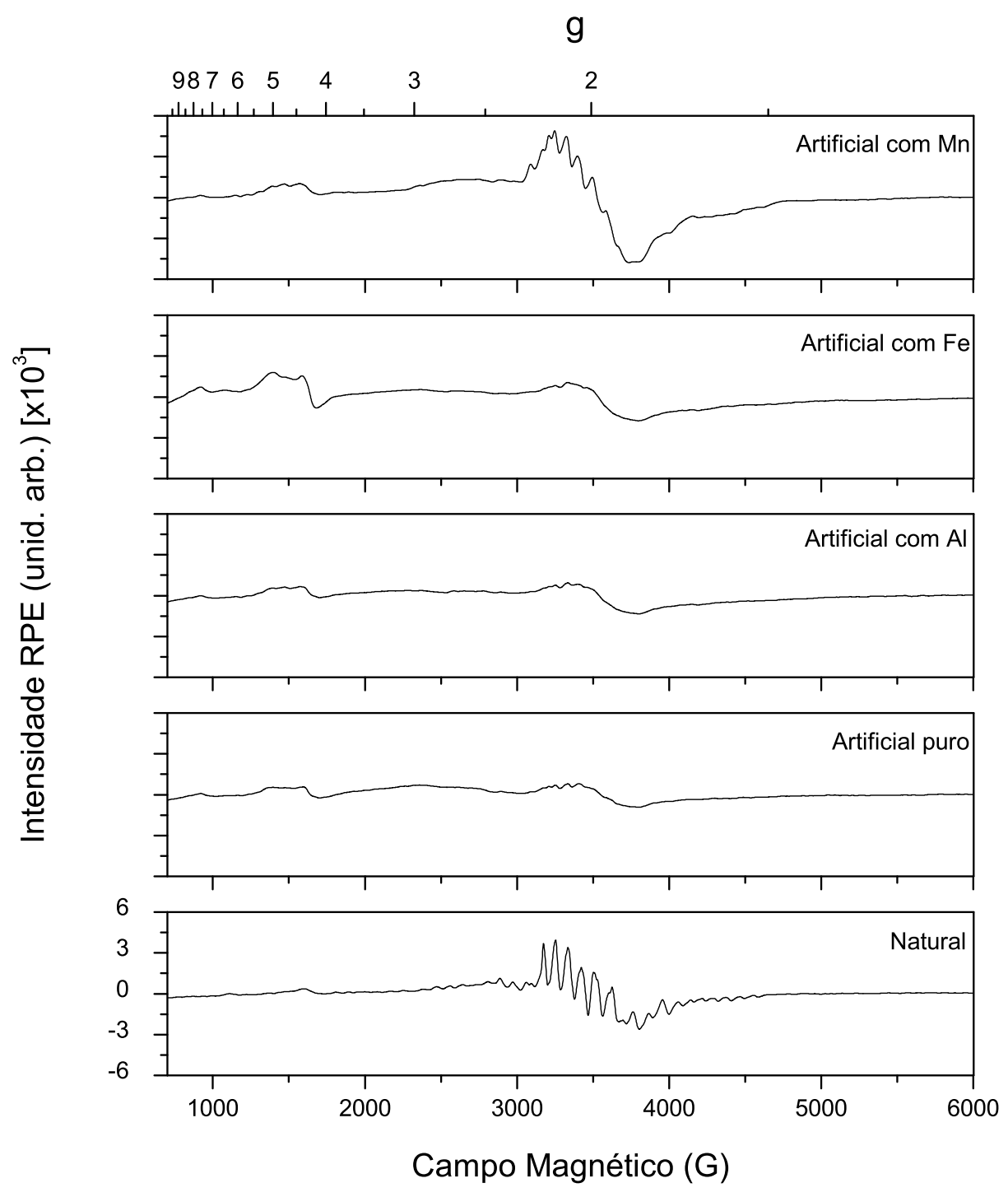

Figura 5.46: Espectro RPE da amostra natural e das amostras artificiais.

\subsection{Medidas no vidro de diopsídio}

O vidro de diopsídio é um co-produto, obtido com um esfriamento rápido dos graõs menores de 0,080 $\mathrm{mm}$ do diopsídio natural, fundido em forno de alta temperatura de $1500{ }^{\circ} \mathrm{C}$. Não se pretende, aqui estudar detalhadamente as propriedades físicas do vidro, sim, uma ou outra propriedade. 
g
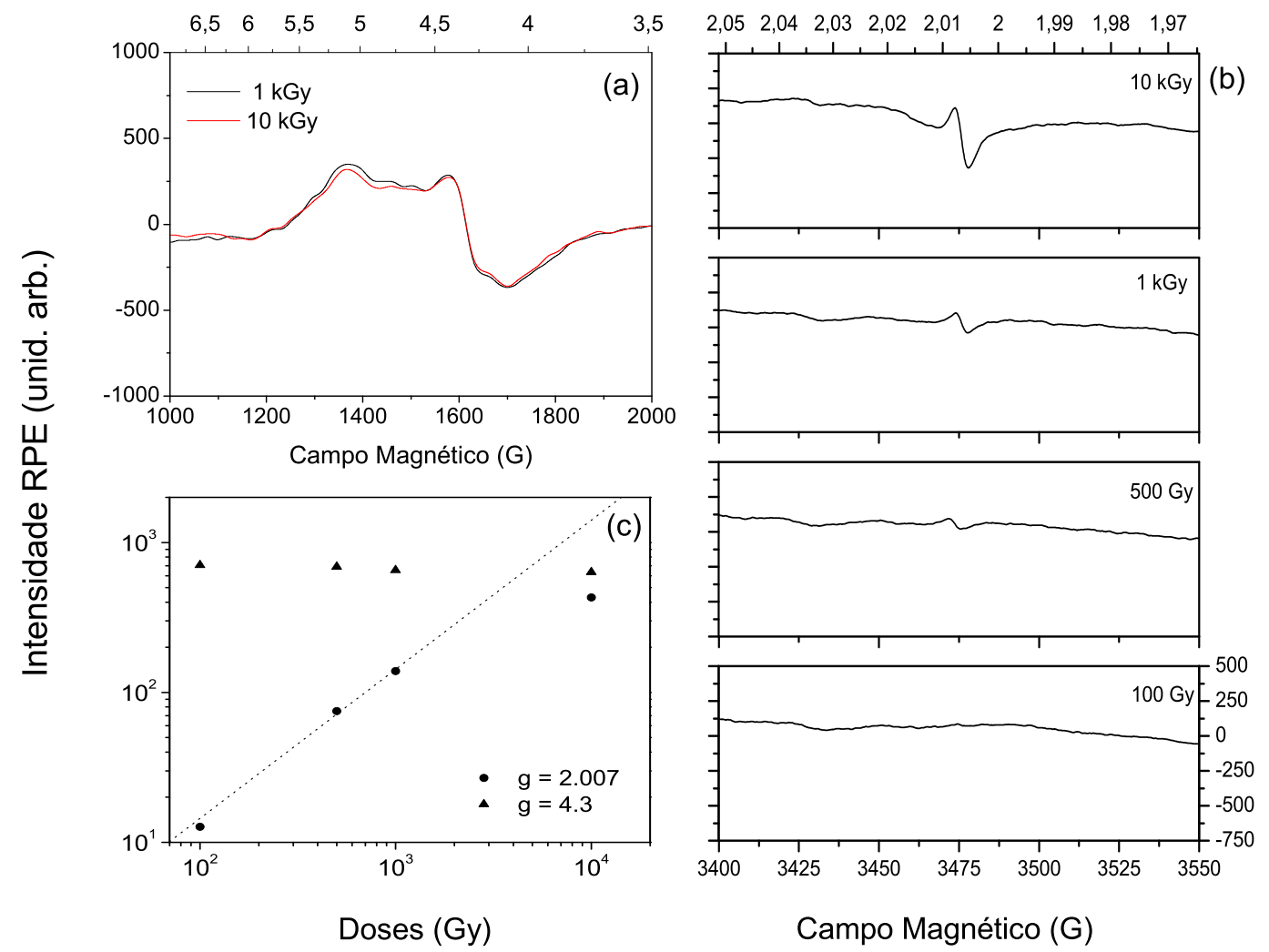

Figura 5.47: Espectro RPE da amostra pura submetida a diferentes doses de radiação gama. (a)-Em g=4,3 . (b)-Em g=2,007 . (c)-Comportamento da intensidade RPE em $g=2,007$ e $g=4,3$ com a irradiação gama.

\subsubsection{Ressonância paramagnética eletrônica}

Na Figura 5.48 apresenta-se o espectro de RPE da amostra de vidro de diopsídio (a) de 0 a 5000 Gauss e (b) de 2500 a 5000 Gauss. Na Figura 5.48a observa-se que aparecem linhas de RPE em três regiões. Essas linhas são atribuídas ao íon $\mathrm{Fe}^{3+}$ [68]. Desde os trabalhos pioneros de RPE em vidros, têm-se mostrado presentes nos espectros de vidros de silicatos, boratos e fosfatos.

O detalhe das linhas da terceira região é apresentado na Figura 5.48b. Nesta figura observam-se seis sinais que são característicos das linhas hiperfinas de íons de $\mathrm{Mn}^{2+}$.

Note-se que o sinal de Fe é 100 vezes mais intenso que o de $\mathrm{Mn}^{2+}$, o que não aconteceu no cristal de diopsídio. É provável que o aquecimento em $1400{ }^{\circ} \mathrm{C}$ para produzir o vidro, tenha transformado todos os íons de $\mathrm{Fe}^{2+}$ em íons de $\mathrm{Fe}^{3+}$. 


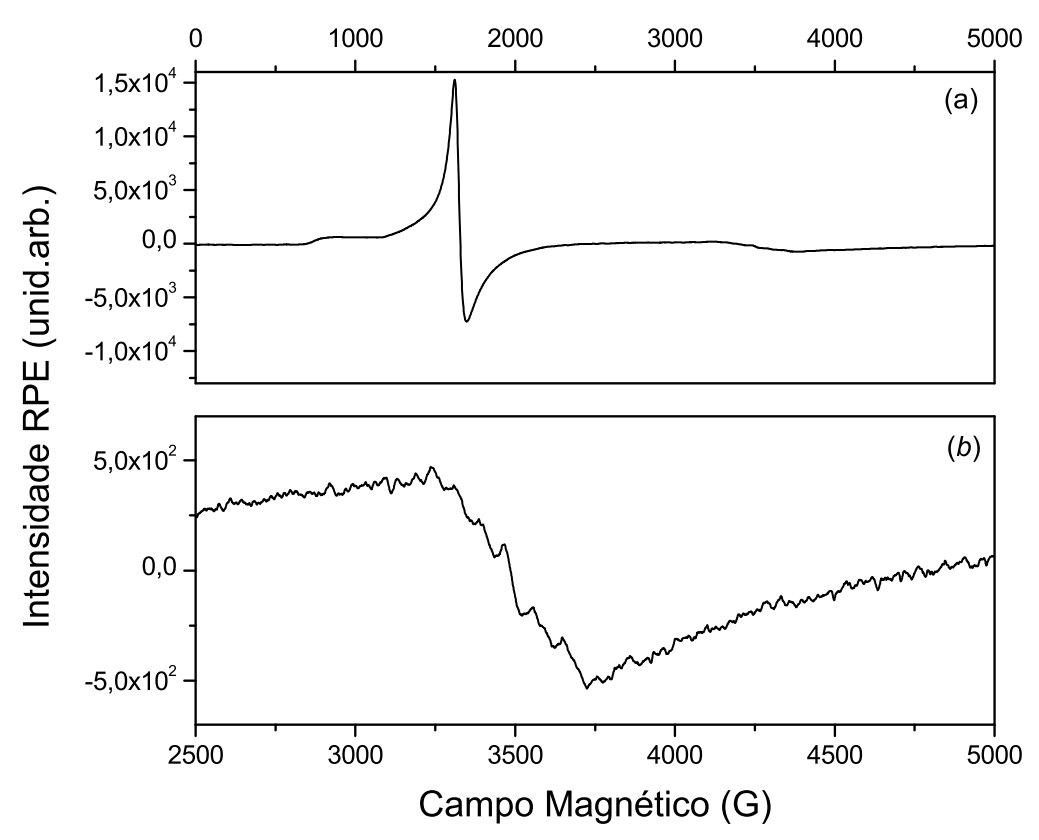

Figura 5.48: Espectro RPE do vidro de diopsídio (a) de 0 a 5000 G (b) de 2500 a 5000.

\subsubsection{Absorção Ótica}

A Figura 5.49 apresenta o espectro de absorção ótica do vidro de diopsídio. Na região do infravermelho observa-se uma banda com um máximo ao redor de 1000 nm (10000

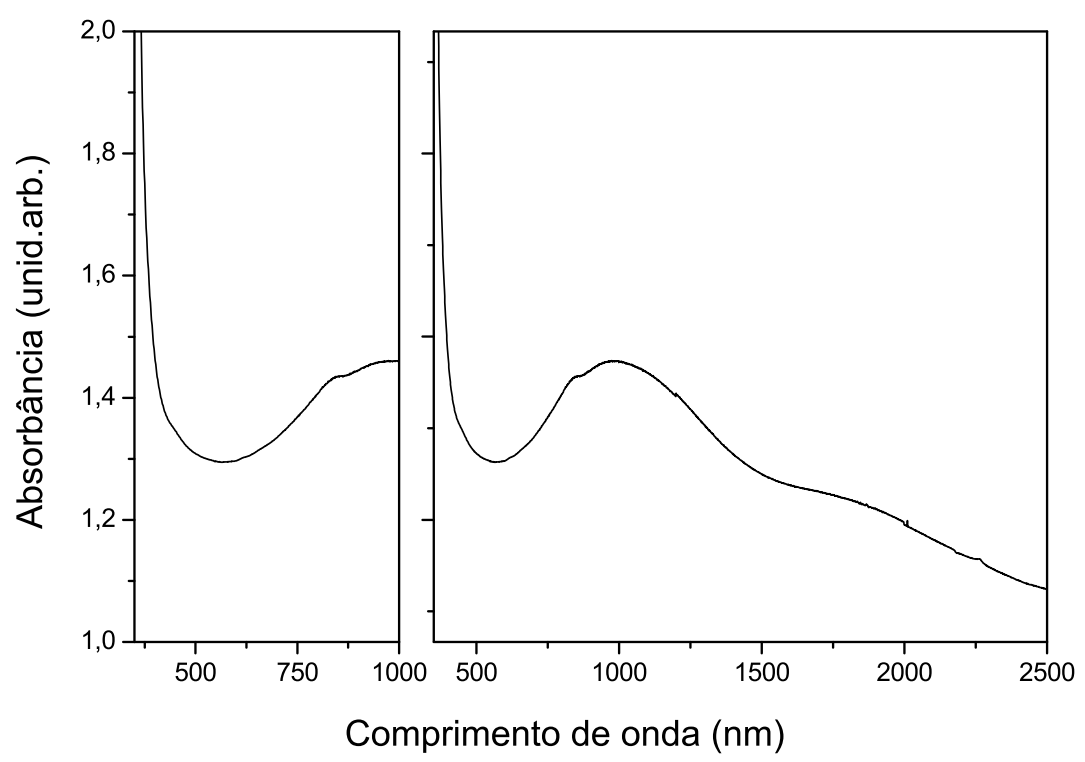

Figura 5.49: Espectro de absorbância do vidro de diopsídio. 
$\mathrm{cm}^{-1}, \mathrm{Fe}^{2+}$ ). Esta banda tem sido observada em diferentes tipos de vidros. A forte absorção UV permanece no vidro, o que quer dizer que o vidro de diopsídio pode ser usado para barrar as radiações UV. 


\section{6}

\section{Discussões}

A análise por fluorescência de raios X identificou uma lista grande de impurezas presentes no diopsídio por se tratar de um mineral natural, como pode ser visto na página 72. Como tem acontecido com outros minerais de silicatos, estudados no Laboratório de Cristais Iônicos, menos de cinco dessas impurezas contribuem para as propriedades investigadas no presente trabalho, são elas: $\mathrm{Al}_{2} \mathrm{O}_{3}(1,56 \% \mathrm{~mol}), \mathrm{Fe}_{2} \mathrm{O}_{3}(0,57 \% \mathrm{~mol})$ e $\mathrm{MnO}(0,013 \% \mathrm{~mol})$. É possível que $\mathrm{TiO}_{2}(0,065 \% \mathrm{~mol})$ e V $(15 \mathrm{ppm})$ tenham papel semelhante ao de $\mathrm{Al}_{2} \mathrm{O}_{3}$ e $\mathrm{Cr}$, respectivamente, pois, nesses cristais, o $\mathrm{Al}^{3+}$, freqüentemente substitui o $\mathrm{Si}$ no tetraedro $\mathrm{SiO}_{4}$; o mesmo tem sido observado com Ti, substituindo $\mathrm{Si}$ no $\mathrm{SiO}_{4}$; em alguns silicatos, o $\mathrm{Cr}$ e o V são responsáveis pela cor verde do mineral. O efeito do Ti e do V será estudado no futuro.

O confronto entre um cristal artificial puro ou dopado com concentração controlada de uma dada impureza, é importante para se ter idéia do papel dessa impureza e por isso, foram produzidos cristais de diopsídio puro ou com Al, Fe e Mn, usando a técnica de devitrificação. Em todos os casos foram constatados que a técnica de devitrificação de uma mistura estequiométrica de compostos, fundida e esfriada controladamente, produz um policristal de diopsídio, cujas propriedades são semelhantes a da amostra natural. A técnica de devitrificação é um processo simples e rápido comparado com outras técnicas de obtenção de cristais (sol-gel ou hidrotérmico). Embora não seja 
possível obter um monocristal, o produto policristalino puro ou dopado serve para o estudo de algumas propriedades do cristal. Os difratogramas dessas amostras, incluindo os da amostra natural, estão apresentados na Figura 5.2 e, para comparação, o do diopsídio padrão (os dados de difração do padrão são de File No 27-88 JCPDSICDD, que possui os dados de difração de raios X). Exceto pela linha em $20 \simeq 22$ graus, que é de cristobalita, o restante é igual. De qualquer modo, todas as amostras têm, sem dúvida, a estrutura cristalina de diopsídio.

Não foram encontrados na literatura, trabalhos que mencionem o estudo da termoluminescência do diopsídio por outros autores.

A curva de emissão TL de uma amostra natural, previamente recozida a $600{ }^{\circ} \mathrm{C}$ para eliminar o efeito da radiação natural, apresenta picos TL em $160-170{ }^{\circ} \mathrm{C}, 205-215$ ${ }^{\circ} \mathrm{C}, 220-230{ }^{\circ} \mathrm{C}, 350-370{ }^{\circ} \mathrm{C}$ e $465-475{ }^{\circ} \mathrm{C}$.

A partir da deconvolução da curva de TL é possível visualizar os picos que não são facilmente destacados devido à forte superposição dos picos. Da deconvolução (Figura 5.21) pode-se ver que a curva de emissão TL é formada por cinco picos em 160, 197, 230, 300 e $350{ }^{\circ} \mathrm{C}$. Assim, o processo TL do diopsídio, pode ser explicar com cinco tipos de armadilhas de elétrons com energias de ativação, em aproximadamente 0,918, $0,966,1,117,1,321$ e $1,490 \mathrm{eV}$, respectivamente.

A Figura 5.18 mostra curvas de emissão de amostras submetidas a aquecimentos isócronos em $120{ }^{\circ} \mathrm{C}, 160{ }^{\circ} \mathrm{C}$, etc., até $360{ }^{\circ} \mathrm{C}$. As áreas das curvas foram plotadas em função de temperatura e a derivada primeira desta curva é mostrada na Figura 5.19b. A curva da derivada primeira mostra a ocorrência de picos TL em torno de $150{ }^{\circ} \mathrm{C}$, $230{ }^{\circ} \mathrm{C}, 300{ }^{\circ} \mathrm{C}$ e, $360{ }^{\circ} \mathrm{C}$.

As curvas de emissão TL da amostra artificial pura, mostra, primeiro, que os picos em torno de $150-160{ }^{\circ} \mathrm{C}$ e entre $205{ }^{\circ} \mathrm{C}$ e $315{ }^{\circ} \mathrm{C}$ são devido a defeitos intrínsecos. O pico largo centrado em torno de $275-280{ }^{\circ} \mathrm{C}$ pode ser proveniente da superposição dos picos em $205-215{ }^{\circ} \mathrm{C}$ e $350-375{ }^{\circ} \mathrm{C}$.

$\mathrm{Na}$ amostra artificial pura, o pico em 150 - $160{ }^{\circ} \mathrm{C}$ é menor do que os que aparecem na região de $210{ }^{\circ} \mathrm{C}$ a $350{ }^{\circ} \mathrm{C}$, comparado com o que acontece com a amostra natural, Figura 5.9. Sabe-se que alguns elementos, principalmente o ferro, é considerado "killer", isto é, o seu efeito é de abafar parcialmente a emissão TL. De fato, a amostra artificial dopada só com ferro, produziu TL de intensidade cerca de 100 vezes menor, Figura 5.32. Esta figura mostra ainda que, o pico em $430-450{ }^{\circ} \mathrm{C}$ é devido ao ferro, possivelmente $\mathrm{Fe}^{3+}$ que, aliás não é afetado pela irradiação. Na página 152 do seu livro "Thermoluminescence of Solids, Cambridge U. Press, 1985", McKeever [40] escreve: "in an effect, known as impurity quenching, is thought to occur via the action of killer 
centers; upon introducing certain elemental impurities into a material, especially heavy metals such as $\mathrm{Cu}, \mathrm{Fe}, \mathrm{Co}, \mathrm{Ni}$ and $\mathrm{Cr}$, the intensity of the luminescence emission is seen to reduce drastically".

Pode-se pensar, então, que a presença de ferro afetou mais os picos em temperatura acima de $200{ }^{\circ} \mathrm{C}$, no caso de Figura 5.9, enquanto que, na Figura 5.28, a ausência de ferro permitiu o crescimento, mais do que o de temperaturas baixas.

O resultado apresentado na Figura 6.1 mostra que, o alumínio não afetou o pico em 150 - $160{ }^{\circ} \mathrm{C}$, mas não deixou crescer muito os de temperaturas altas; o manganês afetou parcialmente o crescimento do pico em $150-160{ }^{\circ} \mathrm{C}$, mas, nada afetou os picos entre $250{ }^{\circ} \mathrm{C}$ e $350{ }^{\circ} \mathrm{C}$.

Note-se que, exceto pela amostra artificial dopada com Al, as intensidades dos picos TL da amostra natural crescem linearmente com a doses- $\gamma$ até cerca de $10^{3}$ Gy, saturando-se depois. Nenhuma supralinearidade foi registrada. A amostra sintética pura cresceu linearmente até cerca de $4 \times 10^{3}$ Gy, também sem supralinearidade. A ausência da supralinearidade é um fato notável também observado em outros silicatos; é um fenômeno observado e bem estudado em cristais de haletos, sulfatos, carbonatos e óxidos.

Mische \& McKeever [55], propõem a existência de dois grupos de armadilhas de elétrons e buracos, em equilíbrio. O primeiro grupo é o de armadilhas de elétrons e buracos formando pares, o segundo grupo não. Os dois grupos de centros têm

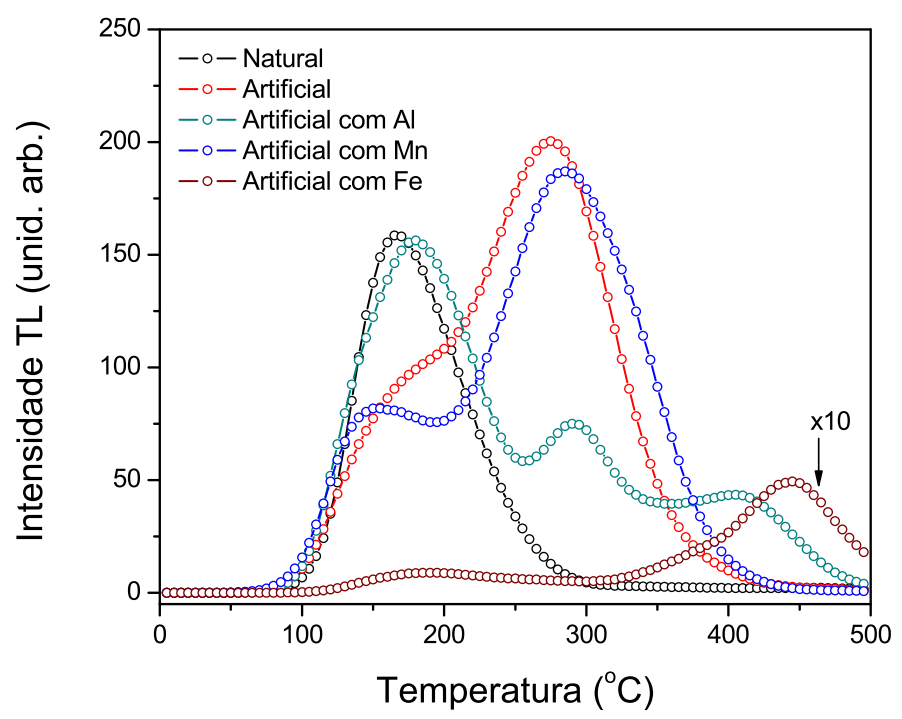

Figura 6.1: Comparativo entre as intensidades TL da amostra natural e das amostras artificiais submetidas a uma dose de 1 kGy. 
uma distribuição isotrópica. Nesse modelo, tanto as armadilhas de elétrons e buracos pareados como os não pareados contribuem para a emissão TL. As armadilhas de elétrons e buracos pareados dão origem à parte linear, e as outras armadilhas não preenchidas de elétrons e buracos que não formam pares podem capturar elétrons e buracos liberados por aquecimento da banda de condução, competindo com os buracos ou elétrons dos centros de recombinação. A competição dá origem ao comportamento supralinear da resposta TL com a dose.

Sunta et al. [56] para explicar o fenômeno de supralinearidade admite que as armadilhas TL são compostas de duas espécies, uma que ao liberar os elétrons por aquecimento, estes se recombinam com buracos no centro de recombinação e emitem luz TL; a outra espécie libera os elétrons que seguem dois caminhos, um leva-os ao centro de recombinação emitindo a luz TL, e o outro a armadilhas profundas (consideradas também armadilhas termicamente desconectadas) sem emissão de luz TL. A primeira espécie de armadilhas dá origem à parte linear, enquanto que a outra dá à resposta supralinear.

O fato de não ter sido observado supralinearidade no diopsídio indica que, ou só há armadilhas pareadas no modelo de Mische \& McKeveer, ou ausência de competidores (armadilhas profundas termicamente desconectadas) no modelo de Sunta. Por que? Ainda não sabemos.

No estudo do efeito da irradiação com luz UV, foi usada uma amostra natural irradiada com $5 \mathrm{kGy}$ de raios- $\gamma$. O pico em $160{ }^{\circ} \mathrm{C}$ era tão proeminente, que, os outros não foram visíveis, por isso, só foi estudado o efeito UV neste pico, que se mostrou muito sensível, como se vê na Figura 5.25. Em 35 min de irradiação, a intensidade TL caiu para $1 / e$ da intensidade inicial $I_{0}$. Deixou, porem, um resíduo de $1 / 40$ de $I_{0}$.

Nos silicatos, já estudados, foi observada a indução de TL pela luz UV. Aliás, foram Blak \& McKeever [69] os que observaram, pela primeira vez, este efeito no berilo, que é, também, um silicato: $\mathrm{Be}_{3} \mathrm{Al}_{2} \mathrm{Si}_{6} \mathrm{O}_{18}$. Sabe-se que, um fóton de UV de $220 \mathrm{~nm}$ (menor $\lambda$ ) tem uma energia de cerca de 5,64 eV. Como o "band gap" num silicato é maior do que $7 \mathrm{eV}$, um fóton $\mathrm{UV}$ de $5,64 \mathrm{eV}$ de energia não seria capaz de promover um elétron da BV para a $\mathrm{BC}$ e, em conseqüência, um fóton UV não poderia induzir termoluminescência. Em 1931, Göppert-Mayer [60] haviam mostrado que há uma probabilidade nada pequena de haver absorção de dois fótons, que foi denominada de processo de dois fótons. Com isso, o elétron ganha energia suficiente para ser promovido para a BC e sendo em seguida capturado por uma armadilha, induzindo a TL.

As curvas de emissão para diferentes tempos de exposição à luz UV mostram, por 
outro lado, uma diferença comparada com as das amostras irradiadas com raios- $\gamma$, Figura 5.7. Um pico em $90{ }^{\circ} \mathrm{C}$ é observado agora, mas os de $205-215{ }^{\circ} \mathrm{C}$ e de $305-$ $315^{\circ} \mathrm{C}$ não são induzidos. O pico em $170{ }^{\circ} \mathrm{C}$ é bem estreito. Por que essa diferença? Afinal, a luz TL é emitida quando o cristal é aquecido e os elétrons armadilhados são liberados e se recombinam com os buracos dos centros de recombinação. Aqui, também, não se encontrou explicação.

Enfim, fica a pergunta: "por que a luz UV faz com que os elétrons promovidos para a $\mathrm{BC}$, procurem armadilhas das quais resultam o pico em $90{ }^{\circ} \mathrm{C}$ e, porque as armadilhas que dão origem aos picos na região de $200{ }^{\circ} \mathrm{C}$ a $320{ }^{\circ} \mathrm{C}$ não capturam elétrons de UV?"

Em outros minerais de silicatos, já estudados, foi observado o efeito, também, encontrado no diopsídio, a saber, o recozimento, antes de irradiação, em temperaturas de $700{ }^{\circ} \mathrm{C}, 800{ }^{\circ} \mathrm{C}$ a $900{ }^{\circ} \mathrm{C}$, aumenta, sensivelmente, a resposta TL do material de silicato. Como se vê na Figura 5.17b, esse efeito atinge o seu máximo entre $900{ }^{\circ} \mathrm{C}$ e $1000{ }^{\circ} \mathrm{C}$; apartir dessas temperaturas, o efeito é drasticamente reduzido, o que é fácil de entender, pois, o diopsídio está entrando na zona de pré-fusão (quebra de unidades estruturais, tais como os octaedros).

Para entender esse efeito de recozimento de uma amostra de diopsídio, em altas temperaturas, invocamos dois fatos:

1. Os picos TL entre $150{ }^{\circ} \mathrm{C}$ e $300{ }^{\circ} \mathrm{C}$ são devido a defeitos intrínsecos; entre estes os predominantes são as vacâncias de oxigênio, relacionados a centros $\mathrm{E}_{1}^{\prime}$.

2. Sabe-se que a concentração de vacâncias num cristal iônico aumenta com a temperatura.

Então se compreende porque o aquecimento do diopsídio em $900-1000{ }^{\circ} \mathrm{C}$ aumenta sua sensibilidade TL.

O espectro da luz TL, Figura 5.22, tem uma só banda, em torno de $435 \mathrm{~nm}$. Isto significa que, só há um centro de recombinação. Qualquer elétron (buraco), que chegou na BC (BV), quando o cristal é aquecido para a leitura TL, necessariamente recombina-se com o buraco (elétron) num único centro de recombinação. Na realidade, não há evidência de que o calor libera o elétron, que procura o centro de buraco para se recombinar. É possível que o calor libere o buraco, que procura o elétron para se recombinar. A condutividade termicamente estimulada (CTS) consiste em capturar os elétrons na BC, antes de se recombinarem com os buracos, isto é, ao se detectar CTS, pode ser provado de que os elétrons são liberados pelo calor, no processo de leitura TL. Este experimento não foi realizado por dificuldade técnica. No futuro será montado um sistema de medição da corrente termicamente estimulada. 


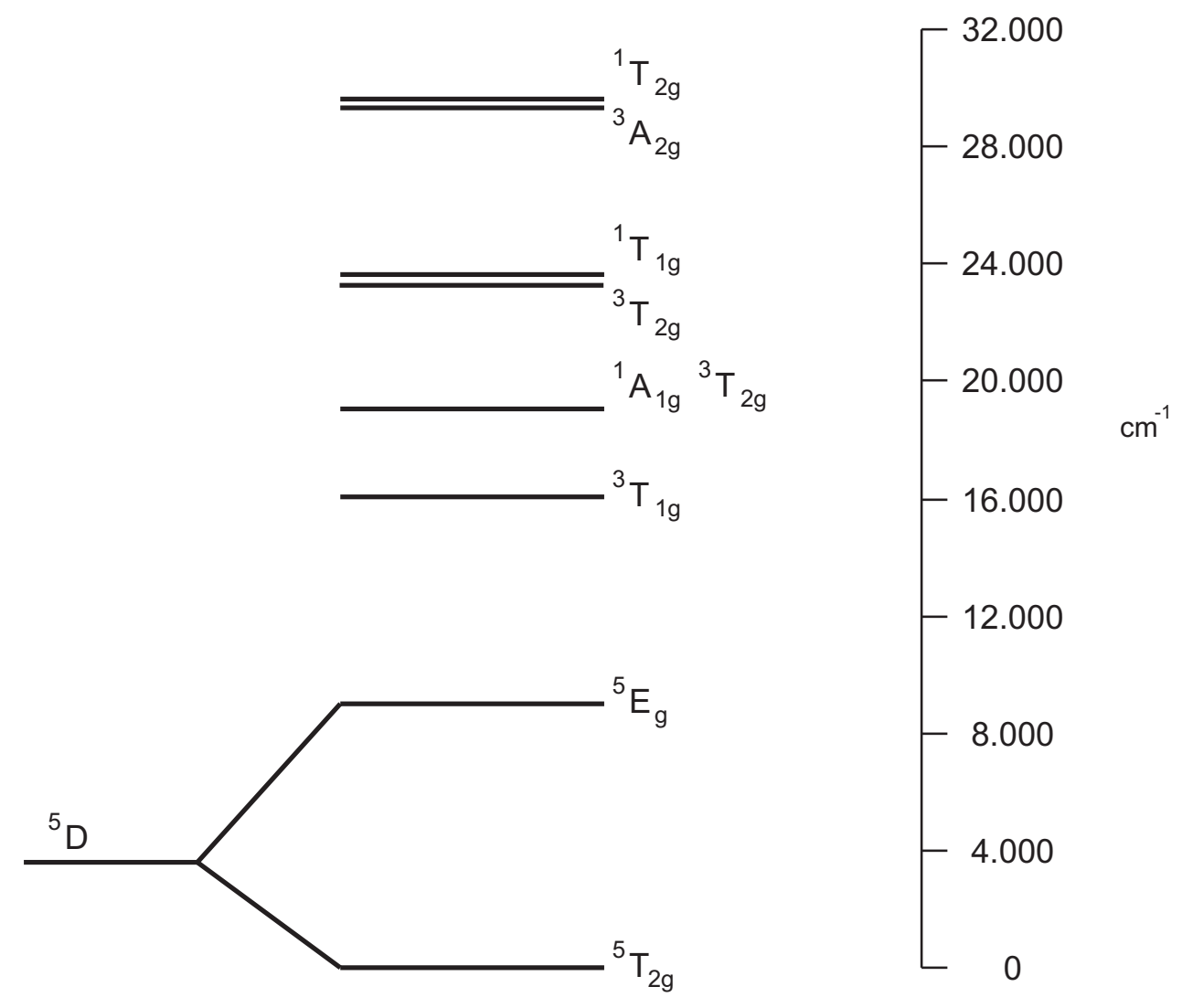

Figura 6.2: Esquema de niveis de energia do ion $\mathrm{Fe}^{2+}$ num campo de simetria octaedrica.

Na Figura 5.36 foram apresentados os espectros de refletância do diopsídio natural. Na região visível predomina a refletância, por isso, o diopsídio natural é branco. Observa-se também que há uma forte absorção no ultravioleta, que se estende até o azul. No infravermelho, há várias bandas de absorção, a mais intensa se dá em torno de $1050 \mathrm{~nm}$ e, é bastante larga, estendendo-se até a região do amarelo; a segunda mais intensa, porém, estreita ocorre em torno de $1910 \mathrm{~nm}$ que, como a banda de absorção em torno de $1310 \mathrm{~nm}$, são devido à água e/ou hidroxila [30, 29].

Os íons do elemento de transição, entre os quais o ferro e o manganês, são os mais comumente encontrados nos cristais de silicatos e entram como impurezas na estrutura do cristal em posições do interior de um poliedro regular (ou as vezes num poliedro um tanto distorcido), cujos vértices são ocupados por íons de oxigênio. Os íons de oxigênio são chamados de ligantes, criando o que é chamado de campo cristalino. O campo cristalino atua sobre o íon de transição, alterando a estrutura de seus níveis de energia. A presença de íon ferroso substituindo o Mg é muito comum em diopsídio [30]. O íon ferroso $\mathrm{Fe}^{2+}\left(3 \mathrm{~d}_{6},{ }^{5} \mathrm{D}\right)$ num ambiente cristalino de simetria octaédrica, $O_{h}$, se desdobra em dois estados multieletrônicos, ${ }^{5} \mathrm{E}_{g}$ e ${ }^{5} \mathrm{~T}_{2 g}$, Figura 6.2 [26]. A única 
transição permitida de spin, ${ }^{5} \mathrm{~T}_{2 g} \rightarrow{ }^{5} \mathrm{E}_{g}$, resulta em uma banda bem intensa em torno de $\sim 1000 \mathrm{~nm}$. As transições do nível fundamental ${ }^{5} \mathrm{~T}_{2 g}$, a outros níveis de maior energia, são proibidas pelo spin e dão origem a bandas de baixa intensidade: para ${ }^{3} \mathrm{~T}_{1 g}$ em $\sim 550 \mathrm{~nm}$, para ${ }^{1} \mathrm{~A}_{1 g}$ em $\sim 510 \mathrm{~nm}$, para ${ }^{3} \mathrm{~T}_{2 g}$ em $\sim 450 \mathrm{~nm}$, e para ${ }^{3} \mathrm{~T}_{1 g}$ em $\sim 430 \mathrm{~nm}$.

Pelo considerado acima, no espectro de refletância a banda bem intensa em $1050 \mathrm{~nm}$ de absorção é devido ao $\mathrm{Fe}^{2+}$ e tem sido observado em outros cristais de silicatos [26]; tem seu coeficiente de absorção variando entre $70 \%$ a $90 \%$. Aliás, a mesma banda em $1050 \mathrm{~nm}$ também foi observada no diopsídio artificial dopado com Fe, Figura 5.46. As outras transições de spin proibido do íon ferroso não foram encontradas no diopsídio natural estudado neste trabalho, exceto a transição proibida $\left[{ }^{5} \mathrm{~T}_{2 g} \rightarrow{ }^{3} \mathrm{~T}_{1 g}\right]$ que produz uma banda em torno de $430 \mathrm{~nm}$ nos cristais artificiais de diopsídio.

O íon manganês $\mathrm{Mn}^{2+}\left(3 \mathrm{~d}^{5},{ }^{6} \mathrm{~S}\right)$ em geral não tem bandas permitidas de spin, pois seu estado fundamental é simétrico e não é desdobrado pelo campo cristalino. Em um ambiente cristalino octaédrico, o estado atômico fundamental ${ }^{6} \mathrm{~S}$ do íon $\mathrm{Mn}^{2+}$ é o nível ${ }^{6} \mathrm{~A}_{1 g}$. As transições proibidas de spin do estado fundamental ${ }^{6} \mathrm{~A}_{1 g}$ a níveis de maior energia são: ${ }^{6} \mathrm{~A}_{1 g} \rightarrow{ }^{4} \mathrm{~T}_{1 g}$ em $340 n m,{ }^{6} \mathrm{~A}_{1 g} \rightarrow{ }^{4} \mathrm{E}_{g}$ em $370 n m,{ }^{6} \mathrm{~A}_{1 g} \rightarrow\left[{ }^{4} \mathrm{~A}_{1 g},{ }^{4} \mathrm{E}_{g}\right]\left({ }^{4} \mathrm{G}\right)$ em $410 \mathrm{~nm},{ }^{6} \mathrm{~A}_{1 g} \rightarrow{ }^{4} \mathrm{~T}_{2 g}\left({ }^{4} \mathrm{G}\right)$ em $450 \mathrm{~nm}$ e, ${ }^{6} \mathrm{~A}_{1 g} \rightarrow{ }^{4} \mathrm{~T}_{1 g}\left({ }^{4} \mathrm{G}\right)$ em $550 \mathrm{~nm}[29,30]$.

As únicas bandas do íon $\mathrm{Mn}^{2+}$ encontradas nos cristais artificiais do diopsídio em torno de $380 \mathrm{~nm}$ e $455 \mathrm{~nm}$ correspondem às transições de $\left[{ }^{6} \mathrm{~A}_{1 g} \rightarrow{ }^{4} \mathrm{E}_{g}\right]$ e $\left[{ }^{6} \mathrm{~A}_{1 g} \rightarrow{ }^{4} \mathrm{~T}_{2 g}\left({ }^{4} \mathrm{G}\right)\right]$ respectivamente.

A irradiação não afeta as bandas, mas, há nítido efeito térmico. A absorção aumenta em toda a faixa do visível, chegando a mais de $70 \%$ em $900{ }^{\circ} \mathrm{C}$; as bandas de refletância em torno de $1050 \mathrm{~nm}$ e $1390 \mathrm{~nm}$ diminuem até cerca de $450{ }^{\circ} \mathrm{C}$, depois aumentam até cerca de $800{ }^{\circ} \mathrm{C}$ a $880{ }^{\circ} \mathrm{C}$, voltando a diminuir. A diminuição das bandas de refletância em 1390 e 1910 nm, indicam que as moleculas de água e/ou hidroxila são liberadas mais ou menos continuamente com o tratamento térmico.

A presença de $0,013 \%$ mol de $\mathrm{MnO}$ dá origem ao espectro típico de linhas hiperfinas de $\mathrm{Mn}^{2+}$ da Figura 5.48. Como era de se esperar, ele não é afetado pela radiação- $\gamma$ e nem pelo calor, como se vê nas Figuras 5.50 e 5.51 .

Por outro lado, o sinal de $g=4,3$, típico do $\mathrm{Fe}^{3+}$, não é afetado pela radiação, mas, apresenta uma variação entre 400 e $450{ }^{\circ} \mathrm{C}$ sofrendo um aumento por um fator de cerca de 1,3, mantendo-se constante depois e só diminuindo pouco para temperaturas acima de $800{ }^{\circ} \mathrm{C}$. Na parte de refletância, vimos que a banda em $\sim 1050 \mathrm{~nm}$ devido ao $\mathrm{Fe}^{2+}$ sofre uma diminuição em $400{ }^{\circ} \mathrm{C}$, recuperando-se para temperaturas maiores. Isto permite a interpretação de que o $\mathrm{Fe}^{2+}$ se converte $\mathrm{em} \mathrm{Fe}^{3+}$ nessa região de temperaturas. 
As medidas a baixas temperaturas mostraram as mesmas linhas de $\mathrm{Mn}^{2+}$ na região de 3000 a 4500 G. O sinal do $\mathrm{Fe}^{3+}$ em $g=4,3$ permaneceu invariável com a temperatura.

$\mathrm{O}$ espectro RPE do monocristal mostrou as linhas típicas do $\mathrm{Mn}^{2+}\left(-\frac{5}{2} \rightarrow-\frac{3}{2}\right.$, $-\frac{3}{2} \rightarrow-\frac{1}{2},-\frac{1}{2} \rightarrow \frac{1}{2}, \frac{1}{2} \rightarrow \frac{3}{2}$ e $\frac{3}{2} \rightarrow \frac{5}{2}$ ), porém não foi possível de se observar essas linhas em amostras em pó, exceto as linhas na região de 3000 a 4500 G. Um espectro muito similar foi encontrado por Michouler et al. [37] numa mostra de diopsídio monocristal aplicando o campo magnético na direção $z$.

A amostra artificial dopada com Mn apresenta um espectro RPE do $\mathrm{Mn}^{2+}$ na mesma região observada na amostra natural. Também há um sinal característico de $\mathrm{Fe}^{3+}$ em torno de $g=4,3$, para todas as amostras artificiais. Pode-se ver que esse sinal é mais intenso na amostra artificial dopada com Fe, o que era de se esperar. Outra linha que foi possível ver na amostra artificial foi em torno de $g \sim 2$, devido ao centro $\mathrm{E}^{\prime}{ }_{1}$, que é muito difícil de observar na amostra natural, pela presença das linhas do $\mathrm{Mn}^{2+}$.

Devido às linhas de $\mathrm{Mn}^{2+}$ encobrirem completamente a região entre $g=2,1$ e $g=1,9$ e, suspeitando-se da possibilidade de que existissem as linhas do centro $\mathrm{E}^{\prime}{ }_{1}$ em torno de $g=2,007$, foi feita a subtração de linhas descrita na página 106. De fato, isto permitiu medir a variação do sinal de $g \simeq 2,007$ em função da dose. Esse resultado pode ser comparado com o resultado da irradiação do diopsídio artificial puro, sem manganês, onde foi detectado o sinal RPE em $g=2,007$, com o mesmo comportamento com a dose- $\gamma$. O sinal cresce linearmente até cerca de $10^{3}$ Gy, saturando-se depois. Aliás, este foi o comportamento da intensidade TL em função da dose da radiação- $\gamma$.

Pergunta-se, como se originam os centros $\mathrm{E}_{1}^{\prime}$ de $g=2,007$ ?

Em primeiro lugar, lembre-se que, o alumínio está sempre em $\mathrm{SiO}_{2}$, em maior ou menor grau. Mesmo o $\mathrm{SiO}_{2}$ nominalmente puro contém alumínio. Quanto ao quartzo e minerais de silicatos naturais sempre contêm alumínio. O alumínio de carga 3+ tem a tendência de substituir o silício no tetraedro $\mathrm{SiO}_{4}$. Como o íon de $\mathrm{Si}$ tem carga 4+, a compensação de carga é executada por um íon de metal alcalino geralmente presente, formando o centro $\left[\mathrm{AlO}_{4} / \mathrm{M}^{+}\right]$. A irradiação remove o elemento alcalino, deixando um buraco e, dando origem a um centro muito conhecido, o centro de alumínio $\left[\mathrm{AlO}_{4} / \mathrm{h}\right]$. Assim, o centro de alumínio é de buraco.

Tanto no quartzo como num silicato, à temperatura ambiente, tem-se mostrado que se formam vacâncias de oxigênio, $\mathrm{VO}^{2-}$ de carga (2-) que para se estabilizar, captura dois elétrons.

1) A irradiação remove um elétron (irradiação muito intensa pode remover até os dois elétrons), dando origem ao centro $\mathrm{E}_{1}^{\prime}$, o elétron liberado se recombina com o buraco no centro de alumínio, emitindo a luz TL. 


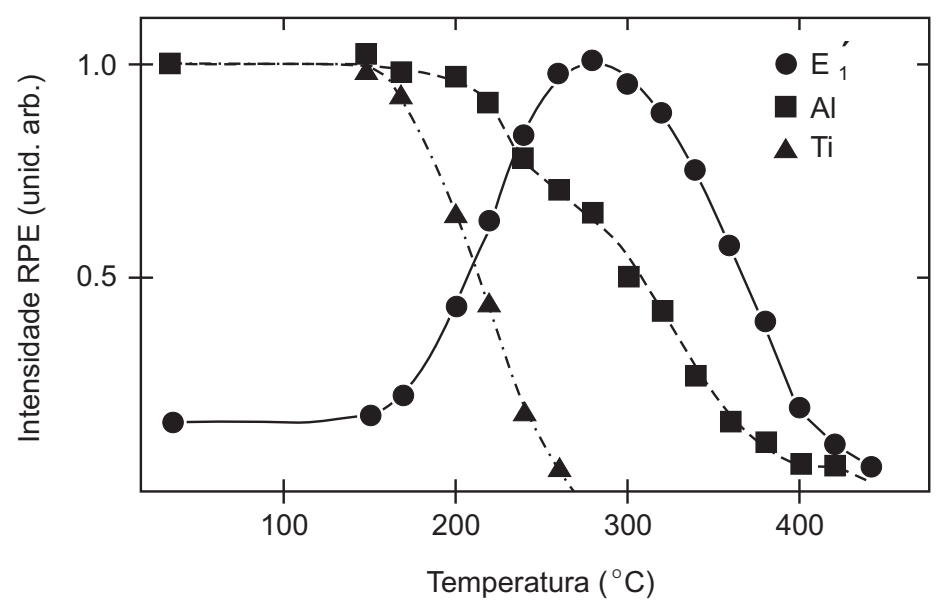

Figura 6.3: Curvas de recozimento isócromo dos centros $E_{1}^{\prime}$, de Al e de Ti.

2) As vacâncias de oxigênio com 2 elétrons, ao serem aquecidas, podem liberar um elétron, formando o centro $\mathrm{E}_{1}^{\prime}$. Isto foi objeto de experimentos de Toyoda e Ikeya [67]. A Figura 6.3, retirada deste trabalho mostra que, enquanto os centros de Ti decaem entre $150{ }^{\circ} \mathrm{C}$ e $250{ }^{\circ} \mathrm{C}$ e os de $\mathrm{Al}$ decaem entre $200{ }^{\circ} \mathrm{C}$ a $400{ }^{\circ} \mathrm{C}$, o centro $\mathrm{E}_{1}^{\prime}$, cresce entre $150{ }^{\circ} \mathrm{C}$ e $300{ }^{\circ} \mathrm{C}$, decaindo subseqüentemente até $400{ }^{\circ} \mathrm{C}$.

Pode-se notar, então, que enquanto os centros de Ti e do $\mathrm{Al}$ decrescem porque cada elétron dos centros de $\mathrm{VO}^{2-}$ se recombina com um buraco dos centros de $\mathrm{Ti}$ e $\mathrm{Al}$, a concentração dos centros $\mathrm{E}_{1}^{\prime}$ aumenta, o que acontece até $300{ }^{\circ} \mathrm{C}$. A partir dessa temperatura, o centro $\mathrm{E}_{1}^{\prime}$, liberam os elétrons e a $400{ }^{\circ} \mathrm{C}$, há exaustão desses elétrons, com o desaparecimento dos os centros $\mathrm{E}_{1}^{\prime}$.

Pode-se inferir, portanto, que:

1) Entre $150{ }^{\circ} \mathrm{C}$ e $250{ }^{\circ} \mathrm{C}$, um elétron do centro formado pela vacância de $\mathrm{O}^{2-}$ que captura dois elétrons, recombina-se com o buraco do centro de Ti e uma parte do centro de $\mathrm{Al}$, dando origem ao pico TL na região de $160{ }^{\circ} \mathrm{C}$. Forma-se o centro $\mathrm{E}_{1}^{\prime}$.

2) Entre $200{ }^{\circ} \mathrm{C}$ e $300{ }^{\circ} \mathrm{C}$, o centro de vacância de $\mathrm{O}^{2-}$ com dois elétrons continua perdendo um elétron, que se recombina com o buraco do centro de alumínio, dando origem ao pico TL na região de $205{ }^{\circ} \mathrm{C}$ e $215^{\circ} \mathrm{C}$. O centro $\mathrm{E}_{1}^{\prime}$ atinge o máximo em $300{ }^{\circ} \mathrm{C}$.

3) Entre $300{ }^{\circ} \mathrm{C}$ e $400{ }^{\circ} \mathrm{C}$, o elétron do centro $\mathrm{E}_{1}^{\prime}$ formado em (1) e (2) é, agora, liberado, recombinando-se com o buraco do centro de alumínio, formando o pico TL entre $300{ }^{\circ} \mathrm{C}$ e $400{ }^{\circ} \mathrm{C}$. Em $400{ }^{\circ} \mathrm{C}$ o centro $\mathrm{E}_{1}^{\prime}$ é totalmente extinto. 
O vidro, obtido a partir do diopsídio natural, estudado neste trabalho, apresenta um sinal RPE muito intenso em torno de 1700 Gauss, que é devido a $\mathrm{Fe}^{3+}$. É um sinal cerca de 100 vezes mais intenso que o de $\mathrm{Mn}^{2+}$ que, no vidro acima, aparece em torno de 3470 Gauss. Sinal de RPE semelhante ao do $\mathrm{Fe}^{3+}$ foi observado em vidro de silicato de sódio, $\mathrm{Na}_{2} \mathrm{O}_{\text {. }} \mathrm{SiO}_{2}$, dopado com $0,2 \%$ em peso de $\mathrm{Fe}_{2} \mathrm{O}_{3}$, por Loveridge \& Parke [70]. Esses mesmos autores encontraram no vidro de $30 \mathrm{~K}_{2} \mathrm{O} .70 \mathrm{SiO}_{2}$ contendo $\mathrm{Fe}_{2} \mathrm{O}_{3}$, um espectro muito mais complexo, com linhas em torno de $g=8,0$, além do sinal em torno de $g=4,3$. Teixeira et al. [71] encontraram em quatro tipos de vidros comerciais contendo de $645 \mu \mathrm{g} / \mathrm{g}$ a $3370 \mu \mathrm{g} / \mathrm{g}$ de $\mathrm{Fe}_{2} \mathrm{O}_{3}$, sinais de RPE em torno de $g=4,3$, além do sinal em torno de $g=2,0$.

O diopsídio, por outro lado, apresentou um sinal de $\mathrm{Fe}^{3+}$ muito pouco intenso comparado com o do $\mathrm{Mn}^{2+}$. No presente trabalho, não foi examinada a razão da diferença do comportamento no vidro e no cristal.

Quanto à absorção ótica, o vidro apresentou a mesma banda, que se estende de cerca de $650 \mathrm{~nm}$ a $1200 \mathrm{~nm}$, devido a $\mathrm{Fe}^{2+}$, porém, não apresentou as bandas na região infravermelha. 


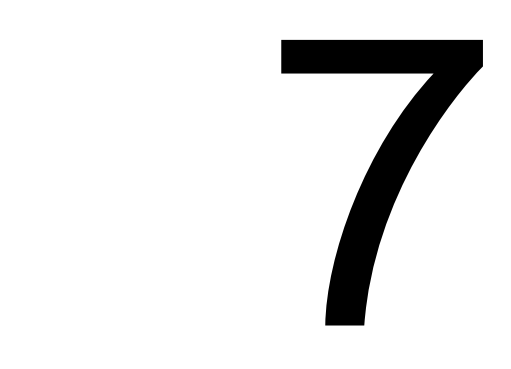

\section{Conclusões}

1. A análise composicional mediante o método de fluorescência de raios X mostrou que a amostra de diopsídio natural estudada neste trabalho, contém majoritariamente os compostos da própria estrutura do cristal de diopsídio $\left(\mathrm{SiO}_{2}-55,81 \%\right.$ mol, $\mathrm{CaO}-23,47 \%$ mol e $\mathrm{MgO}-18,03 \% \mathrm{~mol}$ ). Aparecem outros compostos tais como $\mathrm{Al}_{2} \mathrm{O}_{3}(1,56 \% \mathrm{~mol})$, seguido de $\mathrm{Fe}_{2} \mathrm{O}_{3}(0,57 \% \mathrm{~mol}), \mathrm{K}_{2} \mathrm{O}(0,44 \% \mathrm{~mol})$, $\mathrm{TiO}_{2}(0,065 \% \mathrm{~mol}), \mathrm{P}_{2} \mathrm{O}_{5}(0,026 \% \mathrm{~mol}), \mathrm{MnO}(0,013 \% \mathrm{~mol}), \mathrm{Na}_{2} \mathrm{O}(0,01 \%$ mol). Já Cr (6 ppm), Ni (7 ppm), Sr (46 ppm), V (15 ppm), Zn (29 ppm)e Zr (43 ppm) participam como defeitos extrínsecos na estrutura do cristal em menores concentrações. Dessas impurezas somente o Fe, o Mn e o Al participam das propriedades, aqui estudadas, do diopsídio. Outros metais alcalinos, principalmente o Na participam indiretamente, compensando o desequilíbrio de carga que surge, quando o $\mathrm{Al}^{3+}$ substitui o $\mathrm{Si}^{4+}$.

2. Com a técnica de devitrificação, foram produzidas amostras artificiais de diopsídio puro e dopadas com Fe, Mn e Al. A análise estrutural dessas amostras, incluindo a da amostra natural, mostrou tratar-se de cristal de diopsídio.

Uma diferença considerável foi encontrada no comportamento da curva de emissão TL da amostras artificiais de diopsídio puro e dopadas com Fe, Mn e Al.

Em primeiro lugar, o policristal artificial puro e aquele dopado com Mn apresen- 
taram curva de emissão muito similar sendo que a diferença ficou por conta da temperatura do pico em torno de $260-280{ }^{\circ} \mathrm{C}$, que na amostra pura aparece em $260{ }^{\circ} \mathrm{C}$ e na amostra com $\mathrm{Mn}$, em $280{ }^{\circ} \mathrm{C}$. Parece, portanto, que o Mn não afeta a curva de emissão da amostra natural, na qual são observados todos os picos entre $130{ }^{\circ} \mathrm{C}$ e $400{ }^{\circ} \mathrm{C}$. Todos esses picos são provenientes de defeitos intrínsecos. Contudo, o pico em torno de $160{ }^{\circ} \mathrm{C}$ tem altura cerca de $50 \%$ menor que o da amostra natural e da amostra dopada com alumínio. Nesta última, porém, o pico em torno de $280{ }^{\circ} \mathrm{C}$ tem altura de cerca de um terço da amostra pura, além de apresentar um pico em torno de $420{ }^{\circ} \mathrm{C}$. Assim, o alumínio mantém o mesmo pico da amostra natural e afeta o pico em torno de $280{ }^{\circ} \mathrm{C}$, criando o pico em $420{ }^{\circ} \mathrm{C}$. O Fe, que é conhecido como "killer" abafa todos os picos, exceto o de 450 ${ }^{\circ} \mathrm{C}$. Este foi demonstrado que se mantém inalterado, tanto com irradiação como com o recozimento.

3. As curvas de emissão da amostra natural irradiada com doses gama de 50 Gy até $10 \mathrm{kGy}$ apresentam um pico TL em $160{ }^{\circ} \mathrm{C}$, que cresce linearmente com a dose. Por outro lado, as curvas de emissão das amostras tratadas termicamente a $600{ }^{\circ} \mathrm{C}$ por uma hora e, depois irradiadas com doses variando de 50 Gy até 10 kGy apresentam o mesmo pico TL em $160{ }^{\circ} \mathrm{C}$. Como será comentado no próximo item, este pico é proveniente da superposição de mais dois picos, o em $197^{\circ} \mathrm{C}$ e o em $230{ }^{\circ} \mathrm{C}$.

4. Através do método da subida inicial, e o método GCD foram obtidos os parâmetros das armadilhas de TL que descrevem o fenômeno de termoluminescência do diopsídio natural. Na Tabela 7.1 são mostradas as posições dos picos, as energias de ativação, e os fatores de freqüência obtidos.

Tabela 7.1: Parâmetros associados às cinco armadilhas TL

\begin{tabular}{lcll}
\hline & $\mathrm{T}_{m}\left({ }^{\circ} \mathrm{C}\right)$ & $\mathrm{E}(\mathrm{eV})$ & $\mathrm{s}\left(\mathrm{s}^{-1}\right)$ \\
\hline 1 & 160 & 0,918 & $1,12 \times 10^{10}$ \\
2 & 197 & 0,966 & $4,63 \times 10^{9}$ \\
3 & 230 & 1,117 & $3,15 \times 10^{10}$ \\
4 & 300 & 1,321 & $7,81 \times 10^{10}$ \\
5 & 350 & 1,490 & $2,01 \times 10^{11}$ \\
\hline
\end{tabular}

5. Por tratamentos térmicos isócronos na amostra natural foram revelados picos TL em $150-160{ }^{\circ} \mathrm{C}, 230{ }^{\circ} \mathrm{C}, 300{ }^{\circ} \mathrm{C}$ e $360{ }^{\circ} \mathrm{C}$. 
6. O espectro de emissão TL mostrou que o diopsídio emite luz termoluminescente em $435 \mathrm{~nm}$, isto significa que no diopsídio existe só um centro de recombinação que participa no processo de TL.

7. A sensibilidade TL aumenta com o pré-recozimento antes da irradiação, esse efeito atinge o máximo entre $900{ }^{\circ} \mathrm{C}$ e $1000{ }^{\circ} \mathrm{C}$; após essa temperatura de recozimento, o efeito é reduzido, pois o diopsídio entra na zona de pré-fusão.

8. Nenhuma supralinearidade foi registrada, todos os picos TL crescem linearmente com a dose gama, exceto a amostra artificial dopada com $\mathrm{Al}$ (pico em $410{ }^{\circ} \mathrm{C}$ ) que cresce sublinearmente.

9. A luz UV produz um esvaziamento das armadilhas que resulta na diminuição da intensidade TL com o tempo de irradiação UV. Por outro lado, também induz TL em $90{ }^{\circ} \mathrm{C}$ e $170{ }^{\circ} \mathrm{C}$ nas amostras pré-recozidas a $600{ }^{\circ} \mathrm{C}$ por uma hora. Não encontramos ainda uma explicação de porque a UV produz um pico TL em 90 ${ }^{\circ} \mathrm{C}$, não encontrado, quando a amostra é irradiada com raio- $\gamma$.

10. O espectro de refletância do diopsídio mostrou bandas em 1050, 1390, 1910, 2310 e $2385 \mathrm{~nm}$. A banda em $1050 \mathrm{~nm}$ se deve à transição permitida de spin, ${ }^{5} \mathrm{~T}_{2 g} \rightarrow{ }^{5} \mathrm{E}_{g}$ do $\mathrm{Fe}^{2+}$ substituindo o $\mathrm{Mg}$ na estrutura do cristal de diopsídio, a mesma banda em $1050 \mathrm{~nm}$ também foi observada no diopsídio artificial dopado com Fe; as bandas em 1390 e 1910 nm estão associadas às moléculas de agua e/ou hidroxila que desaparecem com os tratamentos térmicos realizados.

11. O espectro RPE em pó mostrou sinais em $g=4,3$ que foram identificados como sendo devido a $\mathrm{Fe}^{3+}$. A presença de Mn no diopsídio produz as linhas hiperfinas de $\mathrm{Mn}^{2+}$ na região de 3000 a $4500 \mathrm{G}$, esses sinais não são afetados pela radiação gama e nem pelo calor. Também foi identificado na amostra natural o sinal de $\mathrm{E}_{1}^{\prime}$ em $g=2,007$. A existência do centro $\mathrm{E}_{1}^{\prime}$ no diopsídio foi confirmada na amostra artificial pura.

12. O espectro RPE do monocristal de diopsídio natural mostrou todas as linhas típicas do $\mathrm{Mn}^{2+}$ das transições: $-\frac{5}{2} \rightarrow-\frac{3}{2},-\frac{3}{2} \rightarrow-\frac{1}{2},-\frac{1}{2} \rightarrow \frac{1}{2}, \frac{1}{2} \rightarrow \frac{3}{2}$ e $\frac{3}{2} \rightarrow \frac{5}{2}$.

13. O tratamento térmico na região entre 500 e $900{ }^{\circ} \mathrm{C}$, mostrou que o íon ferro na sua valência dois oxida-se com a temperatura e muda para a valência três $\left(\mathrm{Fe}^{2+} \rightarrow \mathrm{Fe}^{3+}+\mathrm{e}^{-}\right)$, que foi confirmado através dos espectros de RPE e refletância nessa região de temperatura. 
14. A análise de fluorescência de raios X do cristal natural de diopsídio mostrou que o $\mathrm{Al}$ e o Ti estão presentes como impurezas. No quartzo e minerais de silicatos naturais o íon $\mathrm{Al}^{3+}$ tem a tendência de substituir o íon $\mathrm{Si}^{4+}$, dando origem ao centro $\left[\mathrm{AlO}_{4}\right]^{-}$. A compensação de carga é executada por um metal alcalino. No diopsídio em estudo foram detectados $\mathrm{Na}_{2} \mathrm{O}(0,01 \% \mathrm{~mol})$ e $\mathrm{K}_{2} \mathrm{O}(0,44 \% \mathrm{~mol})$. A irradiação remove o elemento alcalino, deixando um buraco e, dando origem a um centro muito conhecido, o centro de alumínio de buraco.

$$
\left[\mathrm{AlO}_{4} / \mathrm{M}^{+}\right]^{0} \stackrel{\text { irrad. }}{\longrightarrow}\left[\mathrm{AlO}_{4} / \mathrm{h}\right]^{0}+\mathrm{M}
$$

$\mathrm{M}$ resulta de $\mathrm{M}^{+}$que captura um elétron da ionização.

- No quartzo, como num silicato, a temperatura ambiente, formam-se vacâncias de oxigênio que, para se estabilizar captura de dois elétrons $\left(\mathrm{VO}^{2-}\right)$. A irradiação remove um elétron do $\mathrm{VO}^{2-}$, dando origem ao centro $\mathrm{E}_{1}^{\prime}$. O espectro de RPE do diopsídio mostrou que o sinal em $g=2,007$ devido ao centro $\mathrm{E}_{1}^{\prime}$ cresce com a dose gama.

Por outro lado, o aquecimento também libera um elétron das vacâncias com dois elétrons $\left(\mathrm{VO}^{2-}\right)$, formando o centro $\mathrm{E}_{1}^{\prime}$.

Do trabalho de Toyoda e Ikeya e das considerações acima mencionadas, estão sendo propostos os seguintes mecanismos de emissão TL para o cristal de diopsídio:

- Entre $150{ }^{\circ} \mathrm{C}$ e $250{ }^{\circ} \mathrm{C}$, um elétron do centro $\mathrm{VO}^{2-}$ é liberado pela calor, recombina-se com o buraco do centro de Ti e uma parte do centro de alumínio, dando origem ao pico TL na região de $160{ }^{\circ} \mathrm{C}$. Por outro lado, forma-se o centro $\mathrm{E}_{1}^{\prime}$.

(a) $\mathrm{VO}^{2-} \stackrel{\text { calor }}{\longrightarrow} \mathrm{E}_{1}^{\prime}+\mathrm{e}^{-}$

(b) $\mathrm{e}^{-}+\left[\mathrm{AlO}_{4} / \mathrm{h}\right] \rightarrow\left[\mathrm{AlO}_{4}\right]^{-}+h \nu_{T L(435 n m)}$

- Entre $200{ }^{\circ} \mathrm{C}$ e $300{ }^{\circ} \mathrm{C}$, o centro $\mathrm{VO}^{2-}$ continua perdendo um elétron, que se recombina com o buraco do centro de alumínio, dando origem ao pico TL na região de $205{ }^{\circ} \mathrm{C}$ e $215^{\circ} \mathrm{C}$. O centro $\mathrm{E}_{1}^{\prime}$ atinge o máximo em $300{ }^{\circ} \mathrm{C}$.

(a) $\mathrm{VO}^{2-} \stackrel{\text { calor }}{\longrightarrow} \mathrm{E}_{1}^{\prime}+\mathrm{e}^{-}$

(b) $\mathrm{e}^{-}+\left[\mathrm{AlO}_{4} / \mathrm{h}\right] \rightarrow\left[\mathrm{AlO}_{4}\right]^{-}+h \nu_{T L(435 n m)}$ 
- Entre $300{ }^{\circ} \mathrm{C}$ e $400{ }^{\circ} \mathrm{C}$, o elétron do centro $\mathrm{E}_{1}^{\prime}$ é agora liberado, recombinandose com o buraco do centro de alumínio, formando o pico TL entre $300{ }^{\circ} \mathrm{C}$ e $400{ }^{\circ} \mathrm{C}$. Em $400{ }^{\circ} \mathrm{C}$ o centro $\mathrm{E}_{1}^{\prime}$ é totalmente extinto.
(a) $\mathrm{E}_{1}^{\prime} \stackrel{\text { calor }}{\longrightarrow} \mathrm{VO}+\mathrm{e}^{-}$
(b) $\mathrm{e}^{-}+\left[\mathrm{AlO}_{4} / \mathrm{h}\right] \rightarrow\left[\mathrm{AlO}_{4}\right]^{-}+h \nu_{T L(435 n m)}$

15. O vidro de diopsídio apresenta um sinal de RPE muito intenso em torno de 1700 Gauss, devido a $\mathrm{Fe}^{3+}$ e as linhas características de $\mathrm{Mn}^{2+}$ em torno de $3470 \mathrm{G}$.

16. O espectro de absorção ótica do vidro apresentou uma banda com pico em 1000 $\mathrm{nm}$ que se estende de cerca de $650 \mathrm{~nm}$ a $1200 \mathrm{~nm}$, devido a $\mathrm{Fe}^{2+}$. 


\section{Sugestões para trabalhos futuros}

- Tentar explicar, porque a TL induzida por raios UV é diferente daquela induzida por raios- $\gamma$.

- Estudar as propriedades de RPE e refletância das amostras do diopsídio natural irradiados com luz UV.

- Produzir policristal de diopsídio dopado com Fe, Al, Mn, Ti e Cr em concentrações encontradas no diopsídio natural para ver essas impurezas reproduzem as propriedades de TL, RPE e refletância observadas no mineral natural.

- Fazer medidas de condutividade termicamente estimulada para desvendar quem dos elétrons e buracos são primeiro liberados durante o processo de leitura TL, isto é, por aquecimento.

- Estudar as propriedades térmicas e mecânicas do vidro, obtido a partir do diopsídio natural, com vistas à aplicação prática desse vidro. 


\section{Bibliografia}

[1] Zuckerman B. Interstellar Molecules. Nature, 268:491-495, 1977.

[2] Cosmovici B. C. Molecüle im Interstellaren Raum. Sterne und Weltraum, 19:239, 1980.

[3] Winnewisser G., Mezger P.G., and Breuer H.D. Interstelar Molecules. Top. Curr. Chem., 44:1-81, 1974.

[4] Wada M., Inone A., and Okutani S. I.P.C.R. Airborne Experiments in 1981. Rep. Inst. Phys. Chem. Res., 59:1-19, 1983.

[5] Ronov A.B. and Yaroshevsky A.A. In The Encyclopedia of Geochemistry and Environmental Sciences. Van Nostrand, New York, 1978.

[6] Mieke J.E. Composition of Earth's Crustand Distribution of the Elements. Review of Research on Modern Problems in Geochemistry, 16:13-37, 1979.

[7] Dana J.M. and Hurlbut Jr.C.S. Manual de Mineralogia. Livros Tecnicos e Cientificos, 1978.

[8] Liebau F. Structural Chemistry of Silicates. Springer - Verlag, New York, 1985.

[9] Bermen H. Constitution and Classification of the Natural Silicates. American Mineralogist, 22:342, 1937.

[10] Loeffer B.M. and Burns R.G. Shedding Light Other Color of Gems and Minerals. American Scientist, 64(7):636-647, 1976.

[11] Nassau K. The Origins of Color in Minerals. American Mineralogist, 63(3):219229, 1978.

[12] Morimoto N. Nomenclature of Pyroxenes. American Mineralogist, 73:1123-1133, 1988. 
[13] Deer W.A., Howie R.A., and Zussman J. An Introduction to the Rock-Forming Minerals. Longman: Harlow 2Ed., 1992.

[14] Cameron M. and Papike J.J. Structural and Chemical Variations in Piroxenes. American Mineralogist, 66:1-50, 1981.

[15] Warren B. and Bragg W.L. The Structure of Diopside $\left(\mathrm{CaMgSi}_{2} \mathrm{O}_{6}\right)$. Z. Kristallogr., 69:168-193, 1928.

[16] Clark J.R., Appleman D.E., and Papike J.J. Bonding in Eight Ordered Clinopyroxenes Isostructural with Diopside. Contrib. Mineral. Petrol., 20:81-85, 1968.

[17] Clark J.R., Appleman D.E., and Papike J.J. Crystal-chemical Characterization of Clinopyroxenes Based on Eight New Structure Refinements. Mineral. Soc. Am. Spec. Pap., 2:31-50, 1969.

[18] Cameron M., Sueno S., and Prewitt C.T. High-Temperature Crystal Chemistry of Acmite, Diopside, Hedenbergite, Jade, Spodumene, and Ureyite. American Mineralogist, 58:594-618, 1973.

[19] Finger L.W. and Ohashi Y. The Thermal Expansion of Diopside to $800{ }^{\circ} \mathrm{C}$ and a Refinement of the Crystal Structure at $700{ }^{\circ} \mathrm{C}$. American Mineralogist, 61:303$310,1976$.

[20] Nolan J. and Edgar A.D. An X-ray Investigation of Synthetic Pyroxenes in the System Acmite-Diopside-Water at $1000 \mathrm{~kg} / \mathrm{cm}^{2}$ water vapour pressure. Mineral. Mag., 33:625-634, 1963.

[21] Mirkovich V.V. and Wright I.F. Utilization of Diopside in the Manufacture of Glass: II. Journal of the Canadian Ceramic Society, 44:43-47, 1975.

[22] Alekseev Y.I., Vereshchagin V.I., and Karpova E.A. Influence of diopside on the formation of porcelain and its properties. Glass and Ceramics, 47(9):357-360, 1990.

[23] Leonelli C., Manfredini T., Paganelli M., Pozzi P., and Pellacani G.C. Crystallization of some anorthite-diopside glass precursors. Journal of Materials Science, 26(18):5041-5046, 1990.

[24] Zanotto E.D. Surface nucleation in a diopside glass. Journal of non-crystalline solids, 130(2):217-217, 1991. 
[25] Baldi1 G., Generali E. and Leonelli C., and Manfredini T. and Pellacani G.C. and Siligardi C. Surface nucleation in a diopside glass. Journal of Materials Science, 30(12):3251-3255, 1995.

[26] While W. B. and Keester K. L. Optical absorption spectra of iron in the rockforming silicates. The American Mineralogist, 51:774-791, 1966.

[27] White W.B. and Keester K.L. Selection Rules and Assignments for the Spectra of Ferrous Iron in Pyroxenes. American Mineralogist, 52:1508-1514, 1967.

[28] Bancroft G.M. and Burns R.G. Interpretation of the electronic spectra of iron in pyroxenes. American Mineralogist, 52:1278-1287, 1967.

[29] Hunt G.R. and Salisbury J.W. Visible and near-infrared spectra of minerals and rocks: I. Silicate mineral. Modern Geology, 1:283-300, 1970.

[30] Hunt G.R., Salisbury J.W., and Lenhoff C.J. Visible and near infrared spectra of minerals and rocks: VI. Additional silicates. Modern Geology, 4:85-106, 1973.

[31] Schreiber H.D. On the Natural of Synthetic Blue Diopsíde Crystal: The Stabization of Tetravalent Chromium. American Mineralogist, 62:522-527, 1977.

[32] Herd C.D.K. and Peterson R.C. Violet-Colored Diopside from Southern Baffin Island, Nunavut, Canada. The Canadian Mineralogist, 38:1193-1199, 2000.

[33] Vinokurov V., M. Zaripov M.M., and Stepanov V. G. Paramagnetic resonance of $\mathrm{Mn}^{2+}$ in diopside crystals. Soviet Physics-Solid State, 6(4):870-875, 1964.

[34] Ghose S. and Schindler P. Determination of the distribution of trace amounts of $\mathrm{Mn}^{2+}$ in diopside by electron paramagnetic resonance. Mineralogical Society of America, 2:51, 1969.

[35] Gaite J. M. EPR study of $\mathrm{Mn}^{2+}$ in diopside. J. Phys. C: Solid State Phys., 8:3887-3895, 1975.

[36] Gaite J. M. and Michoulier J. Electron paramagnetic resonance of $\mathrm{Fe}^{3+}$ in diopside and spodumene. The Journal of Chemical Physics, 59(1):488-494, 1973.

[37] Gaite J.M., Michoulier J., and Maffeo B. Résonance paramagnétique électronique de l'ion $\mathrm{Fe}^{3+}$ dans un monocristal de diopside. C. R. Acad. Sc. Paris, 269:578-581, 1969.

[38] Kittel C. Introduction to Solid State Physics. John Wiley \& Sons, 1986. 
[39] Bube R. H. Photoconductivity of Solids. John Wiley \& Sons, New York, 1967.

[40] McKeever S.W.S. Thermoluminescence of Solids. Cambridge University Press, Cambridge, 1985.

[41] Chen R. and Mckeever S.W.S. Theory of Thermoluminescence and Related Phenomena. World Scientific, New Jersey, 1997.

[42] Yukihara E.G. Desvendando a Cor e a Termoluminescência do Topázio. PhD thesis, Instituto de Física - Universidade de São Paulo, São Paulo, 2001.

[43] Kitis G., Gomez-Ros J.M., and Tuyn J.W.N. Thermoluminescence Glow-curve Deconvolution Functions for First, Second and General Orders of Kinetics. $J$. Phys. D: Appl. Phys., 31:2636-2641, 1998.

[44] Randall J.T. and Wilkins M.H.F. Phosphorescence and Electron Traps. I. The Study of Distribution. Proc. R. Soc. (London), 184:366, 1945.

[45] Randall J.T. and Wilkins M.H.F. The Phosphorescence of Various Solids. Proc. R. Soc. (London), 184:390, 1945.

[46] Garlick G.F.J. and Gibson A.F. The electron Trap Mechanism of Luminescence in Sulphide and Silicate Phosphors. Proc. Phys. Soc. London, 60:574-590, 1948.

[47] May C.E. and Partridge J.A. Thermoluminescent Kinetics of Alpha-Irradiated Alkali Halides. J. Chem. Phys., 40:1401-1409, 1964.

[48] Rasheedy M.S. On the General-order Kinetics of the Thermoluminescence Glow Peak. J. Phys.: Condens. Matter, 5:633-636, 1993.

[49] Kivits P. and Hagebeuk H.J.L. Evaluation of the model for thermally stimulated luminescence and conductivity; reliability of trap depth determinations. Journal of Luminescence, 15:1-27, 1977.

[50] Nahum J. and Halperin A. Thermoluminescence and the relation between thermal and optical activation energies in diamond. J. Phys. Chem. Solids, 24:823-834, 1962.

[51] McKeever S.W.S. On the analysis of complex thermoluminescence. glow-curves: Resolution into individual peaks. Physica Status Solidi (a), 62(1):331-340, 1980.

[52] Takenaga M., Yamamoto O., and Yamashita T. A New Phosphor $\mathrm{Li}_{2} \mathrm{~B}_{4} \mathrm{O}_{7}$ : Cu for TLD. Health Physics, 44(4):387-393, 1983. 
[53] Kortov V.S., Milman I.I., Monakhov A.V., and Slesarev A.I. Combined TSL-ESR $\mathrm{MgO}$ Detectors for Ionising and UV Radiations. Ratiation Protection Dosimetry, 47:273-276, 1993.

[54] Zimmerman J. The Radiation-induced Increase of Thermoluminescence Sensitivity of the Dosimetry Phosphor LiF (TLD-100). J. Phys. C: Solid State Phys., 4:3277-3291, 1971.

[55] Mische E.F. and McKeever W.S. Mechanisms of Supralinearity in Lithium Fluoride Thermoluminescence Dosemeters. Radiation Protection Dosimetry, 29(3):159-175, 1989.

[56] Sunta C.M., Yoshimura E.M., and Okuno E. An Analytical Method for the Thermoluminescence Growth Curve and its Validity. J. Phys. D: Appl. Phys., 27:1337-1340, 1994.

[57] Sunta C.M., Yoshimura E.M., and Okuno E. Sensitization and Supralinearity of $\mathrm{CaF}_{2}$ - Natural Thermoluminescence Phosphor - Interpretation Based On Partially Interactive Traps. Phys. Status Solidi A, 142(1):253-264, 1994.

[58] Sunta C.M., Yoshimura E.M., and Okuno E. Supralinearity and Sensitization Factors in Thermoluminescence. Radiation Measurements, 23(4):655-666, 1994.

[59] Lin S.H. Advances in Multi-photon Processes and Spectroscopy. World Scientific, 1984.

[60] Göpper-Mayer M. Über elementarakte mit zwei quantenspr üngen. Annalen der Physik, 401:273-294, 1931.

[61] Ikeja M. New Applications of Electron Spin Resonance. Dating, Dosimetry and Microscopy. World Scientific, 1993.

[62] Zarzycki J. Glasses and Vitreous State. Cambridge University, 1982.

[63] Volmer M. and Weber A. Nuclei Formation in Supersaturated Stated. Z. Phys. Chem., 119:277, 1925.

[64] Becker R. and Döring W. The Kinetic Treatment of Nuclear Formation in Supersaturated Vapors. Ann. Phys., 24:719, 1935.

[65] Walton A. G. Nucleation. Zettlemoyer, New York, 1969. 
[66] Turnbull D. and Fisher J.C. Rate of Nucleation in Condensed Systems. J. Chem. Phys., 17(1):71-73, 1949.

[67] Toyoda S. and Ikeya M. Thermal stabilities of paramagnetic defect and impurity centers in quartz: Basis for ESR dating of thermal history. Geochemical Journal, 25(6):437-445, 1991.

[68] Castner T., Newell G.S., Holton W.C., and Slichter C.P. Note on the paramagnetic resonance of iron in glass. The Journal of Chemical Physics, 32(3):668-673, 1960.

[69] Blak A.R. and McKeever S.W.S. Optical absorption and thermoluminescence in natural beryl. Radiation Protection Dosimetry, 47(1-4):95-98, 1993.

[70] Loveridge D. and Parke S. Electron spin resonance of $\mathrm{Fe}^{3+}, \mathrm{Mn}^{2+}$, and $\mathrm{Cr}^{3+}$ in glasses. Physics and Chemistry of Glasses, 12(1):19-27, 1971.

[71] Teixeira M.I., Ferraz G.M., and Caldas L.V.E. EPR dosimetry using commercial glasses for high gamma doses. Applied Radiation and Isotopes, 62:365-370, 2005. 